\title{
COPD and comorbidity
}

Citation for published version (APA):

Vanfleteren, L. E. G. W. (2015). COPD and comorbidity. [Doctoral Thesis, Maastricht University]. Maastricht University. https://doi.org/10.26481/dis.20150227lv

Document status and date:

Published: 01/01/2015

DOI:

10.26481/dis.20150227lv

Document Version:

Publisher's PDF, also known as Version of record

\section{Please check the document version of this publication:}

- A submitted manuscript is the version of the article upon submission and before peer-review. There can be important differences between the submitted version and the official published version of record.

People interested in the research are advised to contact the author for the final version of the publication, or visit the DOI to the publisher's website.

- The final author version and the galley proof are versions of the publication after peer review.

- The final published version features the final layout of the paper including the volume, issue and page numbers.

Link to publication

\footnotetext{
General rights rights.

- You may freely distribute the URL identifying the publication in the public portal. please follow below link for the End User Agreement:

www.umlib.nl/taverne-license

Take down policy

If you believe that this document breaches copyright please contact us at:

repository@maastrichtuniversity.nl

providing details and we will investigate your claim.
}

Copyright and moral rights for the publications made accessible in the public portal are retained by the authors and/or other copyright owners and it is a condition of accessing publications that users recognise and abide by the legal requirements associated with these

- Users may download and print one copy of any publication from the public portal for the purpose of private study or research.

- You may not further distribute the material or use it for any profit-making activity or commercial gain

If the publication is distributed under the terms of Article $25 \mathrm{fa}$ of the Dutch Copyright Act, indicated by the "Taverne" license above, 


\section{Lowie E.G.W. Vanfleteren}

COPD \&

comorbidity 
Copyright (C) Lowie Vanfleteren, Maastricht 2015

ISBN: 9789461594099

Lay out: Tiny Wouters

Cover design: Christa Viaene

Production: Datawyse | Universitaire Pers Maastricht

The studies presented in chapters 5-9 of this thesis were performed at $\mathrm{CIRO}^{+}$, center of expertise for chronic organ failure, Horn, the Netherlands. The study presented in chapter 2 was performed at Maastricht University Medical Center. The studies presented in chapter 3 and 4 were based on international data collection, of which the study sample in chapter 2 is also part.

The CIROCO study (Chapters 6-9) and the Maastricht BOLD study (Chapter 2) were financially supported by unrestricted grants from AstraZeneca. The international BOLD study (Chapter 3 and 4), which includes the Maastricht BOLD study (Chapter 2) was supported by various funders both at the operating center and at the local sites.

Printing and distribution of this thesis was financially supported by AstraZeneca, Almirall, BioXM, Boehringer-Ingelheim, Chiesi, CIRO+, GlaxoSmithKline, Novartis, Pfizer, Stichting AstmaBestrijding, Takeda, Teva, and Viscovery. 


\title{
COPD
}

\section{$\&$ COMORBIDITY}

\author{
PROEFSCHRIFT
}

ter verkrijging van de graad van doctor aan de Universiteit Maastricht, op gezag van de Rector Magnificus, Prof. dr. L.L.G. Soete, volgens het besluit van het College van Decanen,

in het openbaar te verdedigen op vrijdag 27 februari 2015, om 16:00 uur

door

Lowie E.G.W. Vanfleteren

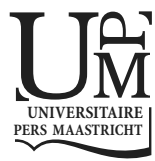




\section{Promotor}

Prof. dr. E.F.M. Wouters

\section{Copromotores}

Dr. F.M.E. Franssen (CIRO ${ }^{+}$, Horn)

Dr. M.A. Spruit $\left(\mathrm{CIRO}^{+}\right.$, Horn)

\section{Beoordelingscommissie}

Prof. dr. C.D.A. Stehouwer (voorzitter)

Prof. dr. H.P. Brunner - La Rocca

Prof. dr. L.M. Fabbri (Universiteit van Modena \& Reggio Emilia, Italy)

Prof. dr. K.M.L. Leunissen

Prof. dr. C. Vogelmeier (Universitair Medisch Centrum Giessen en Marburg, Duitsland) 
Voor Kristien, Lux en haar broertje of zusje 



\section{Table of contents}

Chapter 1 General introduction 9

Chapter 2 The prevalence of COPD in Maastricht, the Netherlands 23

Chapter 3 Sex-related differences in respiratory symptoms: results from 31 the BOLD study

Chapter $4 \quad$ Body mass index and chronic airflow limitation in a worldwide population-based study

Chapter 5 Frequency and relevance of ischemic electrocardiographic findings in patients with COPD

Chapter $6 \quad$ Clusters of comorbidities based on validated objective measurements and systemic inflammation in patients with COPD

Chapter 7 A multimarker approach to identify atherosclerosis in COPD

Chapter 8 Arterial stiffness in patients with COPD: the role of systemic inflammation and the effects of pulmonary rehabilitation

Chapter 9 Objectively identified comorbidities and changes in exercise capacity and health status following pulmonary rehabilitation in patients with COPD

Chapter 10 General discussion

Summary

Samenvatting

Valorization

Dankwoord

Curriculum vitae 



\section{CHAPTER 1}

General introduction 



\section{CHRONIC OBSTRUCTIVE PULMONARY DISEASE, AN UNDERESTIMATED PROBLEM}

Chronic obstructive pulmonary disease (COPD) is a common airway and lung disease characterized by persistent airflow limitation, which is the result of small airway remodeling and loss of elastic recoil due to alveolar destruction. The pathophysiology of COPD is associated with an enhanced inflammatory response to noxious gases, mostly cigarette smoke. Clinically, the disease expresses in the combination of less or more chronic bronchitis and pulmonary emphysema. Most frequent symptoms in COPD are dyspnea, cough, wheeze and chest tightness. The natural history of COPD is usually progressive and patients commonly suffer from exacerbations of the disease. The disease cannot be cured, and main treatment goals are the reduction of symptoms and the prevention of exacerbations. COPD is a serious public health problem throughout the world, with an increasing morbidity and mortality especially in countries with an ageing population. The World Health Organization Global Burden of Disease Project estimated that COPD was the fifth leading cause of death worldwide in 2001 and will be the third leading cause by 2020 , with only heart disease and cerebrovascular disease accounting for more deaths. ${ }^{1}$ The disease imposes increasing demands on the health care systems and is a growing economic burden on societies worldwide. Although COPD primarily affects the elderly, it also affects many patients before they reach retirement age. Lost productivity due to COPD has a particularly high impact on economies. In the Netherlands it accounts for $50 \%$ of the overall COPD-related societal costs. ${ }^{2,3}$

Epidemiologic data on COPD are important. COPD tends to be under-presented to physicians, underdiagnosed and undertreated by healthcare professionals. Thus, it is poorly recognized among the general population. ${ }^{2}$ Improving the diagnosis and management of COPD requires raising awareness of the burden of the disease.

\section{THE FEMALE FACE OF COPD}

While global prevalence of tobacco use in men has peaked in most countries, smoking in women, which historically was much less common than in men, continues to rise. By 2025 over 500 million women will be daily smokers, representing $20 \%$ of the total female population in the world. ${ }^{4}$ Therefore, worldwide prevalence of chronic airway disease is increasing faster in women than men. Despite this fact there is still a scarcity of research that deals with gender-related issues in the etiology, diagnosis, management and perception of symptoms related to COPD. For both men and women, diagnosis and treatment of lung disease often begins with the reporting of respiratory 
symptoms to their physician. Therefore consideration of gender-related differences in symptoms is important.

\section{THE COMPLEXITY OF COPD, FROM BODY COMPOSITION TO MULTIMORBIDITY}

Although COPD is defined by the presence of chronic airflow limitation, it is increasingly recognized that the presence of other chronic conditions (comorbidities) such as cardiovascular disease, depression, osteoporosis, anemia and diabetes substantially contributes to disease severity in patients with chronic airflow limitation. ${ }^{5}$ Comorbidities not only affect symptom burden, functional performance and health status in patients with COPD, ${ }^{6}$ but also the risk of hospitalization ${ }^{7}$ and mortality. ${ }^{7,8}$ As a consequence, COPD is nowadays considered a complex, heterogeneous and multicomponent condition. ${ }^{9}$

Some of the first recognized systemic manifestations of COPD were the changes in nutritional status. Indeed, a low body weight is a common clinical observation in patients with COPD. Not only it is commonly noticed, but also it has important implications as a low BMI in COPD is associated with mortality, ${ }^{10-13}$ independent of disease severity. ${ }^{12}$ The presence of a low BMI was included in one of the best validated and broadly used composite indices to predict mortality in patients with COPD, namely the BODE index. ${ }^{14}$

On the other hand obesity is increasingly recognized as a risk factor for respiratory symptoms ${ }^{15}$ and functional limitation ${ }^{16}$ in subjects with COPD. Furthermore, divergent effects have been noticed with respect to mortality: while obesity may be associated with lower mortality in patients with severe airflow obstruction, a higher mortality rate was seen in mild to moderate COPD patients with obesity. ${ }^{12,17}$

Nevertheless, there is a scarcity of epidemiological studies on the association between $\mathrm{BMI}$ and chronic airflow limitation, that control for other factors that influence BMI, like age, gender, smoking history and geography. Low body weight has only been studied in selected patient populations, ${ }^{13,18}$ and previous studies did not account for the impact of smoking, ${ }^{19}$ gender, $^{20}$ and age. ${ }^{21}$ Data on obesity in subjects with airflow limitation in general population samples were scarce and conflicting. ${ }^{22,23}$

To date, most studies on the impact of comorbidities in COPD used data on selfreported concurrent chronic conditions. This may limit the internal validity of these studies. ${ }^{7,8,24-31}$ Self-reported data are most probably underestimating the true prevalence of comorbidities in COPD. Indeed, in patients with stable COPD, 
cardiovascular morbidity often remains unrecognized. This is most probably due to similarities in presenting symptoms and clinical signs. For example, in a primary care population of patients with COPD, the prevalence of undiagnosed heart failure was about $20 \%$. $^{32}$

Moreover, most comorbidities have been studied separately, while the majority of elderly have two or more chronic morbidities. ${ }^{35}$ Overlap in self-reported comorbidities has been shown in primary care COPD patients. ${ }^{29}$ Although some associations between objectively identified comorbidities, such as vascular stiffness and osteoporosis, ${ }^{36}$ have been studied, it is currently unknown whether and to what extent comorbidities cluster in COPD. Also, it remains unclear whether or not patients with different comorbidity profiles differ in disease severity, pharmacological treatment or other relevant clinical outcomes.

\section{SYSTEMIC INFLAMMATORY RESPONSE IN COPD, AN EPIPHENOMENON?}

Persistent low-grade systemic inflammation may be the link between COPD and comorbidities. ${ }^{37}$ Indeed, markers of inflammation in the systemic circulation have shown to be increased in subjects with COPD as well as in subjects with cardiovascular disease. ${ }^{38}$ Simultaneously elevated inflammatory markers have been associated with an increased risk of comorbidities in COPD, ${ }^{39}$ in particular cardiovascular disease. ${ }^{40}$

However, the Evaluation of COPD Longitudinally to Identify Predictive Surrogate Endpoints (ECLIPSE) study reported that chronic systemic inflammation is a feature in only a small proportion of the COPD patients. ${ }^{41}$ Intriguingly, the risk of chronic systemic inflammation was not increased in patients with self-reported cardiovascular comorbidity, while older age and obese BMI, among other factors, were associated with this feature. These observations shed new light on the role of chronic inflammation in the development of comorbidities in COPD and on the possible etiology of systemic inflammation in COPD.

\section{A ROLE FOR BIOMARKERS IN IDENTIFYING ATHEROSCLEROSIS IN COPD?}

Cardiovascular disease is now well recognized as a major comorbid complication in patients with COPD. It has been associated with increased health care utilization and mortality ${ }^{7,42}$. Therefore, identification of COPD patients at risk is essential for optimal management. 
While traditional cardiovascular risk factors, including age, smoking, body mass index (BMI) and blood pressure, have been associated with atherosclerosis in smokers with airflow limitation, ${ }^{34}$ the pathophysiology of co-occurring COPD and atherosclerosis remains poorly understood. Although it is well-established that atherosclerosis is associated with the presence of a low-grade systemic inflammatory state, traditional biomarkers of inflammation in COPD lack sufficient disease specificity to identify atherosclerotic artery disease. ${ }^{43}$ Throughout the years, multiple biomarkers have been related to different disease manifestations of atherosclerosis in different patient populations. For example, proinflammatory cytokines, ${ }^{40,44,45}$ matrix metalloproteinases, ${ }^{46}$ adipokines, ${ }^{47}$ vascular adhesion molecules, ${ }^{48}$ regulators of fibrosis and fibrinolysis, ${ }^{49}$ the growth hormone - insulin growth factor axis, ${ }^{50}$ body iron, ${ }^{51}$ and bone markers $^{52,53}$ have been reported to have its role in the atherosclerotic process. However, it is unknown whether and to what extent a combination of these biomarkers may provide a more accurate identification of patients with COPD and atherosclerosis, additionally to traditional cardiovascular risk factors.

\section{PULMONARY REHABILITATION AND CARDIOVASCULAR RISK MANAGEMENT}

Comprehensive state-of-the-art pulmonary rehabilitation has proven its benefits in patients with COPD. It results in a reduction of symptoms, an optimization of the functional status, an increased participation and reduction in healthcare costs. ${ }^{54}$ Nevertheless, the effects of pulmonary rehabilitation on cardiovascular risk have not been extensively studied. Exercise-based pulmonary rehabilitation seems to have a beneficial effect on arterial stiffness in patients with COPD. ${ }^{55,56}$ However, these results need to be confirmed in larger samples.

\section{DOES COMORBIDITY PREVENT PULMONARY REHABILITATION SUCCESS?}

Pulmonary rehabilitation is a comprehensive intervention recognized as a core component in the treatment of patients with COPD. ${ }^{54}$ Comorbidities have been suggested to affect outcomes of pulmonary rehabilitation in this population, but conflicting results have been found. ${ }^{26,57-60}$ These studies, however, used charts reviewing, and only the impact of individual comorbidities or arbitrarily grouped comorbidities was studied. 


\section{AIMS OF THE THESIS}

The main objectives of this thesis were:

1. to estimate the prevalence of COPD in the Netherlands;

2. to increase insight in gender differences in COPD-related symptoms;

3. to increase the understanding of the relationship between body mass index and chronic airflow obstruction in a world-wide general population.

4. to study the prevalence of objectively identified ischemic heart disease and to evaluate its clinical consequences in patients with COPD;

5. to investigate the coexistence and clustering of objectified comorbidities in patients with COPD;

6. to study low-grade systemic inflammation in subjects with COPD in relation with (clusters of) comorbidities;

7. to investigate the additional value of atherosclerosis-related biomarkers in cardiovascular risk assessment in COPD;

8. to study the potential of pulmonary rehabilitation in reducing cardiovascular risk in COPD;

9. to study the impact of individual comorbidities and clusters of comorbidities on pulmonary rehabilitation outcomes.

\section{OUTLINE OF THE THESIS}

Country-specific studies on the current and future impact of COPD in the Netherlands are scarce and were mostly based on physician's diagnosis of "COPD", "chronic bronchitis" or "lung emphysema" ${ }^{61}$. Given the well-known under-diagnosis of COPD, these studies can importantly underestimate the real prevalence of COPD ${ }^{62}$. The Burden of Obstructive Lung Disease (BOLD) initiative began in order to develop and use standardized methods to measure the prevalence of COPD and its risk factors in various areas around the world. ${ }^{63} \mathrm{~A}$ study in a random general population implementing rigorous methods to achieve the maximum accuracy and completeness of the surveys and to obtain high-quality post-bronchodilator spirometry, has not been done in the Netherlands. Chapter $\mathbf{2}$ is the BOLD report of the prevalence of COPD in Maastricht, the Netherlands.

From a population-based perspective, little is known about gender-related differences in respiratory symptoms. Since the vast majority of COPD cases goes undetected, particularly for women, ${ }^{64}$ analyses of gender-related differences within populationbased samples are important. Chapter 3 addresses this knowledge-gap with regard to respiratory symptoms in men and women with normal and impaired lung function using data of the international population-based BOLD study. 
Since the association between low body weight and chronic airflow limitation remains incompletely understood as it has only been studied in selected patient populations, ${ }^{65,66}$ the principal objective in chapter 4 is to study in detail the relationship between low and obese BMI and the presence of chronic airflow limitation in a general worldwide population, taking into account the impact of gender, smoking status, age and site-to-site heterogeneity.

Electrocardiography (ECG) is a simple, fast, easily accessible and non-invasive method to evaluate ischemic heart disease. Furthermore, the results from different studies in general population are quite consistent that ischemia-like ECG changes are associated with an approximately twofold increased risk of dying of coronary heart disease, ${ }^{67-69}$ but have never been systematically evaluated in patients with COPD, nor evaluated in relation to clinical outcome. Chapter $\mathbf{5}$ describes the prevalence of ischemic-like electrocardiographic changes in patients with COPD. In addition, differences in clinical outcomes between patients with and without ischemic electrocardiographic findings were studied.

Chapter 6 investigates the frequency of 13 clinically relevant and objectively identified comorbidities as well as the clustering of these comorbidities in a well-characterized cohort of COPD patients. In addition, potential differences in disease severity and clinical characteristics, inflammatory status and current pharmacologic treatment between comorbidity clusters are explored.

Since cardiovascular disease is well recognized as a major comorbid complication in patients with $C O P D,{ }^{70}$ the identification of patients at risk is important for optimal COPD care, but also challenging. In chapter 7 , the degree of (subclinical) atherosclerosis is objectively measured with the use of ultrasound measurement of carotid wall intimamedia thickness (c-IMT). Clinical determinants of c-IMT are studied and the potential value of a combination of multiple atherosclerosis-related biomarkers in the identification of atherosclerosis in COPD is evaluated.

Chapter 8 consists of a study on arterial stiffness in patients with COPD. Arterial stiffness was determined by measuring aortic pulse wave velocity (APWV), a robust predictor of future cardiovascular risk. ${ }^{71}$ The aim of this chapter is to confirm increased arterial stiffness in COPD, to evaluate its correlates including systemic inflammation; and to study whether or not it is influenced by pulmonary rehabilitation.

Chapter 9 evaluates prospectively the impact of both individual and clusters of objectively identified comorbidities (identified in chapter 6) on changes in functional exercise capacity (i.e., walking and cycling) and health status after pulmonary rehabilitation in patients with COPD. 
In chapter $\mathbf{1 0}$ the results of this thesis are discussed in a broader perspective. Additionally the results of a side-project of this thesis concerning the possible role of visceral fat in atherosclerosis in COPD are discussed. 


\section{REFERENCES}

1. Murray CJ, Lopez AD. Alternative projections of mortality and disability by cause 1990-2020: Global Burden of Disease Study. Lancet 1997;349:1498-504.

2. Wouters EF. The societal impact of COPD in North America and Europe: an economic analysis of the Confronting COPD survey. Respir Med 2003;97:S3-14.

3. Wouters EF. The burden of COPD in The Netherlands: results from the Confronting COPD survey. Respir Med 2003;97 Suppl C:S51-9.

4. Ernster V. Women and the tobacco epidemic: challenges for the 21st century. In: Samet JM, Yoon S, editors: Geneva, Switzerland: World Health Organization. 2001.

5. Vestbo J, Hurd SS, Agustí AG, Jones PW, Vogelmeier C, Anzueto A, Barnes PJ, Fabbri LM, Martinez FJ, Nishimura M, Stockley RA, Sin DD, Rodriguez-Roisin R. Global Strategy for the Diagnosis, Management and Prevention of Chronic Obstructive Pulmonary Disease, GOLD Executive Summary. Am J Respir Crit Care Med 2013;187:347-65.

6. von Leupoldt A, Taube K, Lehmann K, Fritzsche A, Magnussen $\mathrm{H}$. The impact of anxiety and depression on outcomes of pulmonary rehabilitation in patients with COPD. Chest 2011;140:730-6.

7. Mannino DM, Thorn D, Swensen A, Holguin F. Prevalence and outcomes of diabetes, hypertension and cardiovascular disease in COPD. Eur Respir J 2008;32:962-9.

8. Divo M, Cote C, de Torres JP, Casanova C, Marin JM, Pinto-Plata V, Zulueta J, Cabrera C, Zagaceta J, Hunninghake G, Celli B; BODE Collaborative Group. Comorbidities and risk of mortality in patients with COPD. Am J Respir Crit Care Med 2012;186:155-61.

9. Agusti A, Calverley PM, Celli B, Coxson HO, Edwards LD, Lomas DA, MacNee W, Miller BE, Rennard S, Silverman EK, Tal-Singer R, Wouters E, Yates JC, Vestbo J; Evaluation of COPD Longitudinally to Identify Predictive Surrogate Endpoints (ECLIPSE) investigators. Characterisation of COPD heterogeneity in the ECLIPSE cohort. Respir Res 2010;11:122.

10. Wilson DO, Rogers RM, Wright EC, Anthonisen NR. Body weight in chronic obstructive pulmonary disease. The National Institutes of Health Intermittent Positive-Pressure Breathing Trial. Am Rev Respir Dis 1989;139:1435-8.

11. Schols AM, Slangen J, Volovics L, Wouters EF. Weight loss is a reversible factor in the prognosis of chronic obstructive pulmonary disease. Am J Respir Crit Care Med 1998;157:1791-7.

12. Landbo $C$, Prescott $E$, Lange $P$, et al. Prognostic value of nutritional status in chronic obstructive pulmonary disease. Am J Respir Crit Care Med 1999;160:1856-61.

13. Chailleux E, Laaban JP, Veale D. Prognostic value of nutritional depletion in patients with COPD treated by long-term oxygen therapy: data from the ANTADIR observatory. Chest 2003;123:1460-6.

14. Celli BR, Cote CG, Marin JM, Casanova C, Montes de Oca M, Mendez RA, Pinto Plata V, Cabral HJ. The body-mass index, airflow obstruction, dyspnea, and exercise capacity index in chronic obstructive pulmonary disease. N Engl J Med 2004;350:1005-12.

15. Cecere LM, Littman AJ, Slatore CG, Udris EM, Bryson CL, Boyko EJ, Pierson DJ, Au DH. Obesity and COPD: associated symptoms, health-related quality of life, and medication use. COPD 2011;8:275-84.

16. Ramachandran K, McCusker C, Connors M, Zuwallack R, Lahiri B. The influence of obesity on pulmonary rehabilitation outcomes in patients with COPD. Chron Respir Dis 2008;5:205-9.

17. Schols AM, Soeters PB, Dingemans AM, Mostert R, Frantzen PJ, Wouters EF. Prevalence and characteristics of nutritional depletion in patients with stable COPD eligible for pulmonary rehabilitation. Am Rev Respir Dis 1993;147:1151-6.

18. Vermeeren MA, Creutzberg EC, Schols AM, Postma DS, Pieters WR, Roldaan AC, Wouters EF; COSMIC Study Group. Prevalence of nutritional depletion in a large out-patient population of patients with COPD. Respir Med 2006;100:1349-55.

19. Wack JT, Rodin J. Smoking and its effects on body weight and the systems of caloric regulation. Am J Clin Nutr 1982;35:366-80. 
20. Finucane MM, Stevens GA, Cowan MJ, Danaei G, Lin JK, Paciorek CJ, Singh GM, Gutierrez HR, Lu Y, Bahalim AN, Farzadfar F, Riley LM, Ezzati M; Global Burden of Metabolic Risk Factors of Chronic Diseases Collaborating Group (Body Mass Index). National, regional, and global trends in body-mass index since 1980: systematic analysis of health examination surveys and epidemiological studies with 960 country-years and 9.1 million participants. Lancet 2011;377:557-67.

21. van den Borst B, Koster A, Yu B, Gosker HR, Meibohm B, Bauer DC, Kritchevsky SB, Liu Y, Newman AB, Harris TB, Schols AM. Is age-related decline in lean mass and physical function accelerated by obstructive lung disease or smoking? Thorax 2011;66:961-9.

22. Vozoris NT, O'Donnell DE. Prevalence, risk factors, activity limitation and health care utilization of an obese, population-based sample with chronic obstructive pulmonary disease. Can Respir J;19:e18-24.

23. Montes de Oca M, Tálamo C, Perez-Padilla R, Jardim JR, Muiño A, Lopez MV, Valdivia G, Pertuzé J, Moreno D, Halbert RJ, Menezes AM; PLATINO Team. Chronic obstructive pulmonary disease and body mass index in five Latin America cities: the PLATINO study. Respir Med 2008;102:642-50.

24. McGarvey LP, John M, Anderson JA, Zvarich M, Wise RA; TORCH Clinical Endpoint Committee. Ascertainment of cause-specific mortality in COPD: operations of the TORCH Clinical Endpoint Committee. Thorax 2007;62:411-5.

25. Antonelli Incalzi R, Fuso L, De Rosa M, Forastiere F, Rapiti E, Nardecchia B, Pistelli R. Co-morbidity contributes to predict mortality of patients with chronic obstructive pulmonary disease. Eur Respir J 1997;10:2794-800.

26. Crisafulli E, Costi S, Luppi F, et al. Role of comorbidities in a cohort of patients with COPD undergoing pulmonary rehabilitation. Thorax 2008;63:487-92.

27. Feary JR, Rodrigues LC, Smith CJ, Hubbard RB, Gibson JE. Prevalence of major comorbidities in subjects with COPD and incidence of myocardial infarction and stroke: a comprehensive analysis using data from primary care. Thorax 2010;65:956-62.

28. Schnell K, Weiss CO, Lee T, Krishnan JA, Leff B, Wolff JL, Boyd C. The prevalence of clinically-relevant comorbid conditions in patients with COPD: a cross-sectional study using data from NHANES 19992008. BMC Pulm Med 2012;12:26.

29. Siebeling L, Puhan MA, Muggensturm P, Zoller M, Ter Riet G. Characteristics of Dutch and Swiss primary care COPD patients - baseline data of the ICE COLD ERIC study. Clinical epidemiology 2011;3:273-83.

30. van Manen JG, Bindels PJ, IJzermans CJ, van der Zee JS, Bottema BJ, Schadé E. Prevalence of comorbidity in patients with a chronic airway obstruction and controls over the age of 40 . J Clin Epidemiol 2001;54:287-93.

31. Soriano JB, Visick GT, Muellerova H, Payvandi N, Hansell AL. Patterns of comorbidities in newly diagnosed COPD and asthma in primary care. Chest 2005;128:2099-107.

32. Rutten FH, Moons KG, Cramer MJ, Grobbee DE, Zuithoff NP, Lammers JW, Hoes AW. Recognising heart failure in elderly patients with stable chronic obstructive pulmonary disease in primary care: cross sectional diagnostic study. BMJ 2005;331:1379.

33. Rutten FH, Cramer MJ, Grobbee DE, Sachs AP, Kirkels JH, Lammers JW, Hoes AW. Unrecognized heart failure in elderly patients with stable chronic obstructive pulmonary disease. Eur Heart J 2005;26: 1887-94.

34. Iwamoto H, Yokoyama A, Kitahara Y, Ishikawa N, Haruta Y, Yamane K, Hattori N, Hara H, Kohno N. Airflow limitation in smokers is associated with subclinical atherosclerosis. Am J Respir Crit Care Med 2009;179:35-40.

35. Barnett K, Mercer SW, Norbury M, Watt G, Wyke S, Guthrie B. Epidemiology of multimorbidity and implications for health care, research, and medical education: a cross-sectional study. Lancet 2012.

36. Sabit R, Bolton CE, Edwards PH, Pettit RJ, Evans WD, McEniery CM, Wilkinson IB, Cockcroft JR, Shale DJ. Arterial stiffness and osteoporosis in chronic obstructive pulmonary disease. Am J Respir Crit Care Med 2007; 175:1259-65.

37. Barnes PJ, Celli BR. Systemic manifestations and comorbidities of COPD. Eur Respir J 2009;33:1165-85.

38. Gan WQ, Man SF, Senthilselvan A, Sin DD. Association between chronic obstructive pulmonary disease and systemic inflammation: a systematic review and a meta-analysis. Thorax 2004;59:574-80.

39. Thomsen M, Dahl M, Lange P, Vestbo J, Nordestgaard BG. Inflammatory biomarkers and comorbidities in chronic obstructive pulmonary disease. Am J Respir Crit Care Med 2012;186:982-8. 
40. Sin DD, Man SF. Why are patients with chronic obstructive pulmonary disease at increased risk of cardiovascular diseases? The potential role of systemic inflammation in chronic obstructive pulmonary disease. Circulation 2003;107:1514-9.

41. Agustí A1, Edwards LD, Rennard SI, MacNee W, Tal-Singer R, Miller BE, Vestbo J, Lomas DA, Calverley PM, Wouters E, Crim C, Yates JC, Silverman EK, Coxson HO, Bakke P, Mayer RJ, Celli B; Evaluation of COPD Longitudinally to Identify Predictive Surrogate Endpoints (ECLIPSE) Investigators. Persistent systemic inflammation is associated with poor clinical outcomes in COPD: a novel phenotype. PloS One 2012; 7:e37483.

42. Divo M, Cote C, de Torres JP, Casanova C, Marin JM, Pinto-Plata V, Zulueta J, Cabrera C, Zagaceta J, Hunninghake G, Celli B; BODE Collaborative Group. Comorbidities and risk of mortality in patients with chronic obstructive pulmonary disease. Am J Respir Crit Care Med 2012;186:155-61.

43. Pearson TA, Mensah GA, Alexander RW, Anderson JL, Cannon RO 3rd, Criqui M, Fadl YY, Fortmann SP, Hong Y, Myers GL, Rifai N, Smith SC Jr, Taubert K, Tracy RP, Vinicor F; Centers for Disease Control and Prevention; American Heart Association. Markers of inflammation and cardiovascular disease: application to clinical and public health practice: A statement for healthcare professionals from the Centers for Disease Control and Prevention and the American Heart Association. Circulation 2003;107:499-511.

44. Sarwar N, Butterworth AS, Freitag DF, Gregson J, Willeit P, Gorman DN, Gao P, Saleheen D, Rendon A, Nelson CP, Braund PS, Hall AS, Chasman DI, Tybjærg-Hansen A, Chambers JC, Benjamin EJ, Franks PW, Clarke R, Wilde AA, Trip MD, Steri M, Witteman JC, Qi L, van der Schoot CE, de Faire U, Erdmann J, Stringham HM, Koenig W, Rader DJ, Melzer D, Reich D, Psaty BM, Kleber ME, Panagiotakos DB, Willeit J, Wennberg P, Woodward M, Adamovic S, Rimm EB, Meade TW, Gillum RF, Shaffer JA, Hofman A, Onat A, Sundström J, Wassertheil-Smoller S, Mellström D, Gallacher J, Cushman M, Tracy RP, Kauhanen J, Karlsson M, Salonen JT, Wilhelmsen L, Amouyel P, Cantin B, Best LG, Ben-Shlomo Y, Manson JE, DaveySmith G, de Bakker PI, O'Donnell CJ, Wilson JF, Wilson AG, Assimes TL, Jansson JO, Ohlsson C, Tivesten Å, Ljunggren Ö, Reilly MP, Hamsten A, Ingelsson E, Cambien F, Hung J, Thomas GN, Boehnke M, Schunkert H, Asselbergs FW, Kastelein JJ, Gudnason V, Salomaa V, Harris TB, Kooner JS, Allin KH, Nordestgaard BG, Hopewell JC, Goodall AH, Ridker PM, Hólm H, Watkins H, Ouwehand WH, Samani NJ, Kaptoge S, Di Angelantonio E, Harari O, Danesh J. Interleukin-6 receptor pathways in coronary heart disease: a collaborative meta-analysis of 82 studies. Lancet 2012;379:1205-13.

45. Zhang L, Peppel K, Sivashanmugam P, Orman ES, Brian L, Exum ST, Freedman NJ. Expression of tumor necrosis factor receptor-1 in arterial wall cells promotes atherosclerosis. Arterioscler Thromb Vasc Biol 2007;27:1087-94.

46. Beaudeux JL, Giral P, Bruckert E, Bernard M, Foglietti MJ, Chapman MJ. Serum matrix metalloproteinase-3 and tissue inhibitor of metalloproteinases-1 as potential markers of carotid atherosclerosis in infraclinical hyperlipidemia. Atherosclerosis 2003;169:139-46.

47. Pischon T, Girman CJ, Hotamisligil GS, Rifai N, Hu FB, Rimm EB. Plasma adiponectin levels and risk of myocardial infarction in men. JAMA 2004;291:1730-7.

48. Blankenberg S, Barbaux S, Tiret L. Adhesion molecules and atherosclerosis. Atherosclerosis 2003;170: 191-203.

49. Peng Y, Liu H, Liu F, Ouyang L, Cheng M, Gao L, Pan F, Liu Y, Chen X, Li J. Atherosclerosis is associated with plasminogen activator inhibitor type-1 in chronic haemodialysis patients. Nephrology (Carlton) 2008;13:579-86.

50. Kawachi S, Takeda N, Sasaki A, Kokubo Y, Takami K, Sarui H, Hayashi M, Yamakita N, Yasuda K. Circulating insulin-like growth factor-1 and insulin-like growth factor binding protein-3 are associated with early carotid atherosclerosis. Arterioscler Thromb Vasc Biol 2005;25:617-21.

51. Wolff B, Völzke H, Lüdemann J, Robinson D, Vogelgesang D, Staudt A, Kessler C, Dahm JB, John U, Felix $\mathrm{SB}$. Association between high serum ferritin levels and carotid atherosclerosis in the study of health in Pomerania (SHIP). Stroke 2004;35:453-7.

52. Trion A, van der Laarse A. Vascular smooth muscle cells and calcification in atherosclerosis. Am Heart J 2004;147:808-14.

53. Venuraju SM, Yerramasu A, Corder R, Lahiri A. Osteoprotegerin as a predictor of coronary artery disease and cardiovascular mortality and morbidity. J Am Coll Cardiol 2010;55:2049-61. 
54. Spruit MA, Singh SJ, Garvey C, ZuWallack R, Nici L, Rochester C, Hill K, Holland AE, Lareau SC, Man WD, Pitta F, Sewell L, Raskin J, Bourbeau J, Crouch R, Franssen FM, Casaburi R, Vercoulen JH, Vogiatzis I, Gosselink R, Clini EM, Effing TW, Maltais F, van der Palen J, Troosters T, Janssen DJ, Collins E, GarciaAymerich J, Brooks D, Fahy BF, Puhan MA, Hoogendoorn M, Garrod R, Schols AM, Carlin B, Benzo R, Meek P, Morgan M, Rutten-van Mölken MP, Ries AL, Make B, Goldstein RS, Dowson CA, Brozek JL, Donner CF, Wouters EF; ATS/ERS Task Force on Pulmonary Rehabilitation. An official american thoracic society/european respiratory society statement: key concepts and advances in pulmonary rehabilitation. Am J Respir Crit Care Med 2013;188:e13-64.

55. Vivodtzev I, Minet C, Wuyam B, Borel JC, Vottero G, Monneret D, Baguet JP, Lévy P, Pépin JL. Significant improvement in arterial stiffness after endurance training in patients with COPD. Chest 2010;137: 585-92.

56. Gale NS, Duckers JM, Enright S, Cockcroft JR, Shale DJ, Bolton CE. Does pulmonary rehabilitation address cardiovascular risk factors in patients with COPD? BMC Pulm Med 2011;11:20.

57. Crisafulli E, Gorgone P, Vagaggini B, Pagani M, Rossi G, Costa F, Guarriello V, Paggiaro P, Chetta A, de Blasio F, Olivieri D, Fabbri LM, Clini EM. Efficacy of standard rehabilitation in COPD outpatients with comorbidities. Eur Respir J 2010;36:1042-8.

58. Walsh JR, McKeough ZJ, Morris NR, Chang AT, Yerkovich ST, Seale HE, Paratz JD. Metabolic disease and participant age are independent predictors of response to pulmonary rehabilitation. J Cardiopulm Rehabil Prev 2013;33:249-56.

59. Walsh JR, Morris NR, McKeough ZJ, Yerkovich ST, Paratz JD. A simple clinical measure of quadriceps muscle strength identifies responders to pulmonary rehabilitation. Pulm Med 2014;2014:782702.

60. Carreiro A, Santos J, Rodrigues F. Impact of comorbidities in pulmonary rehabilitation outcomes in patients with chronic obstructive pulmonary disease. Rev Port Pneumol 2013;19:106-13.

61. Hoeymans N, Melse JM, Schoemaker CG. Gezondheid en determinanten. Deelrapport van de Van gezond naar beter. RIVM report. RIVM, 2010.

62. Wouters EF. The burden of COPD in The Netherlands: results from the Confronting COPD survey. Respir Med 2003;97 Suppl C:S51-9.

63. Buist AS, Vollmer WM, Sullivan SD, Weiss KB, Lee TA, Menezes AM, Crapo RO, Jensen RL, Burney PG. The Burden of Obstructive Lung Disease Initiative (BOLD): rationale and design. COPD 2005;2:277-83.

64. Chapman KR, Tashkin DP, Pye DJ. Gender bias in the diagnosis of COPD. Chest 2001;119:1691-5.

65. Vermeeren MA, Creutzberg EC, Schols AM, et al. Prevalence of nutritional depletion in a large outpatient population of patients with COPD. Respir Med 2006;100:1349-55.

66. Chailleux E, Laaban JP, Veale D. Prognostic value of nutritional depletion in patients with COPD treated by long-term oxygen therapy: data from the ANTADIR observatory. Chest 2003;123:1460-6.

67. De Bacquer D, De Backer G, Kornitzer M, Blackburn H. Prognostic value of ECG findings for total, cardiovascular disease, and coronary heart disease death in men and women. Heart 1998;80:570-7.

68. Greenland P, Xie X, Liu K, Colangelo L, Liao Y, Daviglus ML, Agulnek AN, Stamler J. Impact of minor electrocardiographic ST-segment and/or T-wave abnormalities on cardiovascular mortality during longterm follow-up. Am J Cardiol 2003;91:1068-74.

69. Kumar A, Prineas RJ, Arnold AM, Psaty BM, Furberg CD, Robbins J, Lloyd-Jones DM. Prevalence, prognosis, and implications of isolated minor nonspecific ST-segment and T-wave abnormalities in older adults: Cardiovascular Health Study. Circulation 2008;118:2790-6.

70. Huiart L, Ernst P, Suissa S. Cardiovascular morbidity and mortality in COPD. Chest 2005;128:2640-6.

71. Cavalcante JL, Lima JA, Redheuil A, et al. Aortic stiffness: current understanding and future directions. J Am Coll Cardiol 2011;57:1511-22. 



\section{CHAPTER 2}

The prevalence of COPD

in Maastricht, the Netherlands

Lowie E.G.W. Vanfleteren, Frits M.E. Franssen, Geertjan Wesseling, Emiel F.M Wouters

Respiratory Medicine 2012;106:871-874 


\section{ABSTRACT}

\section{Background}

Chronic obstructive pulmonary disease (COPD) is an increasing public health problem worldwide. Although epidemiologic data on COPD are important to raise awareness of the burden of disease, there are no actual spirometry-based data on the prevalence of COPD in the Netherlands.

\section{Methods}

Using the Burden of Obstructive Lung Disease (BOLD) protocol and study design, a populationbased sample of adults, aged $\geq 40$ years, in the area of Maastricht, the Netherlands was surveyed. Post-bronchodilator spirometry and questionnaires with information on smoking history and reported respiratory disease were collected. COPD was defined as post-bronchodilator $\mathrm{FEV}_{1} / \mathrm{FVC}$ ratio $<0.7$ (GOLD) or <the lower limit of normal (LLN) (95th percentile) of the population distribution for $\mathrm{FEV}_{1} / \mathrm{FVC}$. Data were statistically weighted for the total number of people in the Maastricht population.

\section{Results}

Overall prevalence of COPD was $24 \%$, and was higher for men $(28.5 \%)$ than for women $(19.5 \%)$. (unweighted $\mathrm{p}=0.002$ ) The prevalence of GOLD stage 2 or higher COPD was $10 \%$. The prevalence of LLN defined COPD was $19 \%$ and $10 \%$ for stage 2 or higher. Overall prevalence of current smoking was $23 \%$. The prevalence of COPD increased with age and amount of packyears, although $14 \%$ of never smokers fulfilled spirometric criteria for COPD. The prevalence of doctordiagnosed COPD was only $8.8 \%$.

\section{Conclusion}

Almost one quarter of the Maastricht population aged $\geq 40$ years had COPD. Considering the ageing population and still an important smoking prevalence, this burden is bound to increase and imposes great demands to public health care and society in the Netherlands. 


\section{INTRODUCTION}

Chronic obstructive pulmonary disease (COPD) is a serious and increasing public health problem throughout the world. Although preventable, COPD cannot be cured and causes high levels of disability. This imposes increasing demands on regional health care systems and a growing economic burden on society. Lost productivity due to COPD has a particularly high impact on the economy, accounting for $50 \%$ of the overall COPDrelated societal cost in the Netherlands. ${ }^{1,2}$

Although epidemiologic data on COPD are important to raise awareness of the burden of this disease, country-specific studies on the current and future impact of COPD in the Netherlands are scarce. Available date are mostly based on physician's diagnosis of "COPD", "chronic bronchitis" or "lung emphysema". ${ }^{3}$ Moreover, COPD tends to be underdiagnosed and undertreated by healthcare professionals in the Netherlands. ${ }^{2}$

Therefore, the aim of the present study was to assess the prevalence of COPD and its risk factors in the general population aged 40 years and older in Maastricht, the Netherlands. To achieve both maximum accuracy and completeness of the survey as well as high-quality post-bronchodilator spirometry, the Burden of Obstructive Lung Disease (BOLD) protocol and study design were implemented. ${ }^{4}$

\section{METHODS}

A population-based cross-sectional study of the prevalence of COPD in the area of Maastricht, the Netherlands was conducted from October 2007 till March 2009. The BOLD protocol and definitions of smoking history were followed. ${ }^{4}$ Municipal administrators sampled adults aged $\geq 40$ years at random from the population. Following a recruitment letter, subjects were contacted by phone and a clinic visit was scheduled. All participants gave written informed consent. The study was approved by medical ethical committee of Maastricht University Medical Center.

COPD was defined according to $\mathrm{GOLD}^{5}$ or according to the lower limit of normal (LLN), which is beneath the $95^{\text {th }}$ percentile of population distribution for the $\mathrm{FEV}_{1} / \mathrm{FVC}$ ratio according to NHANES. ${ }^{6}$ COPD stage 2 or higher was defined as $\mathrm{FEV}_{1}<80 \%$ of predicted. Doctor-diagnosed COPD was defined as a self-reported physician's diagnosis of chronic bronchitis, emphysema, or COPD.

Prevalence estimates for the overall Maastricht population, as well as for subgroups defined by gender and either age or pack-years of cigarette smoking were calculated using the Stata package (Stata Corporation, College Station, TX USA). Weighting class adjustments were made to adjust for differential response rates for the eight categories 
defined by gender and age, to assure that the estimated prevalences and SEs properly reflect the sampling design. Differences within the study sample were calculated on the unweighted dataset, using two-sided p-value based on Pearson chi-square test.

\section{RESULTS}

A total of 634 of 1345 subjects (47\%) selected for recruitment signed informed consent. This is $48 \%$ of the 1323 subjects whom the site attempted to contact (22 were ineligible), and $55 \%$ of the 1147 successful contacted subjects. Compared to participants subjects who denied participation or could not be reached were more prevalent in the $70+$ age category $(p<0.05)$, but there were no differences in gender $(p>0.05)$ or smoking history $(p>0.05)$. Forty-two subjects were excluded because of unacceptable post-bronchodilator spirometry. These were more frequently current smokers compared to 592 subjects included in the analyses ( $43 \%$ vs. $23 \%, p<0.01)$ Baseline characteristics are listed in Table 2.1.

Table 2.1 Characteristics of subjects included in the analyses.

\begin{tabular}{llr}
\hline No. & & $592(100 \%)$ \\
Age & $40-49$ & $160(27 \%)$ \\
& $50-59$ & $182(31 \%)$ \\
& $60-69$ & $167(28 \%)$ \\
Gender & $70+$ & $83(14 \%)$ \\
& Male & $300(51 \%)$ \\
Smoking status & Current & $292(49 \%)$ \\
& Ex & $136(23 \%)$ \\
& Never & $252(43 \%)$ \\
Doctor diagnosed asthma & $204(34 \%)$ \\
Doctor diagnosed COPD, chronic bronchitis or emphysema & $60 / 591(10 \%)$ \\
\hline
\end{tabular}

Results are for observed sample only and are not population estimates.

Estimated population prevalence of GOLD- and LLN-defined COPD by age, gender and smoking status is presented in Tables 2.2 and 2.3. The estimated prevalence of doctordiagnosed COPD was $8.8 \%$ (SE:1.2).

The estimated prevalence of current smoking was 23\% (SE:1.8) and was similar for both sexes. (Male 24\% (SE:2.4); female 22\% (SE:2.7)) The prevalence of ever smokers (overall $63 \%(\mathrm{SE}: 2.1))$ was higher in men (70\% (SE:2.7) than in women $(57 \%$ (SE:3.2) $(p<0.001)$. The highest prevalence of ever smokers was in men, 60-69 years old and was $85 \%$ (SE:3.7). Thirty-one percent\% of the population ever smoked more than 20 pack-years. Of these subjects, $22 \%$ had at least GOLD stage 2 COPD and $11 \%$ had doctor diagnosed COPD. 
Table 2.2 Estimated Population Prevalence of GOLD stage 1 or higher, GOLD stage 2 or higher, LLN stage 1 or higher, LLN stage 2 or higher COPD by age and sex.

\begin{tabular}{lcrrr}
\hline & Age & \multicolumn{1}{c}{ Male } & Female & \multicolumn{1}{c}{ Total } \\
\hline GOLD 1+ & 40-49 & $9.0 \%(3.4)$ & $5.8 \%(3.0)$ & $7.4 \%(2.2)$ \\
& $50-59$ & $27.4 \%(4.9)$ & $18.4 \%(4.1)$ & $22.9 \%(3.2)$ \\
& $60-69$ & $37.0 \%(5.3)$ & $18.4 \%(4.2)^{*}$ & $27.6 \%(3.5)$ \\
& $70+$ & $51.2 \%(7.7)$ & $35.6 \%(8.2)$ & $41.6 \%(5.9)$ \\
GOLD 2 & Total & $28.5 \%(2.8)$ & $19.5 \%(2.9)^{*}$ & $23.7 \%(2.0)$ \\
& $40-49$ & $4.4 \%(2.6)$ & $1.2 \%(1.2)$ & $2.8 \%(1.4)$ \\
& $50-59$ & $13.7 \%(3.8)$ & $8.2 \%(3.1)$ & $10.9 \%(2.4)$ \\
& $60-69$ & $18.9 \%(4.4)$ & $6.9 \%(2.7)^{*}$ & $12.8 \%(2.6)$ \\
LLN 1+ & $70+$ & $19.9 \%(6.3)$ & $15.6 \%(7.2)$ & $17.3 \%(5.0)$ \\
& Total & $13.2 \%(2.1)$ & $8.0 \%(2.3)^{*}$ & $10.4 \%(1.5)$ \\
& $40-49$ & $7.8 \%(3.2)$ & $14.0 \%(4.1)$ & $11.0 \%(2.6)$ \\
& $50-59$ & $22.6 \%(4.6)$ & $18.4 \%(4.1)$ & $20.5 \%(3.1)$ \\
& $60-69$ & $20.0 \%(4.5)$ & $16.1 \%(4.0)$ & $18.0 \%(3.0)$ \\
& $70+$ & $33.6 \%(7.4)$ & $22.3 \%(7.7)$ & $26.6 \%(5.5)$ \\
& Total & $19.7 \%(2.4)$ & $17.8 \%(2.7)$ & $18.7 \%(1.8)$ \\
& $40-49$ & $4.4 \%(2.6)$ & $3.5 \%(2.0)$ & $3.9 \%(1.6)$ \\
& $50-59$ & $12.7 \%(3.7)$ & $8.2 \%(3.1)$ & $10.4 \%(2.4)$ \\
& $60-69$ & $12.7 \%(3.7)$ & $6.9 \%(2.7)$ & $9.8 \%(2.3)$ \\
& $70+$ & $19.9 \%(6.3)$ & $15.6 \%(7.2)$ & $17.3 \%(5.0)$ \\
& Total & $11.6 \%(2.0)$ & $8.6 \%(2.3)$ & $10.0 \%(1.5)$ \\
\hline
\end{tabular}

Weighted population estimate, with SE shown in parenthesis. ${ }^{*} p<0.05$ on the unweighted population sample

Table 2.3 Estimated Population Prevalence of GOLD stage 1 or higher, GOLD stage 2 or higher, LLN stage 1 or higher, LLN stage 2 or higher COPD by pack years and sex.

\begin{tabular}{|c|c|c|c|c|}
\hline & Packyears & Male & Female & Total \\
\hline \multirow[t]{5}{*}{ GOLD $1+$} & Never smokers & $10.7 \%(3.5)$ & $16.2 \%(4.1)$ & $14.1 \%(2.8)$ \\
\hline & $0-10$ & $20.4 \%(5.6)$ & $12.0 \%(5.3)$ & $16.1 \%(3.8)$ \\
\hline & $10-20$ & $21.3 \%(6.3)$ & $20.9 \%(7.0)$ & $21.1 \%(4.7)$ \\
\hline & $20+$ & $51.0 \%(5.0)$ & $29.8 \%(6.7)^{*}$ & $41.2 \%(4.0)$ \\
\hline & Total & $28.5 \%(2.8)$ & $19.5 \%(2.9)^{*}$ & $23.7 \%(2.0)$ \\
\hline \multirow[t]{5}{*}{ GOLD $2+$} & Never smokers & $4.8 \%(2.5)$ & $2.0 \%(1.5)$ & $3.1 \%(1.3)$ \\
\hline & $0-10$ & $8.3 \%(4.2)$ & $4.6 \%(3.4)$ & $6.4 \%(2.7)$ \\
\hline & $10-20$ & $4.0 \%(2.8)$ & $7.0 \%(5.2)$ & $5.5 \%(3.0)$ \\
\hline & $20+$ & $26.4 \%(4.5)$ & $20.6 \%(6.7)$ & $23.7 \%$ (3.9) \\
\hline & Total & $13.2 \%(2.1)$ & $8.0 \%(2.3)^{*}$ & $10.4 \%(1.5)$ \\
\hline \multirow[t]{5}{*}{ LLN $1+$} & Never smokers & $4.8 \%(2.5)$ & $10.0 \%(3.1)$ & $8.0 \%(2.2)$ \\
\hline & $0-10$ & $13.2 \%(4.8)$ & $9.4 \%(4.7)$ & $11.2 \%(3.4)$ \\
\hline & $10-20$ & $17.9 \%(5.9)$ & $19.0 \%(6.9)$ & $18.5 \%(4.5)$ \\
\hline & $20+$ & $37.5 \%(4.9)$ & $35.9 \%(6.7)$ & $36.7 \%(4.1)$ \\
\hline & Total & $19.7 \%(2.4)$ & $17.8 \%(2.7)$ & $18.7 \%(1.8)$ \\
\hline \multirow[t]{5}{*}{ LLN $2+$} & Never smokers & $3.8 \%(2.3)$ & $2.0 \%(1.5)$ & $2.7 \%(1.3)$ \\
\hline & $0-10$ & $0.8 \%(4.2)$ & $6.3 \%(3.7)$ & $7.2 \%(2.8)$ \\
\hline & $10-20$ & $2.3 \%(2.3)$ & $7.0 \%(5.2)$ & $4.6 \%(2.9)$ \\
\hline & $20+$ & $23.9 \%(4.4)$ & $21.8 \%(6.7)$ & $22.9 \%(3.9)$ \\
\hline & Total & $11.6 \%(2.0)$ & $8.6 \%(2.3)$ & $10.0 \%(1.5)$ \\
\hline
\end{tabular}

Weighted population estimate, with SE shown in parenthesis. ${ }^{*} p<0.05$ on the unweighted population sample. 


\section{DISCUSSION}

Using BOLD methodology, this study showed that the prevalence of GOLD-defined COPD in the general population aged 40 years and older in Maastricht, the Netherlands is $24 \%$. Ten percent of population had COPD GOLD stage 2 or higher. Using the LLN to define COPD, still 19\% had COPD and 10\% had at least stage 2 . The overall prevalence of GOLD defined COPD was higher in men than in women. The estimated prevalence of current smokers was $23 \%$.

Based on five databases containing registrations of physician's diagnosis of COPD, chronic bronchitis or lung emphysema in primary care, the state institute for public health and environment in the Netherlands (RIVM) estimated the prevalence of COPD in 2007 as $1.8 \%$ for men and $1.6 \%$ for women. ${ }^{3}$ This reported prevalence does not approach the magnitude reported in the present study and probably underestimated the real burden of COPD. Also in the present study, the prevalence of spirometric confirmed COPD was much higher than the prevalence of physician diagnosed COPD. Even the prevalence of at least GOLD stage 2 COPD in subjects who smoked more than 20 pack years (22\%) was twice as high as the physician's diagnosis of COPD in the same group (11\%). This problem of underdiagnosis of COPD has been reported earlier. ${ }^{7,8}$ In the "confronting COPD survey" ${ }^{1}$ COPD was underdiagnosed and undertreated, in the Netherlands as well as in the six other participating countries. In the Netherlands, 19\% of patients were undiagnosed despite having symptoms consistent with COPD.

The prevalence of COPD increases with age and the amount of smoked pack-years.

A fixed ratio for $\mathrm{FEV}_{1} / \mathrm{FVC}$ to classify COPD as proposed by $\mathrm{GOLD}^{5}$ may lead to increasing false positive diagnosis of COPD with age, since $\mathrm{FEV}_{1} / \mathrm{FVC}$ physiologically reduces with age. ${ }^{9}$ This misclassification could be reduced by using the LLN for the $\mathrm{FEV}_{1} / \mathrm{FVC}$ ratio and this could possibly better distinct physiology from pathology. Using the LLN instead of the GOLD criterion to define COPD in subjects older than 70 years in this study population resulted in a reduction in COPD diagnosis from $42 \%$ to $27 \%$. This was still substantially higher than in lower age-categories. Obviously the cumulative effect of smoking history and inhalational exposures influence airflow limitation in the elderly. Current and former smoking by oneself are clearly related to age, with older men (age 60-69 years) having stunning ever-smoking prevalence up to $85 \%$. This magnitude of ever-smoking has to mean that environmental tobacco exposure has also been substantial during the foregone decades before recognition of its harmfulness. ${ }^{10}$

GOLD-defined COPD was found in $14 \%$ of persons who had never smoked. According to the LLN this was still $6 \%$. Although never smokers were less likely to have COPD than ever smokers, never smokers nonetheless comprised one fifth of all subjects with COPD. Predictors of COPD in never smokers in the international BOLD cohort included 
age, education, occupational exposure, childhood respiratory diseases and BMI alterations. $^{11}$

As generally seen among the BOLD sites throughout the world, ${ }^{12}$ also in the present study the overall prevalence of COPD was higher in men than in women. It has been predicted that the expected changes in smoking behaviour will result in a smaller increase of the projected prevalence in men and greater increase in women. ${ }^{13}$ Given men and women smoked equally in the present study, also in Maastricht the gender difference in the prevalence of COPD will equalize or possibly even reverse since women seem to be more vulnerable to develop COPD. ${ }^{14}$ Already in the youngest age group, the prevalence of COPD according to the LLN tended to be higher in women than in men. This is consistent with the remarkably high incidence of COPD in the youngest women in the Rotterdam study. ${ }^{15}$

This study also has limitations. An important limitation is the lower than desirable response rate which causes uncertainty about the representativeness of the results. On the other hand we nearly reached the sample size of at least 300 men and 300 women as requested by the BOLD protocol. The prevalence of non-responders was higher in older age, but the sample individuals were weighted for the whole population of Maastricht. Unacceptable spirometry was more frequent in smokers. Another limitation was that other potential causes of airflow limitation than COPD (e.g. asthma, sarcoidosis, bronchiectasis, bronchiolar diseases) were not excluded. However, BOLD methodology was applied in the current survey, according to published methods and protocol. According to BOLD standards, COPD diagnosis was based on the lung function criteria without requiring documented exposure to a known causative agent. ${ }^{12}$

Although the Netherlands is a developed country and COPD is a preventable disease, a surprisingly high burden of COPD was found. With the ageing population and still an important smoking prevalence, this burden is bound to increase and impose great demands to public health care and society. The government faces the important task to continue the efforts to prevent the population from exposure to noxious substances, most importantly tobacco smoke. Health care professionals should give priority to a better evaluation and diagnosis of patients with COPD, as well as improved management of COPD and take an aggressive attitude on the reduction of tobacco smoking. 


\section{REFERENCES}

1. Wouters EF. The societal impact of COPD in North America and Europe: an economic analysis of the Confronting COPD survey. Respir Med 2003;97(Suppl C:):S3-14.

2. Wouters EF. The burden of COPD in The Netherlands: results from the Confronting COPD survey. Respir Med 2003;97 Suppl C:S51-9.

3. Hoeymans N, Melse JM, Schoemaker CG. Gezondheid en determinanten. Deelrapport van de Van gezond naar beter. RIVM report. RIVM, 2010.

4. Buist AS, Vollmer WM, Sullivan SD, Weiss KB, Lee TA, Menezes AM, Crapo RO, Jensen RL, Burney PG. The Burden of Obstructive Lung Disease Initiative (BOLD): rationale and design. COPD 2005;2:277-83.

5. Rabe KF, Hurd S, Anzueto A, Barnes PJ, Buist SA, Calverley P, Fukuchi Y, Jenkins C, Rodriguez-Roisin R, van Weel C, Zielinski J; Global Initiative for Chronic Obstructive Lung Disease. Global strategy for the diagnosis, management, and prevention of chronic obstructive pulmonary disease: GOLD executive summary. Am J Respir Crit Care Med 2007;176:532-55.

6. Hankinson JL, Odencrantz JR, Fedan KB. Spirometric reference values from a sample of the general U.S. population. Am J Respir Crit Care Med 1999;159:179-87.

7. Schirnhofer L, Lamprecht B, Vollmer WM, Allison MJ, Studnicka M, Jensen RL, Buist AS. COPD prevalence in Salzburg, Austria: results from the Burden of Obstructive Lung Disease (BOLD) Study. Chest 2007;131:29-36.

8. Dirven JA, Muris JW, van Schayck CP. COPD screening in general practice using a telephone questionnaire. COPD 2010;7:352-9.

9. Hardie JA, Buist AS, Vollmer WM, Ellingsen I, Bakke PS, Mørkve O. Risk of over-diagnosis of COPD in asymptomatic elderly never-smokers. Eur Respir J 2002;20:1117-22.

10. Callinan JE, Clarke A, Doherty K, Kelleher C. Legislative smoking bans for reducing secondhand smoke exposure, smoking prevalence and tobacco consumption. Cochrane Database Syst Rev, 2010(4): CD005992.

11. Lamprecht B, McBurnie MA, Vollmer WM, Gudmundsson G, Welte T, Nizankowska-Mogilnicka E, Studnicka M, Bateman E, Anto JM, Burney P, Mannino DM, Buist SA; BOLD Collaborative Research Group. COPD in never smokers: results from the population-based burden of obstructive lung disease study. Chest 2011;139:752-63.

12. Buist AS, McBurnie MA, Vollmer WM, Gillespie $S$, Burney $P$, Mannino DM, Menezes AM, Sullivan SD, Lee TA, Weiss KB, Jensen RL, Marks GB, Gulsvik A, Nizankowska-Mogilnicka E; BOLD Collaborative Research Group. International variation in the prevalence of COPD (the BOLD Study): a populationbased prevalence study. Lancet 2007;370:741-50.

13. Feenstra TL, van Genugten ML, Hoogenveen RT, Wouters EF, Rutten-van Mölken MP. The impact of aging and smoking on the future burden of chronic obstructive pulmonary disease: a model analysis in the Netherlands. Am J Respir Crit Care Med 2001;164:590-6.

14. Foreman MG, Zhang L, Murphy J, Hansel NN, Make B, Hokanson JE, Washko G, Regan EA, Crapo JD, Silverman EK, DeMeo DL; COPDGene Investigators. Early-onset chronic obstructive pulmonary disease is associated with female sex, maternal factors, and African American race in the COPDGene Study. Am J Respir Crit Care Med 2011;184:414-20.

15. van Durme YM, Verhamme KM, Stijnen T, van Rooij FJ, Van Pottelberge GR, Hofman A, Joos GF, Stricker $\mathrm{BH}$, Brusselle GG. Prevalence, incidence, and lifetime risk for the development of COPD in the elderly: the Rotterdam study. Chest 2009;135:368-77. 


\title{
CHAPTER 3
}

\section{Sex-related differences in respiratory}

\author{
symptoms: results from the BOLD study
}

Bernd Lamprecht*, Lowie E.G.W. Vanfleteren*, Michael Studnicka, M.J. Allison, Mary Ann McBurnie, William M. Vollmer, Wan C. Tan, Rune Nielsen, Pawel Nastalek, Louisa Gnatiuc, Bernhard Kaiser, Christer Janson, Emiel F.M. Wouters, Peter Burney, Sonja Buist

* contributed equally to this manuscript and are joint first authors 

For both men and women, the pathway to diagnosis and treatment of lung disease often begins with the reporting of respiratory symptoms to their physician. Men and women with impaired lung function may experience the same symptoms but perceive and/or report them differently.

Physiologic research on dyspnea has provided some information on how gender differences in lung and airway size can influence the experience of dyspnea during exercise, ${ }^{1}$ however there is still a knowledge gap with regard to gender-related differences in other respiratory symptoms, including cough and sputum production.

The objective of this analysis was to address this knowledge-gap with regard to respiratory symptoms in men and women with normal and impaired lung function using data of the international population-based Burden of Obstructive Lung Disease (BOLD) study. ${ }^{2}$

The design and rationale for the BOLD Initiative and preliminary prevalence data have been published elsewhere. ${ }^{2}$

Representative population random sampling plans were used for the recruitment of participants for all study sites. As of June 2011, 20 sites (in 18 countries) had completed data collection and are included in this analysis: Guangzhou (China), Adana (Turkey), Salzburg (Austria), Cape Town (South Africa), Reykjavik (Iceland), Hannover (Germany), Krakow (Poland), Bergen (Norway), Vancouver (Canada), Lexington (USA), Manila (Philippines), Sydney (Australia), London (United Kingdom), Uppsala (Sweden), Mumbai (India), Pune (India), Lisbon (Portugal), Maastricht (The Netherlands), Nampicuan/ Talugtug (Philippines), and Tartu (Estonia).

13,757 participants with acceptable post-bronchodilator spirometry were included in the analyses. The study recorded questionnaire data on respiratory symptoms, health status, and exposure to risk factors for COPD.

We defined airflow limitation consistent with COPD as the ratio of post-bronchodilator forced expiratory volume in one second $\left(\mathrm{FEV}_{1}\right)$ to forced vital capacity (FVC) below the lower limit of normal (LLN), and used $\mathrm{FEV}_{1}$ to further grade the disease: $\mathrm{FEV}_{1}<80 \%$ predicted serving as the threshold for COPD stage 2 and an $\mathrm{FEV}_{1}<50 \%$ predicted serving as the threshold for COPD stage 3 or higher. The third National Health and Nutrition Examination Survey (NHANES) reference equations ${ }^{3}$ were used to calculate predicted values. Following the traditional practice of considering irreversible airflow limitation to be COPD, the COPD diagnosis was strictly based on the post-bronchodilator lung function criteria without requiring documented exposure to a known causative agent. $A$ normal lung function was defined as a post-bronchodilator $\mathrm{FEV}_{1} / \mathrm{FVC}$ ratio $\geq \mathrm{LLN}$ and $F V C \geq 80 \%$. A restrictive lung function pattern was defined present when the $\mathrm{FEV}_{1} / \mathrm{FVC}$ ratio was $\geq$ LLN and FVC was $<80 \%$ predicted. Presence of self-reported cough was assessed using the following question: "Do you usually cough when you don't have a 
cold?" Self reported phlegm was based on the answer to the following question: "Do you usually bring up phlegm from your chest, or do you usually have phlegm in your chest that is difficult to bring up when you don't have a cold?" Self reported wheezing and its intensity were recorded based on the answers to the following questions: "Have you had wheezing or whistling in your chest at any time in the last 12 months?" and, if appropriate, "In the last 12 months, have you had this wheezing or whistling only when you have a cold?" For this analysis wheeze was defined by "yes" to the first and "no" to the second question. Presence and severity of self reported dyspnea was recorded according to the modified Medical Research Council (mMRC) dyspnea scale (0-4). Severe dyspnea was defined as $\mathrm{mMRC}$ grade 3-4.

Logistic regression was used for evaluation of gender-differences and all results were adjusted for smoking status (current/ex/never), age, BMI, co-morbidities (using binary indicators for heart disease, hypertension, stroke, diabetes, and lung cancer), and site.

Any respiratory symptoms (dyspnea, cough, phlegm, or wheeze) were significantly more often reported by females than males with normal lung function ( $50 \%$ vs. $43 \%$, $p<0.001)$, and restrictive lung function pattern ( $55 \%$ vs. $43 \%, p<0.001)$. In contrast, no significant difference in reported respiratory symptoms were seen in COPD stage 3-4 (88\% vs. 91\%, p=0.996).

Overall, female gender was associated with increased odds for reported dyspnea (OR 1.74; 95\% Cl 1.59-1.90; $\mathrm{p}<0.0001$ ) and reported cough (OR 1.26; 95\% Cl 1.16-1.38; $p<0.0001$ ) but not for reported wheeze (OR 1.05; 95\% Cl 0.96-1.15; $p=0.270$ ). In contrast, female gender was associated with decreased odds for reported phlegm (OR $0.91 ; 95 \% \mathrm{Cl} 0.84-0.99 ; \mathrm{p}<0.042$ ). Odds ratios of cough, wheeze, dyspnea, and phlegm by lung function are shown in Figure 3.1. While women compared to men had increased odds for dyspnea in all lung function categories, increased odds for cough were only seen in normal and restrictive lung function. In contrast, decreased odds for phlegm were observed in normal lung function and COPD.

Our results indicate that for the same degree of lung function impairment women tend to report more dyspnea and cough, but less phlegm/sputum production than men.

This is in accordance with results of the Confronting COPD International Survey showing that despite lower packyears of smoking, women were more likely to report severe dyspnea than men, with similar cough and less sputum. ${ }^{4}$ There is evidence that compared with men, women with COPD report more functional dyspnea for the same degree of airflow limitation. ${ }^{5}$

A relationship exists between the sensation of dyspnea and respiratory muscle strength. As men can generate greater maximal inspiratory and expiratory pressures than women, ${ }^{6}$ this could probably explain why female subjects with COPD are more 
dyspneic than men. In addition to this, natural anatomic differences in the size of the lungs, airways and respiratory musculature account for a relatively reduced maximum ventilatory reserve (capacity) in women. ${ }^{7}$

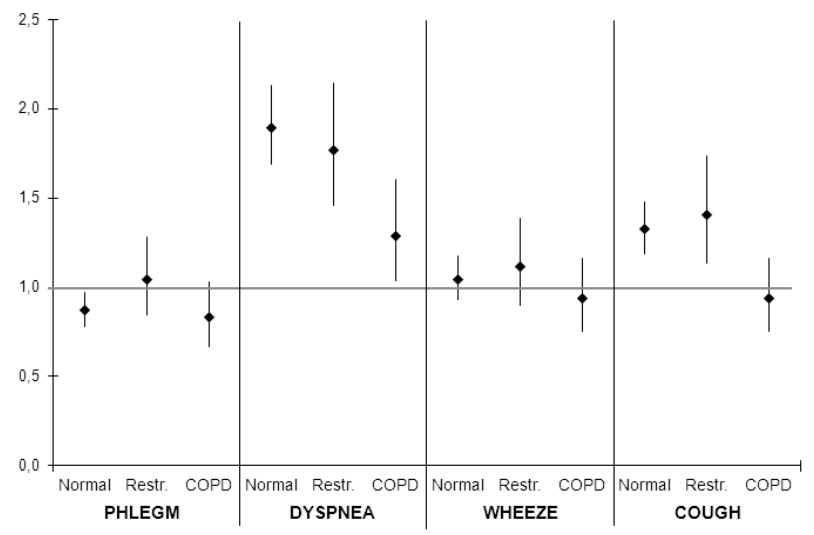

Figure 3.1 Odds ratios of respiratory symptoms in women (compared to men) by lung function. Odds ratios are adjusted for smoking-status, age, BMI, co-morbidities, and site.

Neurobiologic studies demonstrated that women have a higher intrinsic sensitivity to noxious somatic sensations, including dyspnea. ${ }^{8}$ Finally, women are held to an expectation of beauty and youthfulness, whereas men are expected to be physically strong and robust. These expectations may be disrupted by COPD, ${ }^{9}$ however these expectations may influence the perception and expression of respiratory symptoms in men and women. Thus, men might be less likely to describe themselves as breathless than women; and women might be less likely to report sputum or phlegm production. Physicians need to recognize that although a woman may not report sputum or phlegm production and a man may not report dyspnea, a diagnosis of COPD should still be considered.

Power was limited in very severe airflow limitation due to relatively small numbers. Taking into consideration that "COPD" has still a poor term recognition in many of our participating sites we collapsed the reported diagnoses of "COPD", "Emphysema", and "Chronic Bronchitis" when presenting reported diagnoses. For the analyses however, "COPD" was strictly defined by a post-bronchodilator airflow limitation (FEV $1 /$ FVC $<$ LLN) regardless of any reported diagnosis or risk factor.

We conclude that for the same degree of lung function impairment women tend to report more (severe) dyspnea and cough, but less phlegm. The knowledge about this difference in reporting symptoms is important as symptoms often are the first step to a diagnosis of underlying airway disease. 


\section{REFERENCES}

1. Ofir D, McBride I, Webb KA, Dudgeon DJ, O'Donnell DE. Gender differences in exertional dyspnea with advancing age [abstract]. Proc Am Thorac Soc 2006;3:A224.

2. Buist AS, McBurnie MA, Vollmer WM, Gillespie $S$, Burney $P$, Mannino DM, Menezes AM, Sullivan SD, Lee TA, Weiss KB, Jensen RL, Marks GB, Gulsvik A, Nizankowska-Mogilnicka E; BOLD Collaborative Research Group. International variation in the prevalence of COPD (the BOLD Study): a populationbased prevalence study. Lancet 2007;370:741-50.

3. Hankinson JL, Odencrantz JR, Fedan KB. Spirometric reference values from a sample of the general U.S. population. Am J Respir Crit Care Med 1999;159:179-87.

4. Watson L, Vestbo J, Postma DS, Decramer M, Rennard S, Kiri VA, Vermeire PA, Soriano JB. Gender differences in the management and experience of Chronic Obstructive Pulmonary Disease. Respir Med 2004;98:1207-13.

5. de Torres JP, Casanova C, Hernández C, Abreu J, Aguirre-Jaime A, Celli BR. Gender and COPD in patients attending a pulmonary clinic. Chest 2005;128:2012-6.

6. Black LF, Hyatt RE. Maximal respiratory pressures: normal values and relationship to age and sex. $A m$ Rev Respir Dis 1969;99:696-702.

7. Camp PG, O'Donnell DE, Postma DS. Chronic obstructive pulmonary disease in men and women: myths and reality. Proc Am Thorac Soc 2009;6:535-8.

8. Becklake MR, Kauffmann F. Gender differences in airway behaviour over the human life span. Thorax 1999;54:1119-38.

9. Johnson JL, Campbell AC, Bowers M, Nichol AM. Understanding the social consequences of chronic obstructive pulmonary disease: the effects of stigma and gender. Proc Am Thorac Soc 2007;4:680-2. 


\section{CHAPTER 4}

\section{The body mass index and chronic airflow}

limitation in a world-wide

population-based study

Lowie E.G.W. Vanfleteren*, Bernd Lamprecht*, Michael Studnicka, Bernhard Kaiser, Louisa Gnatiuc, Peter Burney, Emiel F.M Wouters, Frits M.E. Franssen

* contributed equally to this manuscript and are joint first authors 


\section{ABSTRACT}

\section{Background}

Nutritional status has been associated with clinical outcome and prognosis in patients with chronic airflow limitation (CAL). However, there is a scarcity of epidemiological studies on the association between body mass index (BMI) and CAL. We aimed to assess the relationship between $\mathrm{BMI}$ and presence of CAL in a worldwide population, taking into account confounding factors.

\section{Methods}

18606 participants ( $49 \%$ male, $21 \%$ current smokers, mean age: $55.8 \pm 11.2$ years, mean BMI: $26.7 \pm 5.5 \mathrm{~kg} / \mathrm{m}^{2}$ ) of the Burden of Obstructive Lung Disease (BOLD) initiative from 26 sites in 23 countries were included. CAL was defined spirometrically as post-bronchodilator $\mathrm{FEV}_{1} / \mathrm{FVC}<$ lower limit of normal. Low $\mathrm{BMI}$ was defined as $<21 \mathrm{~kg} / \mathrm{m}^{2}$, and obese $\mathrm{BMI}$ as $\geq 30 \mathrm{~kg} / \mathrm{m}^{2}$. Multivariate logistic regression analysis controlled for confounders age, sex and smoking, and meta-analysis took account of between-site heterogeneity and clustering.

\section{Results}

Prevalence of low and obese BMI, smoking history and prevalence of CAL was highly variable between sites. After adjustment for age, sex and smoking, the meta-analysis of all sites showed that compared to subjects without CAL, low BMI was more frequent in subjects with CAL, (adjusted odds ratio (OR): 2.23 (95\% confidence interval: 1.75, 2.85)) and conversely, obesity was less frequent in subjects with CAL (adjusted OR: $0.78(0.65,0.94))$.

\section{Conclusions}

In a worldwide population sample the presence of CAL was associated with lower BMI, even after adjusting for confounding factors age, gender, smoking and between-site heterogeneity. These results indicate a CAL-specific association with body composition. 


\section{INTRODUCTION}

Low body weight has been observed in $10-20 \%$ of outpatients with mild to moderate chronic obstructive pulmonary disease (COPD) $)^{1,2}$ and in $37 \%$ of patients with severe disease referred for pulmonary rehabilitation. ${ }^{3}$ Moreover, low body mass index (BMI) is related to increased mortality in these patients, ${ }^{4-7}$ independent of disease severity. ${ }^{6}$ Also, in the general population, increased mortality in subjects with low to normal BMI is mainly due to respiratory diseases. ${ }^{8}$ This inverse association is much stronger for smokers than for non-smokers. ${ }^{8}$ Nevertheless, the association between low body weight and chronic airflow limitation (CAL) remains incompletely understood as it has only been studied in selected patient populations. ${ }^{1,7}$ Earlier studies did not account for the impact of smoking, ${ }^{9}$ gender, ${ }^{10}$ and age ${ }^{11}$ on body weight.

On the other hand obesity is increasingly recognized as a risk factor for respiratory symptoms $^{12}$ and functional limitation ${ }^{13}$ in COPD. Furthermore, while obesity may be associated with low mortality in patients with severe airflow obstruction, a higher mortality rate was seen in mild to moderate COPD patients with obesity. 3,6 Epidemiologic data on obesity in subjects with CAL in general population samples are scarce and conflicting. ${ }^{14,15}$

The Burden of Obstructive Lung Disease (BOLD) initiative is an international populationbased study implementing rigorous standardized methods for estimating CAL prevalence (high-quality postbronchodilator spirometry) and its risk factors. While BMI has already been described in the context of other possible risk factors for the presence of airflow limitation in BOLD, ${ }^{16,17}$ the principal objective of the present study was to study in detail the relation between low and obese BMI and the presence of CAL in a general worldwide population, taking into account the impact of gender, smoking status, age and site-to-site heterogeneity.

\section{METHODS}

\section{STUDY DESIGN AND PARTICIPANTS}

The design and rationale for the BOLD initiative and prevalence data have been previously published. ${ }^{18,19}$

Representative samples of the non-institutionalised population over the age of 39 years were selected for all study sites. As of February 2014, 26 sites (in 23 countries) had completed data collection and are included in this analysis: Adana (Turkey), Annaba (Algeria), Bergen (Norway), Cape Town (South Africa), Fes (Morocco), Guangzhou 
(China), Hannover (Germany), Ife (Nigeria), Krakow (Poland), Lexington (USA), Lisbon (Portugal), London (United Kingdom), Maastricht (the Netherlands), Manila (Philippines), Mumbai (India), Nampicuan/Talugtug (Philippines), Pune (India), Reykjavik (Iceland), Salzburg (Austria), Sousse (Tunisia), Srinagar (India), Sydney (Australia), Tartu (Estonia), Tirana (Albania), Uppsala (Sweden), Vancouver (Canada).

Each participating site aimed to recruit a population-based sample of at least 600 adults (300 men and 300 women) living in a well-defined administrative area in which the total population exceeded 150,000. Approval was obtained from each local ethics committee, and written informed consent was obtained from each participant. All participants included in this analysis performed postbronchodilator spirometry.

\section{SPIROMETRY TESTING}

Spirometry was performed according to American Thoracic Society (ATS) criteria ${ }^{20}$ by trained and certified technicians using the ndd EasyOne spirometer (ndd Medical Technologies; Zurich, Switzerland) with participants in a seated position. Separate measurements of forced expiratory volume in the first second $\left(F E V_{1}\right)$ and forced vital capacity (FVC) were made before and at least 15 min after two puffs of salbutamol (200 $\mu \mathrm{g}$ ) administered with a metered dose inhaler with Volumatic spacer (GlaxoSmithKline; Uxbridge, England). Spirometry data were sent electronically to the Pulmonary Function Quality Control Center in Salt Lake City, Utah, or London where each spirogram was reviewed and graded using ATS guidelines. ${ }^{20}$

\section{DEFINITIONS}

\section{Chronic airflow limitation (CAL)}

The definition of CAL was based on the post-bronchodilator lung function and defined according to lower limit of normal (LLN), which is beneath the $5^{\text {th }}$ percentile of the population distribution for the $\mathrm{FEV}_{1} / \mathrm{FVC}$ ratio. Non-obstructive lung function was defined as a post-bronchodilator $\mathrm{FEV}_{1} / \mathrm{FVC}$ ratio $\geq \mathrm{LLN}$.

\section{Smoking status}

A current or ex-smoker was defined as a person who had smoked $>20$ packs of cigarettes in a lifetime or $>1$ cigarette/day for a year. An ex-smoker was further defined by a self-report of having stopped smoking.

\section{Body mass index}

Body height was measured to the nearest $0.5 \mathrm{~cm}$. Body weight (BW) was assessed to the nearest $0.1 \mathrm{~kg}$ after emptying the bladder and with the subjects standing barefoot and wearing light indoor clothing. BMI was calculated as body weight/height ${ }^{2}\left(\mathrm{~kg} / \mathrm{m}^{2}\right)$. 
A priori, BMI was categorized into low $\left(<21 \mathrm{~kg} / \mathrm{m}^{2}\right)^{6}$, normal $\left(21-24.9 \mathrm{~kg} / \mathrm{m}^{2}\right)$, high $\left(25-29.9 \mathrm{~kg} / \mathrm{m}^{2}\right)^{21}$ and obese $\left(>30 \mathrm{~kg} / \mathrm{m}^{2}\right) .^{21}$

\section{STATISTICAL ANALYSIS}

Statistics were performed using SAS version 9.3. Results are mainly expressed as mean \pm standard deviation for quantitative variables. Independent samples Student's t-test and the Wilcoxon-Mann-Whitney Test were used to investigate differences in mean BMI between subjects with and without CAL. Kernel density estimation (KDE), a non-parametric way to estimate the probability density function of a random variable, was used to create the distribution figures. To test whether two or more distributions are different, the Chi-Square test was used.

The meta-analyses of the calculated adjusted odds ratios and $95 \%$ confidence intervals were calculated using the Cochrane Meta-analysis software RevMan 5.1. The v2-based Cochran's $Q$ statistic and the $I^{2}$ metric were used to quantify between-study heterogeneity. A $p<0.10$ for the $Q$ statistic was considered significant. An $\mathrm{I}^{2}$ metric of $>25 \%$ and $>50 \%$ was considered indicating moderate and large heterogeneity, respectively. Since significant between-study heterogeneity was found, random effects meta-analysis was used to combine data across sites.

\section{RESULTS}

\section{GENERAL CHARACTERISTICS}

A total of 18606 subjects $\geq 40$ years had acceptable postbronchodilator spirometry, weight and height measurement, and available information on smoking status. (Figure 4.1)

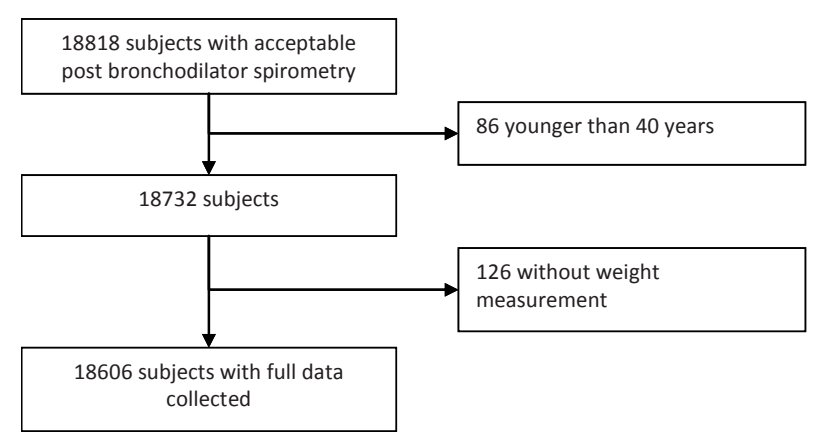

Figure 4.1 Flowchart of the study population. 
In general, subjects were overweight with a mean age of $56 \pm 11$ years. CAL was present in $11 \%$ of subjects. Prevalence of CAL ranged from $6.2 \%$ in Pune, India to $18.9 \%$ in Cape Town, South Africa. More than half of subjects never smoked and almost a quarter were current smokers.

Characteristics for each site are shown in Table 4.1. Important differences in BMI were observed between sites. For example, in Uppsala, Sweden low BMI was only seen in 3\% of subjects while in Nampicuan - Talugtug, the Philippines this percentage was up to $47 \%$. On the other hand obesity was present in only $3 \%$ of Chinese subjects, but was present in $47 \%$ of participants from Lexington, USA.

\section{DISTRIBUTION OF BMI IN THE POOLED DATASET}

Subjects with CAL had lower mean BMI compared to subjects without CAL (mean BMI, $\mathrm{kg} / \mathrm{m}^{2}$ : CAL: $25.4 \pm 5.5$; non-CAL: 26.8 $\pm 5.4 ; \mathrm{p}<0.0001$ ). (Figure 4.2) Likewise, in subjects with CAL compared to subjects without CAL, a higher proportion with a low BMI $(21.8 \%$ versus $12.3 \% ; \mathrm{p}<0.001)$ and lower proportion with an obese $\mathrm{BMI}(17.6 \%$ versus $24.3 \%$; $\mathrm{p}<0.001)$ was found. Even when gender-, age-, and smoking-specific strata were investigated, the presence of CAL was consistently associated with a shift of the distribution towards lower BMI, when compared to subjects without CAL. (Supplemental Figures S4.1-S4.3)

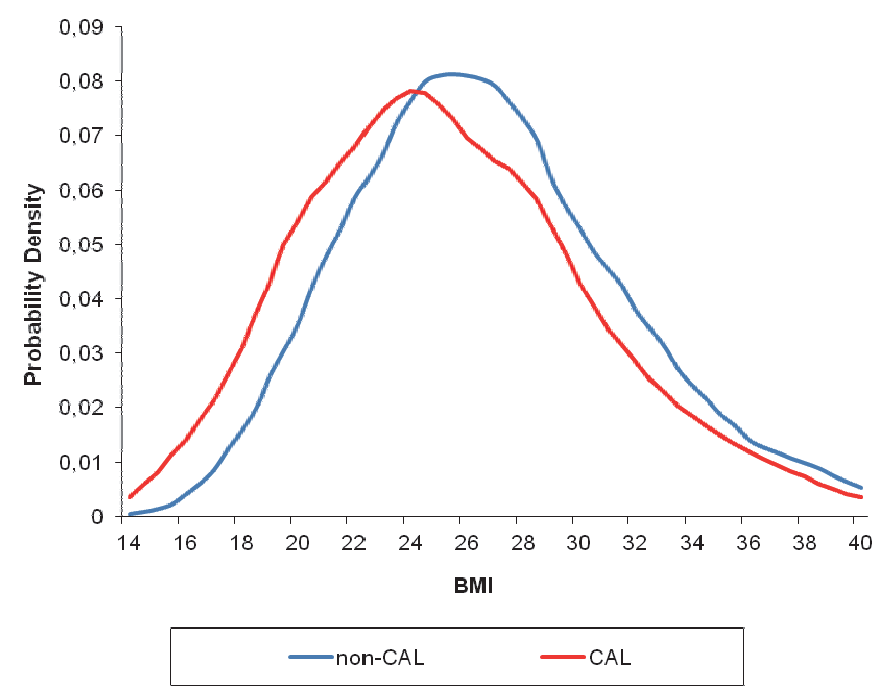

Figure 4.2 Distribution of BMI in subjects with and without chronic airflow limitation.

Mean BMI $\left(\mathrm{kg} / \mathrm{m}^{2}\right)$ : CAL: $25.4 \pm 5.5$ vs. non-CAL: $26.8 \pm 5.4, p<0.001$; difference in KDE: $p<0.001$ 


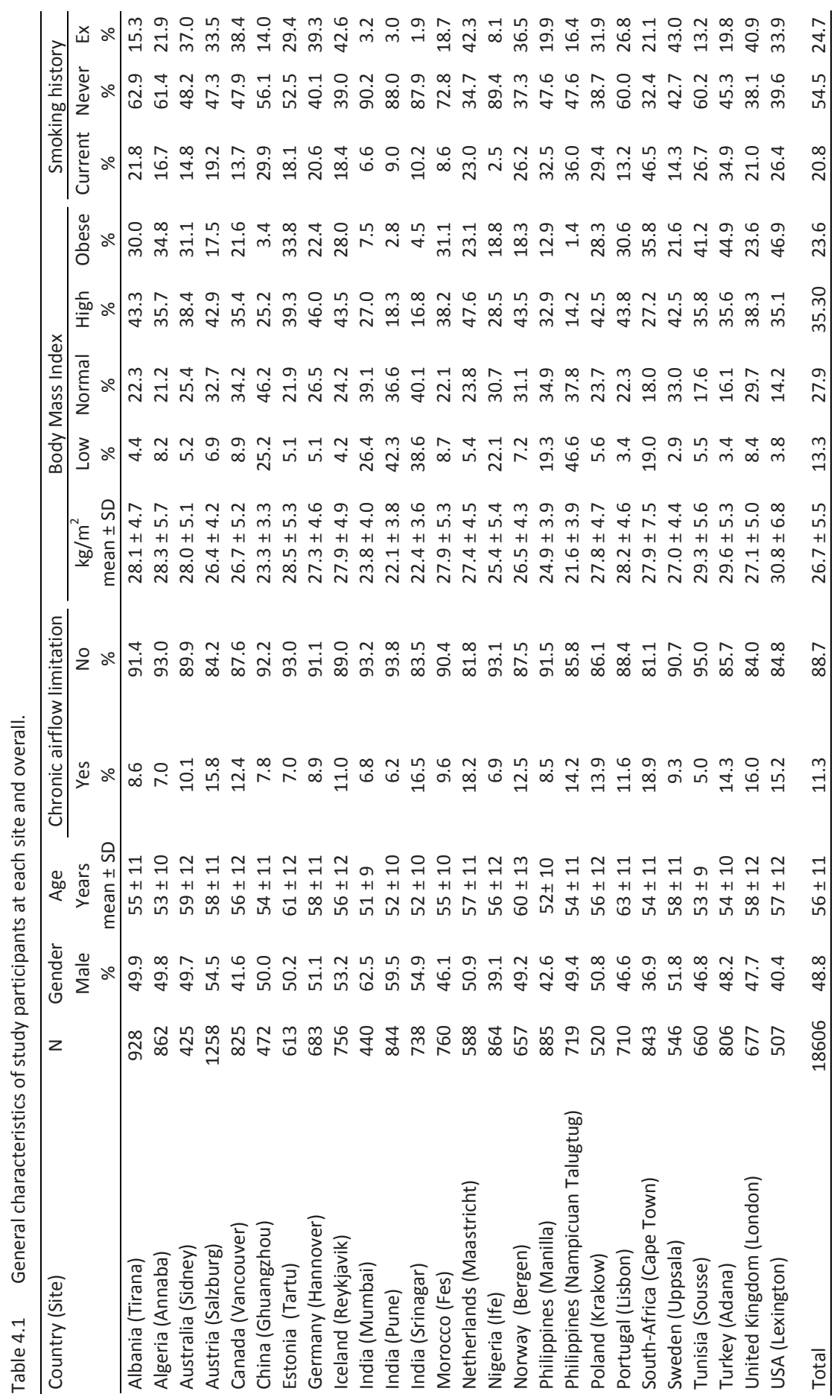




\section{EFFECTS OF SMOKING IN THE POOLED DATASET}

BMI was significantly different between current, former and never smokers (respectively $25.5 \pm 5.2 ; 26.9 \pm 5.2$ and $26.8 \pm 5.6 \mathrm{~kg} / \mathrm{m}^{2} ; \mathrm{p}<0.001$ ) and was lowest in current smokers. The prevalence of low BMI in current smokers with CAL (28.8\%) was significantly increased compared to current smokers without CAL $(16.7 \% ; p<0.001)$ as also compared to never smokers with CAL (21.1\%; $p<0.001)$. Never smokers without CAL had the lowest proportion of subjects with a low BMI (13.1\%) (Figure 4.3).

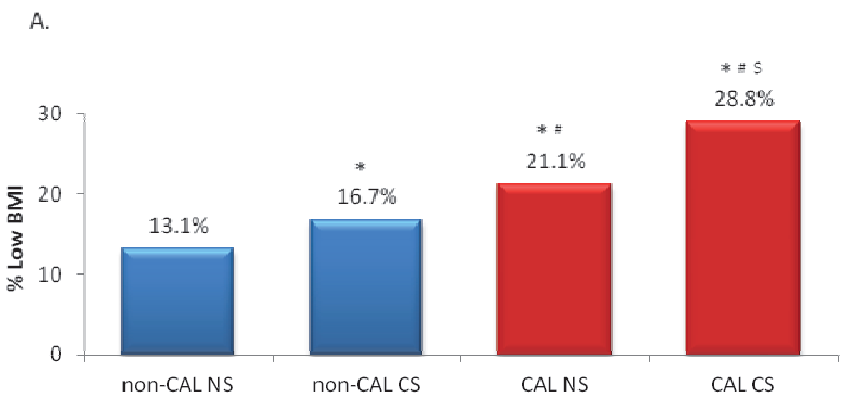

B.

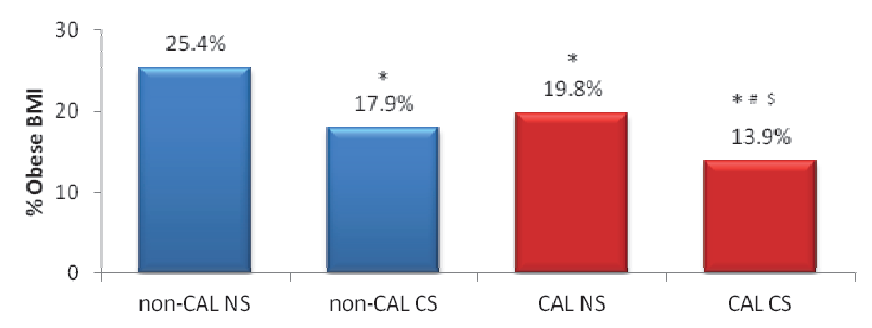

Figure 4.3 Prevalence of low BMI (A.) and obese BMI (B.) in patients with and without chronic airflow limitation according to smoking status.

$\mathrm{CS}=$ current smoker; NS=never smoker; ${ }^{*}=\mathrm{p}<0.01$ compared to non-CAL NS; \# $=\mathrm{p}<0.01$ compared to non-CAL CS; $\$=p<0.01$ compared to CAL NS.

Both in subjects with CAL ( $19.8 \%$ vs. $13.9 \%$; $p<0.001$ ) as well as in subjects without CAL (25.4\% vs. $17.9 \%, p<0.001)$, obesity was more frequent in never smokers compared to current smokers. The lowest prevalence of obesity was in smokers with CAL, which was significantly lower compared to smokers without CAL (resp. 13.9\% vs. $17.9 \%$; $p=0.009$ ) (Figure 4.3). 


\section{A META-ANALYTICAL APPROACH}

The present study consists of different surveys in multiple countries. In order to adjust for confounding by site and also to take into account the clustering of data within sites we performed a meta-analysis of the site-specific odds ratios relating BMI with CAL, adjusting for age, gender and smoking history using multivariate logistic regression. The weighted meta-analyses of adjusted odds ratios for low BMI and obese BMI in subjects with CAL compared to subjects without CAL are shown in Figure 4.4 and 4.5, respectively. For low body weight, a large heterogeneity between sites was found $\left(I^{2}: 59 \%\right)$. But even when taking into account the site-to-site heterogeneity of our data and adjusting for age, gender and smoking status, the odds ratio for low BMI was increased in subjects with CAL, compared to subjects without CAL. Secondly, overall a lower adjusted odds ratio was found for the presence of obesity in CAL subjects. Here, the association seems consistent across sites $\left(I^{2}: 15 \%\right)$.

Differences in mean BMI between subjects with and without CAL for each site are shown in Supplemental Table S4.1.

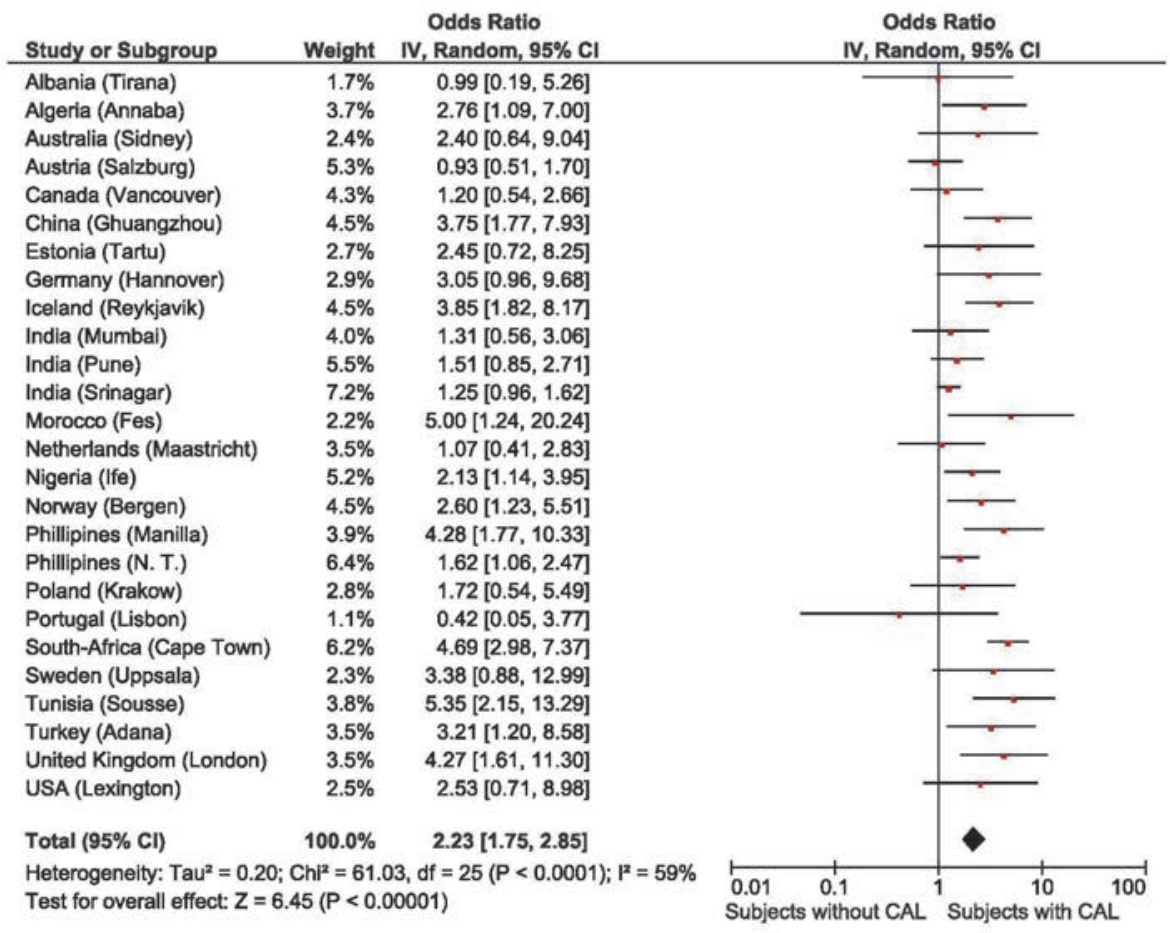

Figure 4.4 Forest plot showing the meta-analysis of age, gender and smoking adjusted site-specific odds ratios for low BMI in subjects with CAL compared to subjects without CAL. 


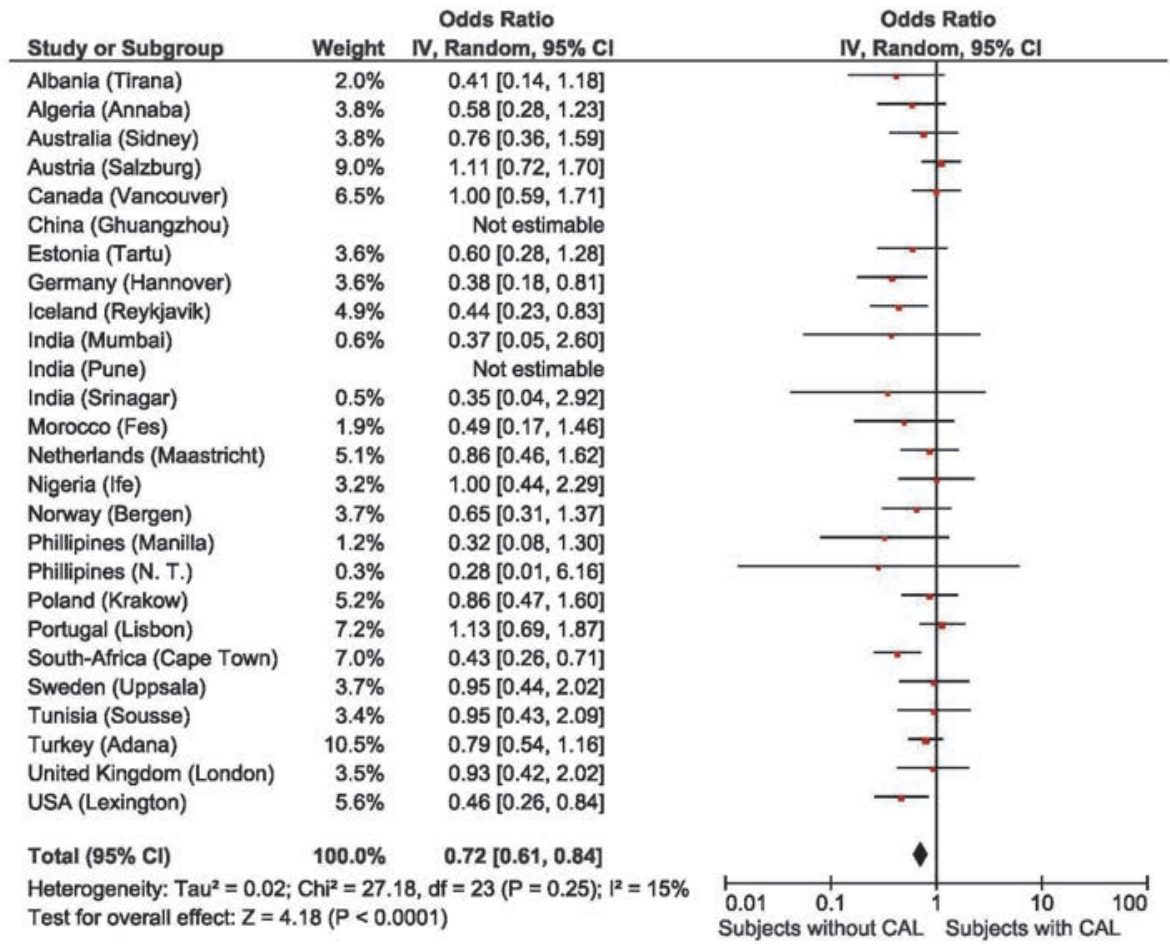

Figure 4.5 Forest plot showing the meta-analysis of adjusted odds ratios for age, gender and smoking, for obese BMI in subjects with CAL compared to subjects without CAL.

Odds ratio was not estimable in China (Ghuangzhou) and India (Pune) because no subjects with CAL had obese BMI. N.T. = Nampicuan - Talugtug.

\section{DISCUSSION}

This study is the first to evaluate BMI in subjects with and without CAL as defined by rigorously standardized post-bronchodilator spirometry in a worldwide populationbased sample of adults, taking into account the possible impact of age, gender, smoking status, and geography. The results of our study indicate a positive association between the presence of CAL and low BMI and a negative association between CAL and obesity. Given the cross-sectional nature of our data the direction of this relationship remains unclear.

The presence of a low body weight in patients with COPD is commonly recognized. A great variation of the reported prevalence of low BMI in COPD was seen in previous studies, depending on the setting and population studied. In an outpatient population 
of moderately severe COPD patients, low BMI was seen in $10 \%$ of males and $18 \%$ of females. ${ }^{1}$ Similarly, $15 \%$ of patients at first diagnosis of COPD had a low BMI. ${ }^{2}$ In the $\mathrm{NIH}$-intermittent positive breathing trial $25 \%$ of 779 male patients with stable but severe COPD had a body weight $<90 \%$ of their ideal body weight and body weight was positively associated with $\mathrm{FEV}_{1}{ }^{4}$. For 255 COPD patients entering an inpatient pulmonary rehabilitation program, Schols et al. showed that the prevalence of underweight was $37 \%$ and increased in parallel with the severity of airflow obstruction and the presence of hypoxia. ${ }^{3}$ These studies showed that underweight is occurring frequently in patients with COPD and that it is related to the severity of the disease. However, these studies were uncontrolled for the effects of age, gender, and smoking, and data were not compared to subjects without airflow limitation. More recently, in a sub-analysis on body composition of the ECLIPSE study, the prevalence of a low BMI was $14 \%$ in COPD, compared to $7 \%$ in controls. ${ }^{22}$ However, the control group was significantly younger, had smoked fewer pack years, and consisted of significantly more current smokers compared to the COPD patients ( $61 \%$ versus $36 \%, p<0.001)$.

Altogether, only two population based studies have reported on $\mathrm{BMI}$ in relation to $\mathrm{CAL}$ and compared results to control subjects. In elderly subjects from the general population participating in the "health $A B C$ " study, no difference in mean BMI was observed between those with pre-bronchodilator defined airflow limitation and smokers without airflow limitation. ${ }^{11}$ Secondly, the South-American population-based PLATINO study reported a 7\% prevalence of spirometrically defined CAL in subjects with $\mathrm{BMI}<20 \mathrm{~kg} / \mathrm{m}^{2}$, which was significantly higher compared to non-CAL subjects, but no adjustments or stratification for smoking or other confounding factors were done. ${ }^{15}$ Hence, although low body weight is commonly observed in COPD or CAL, the relationship between airflow limitation and $\mathrm{BMI}$ per se has not been well studied and the impact of confounding factors has remained unclear.

The present study identified subjects with and without CAL using guideline-based postbronchodilator spirometry. In addition the standardized assessment of smoking status by interviewed questionnaires allowed for stratification. Smoking is not only an important risk factor in the development of CAL but also may adversely affect body composition. ${ }^{9}$ Nicotine has appetite suppressant effects in the brain resulting in lower nutrient intake in smokers. ${ }^{23}$ Also, one of the acute systemic effects of smoking is an increase in resting energy metabolism. ${ }^{24}$ It is well known that quitting is frequently followed by a rapid weight gain. ${ }^{25,26}$ Also in the present study smokers had a lower BMI compared to ex- and never smokers. However, the present study clearly demonstrated that smoking does only partly account for the high prevalence of low BMI in subjects with CAL. 
CAL is importantly associated with older age as years of exposure to tobacco smoke precede the development of CAL. ${ }^{27}$ Older people tend to weigh less than younger adults, and old age is also associated with a tendency to lose weight. ${ }^{11,28}$ However, the present study showed that even after stratification for age, subjects with CAL had a higher prevalence of low BMI compared to subjects with normal lung function. Neither gender nor site-related BMI differences influenced these results. Hence, we conclude that the relationship between the presence of CAL and the presence of low BMI is independent and not influenced by age, gender and smoking.

Having excluded smoking and age as possible reasons for subjects with CAL being more frequently underweight, two possibilities remain: either (at least some) subjects with CAL lose weight or thin subjects are at higher risk of developing CAL.

Weight loss occurs when energy expenditure exceeds energy intake and this balance can be disturbed on both sides in patients with CAL. An elevated resting energy expenditure has been reported in a patients with COPD and has been associated with weight loss. ${ }^{29}$ Also, increased energy expenditure related to physical activities has been reported in COPD, possibly related to decreased mechanical efficiency when performing activity. ${ }^{30}$ The increased oxygen cost of breathing might contribute to the elevated energy expenditure during activities in subjects with COPD. ${ }^{31}$ On the other hand decreased appetite and low dietary intake have been associated with aggravation of disease symptoms related to exacerbations of COPD. ${ }^{32}$. In the present cross-sectional study, data on weight loss, energy balance and exacerbations were not collected. Therefore, it is not possible to attribute the increased prevalence of underweight in subjects with CAL to any of these factors. However, since the present study sample is population-based and not a selected patient population, the frequency of "disease exacerbations" is low.

It has been suggested that subjects with a thin phenotype are at higher risk of developing CAL. A large general population study showed that increased mortality in people with low BMI was mainly associated with respiratory diseases. ${ }^{8}$ More specifically, the Baltimore Longitudinal Study of Aging showed that, at least in men, a low BMI was an independent risk factor for developing CAL. ${ }^{33}$ Also in a previous report of the BOLD study, low BMI was associated with the presence of CAL in never smokers. ${ }^{16}$ In addition, early levels of emphysema have been detected after chronic malnutrition as in patients with anorexia nervosa. ${ }^{34}$ Due to the cross-sectional nature of the present data we cannot determine whether the low BMI preceded the CAL or was a consequence of the disease.

In the present study, on average, only one in five subjects with CAL had low body weight. Referring to the historical description of the pink puffer (emphysematous type 
with underweight) and the blue bloater (chronic bronchitis type with overweight) body weight might discriminate different phenotypes within the umbrella disease COPD. ${ }^{35}$ Recently, in COPD patients entering pulmonary rehabilitation, five different clusters with a specific profile of comorbidities and extra-pulmonary manifestations were identified. One cluster was characterized with a high proportion of underweight, but also muscle wasting, osteoporosis, renal insufficiency and pulmonary function characteristics suggestive of emphysema. ${ }^{36}$ In contrast, and similar to the PAC-COPD study, ${ }^{37}$ an independent subtype of COPD was identified by a milder respiratory status but a higher prevalence of obesity, cardiovascular disease and hyperglycemia, and higher levels of systemic inflammatory markers. ${ }^{36}$

However, data on the prevalence of obesity in COPD or CAL compared to subjects without COPD or CAL, are scarce and have been conflicting, probably as a result of differences in CAL-specific and global risk factors for obesity between studied populations. In the population-based Canadian National Health Survey, the prevalence of obesity was increased in subjects with self-reported COPD (24.6\%) compared to nonCOPD subjects $(17.1 \%),{ }^{38}$ while the South-American population-based PLATINO study reported a lower prevalence of obesity in subjects with CAL, compared to subjects without CAL (23\% versus $30 \%) .{ }^{15}$ In the patient population based ECLIPSE, obesity prevalence was not different in COPD subjects compared to smoking/former smoking controls (resp. $22 \%$ versus. $20 \%$ ). ${ }^{22}$ The present study showed that the prevalence of obesity is lower in subjects with CAL compared to subjects without CAL, also when adjusted for gender, smoking status and age. The present study showed that the influence of smoking history is greater than the influence of CAL on the presence of obesity.

In conclusion, this study was the first to demonstrate that in a worldwide general population, the presence of objectively assessed CAL was associated with increased risk of low BMI and a reduced risk of obese BMI, independent of age, gender, smoking history and geography.

These findings suggest a direct association between CAL and low BMI, although the direction of this association cannot be established from the present cross-sectional data. Both low BMI as a risk factor for development and progression of CAL as well as (mechanisms of) weight loss in CAL need exploration in future studies. In the meantime, clinicians and dieticians should stay aware of what is already known, in fact that low BMI is related to poor outcome in subjects with COPD or CAL and should be appropriately managed. 


\section{REFERENCES}

1. Vermeeren MA, Creutzberg EC, Schols AM, et al. Prevalence of nutritional depletion in a large outpatient population of patients with COPD. Respir Med 2006;100:1349-55.

2. Engelen MP, Schols AM, Baken WC, Wesseling GJ, Wouters EF. Nutritional depletion in relation to respiratory and peripheral skeletal muscle function in out-patients with COPD. Eur Respir J 1994; 7:1793-7.

3. Schols AM, Soeters PB, Dingemans AM, Mostert R, Frantzen PJ, Wouters EF. Prevalence and characteristics of nutritional depletion in patients with stable COPD eligible for pulmonary rehabilitation. Am Rev Respir Dis 1993;147:1151-6.

4. Wilson DO, Rogers RM, Wright EC, Anthonisen NR. Body weight in chronic obstructive pulmonary disease. The National Institutes of Health Intermittent Positive-Pressure Breathing Trial. Am Rev Respir Dis 1989;139:1435-8.

5. Schols AM, Slangen J, Volovics L, Wouters EF. Weight loss is a reversible factor in the prognosis of chronic obstructive pulmonary disease. Am J Respir Crit Care Med 1998;157:1791-7.

6. Landbo C, Prescott E, Lange P, Vestbo J, Almdal TP. Prognostic value of nutritional status in chronic obstructive pulmonary disease. Am J Respir Crit Care Med 1999;160:1856-61.

7. Chailleux E, Laaban JP, Veale D. Prognostic value of nutritional depletion in patients with COPD treated by long-term oxygen therapy: data from the ANTADIR observatory. Chest 2003;123:1460-6.

8. Whitlock G, Lewington S, Sherliker P, Clarke R, Emberson J, Halsey J, Qizilbash N, Collins R, Peto R. Body-mass index and cause-specific mortality in 900000 adults: collaborative analyses of 57 prospective studies. Lancet 2009;373:1083-96.

9. Wack JT, Rodin J. Smoking and its effects on body weight and the systems of caloric regulation. Am J Clin Nutr 1982;35:366-80.

10. Finucane MM1, Stevens GA, Cowan MJ, Danaei G, Lin JK, Paciorek CJ, Singh GM, Gutierrez HR, Lu Y, Bahalim AN, Farzadfar F, Riley LM, Ezzati M; Global Burden of Metabolic Risk Factors of Chronic Diseases Collaborating Group (Body Mass Index). National, regional, and global trends in body-mass index since 1980: systematic analysis of health examination surveys and epidemiological studies with 960 country-years and 9.1 million participants. Lancet 2011;377:557-67.

11. van den Borst B, Koster A, Yu B, Gosker HR, Meibohm B, Bauer DC, Kritchevsky SB, Liu Y, Newman AB, Harris TB, Schols AM. Is age-related decline in lean mass and physical function accelerated by obstructive lung disease or smoking? Thorax 2011;66:961-9.

12. Cecere LM, Littman AJ, Slatore CG, Udris EM, Bryson CL, Boyko EJ, Pierson DJ, Au DH. Obesity and COPD: associated symptoms, health-related quality of life, and medication use. COPD 2011;8:275-84.

13. Ramachandran K, McCusker C, Connors M, Zuwallack R, Lahiri B. The influence of obesity on pulmonary rehabilitation outcomes in patients with COPD. Chron Respir Dis 2008;5:205-9.

14. Vozoris NT, O'Donnell DE. Prevalence, risk factors, activity limitation and health care utilization of an obese, population-based sample with chronic obstructive pulmonary disease. Can Respir J;19:e18-24.

15. Montes de Oca M, Tálamo C, Perez-Padilla R, Jardim JR, Muiño A, Lopez MV, Valdivia G, Pertuzé J, Moreno D, Halbert RJ, Menezes AM; PLATINO Team. Chronic obstructive pulmonary disease and body mass index in five Latin America cities: the PLATINO study. Respir Med 2008;102:642-50.

16. Lamprecht B, McBurnie MA, Vollmer WM, Gudmundsson G, Welte T, Nizankowska-Mogilnicka E, Studnicka M, Bateman E, Anto JM, Burney P, Mannino DM, Buist SA; BOLD Collaborative Research Group. COPD in never smokers: results from the population-based burden of obstructive lung disease study. Chest 2011;139:752-63.

17. Hooper R, Burney P, Vollmer WM, McBurnie MA, Gislason T, Tan WC, Jithoo A, Kocabas A, Welte T, Buist AS. Risk factors for COPD spirometrically defined from the lower limit of normal in the BOLD project. Eur Respir J 2012;39:1343-53.

18. Buist AS, Vollmer WM, Sullivan SD, Weiss KB, Lee TA, Menezes AM, Crapo RO, Jensen RL, Burney PG. The Burden of Obstructive Lung Disease Initiative (BOLD): rationale and design. COPD 2005;2:277-83. 
19. Buist AS, McBurnie MA, Vollmer WM, Gillespie S, Burney P, Mannino DM, Menezes AM, Sullivan SD, Lee TA, Weiss KB, Jensen RL, Marks GB, Gulsvik A, Nizankowska-Mogilnicka E; BOLD Collaborative Research Group. International variation in the prevalence of COPD (the BOLD Study): a populationbased prevalence study. Lancet 2007;370:741-50.

20. Standardization of Spirometry, 1994 Update. American Thoracic Society. Am J Respir Crit Care Med 1995;152:1107-36.

21. WHO Expert Consultation. Appropriate body-mass index for Asian populations and its implications for policy and intervention strategies. Lancet 2004;363:157-63.

22. Rutten EP, Calverley PM, Casaburi R, Agusti A, Bakke P, Celli B, Coxson HO, Crim C, Lomas DA, Macnee W, Miller BE, Rennard SI, Scanlon PD, Silverman EK, Tal-Singer R, Vestbo J, Watkins ML, Wouters EF. Changes in Body Composition in Patients with Chronic Obstructive Pulmonary Disease: Do They Influence Patient-Related Outcomes? Annals of nutrition \& metabolism 2013;63:239-47.

23. Mineur YS, Abizaid A, Rao Y, Salas R, DiLeone RJ, Gündisch D, Diano S, De Biasi M, Horvath TL, Gao XB, Picciotto MR. Nicotine decreases food intake through activation of POMC neurons. Science 2011;332:1330-2.

24. Perkins KA, Epstein LH, Stiller RL, Marks BL, Jacob RG. Acute effects of nicotine on resting metabolic rate in cigarette smokers. Am J Clin Nutr 1989;50:545-50.

25. Aubin HJ, Farley A, Lycett D, Lahmek P, Aveyard P. Weight gain in smokers after quitting cigarettes: meta-analysis. BMJ 2012;345:e4439.

26. Chinn S, Jarvis D, Melotti R, Luczynska C, Ackermann-Liebrich U, Antó JM, Cerveri I, de Marco R, Gislason T, Heinrich J, Janson C, Künzli N, Leynaert B, Neukirch F, Schouten J, Sunyer J, Svanes C, Vermeire $P$, Wjst $M$, Burney $P$. Smoking cessation, lung function, and weight gain: a follow-up study. Lancet 2005;365:1629-35.

27. Vanfleteren LE1, Franssen FM, Wesseling G, Wouters EF. The prevalence of chronic obstructive pulmonary disease in Maastricht, the Netherlands. Respir Med 2012;106:871-4.

28. Soenen S, Chapman IM. Body weight, anorexia, and undernutrition in older people. J Am Med Dir Assoc 2013;14:642-8.

29. Schols AM, Fredrix EW, Soeters PB, Westerterp KR, Wouters EF. Resting energy expenditure in patients with chronic obstructive pulmonary disease. Am J Clin Nutr 1991;54:983-7.

30. Franssen FM, Wouters EF, Baarends EM, Akkermans MA, Schols AM. Arm mechanical efficiency and arm exercise capacity are relatively preserved in chronic obstructive pulmonary disease. Med Sci Sports Exerc 2002;34:1570-6.

31. Levison $\mathrm{H}$, Cherniack RM. Ventilatory cost of exercise in chronic obstructive pulmonary disease. J Appl Physiol 1968;25:21-7.

32. Vermeeren MA, Schols AM, Wouters EF. Effects of an acute exacerbation on nutritional and metabolic profile of patients with COPD. Eur Respir J 1997;10:2264-9.

33. Harik-Khan RI, Fleg JL, Wise RA. Body mass index and the risk of COPD. Chest 2002;121:370-6.

34. Coxson HO, Chan IH, Mayo JR, Hlynsky J, Nakano Y, Birmingham CL. Early emphysema in patients with anorexia nervosa. Am J Respir Crit Care Med 2004;170:748-52.

35. Filley GF, Beckwitt HJ, Reeves JT, Mitchell RS. Chronic obstructive bronchopulmonary disease. II. Oxygen transport in two clinical types. Am J Med 1968;44:26-38.

36. Vanfleteren LE, Spruit MA, Groenen M, Gaffron S, van Empel VP, Bruijnzeel PL, Rutten EP, Op 't Roodt J, Wouters EF, Franssen FM. Clusters of comorbidities based on validated objective measurements and systemic inflammation in patients with chronic obstructive pulmonary disease. Am J Respir Crit Care Med 2013;187:728-35.

37. Garcia-Aymerich J, Gómez FP, Benet M, Farrero E, Basagaña X, Gayete À, Paré C, Freixa X, Ferrer J, Ferrer A, Roca J, Gáldiz JB, Sauleda J, Monsó E, Gea J, Barberà JA, Agustí À, Antó JM; PAC-COPD Study Group. Identification and prospective validation of clinically relevant chronic obstructive pulmonary disease (COPD) subtypes. Thorax 2011;66:430-7.

38. Vozoris NT, O'Donnell DE. Prevalence, risk factors, activity limitation and health care utilization of an obese, population-based sample with chronic obstructive pulmonary disease. Can Respir J 2012;19: e18-24. 


\section{SUPPLEMENTAL MATERIAL}

Table S4.1 Mean BMI in subjects with and without CAL according to gender, smoking status, age and site.

\begin{tabular}{|c|c|c|c|}
\hline & \multicolumn{2}{|c|}{ Body mass index, $\mathrm{kg} / \mathrm{m}^{2}$ (mean $\pm \mathrm{SD}$ ) } & \multirow[b]{2}{*}{$\mathrm{p}$} \\
\hline & Subjects without CAL & Subjects with CAL & \\
\hline \multicolumn{4}{|l|}{ Gender } \\
\hline Male & $26.2 \pm 4.6$ & $24.9 \pm 4.9$ & $<0.001$ \\
\hline Female & $27.4 \pm 5.0$ & $25.9 \pm 5.9$ & $<0.001$ \\
\hline \multicolumn{4}{|l|}{ Smoking status } \\
\hline Current smokers & $25.8 \pm 5.1$ & $24.3 \pm 5.2$ & 0.003 \\
\hline Ex smokers & $27.6 \pm 5.1$ & $26.2 \pm 5.1$ & $<0.001$ \\
\hline Never smokers & $26.9 \pm 5.6$ & $25.7 \pm 5.9$ & $<0.001$ \\
\hline \multicolumn{4}{|l|}{ Age } \\
\hline $40-49$ & $26.2 \pm 5.3$ & $25.0 \pm 6.0$ & $<0.001$ \\
\hline $50-59$ & $27.2 \pm 5.6$ & $25.9 \pm 5.9$ & $<0.001$ \\
\hline $60-69$ & $27.4 \pm 5.5$ & $25.4 \pm 5.3$ & $<0.001$ \\
\hline $70+$ & $26.9 \pm 5.2$ & $25.2 \pm 4.7$ & $<0.001$ \\
\hline \multicolumn{4}{|l|}{ Sites } \\
\hline Albania (Tirana) & $28.2 \pm 4.7$ & $26.7 \pm 4.6$ & 0.002 \\
\hline Algeria (Annaba) & $28.5 \pm 5.5$ & $25.9 \pm 6.8$ & $<0.001$ \\
\hline Australia (Sidney) & $28.0 \pm 4.9$ & $27.7 \pm 6.2$ & 0.418 \\
\hline Austria (Salzburg) & $26.4 \pm 4.2$ & $26.4 \pm 4.5$ & 0.788 \\
\hline Canada (Vancouver) & $26.7 \pm 5.2$ & $26.9 \pm 5.0$ & 0.546 \\
\hline China (Ghuangzhou) & $23.5 \pm 3.3$ & $21.2 \pm 2.8$ & $<0.001$ \\
\hline Estonia (Tartu) & $28.6 \pm 5.3$ & $27.1 \pm 5.1$ & 0.045 \\
\hline Germany (Hannover) & $27.4 \pm 4.6$ & $26.6 \pm 4.7$ & 0.173 \\
\hline Iceland (Reykjavik) & $28.2 \pm 4.9$ & $25.9 \pm 4.5$ & $<0.001$ \\
\hline India (Mumbai) & $23.9 \pm 4.0$ & $22.6 \pm 3.9$ & 0.083 \\
\hline India (Pune) & $22.2 \pm 3.9$ & $20.4 \pm 3.4$ & 0.003 \\
\hline India (Srinagar) & $22.6 \pm 3.6$ & $21.6 \pm 3.3$ & 0.011 \\
\hline Morocco (Fes) & $28.1 \pm 5.2$ & $26.3 \pm 5.6$ & 0.005 \\
\hline Netherlands (Maastricht) & $27.7 \pm 4.6$ & $26.4 \pm 3.9$ & 0.013 \\
\hline Nigeria (Ife) & $25.4 \pm 5.3$ & $24.8 \pm 6.5$ & 0.083 \\
\hline Norway (Bergen) & $26.7 \pm 4.2$ & $25.4 \pm 4.8$ & 0.001 \\
\hline Philippines (Manilla) & $25.1 \pm 4.7$ & $22.8 \pm 4.5$ & $<0.001$ \\
\hline Philippines (Nampicuan Talugtug) & $21.8 \pm 3.9$ & $20.2 \pm 3.6$ & $<0.001$ \\
\hline Poland (Krakow) & $27.8 \pm 4.6$ & $27.3 \pm 5.3$ & 0.144 \\
\hline Portugal (Lisbon) & $28.3 \pm 4.6$ & $27.8 \pm 4.7$ & 0.288 \\
\hline South-Africa (Cape Town) & $28.9 \pm 7.2$ & $23.7 \pm 7.1$ & $<0.001$ \\
\hline Sweden (Uppsala) & $27.0 \pm 4.4$ & $26.8 \pm 3.8$ & 0.994 \\
\hline Tunisia (Sousse) & $29.4 \pm 5.6$ & $26.5 \pm 5.9$ & 0.006 \\
\hline Turkey (Adana) & $29.9 \pm 5.2$ & $28.1 \pm 5.6$ & $<0.001$ \\
\hline United Kingdom (London) & $27.3 \pm 4.9$ & $26.0 \pm 4.9$ & 0.008 \\
\hline USA (Lexington) & $31.3 \pm 6.9$ & $27.8 \pm 5.3$ & $<0.001$ \\
\hline
\end{tabular}

CAL: Chronic airflow limitation 

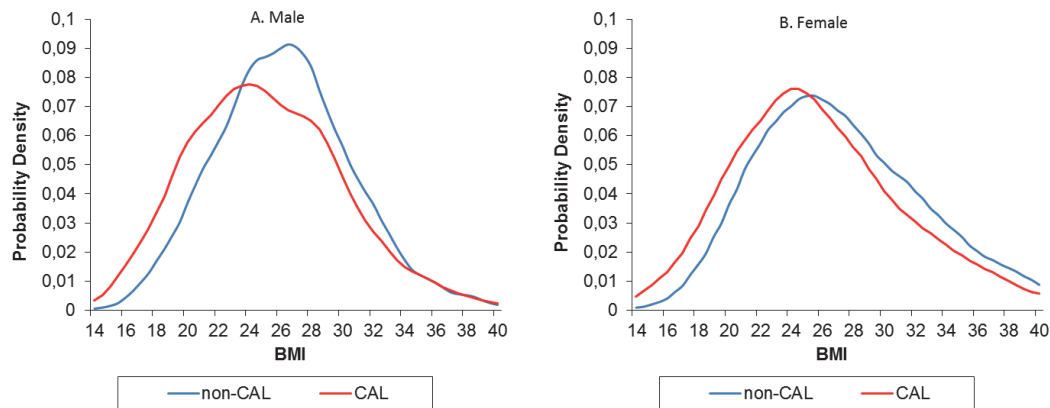

Figure S4.1 Distribution of BMI in subjects with and without CAL, stratified for gender.

A: Male subjects (mean BMI: CAL: $24.9 \pm 5.0$ vs. non-CAL: $26.2 \pm 4.6, p<0.001$; difference in KDE: $\mathrm{p}<0.001$ ). B: Female subjects (mean BMI: CAL: $25.9 \pm 6.0$ vs. non-CAL: $27.4 \pm 6.0 p<0.001$; difference in KDE: $p<0.001$ )
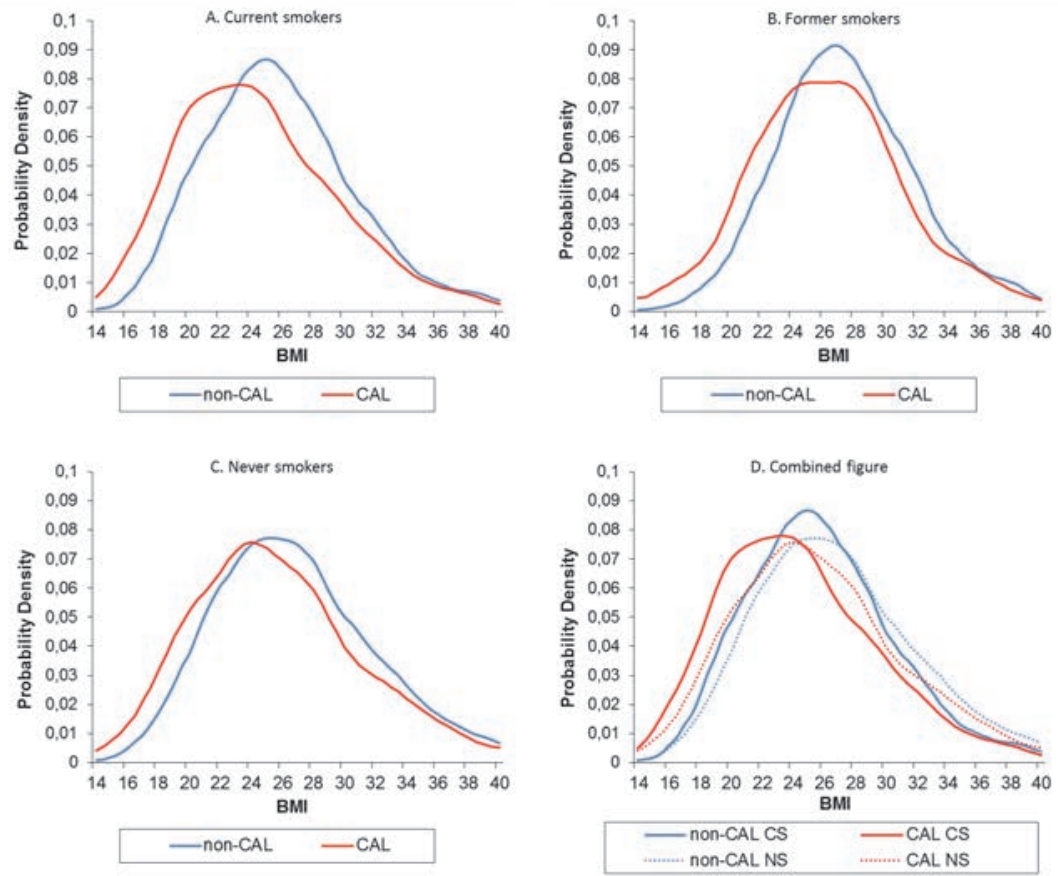

Figure S4.2 Distribution of BMI in subjects with and without CAL stratified for smoking history:

A: Current smokers (mean BMI: CAL: $24.3 \pm 5.2$ vs. non-CAL: $25.8 \pm 5.1, p<0.001$; difference in KDE: $p<0.001$ ), B: Former smokers (mean BMI: CAL: $26.2 \pm 5.1$ vs. non-CAL: $27.6 \pm 5.1, p<0.001$; difference in KDE: $p<0.001$ ), C: Never smokers, (mean BMI: CAL: $25.7 \pm 5.9$ vs. non-CAL: $26.9 \pm 5.6$, $p<0.001$; difference in KDE: $p<0.001) \mathrm{D}$ : Combined figure for current smokers (CS) and never smokers (NS). (mean BMI: CAL CS: $24.3 \pm 5.2$ vs. non-CAL CS: $25.8 \pm 5.1$ vs. CAL NS: $25.7 \pm 5.9$ vs. non-CAL NS: $26.9 \pm 5.6, p<0.001$; difference in KDE: $p<0.001)(p<0.001)$. 

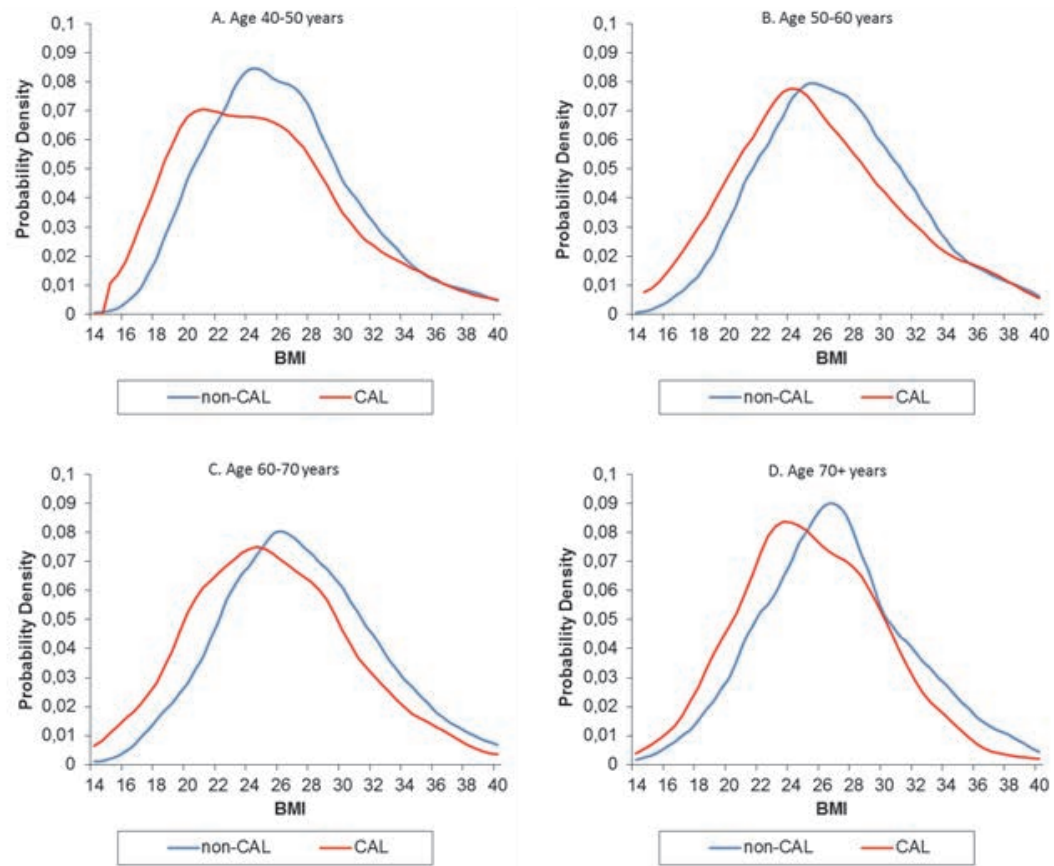

Figure S4.3 Distribution of BMI in subjects with and without CAL, stratified for age categories.

A: age 40-50 years (mean BMI: CAL: $25.0 \pm 6.0$ vs. non-CAL: $26.2 \pm 5.3, p<0.001$; difference in $\mathrm{KDE}$ : $\mathrm{p}<0.001$ ), B: age 50-60 years (mean BMI: CAL: $25.9 \pm 5.9$ vs. non-CAL: $27.2 \pm 5.6, p<0.001$, difference in KDE: $p<0.001$ ), C: age $60-70$ years (mean BMI: CAL: $25.3 \pm 5.3$ vs. non-CAL: $27.4 \pm 5.5$, $p<0.001$, difference in KDE: $p<0.001$ ), $D$ : age $70+$ years (mean BMI: CAL: $25.2 \pm 4.7$ vs. non-CAL: $26.9 \pm 5.2, p<0.001$; difference in KDE: $p<0.001$ ). 


\section{CHAPTER 5}

Frequency and relevance of ischemic electrocardiographic findings in patients

with COPD

Lowie E.G.W. Vanfleteren, Frits M.E. Franssen, Nicole H.M.K. Uszko-Lencer, Martijn A. Spruit, Mieke Celis, Anton P. Gorgels, Emiel F.M Wouters 


\section{ABSTRACT}

\section{Background}

Cardiovascular disease is common in patients with chronic obstructive pulmonary disease (COPD), but often remains unrecognized. Ischemic electrocardiographic (ECG)-changes are associated with a higher risk of dying of coronary heart disease, but have never been systematically evaluated in COPD. Also, their relation with clinical outcome has not been studied. We aimed to determine the frequency of ischemic ECG-changes and its relevance in relation to clinical outcome and predictors of impaired survival in patients with COPD.

\section{Methods}

Clinical characteristics, pulmonary function and co-morbidities were assessed in 536 COPD patients during baseline assessment of a comprehensive pulmonary rehabilitation program. Moreover, resting ECGs were obtained in all patients. All ECGs were scored independently by two cardiologists using the Minnesota scoring system. Major or minor Q or QS pattern, ST junction and segment depression, $\mathrm{T}$-wave items or left bundle branch block were considered as ischemic ECG-changes.

\section{Results}

One hundred thirteen patients (21\%) had ischemic ECG-changes. Moreover, 42 of 293 patients (14\%) without self-reported cardiovascular co-morbidities had ischemic ECG-changes. In addition, patients with ischemic ECG-changes had higher dyspnea gradings (modified Medical Research Council: $2.9 \pm 1.1$ vs. $2.6 \pm 1.1 ; p=0.032$ ), worse exercise performance (six-minute walking distance: $387 \pm 126$ vs. $425 \pm 126 \mathrm{~m} ; \mathrm{p}=0.004$ ), more systemic inflammation (hsCRP: $11.2 \pm 16.2$ vs. $7.9 \pm 10,7 \mathrm{mmol} / \mathrm{l} ; \mathrm{p}=0.01)$, higher scores on the Charlson co-morbidity index $(1.8 \pm 0.9 \mathrm{vs}$. $1.5 \pm 0.8$ points) and higher scores on updated BODE index (based on BMI, airway Obstruction, Dyspnea grade and Exercise capacity; $5.3 \pm 3.7$ vs. $4.5 \pm 3.4$ points; $p=0.033$ ) and ADO index (based on Age, Dyspnea grade and airway Obstruction; $5.2 \pm 1.7$ vs. $4.8 \pm 1.7$ points; $p=0.029$ ) compared to patients without ischemic ECG-changes, while the forced expiratory volume in the first second $\left(\mathrm{FEV}_{1}\right)$ was similar $(40.8 \pm 15.2$ vs. $42.6 \pm 15.9 \% ; \mathrm{p}=0.30)$.

\section{Conclusion}

Ischemic ECG-changes are common in patients with COPD and associated with poor clinical outcome, irrespective of the $\mathrm{FEV}_{1}$. These results suggest an important role for cardiovascular disease in impaired survival in these patients. 


\section{INTRODUCTION}

Patients with chronic obstructive pulmonary disease (COPD) have an increased risk for cardiovascular morbidity and mortality. ${ }^{1-3}$ This risk is related to disease severity ${ }^{4}$ and the presence of low-grade systemic inflammation, ${ }^{5}$ but independent of smoking status or other well-known risk factors for atherosclerosis. In patients with stable COPD, cardiovascular comorbidity often remains undiagnosed and untreated. ${ }^{6}$ Also the impact of cardiovascular disease on clinical outcomes in COPD is currently unclear.

In this study we systematically coded electrocardiographs (ECG) of patients with stable but disabling COPD, using Minnesota criteria. ${ }^{7}$ The first aim was to determine the frequency of ischemic-like electrocardiographic changes (ischemic ECG). In addition, differences in clinical outcomes (pulmonary function, body composition, exercise capacity, dyspnea, systemic inflammation, comorbidities) between patients with and without ischemic ECG findings were studied. Finally, the relations of ischemic ECG findings with clinical predictors of impaired survival in COPD (updated BODE index, ADO index ${ }^{8}$ ) were investigated.

\section{METHODS}

Data were collected and analyzed retrospectively in 543 consecutive COPD patients. These retrospective analyses are IRB exempt due to the use of de-identified, preexisting data. Patients were entering a comprehensive pulmonary rehabilitation program between January 2005 and March 2007 at the dedicated pulmonary rehabilitation center of $\mathrm{CIRO}+$ in Horn, the Netherlands. ${ }^{9}$ Patients were referred by respiratory physicians in South East Netherlands. To avoid the influence of concurrent infection on clinical outcomes, 7 patients with high-sensitivity C-reactive protein (hsCRP) $>100 \mathrm{mmol} / \mathrm{l}$ were excluded. Smoking status, smoked pack years and use of long-term oxygen therapy were recorded. Furthermore, patients' current pharmacological cardiovascular treatment (diuretics, angiotensin converting enzyme inhibitors, angiotensin receptor blockers, beta-blockers, calcium antagonists, nitrates, digitalis, anti-arrhytmics, statins, anti-aggregates or coumarins) and pulmonary treatment (short acting beta-agonists, long acting beta-agonists, short acting anticholinergics, long acting anticholinergics, inhaled corticosteroids, oral corticosteroids, theophylline and leukotrienes) were registered.

Resting ECG was obtained in all patients. ECG data were recorded on analog tape and included the conventional 12 leads (Mac1600 ${ }^{\circledR}$, GE Healthcare, Germany). Paper tracings were produced and scored independently by two cardiologists (NHMKU-L and APG) according to the Minnesota ECG Code rules. ${ }^{7}$ In case of disagreement, consensus 
was achieved in conjunction. Ischemia on ECG was defined as at least one of the following: major or minor Q or QS pattern, ST junction and segment depression, T-wave items or left bundle branch block (LBBB). These patterns are often seen as indications of silent myocardial ischemia. ${ }^{10}$ The Minnesota codes used in this manuscript are listed in Table 5.1.

Table 5.1 ECG patterns suggesting myocardial ischemia (left) with according Minnesota-code (middle). Prevalence of ischemic-like ECG changes (right). Data are expressed as number (percentage).

\begin{tabular}{lcc}
\hline ECG pattern & Minnesota code & All $(\mathrm{n}=536)$ \\
\hline Major Q or QS pattern & 1.1 & $23(4.3 \%)$ \\
Minor Q or QS pattern & $1.2+1.3$ & $15(2.8 \%)$ \\
ST junction (J) and segment depression & $4.1+4.2$ & $19(3.5 \%)$ \\
T-wave items & $5.1-5.3$ & $47(8.8 \%)$ \\
Left bundle branch block & 7.1 & $11(2.1 \%)$ \\
Ischemia & All above & $113(21 \%)$ \\
Right bundle branch block & 7.2 & $35(6.5 \%)$ \\
Atrium fibrillation or flutter & 8.3 & $13(2.4 \%)$ \\
Atrial-Ventricular Conduction Defect, grade 1 & 6.3 & $5(0.9 \%)$ \\
Left axis deviation & 2.1 & $52(9.7 \%)$ \\
High amplitude R waves & $3.1+3.2$ & $8(1.5 \%)$ \\
\hline
\end{tabular}

In every patient the Charlson comorbidity index $(\mathrm{CCl})^{11}$ was calculated. Apart from the cardiovascular features that are included in the $\mathrm{CCl}$, namely myocardial infarction, chronic heart failure, cerebrovascular disease and peripheral arterial disease, also other cardiovascular comorbidities were registered: hypertension, arrhythmia, angina pectoris, coronary heart disease as defined by coronary surgery or percutaneous coronary intervention and abdominal aortic aneurysm repair. "Any cardiovascular comorbidity" was defined as that the patients suffers from at least one of the above listed cardiovascular comorbidities.

Lung function parameters (forced expiratory volume in the first second $\left(F E V_{1}\right)$ and forced vital capacity (FVC)) were collected using standardized post-bronchodilator spirometry. Carbon monoxide diffusion capacity (DLCO) was determined with single breath hold method (MasterScreen ${ }^{\circledR}$ Body, Carefusion, Germany). The degree of airflow limitation was defined according to the classification of the Global Initiative for Chronic Obstructive Lung Disease (GOLD). ${ }^{12}$

Resting arterial oxygen tension $\left(\mathrm{p}_{\mathrm{a}} \mathrm{O}_{2}\right)$ and arterial carbon dioxide tension $\left(\mathrm{p}_{\mathrm{a}} \mathrm{CO}_{2}\right)$ were analyzed with a blood gas analyzer (Radiometer ABL 330, Copenhagen, Denmark). hsCRP was assessed in duplicate (COBAS-MIRA, Radiometer, Copenhagen) on a venous blood sample, collected from all patients in the fasted state. 
Functional exercise capacity was measured with the six-minute walking distance (6MWD), performed according to published guidelines including a practice walk. ${ }^{13,14}$

Body composition was assessed by body mass index (BMI), calculated as body weight/height ${ }^{2}$ and fat-free mass index (FFMI), calculated as fat-free mass/height ${ }^{2}{ }^{15}$ the latter measured by bioelectrical impedance (Bodystat ${ }^{\circledR}$, United Kingdom).

Self-perceived dyspnea in relation to physical disability was assessed by using the modified Medical Research Council (mMRC) dyspnea scale. ${ }^{16}$

The updated BODE index and the ADO index are predictors of 3-year mortality in patients with COPD. The updated BODE index is based on scores on BMI, FEV $1, m M R C$ dyspnea scale, and 6MWD. ${ }^{8}$ The ADO index is based on age, $\mathrm{FEV}_{1}$ and $\mathrm{mMRC}$ dyspnea scale. A higher score means a worse prognosis. ${ }^{8}$

All statistics were performed using Statistical Package for the Social Sciences (SPSS) version 17.0. Results are expressed as mean \pm standard deviation unless indicated otherwise. Independent samples Student's $t$-test was used to investigate differences in clinical outcomes between patients with and without ischemic ECG. Differences between COPD GOLD stages were investigated by one-way analysis of variances, using Fisher's Least Significant Difference as post hoc test. Differences in the proportion of patients with ischemic ECG between different GOLD stages were assessed using Chisquare test. Relationship between ischemic ECG and functional outcome parameters adjusted for $\mathrm{FEV}_{1}$ has been assessed by performing logistic regression analysis with the presence or absence of ischemic ECG and $\mathrm{FEV}_{1}$ as predictors and functional outcome parameters as dependent variables. All dependent variables were entered as continuous variables by forced entry method. Collinearity analysis of the variables "ischemic ECG" and "FEV 1 " revealed a Variance Inflation Factor (VIF) <10, indicating absence of collinearity. A p value $<0.05$ was considered significant. For planned stratification and comparison to a population study, ${ }^{10}$ age was divided into two categories, containing most patients: 55-64 and 65-74 years. Other age-groups were not calculated because of small numbers of subjects and misbalance in sex.

\section{RESULTS}

Baseline characteristics of 536 elderly patients with moderate to very severe COPD are shown in Table 5.2. On average, patients had a normal body composition, an impaired functional exercise performance and experienced moderate to severe dyspnea during daily life. Almost one-third of the patients had a hsCRP $>10 \mathrm{mmol} / \mathrm{l}$, a quarter were 
current smokers, $42 \%$ had one or more self-reported comorbidities and more than half of the patients was on one or more cardiovascular drugs.

Frequencies of different ECG changes are listed in Table 6.1. In total 21\% of patients had an ischemic ECG. The proportion of patients with ischemic ECG was similar after stratification for GOLD stages: 23 of 124 patients (19\%) in GOLD stage 1/2; 39 of 176 patients (22\%) in GOLD stage 3; and 51 of 236 patients (22\%) in GOLD stage 4 . The frequency of ischemic ECG tended to be higher in women but the difference is not significant. (Table 5.3)

Table 5.2 Baseline characteristics in 536 patients with COPD entering pulmonary rehabilitation. Data are expressed as mean \pm standard deviation or number (percentage).

\begin{tabular}{lc}
\hline Men & $330(62 \%)$ \\
Age (years) & $63.7 \pm 9.4$ \\
Body Mass Index $\left(\mathrm{kg} / \mathrm{m}^{2}\right)$ & $25.1 \pm 5.1$ \\
Fat Free Mass Index $\left(\mathrm{kg} / \mathrm{m}^{2}\right)$ & $16.3 \pm 2.3$ \\
Packyears (years) & $39.8 \pm 19.6$ \\
Current smokers & $139(26 \%)$ \\
Long term oxygen therapy & $50(9 \%)$ \\
Forced expiratory volume in the first second (\% predicted) & $42.2 \pm 15.7$ \\
Ratio Forced expiratory volume in the first second - Forced vital capacity (\%) & $41.0 \pm 11.5$ \\
Diffusion lung capacity for carbon monoxide (\% predicted) & $50.9 \pm 17.9$ \\
Six minute walking distance (meter) & $417 \pm 127$ \\
Partial pressure of carbon dioxide $\mathrm{paCO} \mathrm{C}_{2}(\mathrm{kPa})$ & $5.4 \pm 0.8$ \\
Partial pressure of oxygen paO $\mathrm{O}_{2}(\mathrm{kPa})$ & $9.2 \pm 1.4$ \\
high sensitive C-reactive protein (mmol/l) & $8.6 \pm 12.1$ \\
high sensitive C-reactive protein $<10 \mathrm{mmol} / \mathrm{l}$ & $386(72 \%)$ \\
high sensitive C-reactive protein $\geq 10 \mathrm{mmol} / \mathrm{l}$ & $150(28 \%)$ \\
modified Medical Research Council dyspnea scale (points) & $2.7 \pm 1.1$ \\
Charlson comorbidity index (points) & $1.6 \pm 0.9$ \\
$\geq 2$ points on Charlson comorbidity index & $225(42 \%)$ \\
Any cardiovascular comorbidity & $243(45 \%)$ \\
Use of cardiovascular medication & $303(57 \%)$ \\
\hline
\end{tabular}

The proportion of ischemic ECGs was higher in subjects with self-reported cardiovascular comorbidity. They had more frequently a major $\mathrm{Q}$ or QS pattern and a LBBB. There were no differences in minor Q or QS patterns, ST-segment or T-wave items. Also no differences were seen in other non-ischemic ECG items in subjects with and without reported cardiovascular comorbidity, except for atrial fibrillation which was (if reported) included as a cardiovascular comorbidity. (Supplemental Table S5.1) Patients with ischemic ECG had higher scores on the Charlson comorbidity index and its cardiovascular parts, had more frequently hypertension and atrial fibrillation and were more frequently treated for coronary disease or abdominal aortic aneurysm. (Table 5.3) 
The proportion of patients with ischemic ECG was similar after stratification for age in groups 55 to 65 and 65 to 75 years of age. Within both age groups the frequency of ischemic ECG tended to be higher in women, but did not reach statistical significance. (Figure 5.1)

Table 5.3 Characteristics and clinical outcomes of patients with and without ischemic ECG. Data are expressed as mean \pm SD or number (percentage).

\begin{tabular}{|c|c|c|c|}
\hline & $\begin{array}{c}\text { ECG without } \\
\text { ischemic } \\
\text { changes } \\
n=423\end{array}$ & $\begin{array}{c}\text { Ischemic } \\
\text { ECG } \\
n=113\end{array}$ & $\mathrm{p}$-value \\
\hline Age (years) & $63.3 \pm 9.3$ & $64.9 \pm 9.5$ & 0.120 \\
\hline Men & $269(64 \%)$ & $61(54 \%)$ & 0.062 \\
\hline Body mass index $\left(\mathrm{kg} / \mathrm{m}^{2}\right)$ & $25.0 \pm 5.1$ & $25.3 \pm 5.1$ & 0.610 \\
\hline Fat free mass index $\left(\mathrm{kg} / \mathrm{m}^{2}\right)$ & $16.3 \pm 2.3$ & $16.3 \pm 2.2$ & 0.980 \\
\hline Packyears (years) & $40.3 \pm 19.9$ & $38.1 \pm 18.5$ & 0.280 \\
\hline Current smoker & $116(27 \%)$ & $23(20 \%)$ & 0.038 \\
\hline Long term oxygen therapy & $41(10 \%)$ & $9(8 \%)$ & 0.575 \\
\hline Forced expiratory volume in 1 second (\% predicted) & $42.6 \pm 15.9$ & $40.8 \pm 15.2$ & 0.300 \\
\hline Ratio Forced expiratory volume in 1 second - Forced vital capacity (\%) & $41.2 \pm 11.4$ & $40.4 \pm 11.7$ & 0.540 \\
\hline Diffusion lung capacity for carbon monoxide (\% predicted) & $50.6 \pm 17.5$ & $52.3 \pm 19.3$ & 0.800 \\
\hline Six minute walking distance (meter) & $425 \pm 126$ & $387 \pm 126$ & 0.004 \\
\hline Six minute walking distance $<350 \mathrm{~m}$ & $109(26 \%)$ & $40(35 \%)$ & 0.042 \\
\hline Partial pressure of carbon dioxide - $\mathrm{paCO}_{2}(\mathrm{kPa})$ & $5.4 \pm 0.8$ & $5.5 \pm 0.9$ & 0.340 \\
\hline Partial pressure of oxygen - $\mathrm{paO}_{2}(\mathrm{kPa})$ & $9.3 \pm 1.4$ & $9.2 \pm 1.4$ & 0.960 \\
\hline High sensitive C-reactive protein (mmol/L) & $7.9 \pm 10.7$ & $11.2 \pm 16.2$ & 0.010 \\
\hline High sensitive C-reactive protein $<10 \mathrm{mmol} / \mathrm{L}$ & $314(74 \%)$ & $72(64 \%)$ & 0.027 \\
\hline High sensitive C-reactive protein $\geq 10 \mathrm{mmol} / \mathrm{L}$ & $109(26 \%)$ & $41(36 \%)$ & \\
\hline Modified Medical Research Council dyspnea scale (points) & $2.6 \pm 1.1$ & $2.9 \pm 1.1$ & 0.032 \\
\hline Updated BODE index (points) & $4.5 \pm 3.4$ & $5.3 \pm 3.7$ & 0.033 \\
\hline ADO index (points) & $4.8 \pm 1.7$ & $5.2 \pm 1.7$ & 0.029 \\
\hline Charlson comorbidity index (points) & $1.5 \pm 0.8$ & $1.8 \pm 0.9$ & 0.002 \\
\hline Charlson comorbidity index $\geq 2$ & $165(39 \%)$ & $60(53 \%)$ & 0.007 \\
\hline Myocardial infarction & $28(7 \%)$ & $25(22 \%)$ & $<0.001$ \\
\hline Cerebrovascular disease & $24(6 \%)$ & $14(12 \%)$ & 0.012 \\
\hline Chronic heart failure & $15(4 \%)$ & $13(12 \%)$ & 0.001 \\
\hline Peripheral arterial disease & $40(10 \%)$ & $16(14 \%)$ & 0.147 \\
\hline Operated abdominal aortic aneurysm & $10(2 \%)$ & $8(7 \%)$ & 0.013 \\
\hline Invasively treated coronary disease $*$ & $34(8 \%)$ & $25(22 \%)$ & $<0.001$ \\
\hline Angina pectoris & $18(4 \%)$ & $6(5 \%)$ & 0.630 \\
\hline Treated hypertension & $51(12 \%)$ & $22(20 \%)$ & 0.041 \\
\hline Atrial fibrillation or other arrhythmia & $47(10 \%)$ & $21(19 \%)$ & 0.034 \\
\hline Any cardiovascular comorbidity & $172(41 \%)$ & $71(63 \%)$ & $<0.001$ \\
\hline Use of cardiovascular medication & $219(52 \%)$ & $84(74 \%)$ & $<0.001$ \\
\hline
\end{tabular}

* Percutaneous transluminal coronary angioplasty (PTCA) or coronary artery bypass grafting (CABG)

Age, body composition, pack years, the degree of airflow obstruction, the degree of impairment of diffusion capacity, and blood gases were comparable between patients with and without ischemic ECG. On the contrary, patients with ischemic ECG had higher 
hSCRP levels, worse dyspnea grading and a worse functional exercise performance. (Table 5.3) Indeed, the mean 38m difference in 6MWD between patients with and without ischemic ECG clearly exceeded the minimal clinically important difference of $25 \mathrm{~m} .{ }^{17}$ Moreover, scores on the updated BODE and ADO index were significantly higher in patients with ischemic ECG compared to those without ischemic ECG. (Figure 5.2)

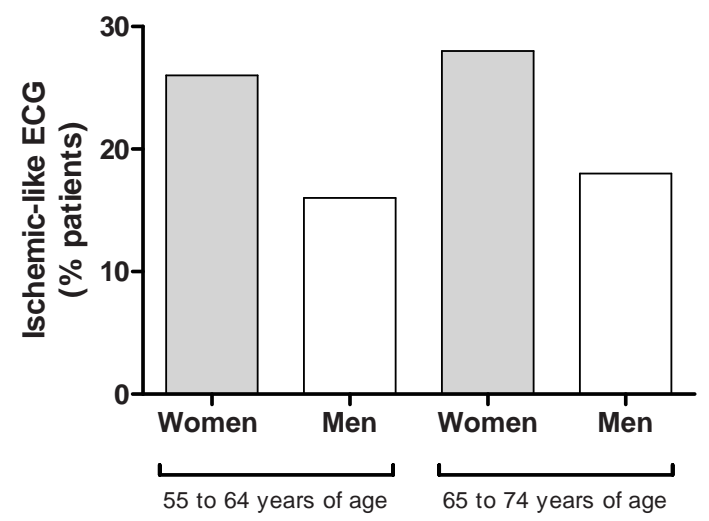

Figure 5.1 Patients with ischemic ECG stratified for age and gender:

Age 55-65: (left bars) $n=189,96$ female (grey bar), 93 male (white bar), respectively $26 \%$ and $16 \%$ - $p=0.095$; age 65-75:(right bars) $n=185,50$ female (grey bar), 133 male (white bar), respectively $28 \%$ and $18 \%-p=0.139$; Other age categories are not studied because of small numbers.

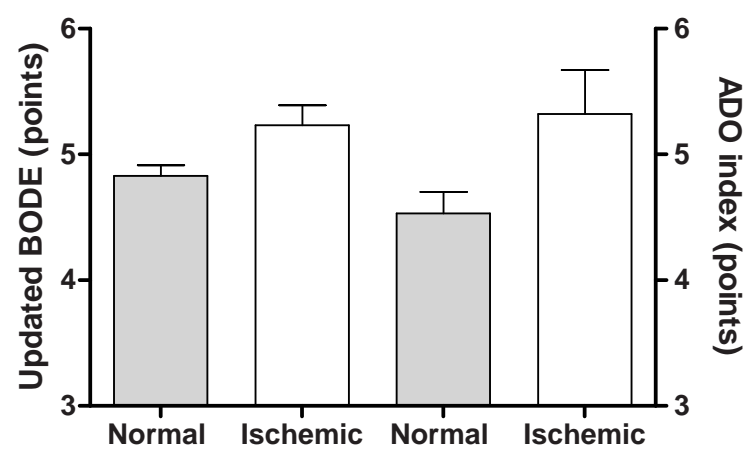

Figure 5.2 Difference in updated BODE index and ADO regarding the presence of ischemic ECG (mean \pm SEM):

Updated BODE index (left bars) and ADO index (right bars) for patients without (grey bars) and with (white bars) ischemic-like ECG changes. $p=0.033$ for updated BODE index and $p=0.029$ for ADO index. 
In a logistic regression model adjusting for $\mathrm{FEV}_{1}$, impaired 6MWD, hsCRP and higher scores on Charlson's comorbidity index remain significantly associated with the presence of ischemic ECG. On the contrary, dyspnea, and the updated BODE and ADO indices (both including $\mathrm{FEV}_{1}$ ), are not associated with the presence of ischemic ECG. (Table 5.4)

Table 5.4 Relationship between ischemic ECG and functional outcome after adjusting for FEV $\mathrm{V}_{1}$ in a logistic regression analysis.

\begin{tabular}{llcc}
\hline & $\beta$ & t-test & p-value \\
\hline Six minute walking distance & -0.106 & -2.7 & 0.007 \\
Modified Medical Research Council dyspnea scale & 0.75 & 1.891 & 0.093 \\
High sensitive C-reactive protein & 0.112 & 2.597 & 0.010 \\
Charlson comorbidity index & 0.141 & 3.288 & 0.001 \\
Updated BODE index & 0.68 & 1.866 & 0.063 \\
ADO index & 0.069 & 1.941 & 0.053 \\
\hline
\end{tabular}

In patients with ischemic ECG, there was no difference in updated BODE index $(5.4 \pm 3.6$ vs. $5.3 \pm 3.8 ; p=0.892)$ or $A D O$ index $(4.9 \pm 1.9$ vs. $5.4 \pm 1.6 ; p=0.152)$ regarding respectively the absence or presence of known cardiovascular disease.

Use of pulmonary medication was similar between both groups, except for short acting anticholinergics who were more frequently used in the group of patients with ischemic ECG. (Supplemental Table S5.2) To evaluate potential bias on the interpretation of ischemia on ECG, we analyzed the frequency of right bundle branch block (RBBB) and left axis deviation in patients with and without ischemic ECG and found that it was similar. (Supplemental Table S5.3) Moreover, neither the presence of RBBB or left axis deviation seems to be associated with worse functional outcome, although those patients were older. (Supplemental Table S5.4) The presence of atrioventricular conductance defect, the presence of atrial fibrillation or flutter and the presence of high $\mathrm{R}$ wave amplitude, which may be a sign of ventricular hypertrophy, is significant more prevalent in subjects with ischemic ECG. (Supplemental Table S5.3)

Also digitalis may complicate the interpretation of ischemia on ECG. In total 22 subjects used digitalis, of which 13 had an ischemic ECG (13 of 113 patients with ischemic ECG vs. 9 of 423 subjects without ischemic ECG; $p<0.001$ ). Two had LBBB, 6 had T-wave items and 5 had ST-depression items.

\section{DISCUSSION}

Main findings of the current study was that ischemic ECG was present in $21 \%$ of all patients with COPD and in $14 \%$ of COPD patients without reported cardiovascular 
comorbidities. In addition, patients with ischemic ECG had a different clinical phenotype (worse dyspnea grading, worse exercise performance, more systemic inflammation, more comorbidities) and higher scores on predictors of impaired survival in COPD (updated BODE index and ADO index) compared to COPD patients without ischemic ECG. This while there were no differences in the degree of airflow limitation, diffusion capacity, hypoxemia, age or body composition. Moreover, the presence of ischemic ECG in patients with COPD predicts - independently from airflow limitation impaired exercise performance, higher systemic inflammation and more comorbidities.

Q-wave patterns, ST- and T- wave changes and left bundle branch block are often seen as indications of silent myocardial ischemia and have been studied earlier. The results from different studies are quite consistent, in that ischemia-like ECG changes are associated with an approximately two-fold increased risk of dying of coronary heart disease. ${ }^{10,18-20}$ While there is a steep increase with age in the frequency of ischemic ECG in general population, ${ }^{10}$ this was not seen in the present study. This could possibly be influenced by impaired survival in patients with ischemic heart disease who have concomitant COPD. Likewise, it was recently shown that increased arteriovascular events in patients with COPD were highest in the youngest age-groups. ${ }^{21} \mathrm{As}$ in general population ${ }^{10}$ there is a tendency to a higher frequency of ischemic ECG in women.

In this study, worse exercise capacity and worse dyspnea were observed in patients with ischemic ECG. The difference in exercise capacity remained after correction for the degree of airflow limitation. Exercise capacity has been shown to predict cardiovascular and total mortality. ${ }^{22}$ In patients with COPD a 6MWD less than 350 meter is associated with increased overall mortality. ${ }^{23}$ In addition, both 6MWD and higher degree of

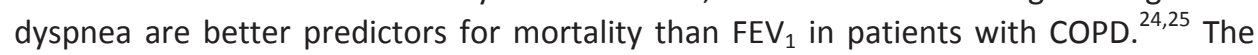
exact mechanism for impaired exercise capacity and worse dyspnea in patients with COPD is not fully understood and appears to be multifactorial. ${ }^{26}$

Among other contributors as skeletal muscle dysfunction ${ }^{27}$ and dynamic hyperinflation, ${ }^{28}$ it is likely that ischemic heart disease contributes importantly to these issues in patients with COPD. The presence of ischemic ECG was associated with the most validated predictors of mortality in patients with COPD: the updated BODE and ADO index. ${ }^{8}$ Since we found no difference in age, body composition and airflow obstruction, the association was mainly based on exercise capacity and dyspnea grade.

It has been shown earlier that the presence of cardiac injury on ECG is associated with low-grade systemic inflammation in patients with COPD. ${ }^{5}$ The latter condition plays an important role in the pathogenesis of atherosclerosis. ${ }^{29}$ We confirmed significant higher systemic inflammation in patients with ischemic ECG, even after adjustment for FEV $_{1}$. 
This emphasizes the importance of systemic inflammation in the development of ischemic heart disease in subjects with COPD.

Almost half of patients in this study had cardiovascular comorbidity and more than half used cardiovascular medication, increasing to almost two on three and three on four patients respectively if ischemic ECG was present. Importantly, on the other hand, more than one on three patients with ischemic ECG was not known with cardiovascular disease. Since additional investigations were not performed, the presence of overt cardiovascular disease cannot conclusively be confirmed in these patients. This could be subject of future studies. It has been shown that cardiovascular disease is under diagnosed in patients with COPD. ${ }^{6}$ Remarkably, also in patients without ischemic ECG, cardiovascular comorbidity (41\%) and medication use (52\%) was prevalent.

Almost $90 \%$ of patients used long acting beta-agonists and $85 \%$ inhaled corticosteroids. The only difference we found in the use of pulmonary medication between patients with and without ischemic ECG was in the use of short-acting anticholinergics. We suppose this difference is due to the physician's choice not to treat patients with heart disease with short acting beta-agonists as rescue medication.

Interestingly, we found that subjects with ischemic ECG were less frequent current smokers. We believe that the diagnosis of heart disease in those subjects has a stronger impact to convince to quit smoking than the diagnosis of COPD.

This study has limitations. First, no healthy control group was included, so the frequency of ischemic ECG in COPD cannot be compared to healthy peers. Secondly, since this is a sample of patients with important disability, entering pulmonary rehabilitation, these findings can possibly not be generalized to the whole population of patients with COPD. Nevertheless the importance of this study is to elucidate the different factors determining disability in patients with COPD. Third, ECG was only performed at rest which is inferior to ECG during exercise for detecting ischemic ECG signs. Fourth, the selected ECG changes in this study may have low specificity to ischemic heart disease. Also, there are factors confounding the interpretation of the ECG for ischemia, e.g. positional $Q$ waves in the inferior leads in case of hyperinflation and the use of digoxin. Finally, RBBB has been associated with advanced COPD. The presence of RBBB possibly complicates the analysis of the ST-segment. Also left axis deviation may have an impact on $Q$ wave morphology. Since the frequency of these ECG patterns in patients with and without ischemic ECG was similar, bias will be minimal. Moreover, neither the presence of RBBB or left axis deviation seems to be associated with worse functional outcome. 


\section{REFERENCES}

1. Huiart L, Ernst P, Suissa S. Cardiovascular morbidity and mortality in COPD. Chest 2005;128:2640-6.

2. Curkendall SM, DeLuise C, Jones JK, Lanes S, Stang MR, Goehring E Jr, She D. Cardiovascular disease in patients with chronic obstructive pulmonary disease, Saskatchewan Canada cardiovascular disease in COPD patients. Ann Epidemiol 2006;16:63-70.

3. Johnston AK, Mannino DM, Hagan GW, Davis KJ, Kiri VA. Relationship between lung function impairment and incidence or recurrence of cardiovascular events in a middle-aged cohort. Thorax 2008; 63:599-605.

4. Schünemann HJ, Dorn J, Grant BJ, Winkelstein W Jr, Trevisan M. Pulmonary function is a long-term predictor of mortality in the general population: 29-year follow-up of the Buffalo Health Study. Chest 2000;118:656-64.

5. Sin DD, Man SF. Why are patients with chronic obstructive pulmonary disease at increased risk of cardiovascular diseases? The potential role of systemic inflammation in chronic obstructive pulmonary disease. Circulation 2003;107:1514-9.

6. Rutten FH, Cramer MJ, Grobbee DE, Sachs AP, Kirkels JH, Lammers JW, Hoes AW. Unrecognized heart failure in elderly patients with stable chronic obstructive pulmonary disease. Eur Heart J 2005;26: 1887-94.

7. Blackburn H, Keys A, Simonson E, Rautaharju P, Punsar S. The electrocardiogram in population studies. A classification system. Circulation 1960;21:1160-75.

8. Puhan MA, Garcia-Aymerich J, Frey M, ter Riet G, Antó JM, Agustí AG, Gómez FP, Rodríguez-Roisín R, Moons KG, Kessels AG, Held U. Expansion of the prognostic assessment of patients with chronic obstructive pulmonary disease: the updated BODE index and the ADO index. Lancet 2009;374:704-11.

9. Spruit MA, Vanderhoven-Augustin I, Janssen PP, Wouters EF. Integration of pulmonary rehabilitation in COPD. Lancet 2008;371:12-3.

10. De Bacquer D, De Backer G, Kornitzer M. Prevalences of ECG findings in large population based samples of men and women. Heart 2000;84:625-33.

11. Charlson ME, Pompei P, Ales KL, MacKenzie CR. A new method of classifying prognostic comorbidity in longitudinal studies: development and validation. J Chronic Dis 1987;40:373-83.

12. Rabe KF, Hurd S, Anzueto A, Barnes PJ, Buist SA, Calverley P, Fukuchi Y, Jenkins C, Rodriguez-Roisin R, van Weel C, Zielinski J; Global Initiative for Chronic Obstructive Lung Disease. Global strategy for the diagnosis, management, and prevention of chronic obstructive pulmonary disease: GOLD executive summary. Am J Respir Crit Care Med 2007;176:532-55.

13. ATS statement: guidelines for the six-minute walk test. Am J Respir Crit Care Med 2002;166:111-7.

14. Hernandes NA, Wouters EF, Meijer K, Annegarn J, Pitta F, Spruit MA. Reproducibility of 6-minute walking test in patients with COPD. Eur Respir J 2011;38:261-7.

15. Schols AM, Wouters EF, Soeters PB, Westerterp KR. Body composition by bioelectrical-impedance analysis compared with deuterium dilution and skinfold anthropometry in patients with chronic obstructive pulmonary disease. Am J Clin Nutr 1991;53:421-4.

16. Spruit MA, Pennings HJ, Janssen PP, Does JD, Scroyen S, Akkermans MA, Mostert R, Wouters EF. Extrapulmonary features in COPD patients entering rehabilitation after stratification for MRC dyspnea grade. Respir Med 2007; 101:2454-63.

17. Holland AE, Hill CJ, Rasekaba T, Lee A, Naughton MT, McDonald CF. Updating the minimal important difference for six-minute walk distance in patients with chronic obstructive pulmonary disease. Arch Phys Med Rehabil 2010;91:221-5.

18. De Bacquer D, De Backer G, Kornitzer M, Blackburn H. Prognostic value of ECG findings for total, cardiovascular disease, and coronary heart disease death in men and women. Heart 1998;80:570-7.

19. Greenland P, Xie X, Liu K, Colangelo L, Liao Y, Daviglus ML, Agulnek AN, Stamler J. Impact of minor electrocardiographic ST-segment and/or T-wave abnormalities on cardiovascular mortality during longterm follow-up. Am J Cardiol 2003;91:1068-74.

20. Kumar A, Prineas RJ, Arnold AM, Psaty BM, Furberg CD, Robbins J, Lloyd-Jones DM. Prevalence, prognosis, and implications of isolated minor nonspecific ST-segment and T-wave abnormalities in older adults: Cardiovascular Health Study. Circulation 2008;118:2790-6. 
21. Feary JR, Rodrigues LC, Smith CJ, Hubbard RB, Gibson JE. Prevalence of major comorbidities in subjects with COPD and incidence of myocardial infarction and stroke: a comprehensive analysis using data from primary care. Thorax 2010;65:956-62.

22. Gulati M, Black HR, Shaw LJ, Arnsdorf MF, Merz CN, Lauer MS, Marwick TH, Pandey DK, Wicklund RH, Thisted RA. The prognostic value of a nomogram for exercise capacity in women. N Engl J Med 2005; 353:468-75.

23. Cote CG, Casanova C, Marín JM, Lopez MV, Pinto-Plata V, de Oca MM, Dordelly L, Nekach H, Celli BR. Validation and comparison of reference equations for the 6-min walk distance test. Eur Respir J 2008; 31:571-8.

24. Pinto-Plata VM, Cote C, Cabral H, Taylor J, Celli BR. The 6-min walk distance: change over time and value as a predictor of survival in severe COPD. Eur Respir J 2004;23:28-33.

25. Nishimura K, Izumi T, Tsukino M, Oga T. Dyspnea is a better predictor of 5-year survival than airway obstruction in patients with COPD. Chest 2002;121:1434-40.

26. Spruit MA, Watkins ML, Edwards LD, Vestbo J, Calverley PM, Pinto-Plata V, Celli BR, Tal-Singer R, Wouters EF; Evaluation of COPD Longitudinally to Identify Predictive Surrogate Endpoints (ECLIPSE) study investigators. Determinants of poor 6-min walking distance in patients with COPD: the ECLIPSE cohort. Respir Med 2010;104:849-57.

27. Broekhuizen R1, Grimble RF, Howell WM, Shale DJ, Creutzberg EC, Wouters EF, Schols AM. Pulmonary cachexia, systemic inflammatory profile, and the interleukin 1beta -511 single nucleotide polymorphism. Am J Clin Nutr 2005;82:1059-64.

28. O'Donnell DE, Revill SM, Webb KA. Dynamic hyperinflation and exercise intolerance in chronic obstructive pulmonary disease. Am J Respir Crit Care Med 2001;164:770-7.

29. Ross R. Atherosclerosis--an inflammatory disease. N Engl J Med 1999;340:115-26. 


\section{SUPPLEMENTAL MATERIAL}

Table S5.1 Frequency of ECG patterns according to the presence of cardiovascular disease. Data are expressed as number (percentage).

\begin{tabular}{|c|c|c|c|c|c|}
\hline ECG pattern & $\begin{array}{l}\text { Minnesota } \\
\text { code }\end{array}$ & All $(n=536)$ & $\begin{array}{l}\text { No reported } \\
\text { cardiovascular } \\
\text { disease } \\
(n=293)\end{array}$ & $\begin{array}{c}\text { Reported } \\
\text { cardiovascular } \\
\text { disease } \\
(n=243)\end{array}$ & p-value \\
\hline \multicolumn{6}{|l|}{ Ischemic patterns } \\
\hline Major Q or QS pattern & 1.1 & $23(4.3 \%)$ & $7(2.4 \%)$ & $16(6.6 \%)$ & 0.017 \\
\hline Minor Q or QS pattern & $1.2+1.3$ & $15(2.8 \%)$ & $6(2.0 \%)$ & $9(3.7 \%)$ & 0.247 \\
\hline $\begin{array}{l}\text { ST junction }(J) \text { and segment } \\
\text { depression }\end{array}$ & $4.1+4.2$ & $19(3.5 \%)$ & $6(2.0 \%)$ & $13(5.4 \%)$ & 0.040 \\
\hline T-wave items & $5.1-5.3$ & $47(8.8 \%)$ & $20(6.8 \%)$ & 27 (11.1\%) & 0.081 \\
\hline Left bundle branch block & 7.1 & $11(2.1 \%)$ & $2(0.7 \%)$ & $9(3.7 \%)$ & 0.014 \\
\hline Ischemia & All above & $113(21 \%)$ & $42(14.3 \%)$ & $71(29.2 \%)$ & $<0.001$ \\
\hline \multicolumn{6}{|l|}{ Non-ischemic patterns } \\
\hline Right Bundle Branch Block & 7.2 & $35(6.5 \%)$ & $21(7.2 \%)$ & $14(5.8 \%)$ & 0.512 \\
\hline Atrium fibrillation or flutter & 8.3 & $13(2.4 \%)$ & $0(0 \%)$ & $13(5.3 \%)$ & $<0.001$ \\
\hline $\begin{array}{l}\text { Atrial-ventricular conduction defect, } \\
\text { grade } 1\end{array}$ & 6.3 & $5(0.9 \%)$ & $2(0.7 \%)$ & $3(1.2 \%)$ & 0.508 \\
\hline Left axis deviation & 2.1 & $52(9.7 \%)$ & $25(8.5 \%)$ & $27(9.9 \%)$ & 0.315 \\
\hline High amplitude $\mathrm{R}$ waves & $3.1+3.2$ & $8(1.5 \%)$ & $4(1.4 \%)$ & $4(1.6 \%)$ & 0.789 \\
\hline
\end{tabular}

Table S5.2 Proportion of patients using pulmonary drug regarding the presence of ischemic ECG. Data are expressed as number (percentage).

\begin{tabular}{lccc}
\hline & $\begin{array}{c}\text { ECG without ischemic changes } \\
(\mathrm{n}=423)\end{array}$ & $\begin{array}{c}\text { ischemic ECG } \\
(\mathrm{n}=113)\end{array}$ & $\mathrm{p}$-value \\
\hline Short-acting beta-agonists & $255(60 \%)$ & $65(58 \%)$ & 0.595 \\
Long-acting beta-agonists & $373(88 \%)$ & $101(89 \%)$ & 0.723 \\
Short-acting anticholinergics & $178(42 \%)$ & $62(52 \%)$ & 0.015 \\
Long-acting anticholinergics & $258(61 \%)$ & $63(56 \%)$ & 0.313 \\
Inhaled corticosteroids & $360(85 \%)$ & $96(85 \%)$ & 0.968 \\
Oral corticosteroids & $87(21 \%)$ & $31(27 \%)$ & 0.118 \\
Theophylline & $75(18 \%)$ & $27(24 \%)$ & 0.138 \\
Antileukotrienes & $15(4 \%)$ & $2(2 \%)$ & 0.338 \\
\hline
\end{tabular}


Table S5.3 Frequency of non-ischemic ECG patterns in patients with and without ischemic ECG. Data are expressed as number (percentage).

\begin{tabular}{lccc}
\hline & $\begin{array}{c}\text { ECG without ischemic changes } \\
(\mathrm{n}=423)\end{array}$ & $\begin{array}{c}\text { Ischemic ECG } \\
(\mathrm{n}=113)\end{array}$ & $\mathrm{p}$-value \\
\hline Right bundle branch block & $29(6.9 \%)$ & $6(5.3 \%)$ & 0.555 \\
Atrium fibrillation or flutter & $6(1.4 \%)$ & $7(6.2 \%)$ & 0.003 \\
Atrial-Ventricular conduction defect, grade 1 & $0(0 \%)$ & $5(4.4 \%)$ & 0.001 \\
Left axis deviation & $45(10.6 \%)$ & $7(6.2 \%)$ & 0.156 \\
High R wave amplitude & $4(1.0 \%)$ & $4(3.5 \%)$ & 0.043 \\
\hline
\end{tabular}

Table S5.4 Functional outcome in patients with and without right bundle branch block (up) and left axis deviation (down). Data are expressed as mean \pm SD.

\begin{tabular}{|c|c|c|c|}
\hline & $\begin{array}{l}\text { Patients without } \\
\text { right bundle } \\
\text { branch block } \\
n=501\end{array}$ & $\begin{array}{l}\text { Patients with } \\
\text { right bundle } \\
\text { branch block } \\
n=35\end{array}$ & p-value \\
\hline Modified Medical Research Council dyspnea scale (points) & $2.7 \pm 1.1$ & $2.5 \pm 1.3$ & 0.340 \\
\hline Updated BODE index (points) & $4.7 \pm 3.4$ & $5.2 \pm 4.1$ & 0.410 \\
\hline ADO index (points) & $4.9 \pm 1.7$ & $5.2 \pm 1.7$ & 0.260 \\
\hline Forced expiratory volume in 1 second (\% predicted) & $42.4 \pm 15.9$ & $38.6 \pm 11.9$ & 0.170 \\
\hline Packyears (years) & $40.0 \pm 19.8$ & $38.2 \pm 15.8$ & 0.600 \\
\hline Six minute walking distance (meter) & $419 \pm 126$ & $394 \pm 143$ & 0.280 \\
\hline Partial pressure of oxygen - $\mathrm{paO}_{2}(\mathrm{kPa})$ & $9.3 \pm 1.4$ & $8.9 \pm 1.2$ & 0.090 \\
\hline Age (years) & $63.4 \pm 9.4$ & $66.9 \pm 9.0$ & 0.037 \\
\hline \multirow[t]{2}{*}{ Body mass index $\left(\mathrm{kg} / \mathrm{m}^{2}\right)$} & $25.0 \pm 5.1$ & $26.1 \pm 5.2$ & 0.215 \\
\hline & $\begin{array}{c}\text { Patients without } \\
\text { left axis deviation } \\
n=484\end{array}$ & $\begin{array}{c}\text { Patients with left } \\
\text { axis deviation } \\
n=52\end{array}$ & p-value \\
\hline Modified Medical Research Council dyspnea scale (points) & $2.7 \pm 1.1$ & $2.7 \pm 1.2$ & 0.990 \\
\hline Updated BODE index (points) & $4.7 \pm 3.5$ & $4.6 \pm 3.6$ & 0.860 \\
\hline ADO index (points) & $4.9 \pm 1.8$ & $5.2 \pm 1.5$ & 0.190 \\
\hline Forced expiratory volume in 1 second (\% predicted) & $42.0 \pm 15.7$ & $44.7 \pm 15.8$ & 0.220 \\
\hline Packyears (years) & $39.5 \pm 19.4$ & $43.3 \pm 20.7$ & 0.180 \\
\hline Six minute walking distance (meter) & $418 \pm 128$ & $404 \pm 119$ & 0.420 \\
\hline Partial pressure of oxygen - $\mathrm{paO}_{2}(\mathrm{kPa})$ & $9.3 \pm 1.4$ & $9.0 \pm 1.2$ & 0.180 \\
\hline Age (years) & $63.2 \pm 9.4$ & $67.6 \pm 8.6$ & 0.001 \\
\hline Body mass index $\left(\mathrm{kg} / \mathrm{m}^{2}\right)$ & $25.0 \pm 5.1$ & $25.2 \pm 4.9$ & 0.788 \\
\hline
\end{tabular}





\title{
CHAPTER 6
}

\section{Clusters of comorbidities based on validated}

\author{
objective measurements and systemic
} inflammation in patients with COPD

Lowie E.G.W. Vanfleteren, Martijn A. Spruit, Miriam Groenen, Swetlana Gaffron, Vanessa P.M. van Empel, Piet L.B. Bruijnzeel, Erica P.A. Rutten, Jos Op 't Roodt, Emiel F.M. Wouters, Frits M.E. Franssen American Journal of Respiratory and Critical Care Medicine 2013;187:728-735 


\section{ABSTRACT}

\section{Rationale}

Comorbidities contribute to disease severity and mortality in patients with COPD. Comorbidities have been studied individually and were mostly based on self-reports. The co-existence of objectively identified comorbidities and the role of low-grade systemic inflammation in the pathophysiology of COPD remains to be elucidated.

\section{Objectives}

To cluster 13 clinically important objectively identified comorbidities, and to characterize the comorbidity clusters in terms of clinical outcomes and systemic inflammation.

\section{Methods}

213 COPD patients $\left(\mathrm{FEV}_{1}: 51 \pm 17 \%\right.$ predicted, men: $59 \%$, age: $64 \pm 7$ years) were included prospectively. Comorbidities were based on well-known cut-offs identified in the peer-reviewed English literature. Systemic inflammatory biomarkers were determined in all patients. Selforganizing maps were used to generate comorbidity clusters.

\section{Measurements and main results}

$97.7 \%$ of all patients had $\geq 1$ comorbidities and $53.5 \%$ had $\geq 4$ comorbidities. Five comorbidity clusters were identified: "Less comorbidity"; "Cardiovascular"; "Cachectic"; "Metabolic"; and "Psychological". Comorbidity clusters differed in health status but were comparable with respect to disease severity. An increased inflammatory state was observed only for TNF-receptors in the "metabolic" cluster (geometric mean (lower and upper limit): sTNFR1: 2377 (1850, 3055) pgs/ml, confidence: $98.5 \%$; sTNFR2: $4080(3115,5344) \mathrm{pgs} / \mathrm{ml}$, confidence: $98.8 \%)$ and only for IL-6 in the "cardiovascular" cluster (IL-6: $3.4(1.8,6.6)$ pgs/ml, confidence: 99.8\%).

\section{Conclusion}

Multimorbidity is common in patients with COPD, and different comorbidity clusters can be identified. Low-grade systemic inflammation is mostly comparable among comorbidity clusters. Increasing knowledge on the interactions between comorbidities will increase the understanding of their development and contribute to strategies for prevention or improved treatment. 


\section{INTRODUCTION}

Chronic obstructive pulmonary disease (COPD) is a major global health concern, causing considerable morbidity and mortality around the world. Although defined by the presence of chronic airflow limitation, COPD is nowadays considered a complex, heterogeneous and multi-component condition. ${ }^{1}$ It is increasingly recognized that the presence of other chronic conditions (comorbidities) such as cardiovascular disease, depression, osteoporosis, anemia and diabetes substantially contributes to the severity of the disease. ${ }^{2}$ Comorbidities not only affect symptom burden, functional performance and health status in patients with $\mathrm{COPD}^{3}$, but also the risk of hospitalization ${ }^{4}$ and mortality. ${ }^{4,5}$

To date, most studies on the impact of comorbidities in COPD used data on selfreported concurrent chronic conditions. This may limit the internal validity of these studies. $^{4-13}$ Indeed, self-reported data are most probably underestimating the true prevalence of comorbidities in COPD. ${ }^{14}$ Moreover, most comorbidities have been studied separately, while the majority of elderly have two or more chronic morbidities. ${ }^{15}$ Overlap in self-reported comorbidities has been shown in primary care COPD patients. ${ }^{11}$ Although some associations between objectively identified comorbidities, such as vascular stiffness and osteoporosis, ${ }^{16}$ have been studied, it is currently unknown whether and to what extent comorbidities cluster in COPD. Also, it remains unclear whether or not patients with different comorbidity profiles differ in disease severity, pharmacological treatment or other relevant clinical outcomes.

Persistent low-grade systemic inflammation may be the link between COPD and comorbidities. ${ }^{17}$ Simultaneously elevated inflammatory markers have been associated with an increased risk of comorbidities. ${ }^{18}$ However, the ECLIPSE study reported that chronic systemic inflammation is a feature in only a small proportion of the COPD patients. ${ }^{19}$ Intriguingly, the risk of chronic systemic inflammation was not increased in patients with self-reported cardiovascular comorbidity, while older age and obese BMI, among other factors, were associated with this feature. These observations shed new light on the role of chronic inflammation in the development of comorbidities in COPD and on the possible etiology of systemic inflammation in COPD.

Therefore, the present study investigated the frequency of 13 clinically relevant and objectively identified comorbidities as well as the clustering of these comorbidities in a well-characterized cohort of COPD patients. In addition, potential differences in disease severity and clinical characteristics, inflammatory status and current pharmacologic treatment between comorbidity clusters were explored. 
Some of the results of this study have been previously reported in the form of an abstract. $^{20}$

\section{METHODS}

Please see supplemental material for details and references.

\section{STUDY DESIGN AND PATIENTS}

The current analysis was based on data collected as part of the CIRO CO-morbidity (CIROCO) study, an observational single-center study. All subjects provided written informed consent and the study was approved by the local ethics and review boards (MEC 10-3-067). Patients with moderate to very severe COPD (Global Initiative for Obstructive Lung Disease [GOLD] grades 2 to 4$)^{2}$, aged 40 to 80 years and in a clinically stable state were prospectively recruited between November 2007 and November 2010 during the initial evaluation of a comprehensive pulmonary rehabilitation program at $\mathrm{CIRO}+.^{21}$ Patients with a history of asthma, alpha-1 antitrypsin deficiency, any previous lung surgery, active inflammatory disease, acute myocardial infarction within the last 6 months, any known bone disease other than osteoporosis, current or recently (i.e. $<5$ years prior to the study) treated malignant disease or high dose systemic glucocorticosteroids (i.e. $>10 \mathrm{mg}$ prednisolone) use were excluded from the study.

\section{ASSESSMENTS}

At study entry, patients' demographics, smoking status, medications and long-term oxygen use were documented. In addition, the following assessments were performed: lung function: post-bronchodilator spirometry, static lung volumes and carbon monoxide diffusion capacity (DLCO); body composition: body mass index (BMI), fat free mass index (FFMI) and bone mineral density (BMD) at the hip, lumbar spine and wholebody using dual energy absorptiometry (DEXA) scan; vascular status: carotid intimamedia thickness (c-IMT), cardiac infarction injury score (CIIS) based on a resting 12-lead ECG and peripheral blood pressure; functional exercise capacity: six minute walk distance (6MWD); dyspnea: modified Medical Research Questionnaire (mMRC); psychological and health status: Hospital Anxiety and Depression Scale (HADS) and St. George's Respiratory Questionnaire (SGRQ). For evaluation of the generalizability of the results, the (age-adjusted) Charlson comorbidity index was assessed to compare to existing patient cohorts. Venous blood was obtained in fasting state for assessment of hematology, chemistry and inflammatory status (leukocytes, C-reactive protein [CRP], soluble tumor necrosis factor- $\alpha$ receptors 1 and 2 [STNFR1, sTNFR2], interleukins 6 
[IL-6] and 8 [IL-8]). Finally, updated-BODE and Framingham risk scores were calculated as prognostic markers.

\section{DEFINITIONS OF COMORBIDITIES}

Thirteen comorbidities were identified in all patients based on pre-defined cut-offs as suggested by relevant international societies (for references: see supplemental material): chronic kidney disease (estimated glomerular filtration rate (eGFR) $<60 \mathrm{ml} / \mathrm{min}$ ); anemia (hemoglobin level $<8.1 \mathrm{mmol} / \mathrm{l}$ in men and $<7.5 \mathrm{mmol} / \mathrm{l}$ in women; hypertension (systolic blood pressure $>140 \mathrm{~mm} \mathrm{Hg}$ or diastolic pressure $>90$ $\mathrm{mm} \mathrm{Hg}$ ); obesity (BMI $\geq 30 \mathrm{~kg} / \mathrm{m}^{2}$ ); underweight (BMI $<21 \mathrm{~kg} / \mathrm{m}^{2}$ ); muscle wasting (FFMI $<16 \mathrm{~kg} / \mathrm{m}^{2}$ for men or $<15 \mathrm{~kg} / \mathrm{m}^{2}$ for women); hyperglycemia (fasting glucose level above $5.6 \mathrm{mmol} / \mathrm{l}$; dyslipidemia (triglyceride level $>1.7 \mathrm{mmol} / \mathrm{I}$ or $\mathrm{HDL}$ cholesterol level $<1.03 \mathrm{mmol} / \mathrm{l}$ in men or <1.29 mmol/l in women); osteoporosis (T-score <-2.5); symptoms of anxiety and depression (HADS score $\geq 10$ points); atherosclerosis (c-IMT $>0.9 \mathrm{~mm}$ ) and myocardial infarction (CIIS $\geq 20$ ).

\section{STATISTICS}

All statistical analyses were performed using Viscovery Profiler 5.3 by Viscovery Software $\mathrm{GmbH}$, (www.viscovery.net). Self-organizing maps (SOMs, also referred to as Kohonen maps) were used to create an ordered representation of the comorbidity data. The SOM method can be viewed as a non-parametric regression technique that converts multi-dimensional data spaces into lower dimensional abstractions. A SOM generates a non-linear representation of the data distribution and allows the user to identify homogenous data groups visually.

Patients have been ordered by their overall similarity concerning their present comorbidities and also the degree of its presence given by parameters the comorbidities are calculated from. Based on the created SOM model, clusters have been generated using the SOM-Ward Cluster algorithm of Viscovery, a hybrid algorithm that applies the classical hierarchical method of Ward on top of the SOM topology. Summary variables on comorbidities and clinical characteristics for the study sample and for each cluster are presented as mean \pm standard deviation for quantitative variables, and percentage for discrete variables. Data of the inflammatory markers were log-transformed to mitigate the effects of extreme values. Here, summary variables are presented as geometric mean with lower and upper limit. Viscovery automatically identified for each cluster the comorbidities, clinical characteristics as well as the inflammatory markers that differ significantly from the average of the whole study sample of 213 patients using the integrated two-sided T-test with a confidence of $95 \%$. 


\section{RESULTS}

\section{GENERAL PATIENT CHARACTERISTICS}

Of 255 patients prospectively recruited from patients admitted to CIRO, 42 were ineligible. The final study population consisted of 213 patients with moderate to severe COPD, substantial smoking history, moderately impaired diffusion capacity and increased static lung volumes (Table 6.1). In 30 patients, data on one of the selected comorbidities was missing; 13 patients lacked acceptable quality c-IMT measurement, 6 did not fill out the HADS and 11 lacked an acceptable ECG, impeding to determine the CIIS. Data on the self-reported (age-adjusted) Charlson comorbidity index are in the supplemental material (Supplemental Table S6.1).

Table 6.1 Patients characteristics

\begin{tabular}{lc}
\hline & All subjects \\
& $\mathrm{n}=213$ \\
\hline Age, years & $63.6 \pm 7.0$ \\
Male, \% & 59 \\
$\mathrm{BMI}, \mathrm{kg} / \mathrm{m}^{2}$ & $26.2 \pm 5.1$ \\
FFMI, kg/m & $17.0 \pm 2.4$ \\
mMRC dyspnea grade & $2.1 \pm 1.09$ \\
Current smoker, \% & 28 \\
Packyears & $46 \pm 26$ \\
Long-term oxygen therapy, \% & 17 \\
FEV 1, liters & $1.40 \pm 0.54$ \\
FEV $1, \%$ predicted & $51.2 \pm 16.9$ \\
FEV ${ }_{1} /$ FVC & $0.40 \pm 0.11$ \\
ITGV, \% predicted & $148 \pm 33$ \\
DLCO, \% predicted & $56 \pm 17$ \\
6MWD, meters & $470 \pm 106$ \\
SGRQ, total score & $51.3 \pm 17.5$ \\
Updated BODE score & $2.9 \pm 2.5$ \\
Framingham 10-year risk \% & $9.4 \pm 6.7$ \\
\hline
\end{tabular}

Summary variables are presented as mean \pm standard deviation for quantitative variables, and percentage for discrete variables. BMI: body mass index; FFMI: fat free mass index; mMRC: Modified Medical Research Council; 6MWD: Six minute walking distance; $\mathrm{FEV}_{1}$ : Forced expiratory volume in the first second; ITGV: Intrathoracic gas volume; DLCO: Diffusion factor for carbon monoxide; SGRQ: St.-George's Respiratory Questionnaire, BODE index: Based on BMI, Obstruction ( $\left.\mathrm{FEV}_{1}\right)$, Dyspnea, Exercise (6MWD).

\section{FREQUENCY OF OBJECTIVELY IDENTIFIED COMORBIDITIES}

All comorbidities were present in the COPD population, although the frequencies ranged from 5 to 54\% (Figure 6.1). Hyperglycemia, atherosclerosis, hypertension, dyslipidemia and osteoporosis were the five most prevalent comorbidities. 


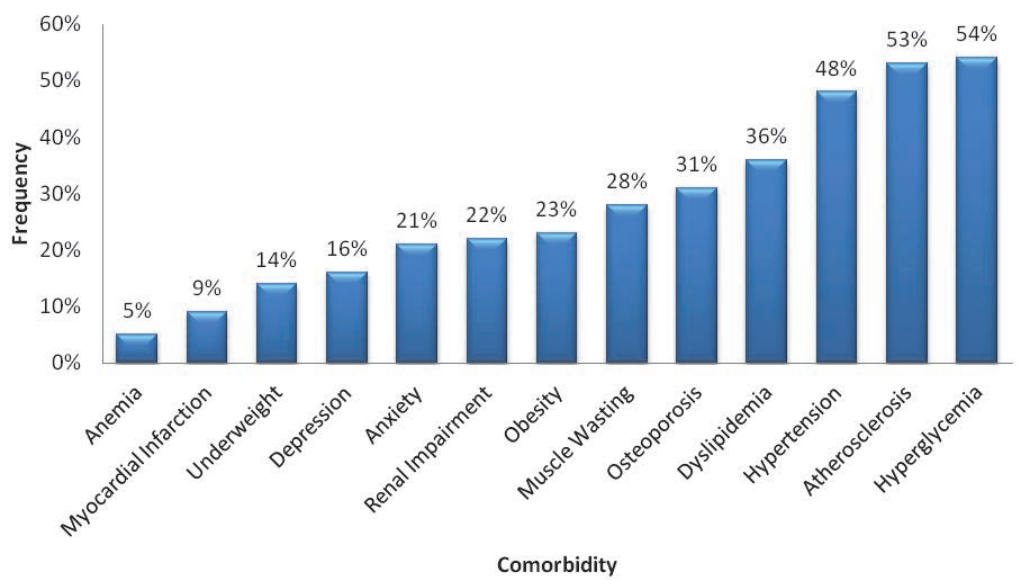

Figure 6.1 Frequencies of objectively identified comorbidities.

\section{NUMBER OF COMORBIDITIES}

Almost all subjects (97.7\%) had one or more comorbidities and more than half of the patients had at least four comorbidities (Figure 6.2). The frequencies of different individual comorbidities in patients with each of the 13 specific comorbidities are shown in Figure 6.3. For example, muscle wasting and osteoporosis were highly prevalent in underweight patients, while they were almost absent in obesity.

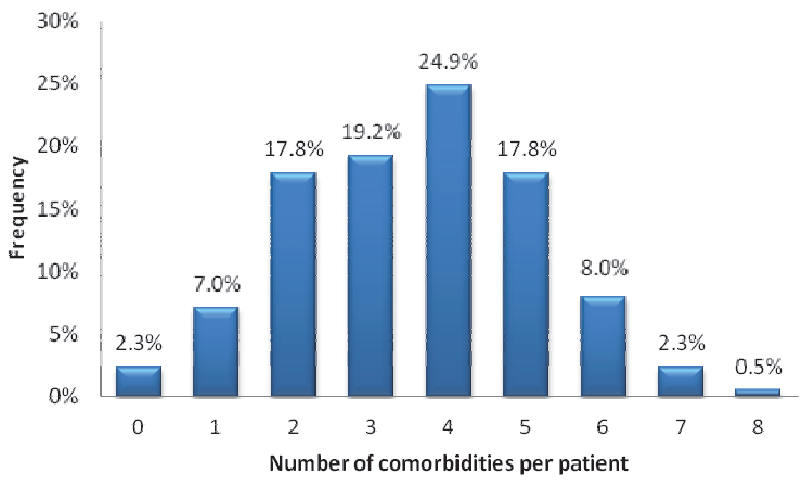

Figure 6.2 Number of objectively identified comorbidities. 


\begin{tabular}{|c|c|c|c|c|c|c|c|c|c|c|c|c|c|}
\hline $\begin{array}{l}<20 \% \\
20-40 \% \\
40-60 \% \\
>60 \%\end{array}$ & 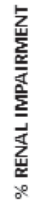 & 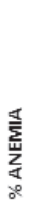 & 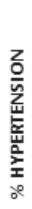 & 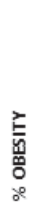 & 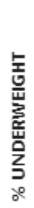 & 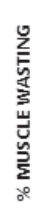 & 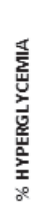 & 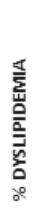 & 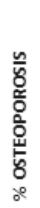 & 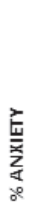 & 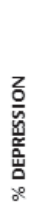 & 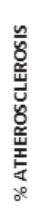 & 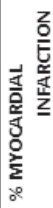 \\
\hline RENAL IMPAIRMENT $(n=47)$ & & 6 & 49 & 9 & 32 & 45 & 43 & 36 & 38 & 13 & 11 & 47 & 11 \\
\hline ANEMIA $(n=11)$ & 27 & & 45 & 36 & 9 & 18 & 64 & 18 & 36 & 18 & 18 & 73 & 0 \\
\hline HYPERTENSION $(n=103)$ & 22 & 5 & & 27 & 12 & 23 & 58 & 35 & 26 & 20 & 16 & 62 & 12 \\
\hline OBESITY $(n=50)$ & 8 & 8 & 56 & & 0 & 0 & 72 & 42 & 18 & 12 & 18 & 72 & 4 \\
\hline UNDERWEIGHT $(n=30)$ & 50 & 3 & 40 & 0 & & 93 & 37 & 27 & 57 & 21 & 4 & 17 & 3 \\
\hline MUSCLE WASTING $(n=60)$ & 35 & 3 & 40 & 0 & 47 & & 42 & 22 & 55 & 33 & 14 & 29 & 9 \\
\hline HYPERGLYCEMIA $(n=116)$ & 17 & 6 & 52 & 31 & 10 & 22 & & 41 & 29 & 22 & 20 & 55 & 12 \\
\hline DYSLIPIDEMIA $(n=77)$ & 22 & 3 & 47 & 27 & 10 & 17 & 62 & & 20 & 14 & 18 & 63 & 11 \\
\hline OSTEOPOROSIS ( $n=66$ ) & 27 & 6 & 41 & 14 & 26 & 50 & 52 & 23 & & 29 & 23 & 49 & 13 \\
\hline ANXIETY $(n=43)$ & 14 & 5 & 47 & 14 & 14 & 44 & 58 & 26 & 42 & & 40 & 46 & 12 \\
\hline DEPRESSION $(n=33)$ & 15 & 6 & 49 & 27 & 3 & 24 & 67 & 42 & 42 & 52 & & 70 & 19 \\
\hline ATHEROSCLEROSIS $(n=106)$ & 20 & 8 & 57 & 31 & 5 & 15 & 57 & 43 & 28 & 17 & 21 & & 14 \\
\hline MYOCARDIAL INFARCTION $(n=19)$ & 26 & 0 & 63 & 11 & 5 & 26 & 68 & 42 & 42 & 29 & 35 & 75 & \\
\hline
\end{tabular}

Figure 6.3 The frequencies of objectively identified comorbidities in COPD patients with each of the 13 selected specific comorbidities.

\section{COMORBIDITY CLUSTERS}

Five clusters with a significantly different comorbidity profile were identified (Figure 6.4; Table 6.2). Cluster 1 ("less comorbidity cluster") had significantly less comorbidities compared to the other clusters. Cluster 2 ("cardiovascular cluster") had a significantly higher prevalence of hypertension and atherosclerosis compared to the other clusters. On the other hand, dyslipidemia, hyperglycemia, underweight and muscle wasting were less prevalent compared to the other clusters. Cluster 3 ("cachectic cluster") had a higher prevalence of underweight, muscle wasting, osteoporosis and renal impairment, while obesity and atherosclerosis were less often identified. This cluster 3 had a high number of comorbidities. Cluster 4 ("metabolic cluster") also had a higher number of comorbidities. This cluster contained more patients with obesity, atherosclerosis, dyslipidemia, hyperglycemia and hypertension, but less patients with anxiety, underweight, muscle wasting and osteoporosis. Finally, cluster 5 ("psychological 
cluster") had the highest proportion of patients with psychological disorders: anxiety and depression, but also the highest prevalence of myocardial infarction. A detailed description of the five clusters is presented in Table 6.2.

Table 6.2 Detailed description of the five clusters in terms of the number of comorbidities and the prevalence of each comorbidity.

\begin{tabular}{lccccc}
\hline Comorbidities & $\begin{array}{c}\text { CLUSTER 1 } \\
\text { 'less comorbidity' }\end{array}$ & $\begin{array}{c}\text { CLUSTER 2 } \\
\text { 'cardiovascular' }\end{array}$ & $\begin{array}{c}\text { CLUSTER 3 } \\
\text { 'cachectic' }\end{array}$ & $\begin{array}{c}\text { CLUSTER 4 } \\
\text { 'metabolic' }\end{array}$ & $\begin{array}{c}\text { CLUSTER 5 } \\
\text { 'psychologic' }\end{array}$ \\
\hline $\mathrm{n}$ & 67 & 49 & 44 & 33 & 20 \\
Number of Comorbidities & $2.5 \pm 1.4$ & $3.8 \pm 1.7$ & $4.2 \pm 1.4$ & $4.4 \pm 1.1$ & $4.1 \pm 1.8$ \\
Renal Impairment, \% & 16 & 24 & 45 & 9 & 5 \\
Anemia, \% & 9 & 4 & 2 & 3 & 5 \\
Hypertension, \% & 3 & 98 & 43 & 100 & 5 \\
Obesity, \% & 30 & 14 & 0 & 61 & 15 \\
Underweight, \% & 0 & 0 & 66 & 3 & 0 \\
Muscle Wasting, \% & 12 & 10 & 98 & 0 & 20 \\
Hyperglycemia, \% & 52 & 41 & 43 & 91 & 60 \\
Dyslipidemia, \% & 42 & 16 & 25 & 67 & 40 \\
Osteoporosis, \% & 27 & 37 & 52 & 0 & 35 \\
Anxiety, \% & 5 & 28 & 26 & 0 & 84 \\
Depression, \% & 6 & 23 & 7 & 6 & 68 \\
Atherosclerosis, \% & 56 & 67 & 12 & 81 & 53 \\
Myocardial Infarction, \% & 2 & 11 & 7 & 13 & 32 \\
\hline
\end{tabular}

Summary variables are presented as mean \pm standard deviation for quantitative variables, and percentage for discrete variables. Light grey: less prevalent compared to the whole study sample ( $95 \%$ confidence interval); dark grey: more prevalent compared to the whole study sample ( $95 \%$ confidence interval).

\section{DIFFERENCES IN PATIENT CHARACTERISTICS BETWEEN CLUSTERS OF COMORBIDITY}

$\mathrm{FEV}_{1}$ (\% predicted), smoking history, functional exercise capacity, long-term oxygen use and updated BODE scores were not different between the comorbidity clusters (Table 6.3).

Then again, patients in cluster 1 ("less comorbidity cluster") had a lower mean age, a higher mean diffusion capacity and a better mean health related quality of life. Moreover, a higher proportion of patients used cholesterol lowering drugs, antiaggregates or oral anti-diabetics (Supplemental Table S6.2). Cluster 2 ("cardiovascular cluster") included older patients who were less frequently active smokers but with a worse quality of life and a higher predicted cardiovascular risk according to the Framingham risk score. Cluster 3 ("cachectic cluster") had a higher proportion of women and active smokers. In addition, patients in this cluster had on average more static hyperinflation and lower diffusion capacity. Surprisingly they also had on average a lower dyspnea score, a better health-related quality of life and a lower cardiovascular risk prediction score. In line with this, a lower proportion of patients used angiotensin 
converting enzyme inhibitors or angiotensin receptor blockers (ACE/ARB), any other antihypertensive therapy or cholesterol lowering drugs in this cluster. Patients in cluster 4 ("metabolic cluster") were more frequently male, had less static hyperinflation and had on average a higher cardiovascular risk prediction score. Also, the proportion of patients using LABA/ICS inhalers or short acting rescue medication was lower in this cluster (Supplemental Table S6.3). Patients in cluster 5 ("psychological cluster") reported on average more dyspnea and a worse health-related quality of life. Patients in this cluster more frequently used benzodiazepines and nitrates, as also short acting "rescue" bronchodilators.
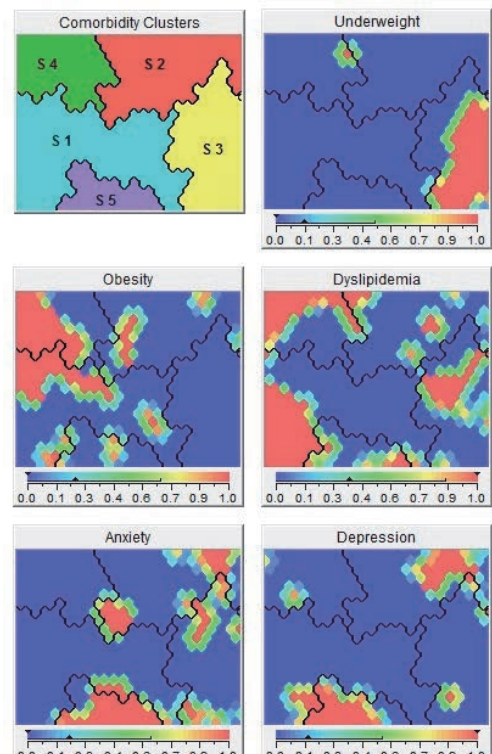

\begin{tabular}{llllllllllll}
0.0 & 0.1 & 0.3 & 0.4 & 0.6 & 0.7 & 0.9 & 1.0 \\
\hline
\end{tabular}
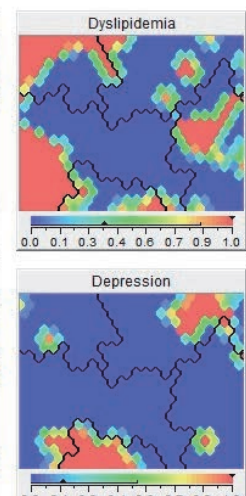

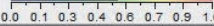
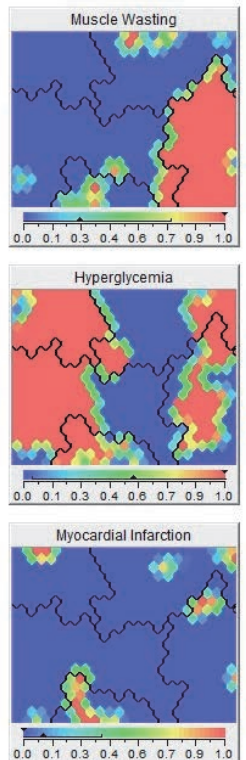
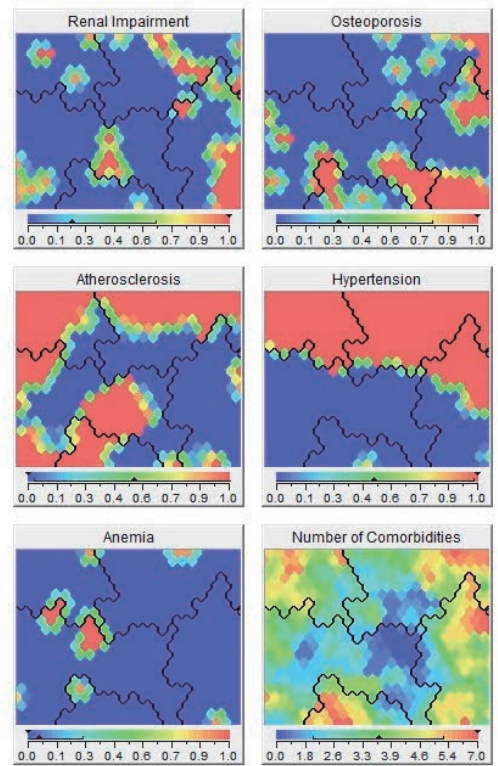

Figure 6.4 The Viscovery ${ }^{\circledR}$ program placed all subjects on a specific position on the map based on their profile of comorbidities. The more subjects resemble in terms of their comorbidity the closer they are on the map. Contrarily the more they do differ the further they are away from each other. When looking at a comorbidity, subjects "raise a red flag" if the comorbidity is present and "a blue one" when absent. In this way the maps can be interpreted. By drawing lines on the map, the Viscovery ${ }^{\circledR}$ program could identify five different clusters of COPD patients with a significant different profile of comorbidities. (95\% confidence interval) 
Table 6.3 Clinical characteristics of the subjects in the five clusters.

\begin{tabular}{lccccc}
\hline Clinical characteristics & $\begin{array}{c}\text { CLUSTER 1 } \\
\text { 'less comorbidity' }\end{array}$ & $\begin{array}{c}\text { CLUSTER 2 } \\
\text { 'cardiovascular' }\end{array}$ & $\begin{array}{c}\text { CLUSTER 3 } \\
\text { 'cachectic' }\end{array}$ & $\begin{array}{c}\text { CLUSTER 4 } \\
\text { 'metabolic' }\end{array}$ & $\begin{array}{c}\text { CLUSTER 5 } \\
\text { 'psychologic' }\end{array}$ \\
\hline $\mathrm{n}$ & 67 & 49 & 44 & 33 & 20 \\
Age, years & $62.1 \pm 6.8$ & $67.2 \pm 5.8$ & $62.5 \pm 7.2$ & $63.1 \pm 7.3$ & $62.8 \pm 6.8$ \\
Male, \% & 60 & 65 & 43 & 79 & 45 \\
mMRC dyspnea grade & $1.99 \pm 1.01$ & $2.29 \pm 1.21$ & $1.73 \pm 0.9$ & $2.12 \pm 1.11$ & $2.84 \pm 1.12$ \\
Current smoker, \% & 30 & 16 & 45 & 15 & 35 \\
Packyears & $44 \pm 20$ & $45 \pm 26$ & $49 \pm 30$ & $51 \pm 34$ & $42 \pm 16$ \\
LTOT, \% & 13 & 18 & 18 & 15 & 25 \\
6MWD, meter & $474 \pm 102$ & $446 \pm 133$ & $496 \pm 101$ & $473 \pm 91$ & $459 \pm 74$ \\
FEV $1, \%$ predicted & $52.7 \pm 17.4$ & $50.9 \pm 17.7$ & $48.3 \pm 16.3$ & $54.2 \pm 16$ & $48.3 \pm 15.4$ \\
ITGV, \% predicted & $143 \pm 33$ & $148 \pm 29$ & $166 \pm 34$ & $134 \pm 33$ & $146 \pm 28$ \\
DLCO, \% predicted & $60 \pm 16$ & $57 \pm 18$ & $44 \pm 13$ & $60 \pm 14$ & $55 \pm 14$ \\
SGRQ Total score & $47.6 \pm 15.3$ & $56.5 \pm 17.2$ & $45.8 \pm 19.4$ & $49.9 \pm 16.1$ & $65.9 \pm 12.5$ \\
SGRQ symptoms, score & $49.1 \pm 18.1$ & $58.8 \pm 20.7$ & $55.5 \pm 23.1$ & $52.8 \pm 20.2$ & $69.9 \pm 14.4$ \\
SGRQ activity, score & $68.3 \pm 20.2$ & $70.2 \pm 22.0$ & $60.4 \pm 24.9$ & $66.4 \pm 20.5$ & $83.5 \pm 13.9$ \\
SGRQ impact, score & $36.3 \pm 17.9$ & $43.6 \pm 21.2$ & $35.1 \pm 21.5$ & $39.6 \pm 18.1$ & $52.6 \pm 16.6$ \\
Updated BODE score & $2.4 \pm 2.6$ & $3.4 \pm 3.3$ & $3.0 \pm 1.8$ & $2.6 \pm 2.3$ & $3.1 \pm 1.9$ \\
Framingham 10 year risk(\%) & $8.6 \pm 6.6$ & $11.5 \pm 6.6$ & $7.6 \pm 6$ & $11.9 \pm 7.3$ & $6.6 \pm 4.5$ \\
\hline
\end{tabular}

Summary variables are presented as mean \pm standard deviation for quantitative variables, and percentage for discrete variables. Light grey: less prevalent compared to the whole study sample ( $95 \%$ confidence interval); dark grey: more prevalent compared to the whole study sample ( $95 \%$ confidence interval). mMRC: Modified

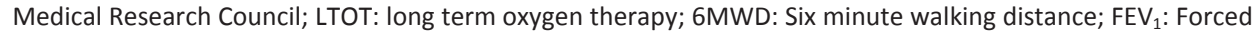
expiratory volume in the first second; ITGV: Intrathoracic gas volume; DLCO: Diffusion capacity for carbon monoxide; SGRQ: St.-George's Respiratory Questionnaire, BODE: BMI, Obstruction (FEV $)_{1}$, Dyspnea, Exercise (6MWD).

\section{SYSTEMIC INFLAMMATION}

Table 6.4 shows circulating levels of inflammatory markers in the five identified clusters. Supplemental Figure S6.1 shows the data point distribution of all inflammatory markers for each cluster. There were no significant differences in CRP, IL-8 or leukocytes between comorbidity clusters. STNFR1 and STNFR2 were significantly increased in the "metabolic cluster", compared to the whole COPD population. sTNFR1 was lower in the "cachectic cluster" and IL-6 was increased in the "cardiovascular cluster". 
Table 6.4 Inflammatory markers among the five clusters.

\begin{tabular}{lccccc}
\hline & $\begin{array}{c}\text { CLUSTER 1 } \\
\text { 'less comorbidity' }\end{array}$ & $\begin{array}{c}\text { CLUSTER 2 } \\
\text { 'cardiovascular' }\end{array}$ & $\begin{array}{c}\text { CLUSTER 3 } \\
\text { 'cachectic' }\end{array}$ & $\begin{array}{c}\text { CLUSTER 4 } \\
\text { 'metabolic' }\end{array}$ & $\begin{array}{c}\text { CLUSTER 5 } \\
\text { 'psychologic' }\end{array}$ \\
\hline CRP, ngs/ml & $2286(844,6188)$ & $3380(947,12062)$ & $2005(677,5938)$ & $3860(1073,13886)$ & $2519(767,8283)$ \\
IL-6, $\mathrm{pgs} / \mathrm{ml}$ & $2.4(1.3,4.3)$ & $3.4(1.8,6.6)$ & $2.2(1.1,4.7)$ & $2.7(1.6,4.5)$ & $2.2(1.3,3.6)$ \\
IL-8, $\mathrm{pgs} / \mathrm{ml}$ & $12.3(8.2,18.6)$ & $12.9(9.3,17.9)$ & $12.1(7.8,18.7)$ & $10.8(7.6,15.2)$ & $11.1(6.6,18.7)$ \\
sTNFR1, $\mathrm{pgs} / \mathrm{ml}$ & $2013(1508,2689)$ & $2229(1513,3285)$ & $1896(1434,2505)$ & $2377(1850,3055)$ & $2133(1685,2699)$ \\
sTNFR2, $\mathrm{pgs} / \mathrm{ml}$ & $3417(2454,4758)$ & $3698(2399,5701)$ & $3302(2478,4401)$ & $4080(3115,5344)$ & $3419(2675,4371)$ \\
Leucocytes *109/l & $7.3(5.6,9.5)$ & $7.1(5.5,9.4)$ & $7.0(5.3,9.1)$ & $7.2(5.9,8.7)$ & $7.3(6.0,8.9)$ \\
\hline
\end{tabular}

Data were log-transformed to mitigate the effects of extreme values. Summary variables are presented as geometric mean (lower and upper limit). Light grey: less prevalent compared to the whole study sample (95\% confidence interval); dark grey: more prevalent compared to the whole study sample $(95 \%$ confidence interval).

\section{DISCUSSION}

In a cohort of moderate to very severe patients with COPD, five clusters of clinically important and objectively diagnosed comorbidities were identified. While disease severity was comparable between comorbidity clusters, they were markedly different in terms of health status. Mostly, inflammatory markers were comparable between the clusters. Although increased levels of TNF receptors were observed in the "metabolic cluster" and increased levels of IL-6 in the "cardiovascular" cluster.

Multiple studies have shown that comorbid chronic conditions occur more frequently in patients with COPD than in non-COPD subjects and contribute to adverse clinical outcomes in these patients. ${ }^{1,4-13}$ Moreover, the frequency of comorbidities was shown to be independent of the degree of airflow limitation. ${ }^{1,8}$ In the present study, comorbidity clusters also had similar degree of airflow limitation.

Previous studies used self-reported comorbidities ${ }^{1,4-13}$ or health-care databases that were not specifically designed to evaluate comorbidities. ${ }^{4,9,10,13}$ These methods most probably underestimate the true prevalence of comorbidities in COPD. Here, thirteen clinically relevant and well-known comorbidities were diagnosed using pre-defined internationally accepted cut-offs in a moderately-sized, well-characterized sample of COPD patients. This study confirms the high frequency of individual comorbidities reported previously.

In the general population, there is a growing public attention to the concept of multimorbidity, since the presence of multiple chronic morbidities is associated with 
poor outcome and increased health care utilization. ${ }^{22}$ Only few studies have investigated the co-existence of two or more comorbidities in individuals with COPD. For example, Siebeling and colleagues reported an overlap in (self-reported) diabetes, musculoskeletal conditions and cardiovascular disease in primary care COPD patients. ${ }^{11}$ The present study is the first to identify clusters of objectively identified comorbidities in patients with COPD. The unbiased approach to identify these comorbidity clusters is a major strength of the current analyses. Indeed, the use of self-organizing maps may be the most compact way to represent a data distribution, as data dependency can be understood easily if one is familiar with the map visualization.

Cluster analyses have been used before in patients with COPD. ${ }^{23-26}$ Only two studies ${ }^{24,25}$ used comorbidities in their cluster analyses, which also included all type of other clinical characteristics. Both studies identified a comorbidity predominant subtype of patients with milder respiratory status but a higher prevalence of obesity, cardiovascular disease and diabetes. In the PAC-COPD cohort, also higher levels of systemic inflammatory markers were identified in that cluster. ${ }^{24}$ These clusters seem to resemble the "metabolic" cluster in the present study.

In total, five distinct clusters were recognized based on the comorbidity profiles. Patients in the "cachectic" cluster had a lower diffusion capacity and more static hyperinflation compared to the other clusters, which probably is consistent with a higher amount of emphysema. Previously, osteoporosis and renal impairment ${ }^{27,28}$ were associated with emphysema, and osteoporosis was linked to muscle wasting. ${ }^{29}$ This suggests that there may be a common pathophysiological pathway for the cooccurrence of these chronic conditions.

Contrary to the "cachectic cluster", a "metabolic" cluster was identified. These patients had less severe pulmonary impairment compared to the other clusters, but more pronounced metabolic disorders and a low-grade systemic inflammation. The identification of these two distinct clusters is reminiscent of the historical description of the pink puffer (emphysematous type with a "cachectic" impression) and the blue bloater (chronic bronchitis type with a "metabolic" impression). ${ }^{30}$

Despite comparable increased cardiovascular risk according to the Framingham risk score, the "cardiovascular" cluster, characterized by increased blood pressure and (subclinical) atherosclerosis, was clearly different from the "metabolic" cluster. The former cluster had significantly less obesity, dyslipidemia or hyperglycemia, and a different inflammatory marker is increased. (IL-6 in the "cardiovascular" cluster, compared to TNF receptors in the "metabolic" cluster). This suggests that different pathways may be involved in the development of cardiovascular comorbidity in COPD. 
A large subgroup of patients with significantly less comorbidity was clustered. These patients were younger and a higher proportion was treated with oral antidiabetics and cholesterol lowering drugs. This may partially explain why these patients had less comorbidity.

The "psychologic" cluster, including a high proportion of patients with increased symptoms of anxiety and depression, and ischemic heart injury, is considered an important finding. Indeed, anxiety was reported to be the strongest independent predictor of mortality in patients with COPD. ${ }^{5}$ The (unbiased) recognition of a psychopathological cluster is consistent with growing literature as mental conditions are recognized as a relevant factor of multimorbidity in the general population. ${ }^{31}$ The high prevalence of anxiety and depression after myocardial infarction may explain the high proportion of patients with ECG abnormalities in this cluster. ${ }^{32}$ Whether and to what extent the higher prevalence of ECG abnormalities in anxious patients with COPD may explain the worse prognosis in these patients remains currently unknown.

A direct link between (chronic low-grade) systemic inflammation and comorbidities in patients with COPD remains equivocal. For example, bivariate associations between various systemic inflammatory biomarkers and pulmonary cachexia, ${ }^{33}$ subclinical atherosclerosis, ${ }^{34}$ metabolic syndrome ${ }^{35}$ and ischemic heart disease have been reported in patients with COPD. ${ }^{36}$ Moreover, CRP, fibrinogen and leucocyte count were associated with increased risk of comorbidities in patients with COPD. ${ }^{18}$ Then again, many studies showed comparable circulating levels of inflammatory biomarkers in COPD patients with and without comorbidities, such as cachexia, ${ }^{37}$ osteoporosis, ${ }^{38}$ cardiovascular disease ${ }^{39}$ and depression. ${ }^{40}$ So, a causal relationship between low-grade systemic inflammation and comorbidities in COPD has not been proven yet. The current findings also show that the possible interactions between biomarkers of systemic inflammation and comorbidities in patients with COPD are very complex, if present at all.

Chronic low-grade systemic inflammation is a hallmark of obesity in the general population, ${ }^{41}$ suggesting a systemic origin of inflammation. Increased levels of systemic inflammation have also been reported in patients with COPD, in particular in obese patients. ${ }^{19,42-44}$ This may partially explain the low-grade systemic inflammation in the "metabolic" cluster, and its lesser presence in the "cachectic" cluster. Similarly, the increased IL- 6 in the "cardiovascular" cluster might be due to the significant older age in that cluster. Indeed, a wealth of data indicates that normal aging is associated with low-grade systemic inflammation, including IL-6. ${ }^{45}$ 


\section{METHODOLOGICAL CONSIDERATIONS}

The present study included GOLD grade 2 to 4 patients. Therefore, the current finding should not be extrapolated to GOLD grade 1 patient subsets. Moreover, patients were recruited in a tertiary care pulmonary rehabilitation setting, which may also limit the external validity of the current findings. However, the following arguments do support the generalizability of our findings to a broader population: The prevalence of objectively identified renal impairment in our study was similar to results from COPD patients attending the pulmonary medicine outpatient facilities of 15 centers located throughout Italy. ${ }^{46}$ Furthermore, the Charlson comorbidity index score in the present study (1.6 \pm 0.9 points; age-adjusted: $3.5 \pm 1.3$ points) was comparable to the PAC-COPD cohort $\left(2.0 \pm 1.3\right.$ points), ${ }^{24}$ and the ESMI cohort $\left(3.1 \pm 2.0\right.$ points), respectively. ${ }^{47}$ Furthermore, the prevalence of self-reported cardiovascular comorbidities (as recorded in the Charlson comorbidity index) in the present study was comparable to previous studies. ${ }^{1,5,19}$ So, the prevalence of comorbidities in the present study seems comparable with data obtained in the secondary outpatient care setting.

Another limitation considering comorbidities might be that patients with active malignant diseases, active inflammatory diseases or recent myocardial infarction were excluded from participation in the study as these patients are not suitable for pulmonary rehabilitation.

Although, the elected biomarkers in the present study are well studied in COPD, it should be mentioned that the concept of systemic inflammation is more complex than that can be captured in a short series of biomarkers. The strength of measuring comorbidities in an objective manner brings with it the limitation of having evaluated only a limited number of comorbidities. Due to logistical constraints, chronic heart failure, obstructive sleep apnea and degenerative joint disease were not assessed, although it is known that these conditions are common in COPD. ${ }^{5}$ Also, it is desirable to validate the current findings in an external replication cohort. In addition, it would be interesting to evaluate clusters of comorbidities in subjects with another index disease (for example diabetes mellitus) and in the general population. Furthermore the longitudinal stability of comorbidity clusters and the prognostic outcome of the different clusters are interesting future research questions.

This is the first study that objectively identified multiple comorbidities in a wellcharacterized cohort of patients with COPD. The self-organizing maps are new in the field of COPD research and provide easy-to-use graphs of the five independent comorbidity clusters that were identified. The current findings will increase the awareness amongst physicians that multiple comorbidities can be present in patients with COPD. This will also enhance treatment strategies and facilitate the combination of future treatment guidelines for different comorbidities. Interestingly, the degree of 
airflow limitation, exercise capacity and the score on the updated BODE index were similar between the comorbidity clusters. This emphasizes the fact that comorbidities are an additional clinical attribute in patients with COPD, which cannot be predicted by the aforementioned clinical outcomes. In addition, low-grade systemic inflammation was mostly comparable among comorbidity clusters. This shows that the presumed association between systemic inflammation and comorbidities in patients with COPD is more complex than assumed at present. 


\section{REFERENCES}

1. Agusti A, Calverley PM, Celli B, Coxson HO, Edwards LD, Lomas DA, MacNee W, Miller BE, Rennard S, Silverman EK, Tal-Singer R, Wouters E, Yates JC, Vestbo J. Characterisation of copd heterogeneity in the eclipse cohort. Respir Res 2010;11:122.

2. Vestbo J, Hurd SS, Agusti AG, Jones PW, Vogelmeier C, Anzueto A, Barnes PJ, Fabbri LM, Martinez FJ, Nishimura M, Stockley RA, Sin DD, Rodriguez-Roisin R. Global strategy for the diagnosis, management and prevention of chronic obstructive pulmonary disease, gold executive summary. Am J Respir Crit Care Med 2013;187:347-65

3. von Leupoldt A, Taube K, Lehmann K, Fritzsche A, Magnussen H. The impact of anxiety and depression on outcomes of pulmonary rehabilitation in patients with copd. Chest 2011;140:730-736.

4. Mannino DM, Thorn D, Swensen A, Holguin F. Prevalence and outcomes of diabetes, hypertension and cardiovascular disease in copd. Eur Respir J 2008;32:962-9.

5. Divo M, Cote C, de Torres JP, Casanova C, Marin JM, Pinto-Plata V, Zulueta J, Cabrera C, Zagaceta J, Hunninghake G, Celli B. Comorbidities and risk of mortality in patients with copd. Am J Respir Crit Care Med 2012;186:155-61.

6. McGarvey LP, John M, Anderson JA, Zvarich M, Wise RA. Ascertainment of cause-specific mortality in copd: Operations of the torch clinical endpoint committee. Thorax 2007;62:411-5.

7. Antonelli Incalzi R, Fuso L, De Rosa M, Forastiere F, Rapiti E, Nardecchia B, Pistelli R. Co-morbidity contributes to predict mortality of patients with chronic obstructive pulmonary disease. Eur Respir J 1997;10:2794-800.

8. Crisafulli E, Costi S, Luppi F, Cirelli G, Cilione C, Coletti O, Fabbri LM, Clini EM. Role of comorbidities in a cohort of patients with copd undergoing pulmonary rehabilitation. Thorax 2008;63:487-92.

9. Feary JR, Rodrigues LC, Smith CJ, Hubbard RB, Gibson JE. Prevalence of major comorbidities in subjects with copd and incidence of myocardial infarction and stroke: A comprehensive analysis using data from primary care. Thorax 2010;65:956-62.

10. Schnell KM, Weiss CO, Lee T, Krishnan JA, Leff B, Wolff JL, Boyd C. The prevalence of clinically-relevant comorbid conditions in patients with copd: A cross-sectional study using data from nhanes 1999-2008. BMC Pulm Med 2012;12:26.

11. Siebeling L, Puhan MA, Muggensturm P, Zoller M, Ter Riet G. Characteristics of dutch and swiss primary care copd patients - baseline data of the ice cold eric study. Clin Epidemiol 2011;3:273-83.

12. van Manen JG, Bindels PJ, CJ IJ, van der Zee JS, Bottema BJ, Schade E. Prevalence of comorbidity in patients with a chronic airway obstruction and controls over the age of 40. J Clin Epidemiol 2001;54:287-93.

13. Soriano JB, Visick GT, Muellerova H, Payvandi N, Hansell AL. Patterns of comorbidities in newly diagnosed copd and asthma in primary care. Chest 2005;128:2099-107.

14. Vanfleteren LE, Franssen FM, Uszko-Lencer NH, Spruit MA, Celis M, Gorgels AP, Wouters EF. Frequency and relevance of ischemic electrocardiographic findings in patients with chronic obstructive pulmonary disease. Am J Cardiol 2011;108:1669-74.

15. Barnett K, Mercer SW, Norbury M, Watt G, Wyke S, Guthrie B. Epidemiology of multimorbidity and implications for health care, research, and medical education: A cross-sectional study. Lancet 2012; 380:37-43.

16. Sabit R, Bolton CE, Edwards PH, Pettit RJ, Evans WD, McEniery CM, Wilkinson IB, Cockcroft JR, Shale DJ. Arterial stiffness and osteoporosis in chronic obstructive pulmonary disease. AmJ Respir Crit Care Med 2007;175:1259-65.

17. Barnes PJ, Celli BR. Systemic manifestations and comorbidities of copd. Eur Respir J 2009;33:1165-85.

18. Thomsen M, Dahl M, Lange $\mathrm{P}$, Vestbo J, Nordestgaard BG. Inflammatory biomarkers and comorbidities in chronic obstructive pulmonary disease. AmJ Respir Crit Care Med 2012;186:982-8.

19. Agusti A, Edwards LD, Rennard SI, MacNee W, Tal-Singer R, Miller BE, Vestbo J, Lomas DA, Calverley PM, Wouters E, Crim C, Yates JC, Silverman EK, Coxson HO, Bakke P, Mayer RJ, Celli B. Persistent systemic inflammation is associated with poor clinical outcomes in copd: A novel phenotype. PloS One 2012; 7:e37483. 
20. Vanfleteren LE, Spruit MA, Franssen FM, Groenen M, Wouters EFM. Objectified co-morbidities in patients with copd: The ciroco study. AmJ Respir Crit Care Med 2012;185:A3674.

21. Spruit MA, Vanderhoven-Augustin I, Janssen PP, Wouters EF. Integration of pulmonary rehabilitation in copd. Lancet 2008;371:12-3.

22. Tooth L, Hockey R, Byles J, Dobson A. Weighted multimorbidity indexes predicted mortality, health service use, and health-related quality of life in older women. J Clin Epidemiol 2008;61:151-9.

23. Burgel PR, Paillasseur JL, Caillaud D, Tillie-Leblond I, Chanez P, Escamilla R, Court-Fortune I, Perez T, Carre P, Roche N. Clinical copd phenotypes: A novel approach using principal component and cluster analyses. Eur Respir J 2010;36:531-9.

24. Garcia-Aymerich J, Gomez FP, Benet M, Farrero E, Basagana X, Gayete A, Pare C, Freixa X, Ferrer J, Ferrer A, Roca J, Galdiz JB, Sauleda J, Monso E, Gea J, Barbera JA, Agusti A, Anto JM. Identification and prospective validation of clinically relevant chronic obstructive pulmonary disease (copd) subtypes. Thorax 2011;66:430-7.

25. Burgel PR, Paillasseur JL, Peene B, Dusser D, Roche N, Coolen J, Troosters T, Decramer M, Janssens W. Two distinct chronic obstructive pulmonary disease (copd) phenotypes are associated with high risk of mortality. PloS One 2012;7:e51048.

26. Burgel PR, Roche N, Paillasseur JL, Tillie-Leblond I, Chanez P, Escamilla R, Court-Fortune I, Perez T, Carre P, Caillaud D. Clinical copd phenotypes identified by cluster analysis: Validation with mortality. Eur Respir J 2012;40:495-6.

27. Chandra D, Stamm JA, Palevsky PM, Leader JK, Fuhrman CR, Zhang Y, Bon J, Duncan SR, Branch RA, Weissfeld J, Gur D, Gladwin MT, Sciurba FC. The relationship between pulmonary emphysema and kidney function in smokers. Chest 2012;142:655-62.

28. Bon J, Fuhrman CR, Weissfeld JL, Duncan SR, Branch RA, Chang CC, Zhang Y, Leader JK, Gur D, Greenspan SL, Sciurba FC. Radiographic emphysema predicts low bone mineral density in a tobaccoexposed cohort. AmJ Respir Crit Care Med 2011;183:885-90.

29. Bolton CE, lonescu AA, Shiels KM, Pettit RJ, Edwards PH, Stone MD, Nixon LS, Evans WD, Griffiths TL, Shale DJ. Associated loss of fat-free mass and bone mineral density in chronic obstructive pulmonary disease. AmJ Respir Crit Care Med 2004;170:1286-93.

30. Filley GF, Beckwitt HJ, Reeves JT, Mitchell RS. Chronic obstructive bronchopulmonary disease. li. Oxygen transport in two clinical types. Am J Med 1968;44:26-38.

31. Kirchberger I, Meisinger C, Heier M, Zimmermann AK, Thorand B, Autenrieth CS, Peters A, Ladwig KH, Doring A. Patterns of multimorbidity in the aged population. Results from the kora-age study. PloS One 2012; 7:e30556.

32. Hanssen TA, Nordrehaug JE, Eide GE, Bjelland I, Rokne B. Anxiety and depression after acute myocardial infarction: An 18-month follow-up study with repeated measures and comparison with a reference population. Eur J Cardiovasc Prev Rehabil 2009;16:651-9.

33. Di Francia M, Barbier D, Mege JL, Orehek J. Tumor necrosis factor-alpha levels and weight loss in chronic obstructive pulmonary disease. AmJ Respir Crit Care Med 1994;150:1453-5.

34. Iwamoto H, Yokoyama A, Kitahara Y, Ishikawa N, Haruta Y, Yamane K, Hattori N, Hara H, Kohno N. Airflow limitation in smokers is associated with subclinical atherosclerosis. Am J Respir Crit Care Med 2009;179:35-40.

35. Watz H, Waschki B, Kirsten A, Muller KC, Kretschmar G, Meyer T, Holz O, Magnussen H. The metabolic syndrome in patients with chronic bronchitis and copd: Frequency and associated consequences for systemic inflammation and physical inactivity. Chest 2009;136:1039-46.

36. Sin DD, Man SF. Why are patients with chronic obstructive pulmonary disease at increased risk of cardiovascular diseases? The potential role of systemic inflammation in chronic obstructive pulmonary disease. Circulation 2003;107:1514-9.

37. Broekhuizen R, Grimble RF, Howell WM, Shale DJ, Creutzberg EC, Wouters EF, Schols AM. Pulmonary cachexia, systemic inflammatory profile, and the interleukin 1beta -511 single nucleotide polymorphism. Am J Clin Nutr 2005;82:1059-64.

38. Graat-Verboom L, Spruit MA, van den Borne BE, Smeenk FW, Martens EJ, Lunde R, Wouters EF. Correlates of osteoporosis in chronic obstructive pulmonary disease: An underestimated systemic component. Respir Med 2009;103:1143-51. 
39. Mills NL, Miller JJ, Anand A, Robinson SD, Frazer GA, Anderson D, Breen L, Wilkinson IB, McEniery CM, Donaldson K, Newby DE, Macnee W. Increased arterial stiffness in patients with chronic obstructive pulmonary disease: A mechanism for increased cardiovascular risk. Thorax 2008;63:306-11.

40. Quint JK, Baghai-Ravary R, Donaldson GC, Wedzicha JA. Relationship between depression and exacerbations in copd. Eur Respir J 2008;32:53-60.

41. Goossens $\mathrm{GH}$. The role of adipose tissue dysfunction in the pathogenesis of obesity-related insulin resistance. Physiol Behav 2008;94:206-18.

42. Poulain M, Doucet M, Drapeau V, Fournier G, Tremblay A, Poirier P, Maltais F. Metabolic and inflammatory profile in obese patients with chronic obstructive pulmonary disease. Chron Respir Dis 2008;5:35-41.

43. Breyer MK, Spruit MA, Celis AP, Rutten EP, Janssen PP, Wouters EF. Highly elevated c-reactive protein levels in obese patients with copd: A fat chance? Clin Nutr 2009;28:642-7.

44. Rutten EP, Breyer MK, Spruit MA, Hofstra T, van Melick PP, Schols AM, Wouters EF. Abdominal fat mass contributes to the systemic inflammation in chronic obstructive pulmonary disease. Clin Nutr 2010;29:756-60.

45. Ershler WB, Keller ET. Age-associated increased interleukin-6 gene expression, late-life diseases, and frailty. Ann Rev Med 2000;51:245-70.

46. Incalzi RA, Corsonello A, Pedone C, Battaglia S, Paglino G, Bellia V. Chronic renal failure: A neglected comorbidity of copd. Chest 2010;137:831-7.

47. Almagro P, Cabrera FJ, Diez J, Boixeda R, Ortiz B, Murio C, Soriano JB. Comorbidities and short-term prognosis in patients hospitalized for acute exacerbation of COPD: the EPOC and ESMI study. Chest 2012;142:1126-33. 


\section{SUPPLEMENTAL MATERIAL}

\section{METHODS}

\section{Study design}

This is a single center, observational study.

\section{Subjects}

Data were collected prospectively between November 2007 and November 2010 during the initial evaluation of a comprehensive pulmonary rehabilitation program at CIRO+, a center of expertise for chronic organ failure in Horn, the Netherlands. ${ }^{1}$ Patients were referred by chest physicians of 9 hospitals in South East of the Netherlands. Patients were eligible to participate when they fulfilled all inclusion criteria: diagnosis of COPD GOLD grade 2 to $4 ;^{2} 40$ to 80 years of age; and a smoking history of $\geq 10$ pack years or relevant occupational exposure. Exclusion criteria were: a history of asthma or any other significant respiratory disease; a diagnosis of alpha-1 antitrypsin deficiency; any previous lung surgery; a history of rheumatoid arthritis or any other significant inflammatory disease; acute myocardial infarction within the last 6 months; any known bone disease other than osteoporosis; current malignant disease (except basal cell carcinoma of the skin) or a diagnosis of malignancy in the 5 years prior to the first visit; an exacerbation requiring oral corticosteroid or hospitalization during the 4 weeks prior to the first visit; long term systemic corticosteroid therapy higher than $10 \mathrm{mg}$ daily; inability to walk; any blood transfusion 4 weeks prior to the first visit; blood donor in the last 3 months prior to the first visit; suspicion of alcohol or drug abuse or any other condition associated with poor compliance in the investigator's opinion; and known infectious transmissible disease: Human Immune-deficiency virus (HIV), hepatitis B or C.

The institutional review board of Maastricht University Medical Centre (MUMC+) in Maastricht (the Netherlands) approved the CIROCO study (MEC 10-3-067). All patients gave written informed consent.

Participants demographics, smoking history and use of long-term oxygen therapy were recorded. Furthermore, patients' current pharmacological treatment was documented.

\section{ASSESSMENT}

\section{Pulmonary function}

Lung function parameters (post-bronchodilator forced expiratory volume in the first second, $\mathrm{FEV}_{1}$; and forced vital capacity, FVC) were collected using standardized spirometry (MasterScreen ${ }^{\circledR}$ Body, Carefusion, Germany). Static lung volumes (intrathoracic gas volume [ITGV]) and carbon monoxide transfer factor (DLCO, single 
breath hold method) were determined in all patients (MasterScreen ${ }^{\circledR}$ Body, Carefusion, Germany).

\section{Body composition analyses}

Height was measured to the nearest $0.1 \mathrm{~cm}$. Body weight was assessed by using an electronic beam scale with digital readout to the nearest $0.1 \mathrm{~kg}$ after emptying the bladder and with the subjects standing barefoot and wearing light indoor clothing. BMI was calculated as body weight/height ${ }^{2}$. Fat free mass (FFM) has been assessed using an overnight-fasting bioelectrical impedance assessment (Bodystat ${ }^{\circledR}$, United Kingdom). In two patients FFM was measured with dual-energy X-ray Absorptiometry. Bioelectrical impedance assessment was not possible due to total hip replacement $(n=1)$ or presence of iron after sternal surgery ( $n=1)$. FFM index (FFMI) was calculated as FFM in kilogram divided by squared height in meters. ${ }^{3}$ Hip, lumbar spine and whole-body bone mineral density (BMD) were determined using a Dual-energy X-ray Absorptiometry (DEXA) scan (Lunar Prodigy ${ }^{\circledR}$, Ge-Lunar).

\section{Carotid intima media thickness}

Carotid intima media thickness (c-IMT) was assessed using high-resolution B-mode ultrasound with a 10-MHz linear transducer (Art.Lab Esaote Picus, Pie-medical Netherlands/Italie). The ultrasound device was connected to an acquisition modem with an automatic boundary detection system (Art.Lab Esaote Picus). c-IMT was thus quantified semi automatically, reducing the interobserver variability. ${ }^{4}$ With the patient in a supine position, measurements of the c-IMT were performed throughout $10-\mathrm{mm}$ segments across the far wall of the left and right common carotid arteries, at a point most proximal to the carotid bifurcation free of visual plaques. The probe was moved to obtain measurements of the common carotid artery at 4 angles on both sides $\left(180^{\circ}\right.$, $150^{\circ}, 120^{\circ}$, and $90^{\circ}$ ). For each measured segment mean and maximum c-IMT values were acquired automatically throughout the $10-\mathrm{mm}$ vessel length. The average of segmental maximum c-IMT values was determined as c-IMT per patient.

\section{The Cardiac Infarction Injury Score (CIIS)}

A resting ECG was obtained in all patients and CIIS was scored by a cardiologist (V.v.E.) blinded for medical history and outcome measures. CIIS is an electrocardiographic (ECG) classification system that was developed as a diagnostic tool to determine the presence of myocardial infarctions. It is based on the power of certain electrocardiographic characteristics to discriminate between myocardial infarction patients and healthy individuals. These characteristics are weighted and combined into a single score. ${ }^{5}$

\section{Hemodynamics}

Subjects were studied in early morning time by a trained medical technologist, blinded for clinical outcomes. All tests were performed after 15 minutes in a resting supine 
position. A small head pillow was accepted. Peripheral blood pressure was measured three times with interval of 5 minutes, after 15 minutes of supine rest in early morning time. Mean values were calculated.

\section{Exercise capacity}

Functional exercise capacity was measured with the six-minute walk distance (6MWD), performed according to published guidelines including a practice walk. The best 6MWD was used for further analyses. ${ }^{6}$

\section{Dyspnea}

Self-perceived dyspnea in relation to physical disability has been assessed by using the modified Medical Research Council (mMRC) dyspnea scale. ${ }^{7}$

\section{Hospital Anxiety and Depression Scale (HADS)}

Anxiety and depression have been assessed by using the Hospital Anxiety and Depression Scale (HADS), a validated and reliable measurement instrument used widely in medically ill patients to screen for clinically relevant symptoms of anxiety and/or depression. ${ }^{8}$ The HADS is a self-administered questionnaire, consisting of 14 questions. The HADS is divided in an anxiety subscale (HADS-A) and a depression subscale (HADS-D), both containing seven items. Total scores for each subscale can range from 0 (optimal) to 21 (worst) points.

\section{Health status}

To assess disease-specific health status, the St. George Respiratory Questionnaire (SGRQ) has been used. ${ }^{9}$ The SGRQ is a self-administered questionnaire, designed for measurement of health impairment in patients with COPD. The SGRQ consists of 50 items, divided in three domains (symptoms, activities and impact), providing three domain scores. A total score is also provided. Scores can range from 0 (optimal) to 100 points (worst).

\section{Laboratory analysis}

A venous blood sample was collected from all patients in the fasted state. Serum samples were stored at $-80^{\circ} \mathrm{C}$ prior to their analysis. Hemoglobin, leukocytes, glucose, creatinin, high density lipoprotein (HDL), and triglycerides were determined in all subjects. Measurements of the inflammatory serum markers was carried out on the MSD multiplex platform (Meso Scale Discovery, Gaithersburg, Maryland) using a preformatted panel to measure $\mathrm{C}$-reactive protein (CRP) and validated, custom made arrays to determine the levels of interleukin 6 and 8 (IL-6, IL-8) and soluble tumor necrosis factor $\alpha$ receptors (sTNFR1 and sTNFR2). 


\section{Updated BODE index}

The updated BODE index is a predictor of 3-year mortality in patients with COPD based on scores on BMI, FEV 1, MRC dyspnea scale, and 6MWD. The updated BODE index grades from 0 to 15 points. A higher score means a worse prognosis. ${ }^{10}$

\section{Framingham risk score}

Framingham risk score is a sex-specific scoring system that estimates the ten years risk in percentage of coronary heart disease based on age, diabetes, smoking, blood pressure, total and LDL cholesterol. It is validated for an age from 30 to 74 years. ${ }^{11}$

\section{Selfreported comorbidity}

In every patient the Charlson comorbidity index and the age-adjusted Charlson comorbidity index was calculated. ${ }^{12}$

\section{DEFINITIONS OF COMORBIDITIES}

COPD and grades of severity was classified according to the GOLD document. ${ }^{2}$

Renal function was established by the estimated glomerular filtration rate (eGFR), using the Cockroft-Gault formula. ${ }^{13}$ Chronic kidney disease was defined as eGFR $<60 \mathrm{ml} / \mathrm{min}$, corresponding with stage 3 chronic kidney disease according to the the National Kidney Foundation Kidney Disease Outcome Quality Initiative (NKF KDOQI) guidelines. ${ }^{14}$

Anemia was defined as hemoglobin level $<13 \mathrm{~g} / \mathrm{dl}(8,1 \mathrm{mmol} / \mathrm{l})$ in men and $<12 \mathrm{~g} / \mathrm{dl}$ $(7,5 \mathrm{mmol} / \mathrm{l})$ in women, according to the World Health Organization criteria. ${ }^{15}$

Hypertension grade 1 or higher is defined as a systolic blood pressure above $140 \mathrm{~mm}$ $\mathrm{Hg}$ or diastolic pressure above $90 \mathrm{~mm} \mathrm{Hg}$, in line with the European Society of Hypertension (ESH)/European Society of Cardiology (ESC) guidelines. ${ }^{16}$

BMI was categorized into underweight $\left(<21 \mathrm{~kg} / \mathrm{m}^{2}\right)$, normal $\left(21-24.9 \mathrm{~kg} / \mathrm{m}^{2}\right)$, overweight $\left(25-29.9 \mathrm{~kg} / \mathrm{m}^{2}\right)$ and obese $\left(\geq 30 \mathrm{~kg} / \mathrm{m}^{2}\right)$. A BMI lower than $21 \mathrm{~kg} / \mathrm{m}^{2}$ has shown to be independently associated with one year mortality in COPD and was included in the best validated clinical model to predict mortality in COPD, namely the BODE index. ${ }^{17}$ Obese BMI was defined according to the WHO international classification of BMI. ${ }^{18}$

Muscle wasting was defined as an FFMI $<16$ for men or $<15$ for women. ${ }^{19}$

Hyperglycemia was defined as fasting glucose level above $5.6 \mathrm{mmol} / \mathrm{l}$ according to the American Diabetes Association. ${ }^{20}$

Dyslipidemia was defined as a triglyceride level above $1.7 \mathrm{mmol} / \mathrm{I}$ or a HDL cholesterol level below $1.03 \mathrm{mmol} / \mathrm{l}$ in males or below $1.29 \mathrm{mmol} / \mathrm{l}$ in females. ${ }^{21}$ 
Osteoporosis was defined by a T-score of <-2.5 on the local sites hip and lumbar spine or on the whole body DEXA. ${ }^{22}$ In one patient with bilateral total hip replacement, diagnosis was based on lumbar spine and whole body DXA. Five patients were too obese for successful whole-body DXA and diagnosis was based on hip and spine measurements only.

Symptoms of anxiety and depression was defined as a score equal to or greater than 10 points by using the Hospital Anxiety and Depression Scale (HADS). This has been defined as abnormally high and may indicate the presence of clinically relevant symptoms of anxiety and/or depression. ${ }^{8}$

Atherosclerosis was defined as a c-IMT $>0.9 \mathrm{~mm}$, which is according to the ESH/ESC guidelines compatible with subclinical organ damage. ${ }^{16}$

Myocardial infarction was defined as a CIIS $\geq 20$, which is compatible with $99 \%$ specificity and $71 \%$ sensitivity to identify a previous myocardial infarction. ${ }^{5}$

\section{STATISTICS}

All statistical analyses were performed using Viscovery Profiler 5.3 by Viscovery Software $\mathrm{GmbH}$, (www.viscovery.net). Self-organizing maps (SOMs, also referred to as Kohonen maps) were used to create an ordered representation of the comorbidity data. The SOM method can be viewed as a non-parametric regression technique that converts multi-dimensional data spaces into lower dimensional abstractions. A SOM generates a non-linear representation of the data distribution and allows the user to identify homogenous data groups visually.

Patients have been ordered by their overall similarity concerning their present comorbidities and also the degree of its presence given by parameters the comorbidities are calculated from. Based on the created SOM model, clusters have been generated using the SOM-Ward Cluster algorithm of Viscovery, a hybrid algorithm that applies the classical hierarchical method of Ward on top of the SOM topology. Summary variables on comorbidities and clinical characteristics for the study sample and for each cluster are presented as mean \pm standard deviation for quantitative variables, and percentage for discrete variables. Data of the inflammatory markers were log-transformed to mitigate the effects of extreme values. Here, summary variables are presented as geometric mean with lower and upper limit.

Viscovery automatically identified for each cluster the comorbidities, clinical characteristics as well as the inflammatory markers that differ significantly from the average of the whole study sample of 213 patients using the integrated two-sided T-test with a confidence of $95 \%$. 


\section{REFERENCES}

1. Spruit MA, Vanderhoven-Augustin I, Janssen PP, Wouters EF. Integration of pulmonary rehabilitation in copd. Lancet 2008;371:12-13.

2. Vestbo J, Hurd SS, Agusti AG, Jones PW, Vogelmeier C, Anzueto A, Barnes PJ, Fabbri LM, Martinez FJ, Nishimura M, Stockley RA, Sin DD, Rodriguez-Roisin R. Global strategy for the diagnosis, management and prevention of chronic obstructive pulmonary disease, gold executive summary. Am J Respir Crit Care Med 2012.

3. Schols AM, Wouters EF, Soeters PB, Westerterp KR. Body composition by bioelectrical-impedance analysis compared with deuterium dilution and skinfold anthropometry in patients with chronic obstructive pulmonary disease. Am J Clin Nutr 1991;53:421-424.

4. Rossi AC, Brands PJ, Hoeks AP. Automatic recognition of the common carotid artery in longitudinal ultrasound b-mode scans. Med Image Anal 2008;12:653-665.

5. Rautaharju PM, Warren JW, Jain U, Wolf HK, Nielsen CL. Cardiac infarction injury score: An electrocardiographic coding scheme for ischemic heart disease. Circulation 1981;64:249-256.

6. Hernandes NA, Wouters EF, Meijer K, Annegarn J, Pitta F, Spruit MA. Reproducibility of 6-minute walking test in patients with copd. Eur Respir J 2011;38:261-267.

7. Bestall JC, Paul EA, Garrod R, Garnham R, Jones PW, Wedzicha JA. Usefulness of the medical research council ( $\mathrm{mrc}$ ) dyspnoea scale as a measure of disability in patients with chronic obstructive pulmonary disease. Thorax 1999;54:581-586.

8. Zigmond AS, Snaith RP. The hospital anxiety and depression scale. Acta Psychiatr Scand 1983;67: 361-370.

9. Jones PW, Quirk FH, Baveystock CM, Littlejohns P. A self-complete measure of health status for chronic airflow limitation. The st. George's respiratory questionnaire. Am Rev Respir Dis 1992;145:1321-1327.

10. Puhan MA, Garcia-Aymerich J, Frey M, ter Riet G, Anto JM, Agusti AG, Gomez FP, Rodriguez-Roisin R, Moons KG, Kessels AG, Held U. Expansion of the prognostic assessment of patients with chronic obstructive pulmonary disease: The updated bode index and the ado index. Lancet 2009;374:704-711.

11. Wilson PW, D'Agostino RB, Levy D, Belanger AM, Silbershatz H, Kannel WB. Prediction of coronary heart disease using risk factor categories. Circulation 1998;97:1837-1847.

12. Charlson M, Szatrowski TP, Peterson J, Gold J. Validation of a combined comorbidity index. J Clin Epidemiol 1994;47:1245-1251.

13. Cockcroft DW, Gault MH. Prediction of creatinine clearance from serum creatinine. Nephron 1976;16:31-41.

14. Kdoqi clinical practice guidelines and clinical practice recommendations for diabetes and chronic kidney disease. Am J Kidney Dis 2007;49:S12-154.

15. Blanc B, Finch C, Hallberg L. Nutritional anaemias. Report of a who scientific group. . WHO Tech Rep Ser 1968:1-40.

16. Mansia G, De Backer G, Dominiczak A, Cifkova R, Fagard R, Germano G, Grassi G, Heagerty AM, Kjeldsen SE, Laurent S, Narkiewicz K, Ruilope L, Rynkiewicz A, Schmieder RE, Struijker Boudier HA, Zanchetti A. 2007 esh-esc guidelines for the management of arterial hypertension: The task force for the management of arterial hypertension of the european society of hypertension (esh) and of the european society of cardiology (esc). Blood Press 2007;16:135-232.

17. Celli BR, Cote CG, Marin JM, Casanova C, Montes de Oca M, Mendez RA, Pinto Plata V, Cabral HJ. The body-mass index, airflow obstruction, dyspnea, and exercise capacity index in chronic obstructive pulmonary disease. N Engl J Med 2004;350:1005-1012.

18. Appropriate body-mass index for asian populations and its implications for policy and intervention strategies. Lancet 2004;363:157-163.

19. Schols AM, Broekhuizen R, Weling-Scheepers CA, Wouters EF. Body composition and mortality in chronic obstructive pulmonary disease. Am J Clin Nutr 2005;82:53-59.

20. Diagnosis and classification of diabetes mellitus. Diabetes Care 2010;33 Suppl 1:S62-69.

21. Alberti KG, Zimmet P, Shaw J. The metabolic syndrome--a new worldwide definition. Lancet 2005;366:1059-1062.

22. Graat-Verboom L, Spruit MA, van den Borne BE, Smeenk FW, Wouters EF. Whole-body versus local dxascan for the diagnosis of osteoporosis in copd patients. J Osteoporos 2010;2010:640878. 
Table S6.1 Selfreported comorbidity.

\begin{tabular}{lc}
\hline & $\mathrm{n}=213$ \\
\hline Charlson comorbidity index & $1.6 \pm 0.9$ \\
Combined age-Charlson comorbidity index & $3.5 \pm 1.3$ \\
Cardiovascular disease, \% & 31 \\
Acute myocardial infarction, \% & 10.3 \\
Chronic heart failure, \% & 2.8 \\
Peripheral vascular disease, \% & 16.9 \\
Cerebrovascular disease, \% & 9.4 \\
COPD, \% & 100 \\
Gastric-duodenal ulcer, \% & 5.6 \\
Liver disease, \% & 0.5 \\
Diabetes, \% & 5.6 \\
Renal disease, \% & 0.9 \\
\hline
\end{tabular}

Summary variables are presented as mean \pm standard deviation for quantitative variables, and percentage for discrete variables. (Dementia, connective tissue disease, malignant diseases and AIDS are not mentioned as these were exclusion criteria.)

Table S6.2 Non-pulmonary medication use of subjects in the five clusters.

\begin{tabular}{lcccrr}
\hline & $\begin{array}{c}\text { CLUSTER 1 } \\
\text { 'less comorbidity' }\end{array}$ & $\begin{array}{c}\text { CLUSTER 2 } \\
\text { 'cardiovascular' }\end{array}$ & $\begin{array}{c}\text { CLUSTER 3 } \\
\text { 'cachectic' }\end{array}$ & $\begin{array}{c}\text { CLUSTER 4 } \\
\text { 'metabolic' }\end{array}$ & $\begin{array}{c}\text { CLUSTER 5 } 5 \\
\text { 'psychologic' }\end{array}$ \\
\hline $\mathrm{N}$ & 67 & 49 & 44 & 33 & 20 \\
Antihypertensives, \% & 51 & 53 & 27 & 45 & 30 \\
ACE or ARB, \% & 34 & 37 & 14 & 21 & 10 \\
Beta-blockers, \% & 22 & 18 & 14 & 15 & 15 \\
Calcium blockers, \% & 13 & 10 & 11 & 21 & 15 \\
Anti-arrythmica, \% & 7 & 4 & 2 & 3 & 5 \\
Nitrates, \% & 13 & 6 & 7 & 3 & 25 \\
Diuretics, \% & 15 & 14 & 11 & 21 & 10 \\
Cholesterol lowering drugs, \% & 39 & 31 & 14 & 30 & 15 \\
Antiaggregants, \% & 40 & 29 & 23 & 18 & 30 \\
Coumarins, \% & 6 & 6 & 9 & 6 & 0 \\
Oral antidiabetics, \% & 10 & 2 & 5 & 3 & 0 \\
Insulin, \% & 1 & 4 & 0 & 0 & 0 \\
Calcium suppletion, \% & 7 & 12 & 11 & 6 & 10 \\
Biphosphonates, \% & 9 & 9 & 3 & 1 \\
Antidepressives, \% & 9 & 9 & 9 & 20 \\
Benzodiazepines, \% & 9 & 25 & 12 & 35 \\
Painkillers, \% & 12 & 16 & 15 & 21 & 40 \\
Antacids, \% & 13 & 14 & 23 & 48 & 55 \\
Other, \% & 22 & 33 & 48 & & 5 \\
\hline
\end{tabular}

Summary variables are presented as percentage. Light grey: less prevalent compared to the whole study sample ( $95 \%$ confidence interval); dark grey: more prevalent compared to the whole study sample $(95 \%$ confidence interval). ACE: angiotensin converting enzyme, ARB: angiotensin receptor blocker. 
Table S6.3 Pulmonary medication use of subjects in the five clusters.

\begin{tabular}{lccccc}
\hline & $\begin{array}{c}\text { CLUSTER 1 } \\
\text { 'less comorbidity' }\end{array}$ & $\begin{array}{c}\text { CLUSTER 2 } \\
\text { 'cardiovascular' }\end{array}$ & $\begin{array}{c}\text { CLUSTER 3 } \\
\text { 'cachectic' }\end{array}$ & $\begin{array}{c}\text { CLUSTER 4 } \\
\text { 'metabolic' }\end{array}$ & $\begin{array}{c}\text { CLUSTER 5 } \\
\text { 'psychologic' }\end{array}$ \\
\hline $\mathrm{n}$ & 67 & 49 & 44 & 33 & 20 \\
SABA, \% & 36 & 24 & 27 & 24 & 55 \\
SAMA, \% & 13 & 14 & 14 & 0 & 25 \\
SABA/SAMA, \% & 18 & 16 & 16 & 24 & 10 \\
LABA, \% & 15 & 18 & 18 & 30 & 20 \\
LAMA, \% & 79 & 73 & 84 & 85 & 60 \\
ICS, \% & 12 & 10 & 14 & 18 & 5 \\
ICS/LABA, \% & 79 & 80 & 82 & 61 & 70 \\
Theophyllin, \% & 15 & 18 & 16 & 6 & 5 \\
Oral Corticosteroids, \% & 9 & 8 & 9 & 9 & 15 \\
Antileukotrienes, \% & 1 & 0 & 2 & 6 & 15 \\
Antihistamines, \% & 3 & 4 & 2 & 0 & 0 \\
Nasal corticosteroids, \% & 9 & 4 & 9 & 6 & 5 \\
Antibiotics, \% & 6 & 6 & 7 & 3 & 5 \\
Mucolytics, \% & 27 & 35 & 32 & 21 & 30 \\
\hline
\end{tabular}

Summary variables are presented as percentage. Light grey: less prevalent compared to the whole study sample ( $95 \%$ confidence interval); dark grey: more prevalent compared to the whole study sample $(95 \%$ confidence interval). SABA: short acting beta-agonist, SAMA: short acting muscarin antagonist, LABA: long acting beta-agonist, LAMA: long acting muscarin antagonist, ICS: inhalation corticosteroid. 

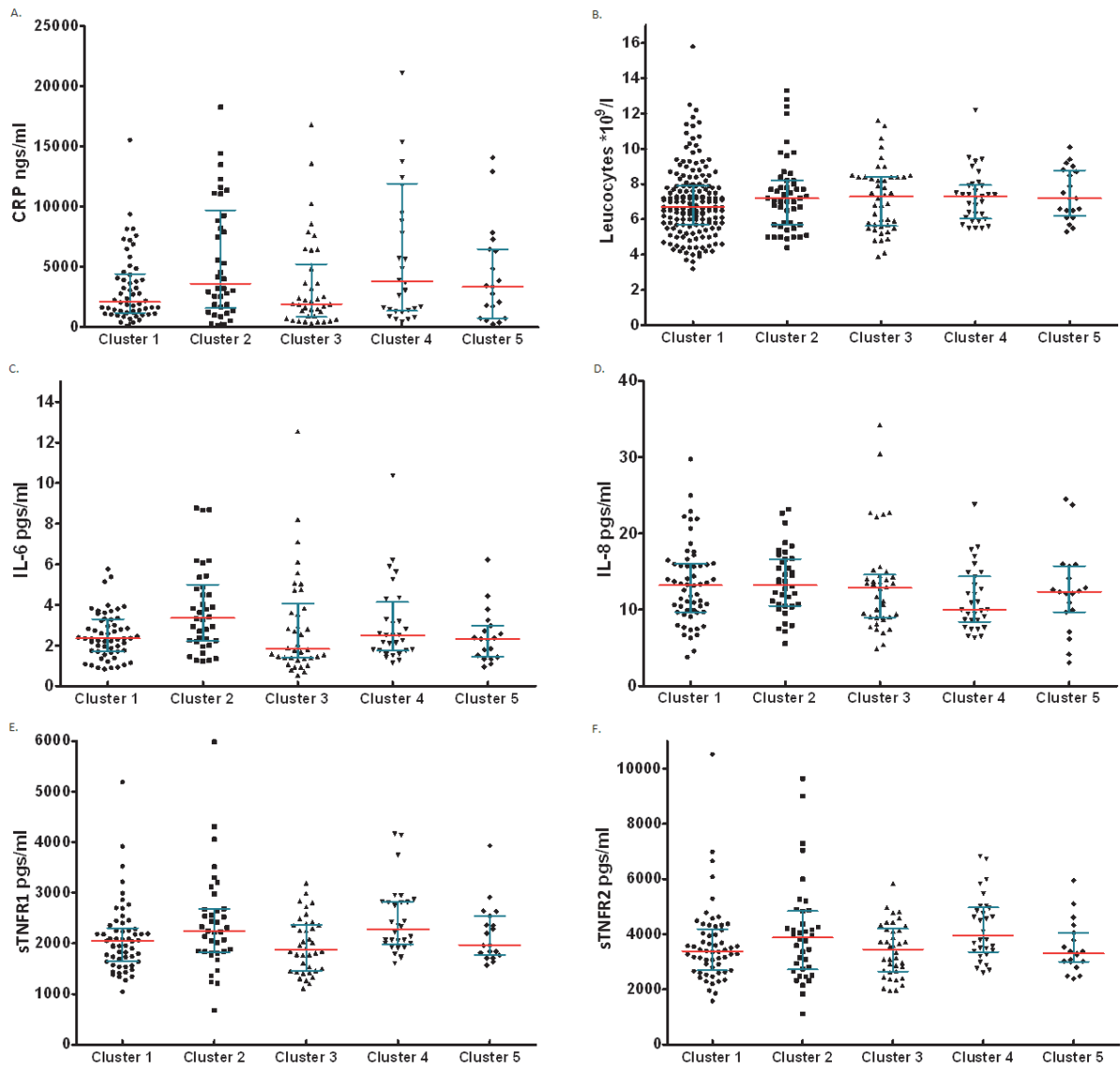

Figure S6.1 Data point distribution of inflammatory markers for each cluster.

The median is shown with a red line and interquartile ranges with a blue line. A: CRP; B: Leucocytes; C: IL-6; D: IL-8; E: sTNFR1; F: sTNFR2. 


\section{CHAPTER 7

\section{A multimarker approach to identify atherosclerosis in COPD}

Lowie E.G.W. Vanfleteren, Martijn A. Spruit, Miriam T.J. Groenen, Erica P.A. Rutten, Piet L.B. Bruijnzeel, Emiel F.M. Wouters, Frits M.E. Franssen 


\section{ABSTRACT}

\section{Background}

Cardiovascular risk assessment is important in the management of COPD. The value of atherosclerosis-related biomarkers to traditional cardiovascular risk factors in COPD is currently unknown. Therefore we aimed to investigate the clinical determinants and the potential role of biomarkers of carotid intima-media thickness (c-IMT) in COPD.

\section{Methods}

c-IMT was cross-sectional determined in 200 COPD patients (53\% males, mean age: $63.6 \pm 7.0$ years; mean $\mathrm{FEV}_{1} \%$ predicted: $51.0 \pm 16.8$ ). Assessment of integrated health status was performed in all patients as part of a pre-pulmonary rehabilitation assessment. Thirty-four different serum biomarkers were determined in 171 COPD patients.

\section{Results}

Mean c-IMT was $0.93 \pm 0.18 \mathrm{~mm}$. Age, body mass index, mean blood pressure and $\mathrm{FEV}_{1}$ percentage predicted were independent clinical predictors of $c-I M T$, explaining $31 \%$ of the variance. A model of blood biomarkers (C-reactive protein, serum amyloid $A$, triglycerides, fetuin A, insulin growth factor binding protein 1 , soluble intercellular adhesion molecule 1 , soluble vascular cell adhesion protein 1 , osteoprotogerin, osteonectin, beta-2 microglobulin, monocyte chemo-attractant protein 4) together explained $30 \%$ of the c-IMT variance. Combining clinical determinants and biomarkers in a multimarker approach had incremental value in predicting C-IMT (explained variance 38\%). Biomarkers that were retained in the combined model with the clinical variables were triglycerides, serum amyloid $A$, and osteonectin.

\section{Conclusions}

In addition to traditional risk factors and the degree of airflow limitation, a combination of blood biomarkers provided additional value in the prediction of increased C-IMT in COPD. Further exploration of these biomarkers may contribute to a better identification and understanding of cardiovascular risk in COPD patients. 


\section{INTRODUCTION}

Cardiovascular disease is now well recognized as a major comorbid complication in patients with chronic obstructive pulmonary disease (COPD). It is associated with increased health care utilization and mortality. ${ }^{1,2}$ Identification of patients at risk is challenging, but seems important for integrated COPD care.

The development of ultrasound measurement of carotid wall intima-media thickness (c-IMT) has greatly enhanced the ability to objectively identify the degree of (subclinical) atherosclerosis. It has been validated as a marker of the progression of atherosclerosis, ${ }^{3}$ and as a robust predictor of cardiovascular events. ${ }^{4}$ Increased c-IMT was reported in smokers with airflow limitation compared to smoking and non-smoking controls $^{5}$ and was associated with increased total and cardiovascular mortality in COPD. ${ }^{6}$

While traditional cardiovascular risk factors, including age, smoking, body mass index (BMI) and blood pressure, have been associated with increased c-IMT in smokers with airflow limitation ${ }^{5}$, the pathophysiology of co-occurring COPD and atherosclerosis remains poorly understood. Although it is well-established that atherosclerosis is associated with the presence of a low-grade systemic inflammatory state, traditional biomarkers of inflammation in COPD lack sufficient disease specificity to identify atherosclerotic artery disease. ${ }^{7}$ Previously, multiple biomarkers have been related to different disease manifestations of atherosclerosis in different patient populations. For example, pro-inflammatory cytokines, ${ }^{8-10}$ matrix metalloproteinases, ${ }^{11}$ adipokines, ${ }^{12}$ hepatokines, ${ }^{13}$ vascular adhesion molecules, ${ }^{14}$ regulators of fibrosis and fibrinolysis, ${ }^{15}$ the growth hormone - insulin growth factor axis, ${ }^{16}$ body iron, ${ }^{17}$ and bone markers ${ }^{18,19}$ have been reported to have, at least partly, their role in the atherosclerotic process.

However, the role of these biomarkers in the identification of the presence of atherosclerosis in COPD has not been studied. In addition, due to the heterogeneous nature of COPD and atherosclerosis, it can be hypothesized that a single biomarker may not provide sufficient biological information. So, a combination of multiple biomarkers may provide a more accurate identification. Also, it is unknown whether and to what extent biomarkers additionally explain the variance in c-IMT next to clinical determinants.

The aims of the present study were to investigate 1. the clinical determinants of c-IMT; 2. which combination of biomarkers can explain the c-IMT variance; and 3. the incremental value of biomarkers to the clinical determinants in predicting C-IMT in patients with COPD. 


\section{METHODS}

\section{STUDY DESIGN AND SUBJECTS}

The CIRO comorbidity (CIROCO) study (MEC 10-3-067) was a 2-year prospective singlecentre study. Patients with COPD were recruited at the start of a pulmonary rehabilitation program at $\mathrm{CIRO}+{ }^{20}$ Study design, in- and exclusion criteria and details of the assessments have been published. ${ }^{21}$

\section{CAROTID INTIMA-MEDIA THICKNESS}

C-IMT was assessed using high-resolution B-mode ultrasound with a 10-MHz linear transducer (Art.Lab Esaote Picus, Pie-medical Netherlands/Italie). The ultrasound device was connected to an acquisition modem with an automatic boundary detection system (Art.Lab Esaote Picus). c-IMT was thus quantified semi automatically, reducing the interobserver variability. With the patient in a supine position, measurements of c-IMT were performed throughout 10-mm segments across the far wall of the left and right common carotid arteries, at a point most proximal to the carotid bifurcation free of visual plaques. The probe was moved to obtain measurements of the common carotid artery at 4 angles on both sides $\left(180^{\circ}, 150^{\circ}, 120^{\circ}\right.$, and $\left.90^{\circ}\right)$. For each measured segment maximum c-IMT values were acquired automatically throughout the $10-\mathrm{mm}$ vessel length. The average of segmental maximum c-IMT values was determined as c-IMT per patient. All measurements complied with consensus recommendations that were recently proposed to standardize c-IMT methods and to restrict variations in the definition of c-IMT, location of measurements, and technique used (manual or semiautomatic edge-detecting systems). ${ }^{23}$

\section{BIOMARKERS}

A venous blood sample was collected from all patients in the fasted state. Serum samples were stored at $-80^{\circ} \mathrm{C}$ prior to their analysis. Measurement of leucocytes, high density lipoprotein (HDL), low density lipoprotein (LDL), triglycerides and glucose were determined in the CIRO+ laboratory (validated, custom made arrays). Thirty-four different biomarkers, identified in the English literature as being associated with cardiovascular outcomes, were evaluated against c-IMT. ${ }^{8-12,14-19,24-30}$ (Figure 7.2) Measurement of the inflammatory serum markers was carried out on multiplex platforms (Meso Scale Discovery (Gaithersburg, Maryland) and Myriad RBM (Austin, Texas)). If the level of a specific biomarker was below the detection threshold, the level of the threshold was included for analysis. 


\section{STATISTICS}

Statistics were performed using SPSS version 22.0. Results are expressed as mean \pm standard deviation, or count with percentage. All biomarkers were logtransformed because the majority of biomarkers were not normally distributed. For comparison, Chi square tests or independent samples Student's $t$-test were used where applicable. Relationships between continuous variables were analysed using simple and/or multivariate backward linear regression. The correlations between all variables were examined to assess potential sources of multi-collinearity. Assumptions, outliers and residuals were checked for the multiple regression analysis. Correlations between all variables were examined to assess potential sources of multi-collinearity. A variance inflation factor (VIF) less than 10 was set to determine multi-collinearity. Cook's distance, Mahalanobis distance, DFBeta, and covariance ratio were used to examine outliers and influential cases. With P-P plots the normality of the residuals were checked and with a scatterplot was the chance of heteroscedasticity within the data was examined. A two-sided $p$ value of $\leq 0.05$ was considered to be statistically significant. For the backward regression a $\mathrm{p}$ value of 0.10 was used to exclude variables from the model.

\section{RESULTS}

\section{CHARACTERISTICS}

Of 255 prospectively screened patients, 42 (16.5\%) were ineligible (Figure 7.1). Thirteen of the 213 eligible COPD patients (6.1\%) were excluded because of unsuccessful c-IMT measurement. The final study sample consisted of 200 patients with moderate to severe COPD, substantial smoking history, moderately impaired diffusion capacity, and increased static lung volumes (Table 7.1). Thirty-one percent of the patients (61 subjects) had self-reported cardiovascular comorbidity, and $28 \%$ used anti-lipemics. Table 7.1 summarizes the cardiovascular risk related and COPD specific characteristics and Table 7.2 summarizes the cardiovascular comorbidity and medication use. In 29 subjects, $\geq 1$ biomarker value was missing. These subjects were excluded for the biomarker analysis. 


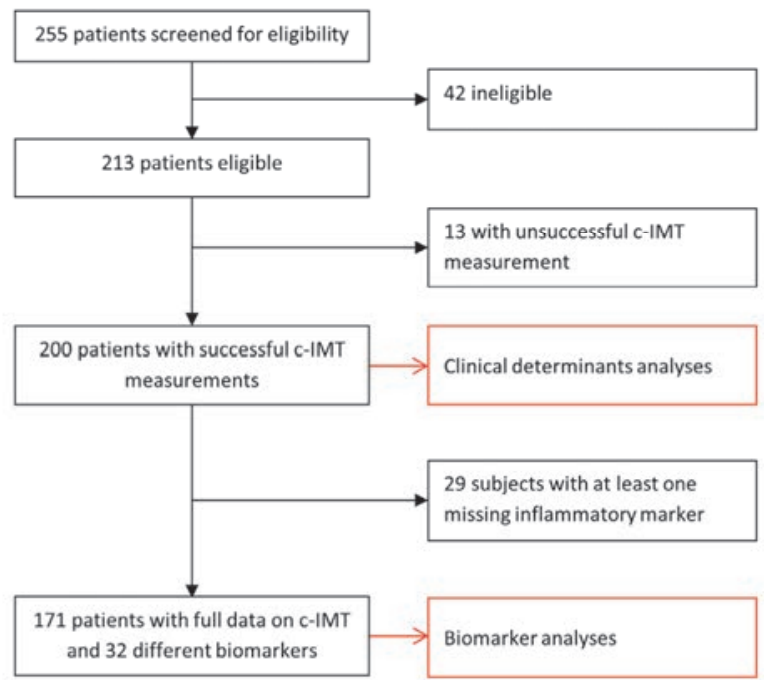

Figure 7.1 Study flow chart.

Table 7.1 Patients characteristics.

\begin{tabular}{|c|c|}
\hline & $\begin{array}{c}\text { All subjects } \\
n=200\end{array}$ \\
\hline \multicolumn{2}{|l|}{ Cardiovascular risk related variables } \\
\hline Age, years & $64 \pm 7$ \\
\hline Male, $\mathrm{n}(\%)$ & $105(53)$ \\
\hline Current smoker, n (\%) & $56(28)$ \\
\hline Packyears & $47 \pm 26$ \\
\hline Mean blood pressure, $\mathrm{mmHg}$ & $101 \pm 12$ \\
\hline Body mass index, $\mathrm{kg} / \mathrm{m}^{2}$ & $26.2 \pm 5.1$ \\
\hline $\mathrm{HDL}, \mathrm{mmol} / \mathrm{l}$ & $1.7 \pm 0.5$ \\
\hline LDL, mmol// & $3.0 \pm 1.0$ \\
\hline Glycemia, mmol/l & $5.7 \pm 0.9$ \\
\hline \multicolumn{2}{|l|}{ COPD specific variables } \\
\hline Long-term oxygen therapy, n (\%) & $33(17)$ \\
\hline $\mathrm{FEV}_{1}$, liters & $1.40 \pm 0.54$ \\
\hline $\mathrm{FEV}_{1}, \%$ predicted & $51.0 \pm 16.8$ \\
\hline $\mathrm{FEV}_{1} / \mathrm{FVC}$ & $0.40 \pm 0.11$ \\
\hline RV, \% predicted ( $n=199)$ & $166 \pm 48$ \\
\hline DLCO, \% predicted $(n=197)$ & $55 \pm 17$ \\
\hline $\mathrm{PaCO}_{2}, \mathrm{kPa}$ & $5.4 \pm 0.6$ \\
\hline $\mathrm{PaO}_{2}, \mathrm{kPa}$ & $9.4 \pm 1.1$ \\
\hline Resting $\mathrm{O}_{2}$ saturation, $\%$ & $95 \pm 1.9$ \\
\hline $6 \mathrm{MWD}$, meters & $472 \pm 108$ \\
\hline mMRC dypnea grade (n=199) & $2.1 \pm 1.1$ \\
\hline SGRQ, total score $(n=187)$ & $51 \pm 18$ \\
\hline
\end{tabular}

HDL: high-density lipoprotein; LDL: low-density lipoprotein; FFMI: fat free mass index; mMRC: modified medical research council; 6MWD: six minute walking distance; $F E V_{1}$ : forced expiratory volume in the first second; FVC: forced vital capacity; RV: residual volume; DLCO: diffusing capacity for carbon monoxide; SGRQ: St. George's Respiratory Questionnaire. 
Table 7.2 Comorbidities and cardiovascular medication use in the study sample.

\begin{tabular}{lr}
\hline & COPD \\
& $\mathrm{n}=200$ \\
\hline Charlson comorbidity index & $21(11)$ \\
Myocardial infarction, $\mathrm{n}(\%)$ & $6(3.0)$ \\
Heart failure, $\mathrm{n}(\%)$ & $32(16)$ \\
Peripheral arterial disease, $\mathrm{n}(\%)$ & $10(5.0)$ \\
Diabetes, $\mathrm{n}(\%)$ & \\
Cardiovascular medication use & $56(26.3)$ \\
ACE or ARB, $\mathrm{n}(\%)$ & $35(17.5)$ \\
Beta-blockers, $\mathrm{n}(\%)$ & $26(13.0)$ \\
Calcium blockers, $\mathrm{n}(\%)$ & $59(29.5)$ \\
Antiaggregants, $\mathrm{n}(\%)$ & $57(28.5)$ \\
Antilipemics, $\mathrm{n}(\%)$ & $9(4.5)$ \\
Antidiabetics, $\mathrm{n}(\%)$ & \\
\hline
\end{tabular}

\section{CLINICAL DETERMINANTS OF C-IMT IN COPD PATIENTS}

In univariate linear regression, c-IMT was positively associated with age, male gender, mean blood pressure, BMI, diffusion capacity (DLCO), dyspnea grade and negatively with the six-minute walking distance. (Table 7.3)

Table 7.3 Univariate linear regression with c-IMT as the dependent variable in patients with COPD.

\begin{tabular}{|c|c|c|}
\hline & $r$ & p-value \\
\hline \multicolumn{3}{|l|}{ Cardiovascular risk related variables } \\
\hline Age, years & 0.259 & $<0.001$ \\
\hline Female gender & -0.163 & 0.021 \\
\hline Current smoker, n (\%) & -0.110 & 0.122 \\
\hline Packyears & 0.046 & 0.520 \\
\hline Peripheral mean blood pressure, $\mathrm{mm} \mathrm{Hg}$ & 0.232 & 0.001 \\
\hline Body mass index, $\mathrm{kg} / \mathrm{m}^{2}$ & 0.440 & $<0.001$ \\
\hline $\mathrm{HDL}, \mathrm{mmol} / \mathrm{l}$ & -0.114 & 0.109 \\
\hline LDL, mmol/l & 0.046 & 0.520 \\
\hline Glycemia, mmol/l & 0.059 & 0.404 \\
\hline \multicolumn{3}{|l|}{ COPD specific variables } \\
\hline Long-term oxygen therapy, n (\%) & 0.097 & 0.171 \\
\hline $\mathrm{FEV}_{1}, \%$ predicted & -0.099 & 0.164 \\
\hline $\mathrm{FEV}_{1} / \mathrm{FVC}, \%$ & -0.046 & 0.514 \\
\hline $\mathrm{RV}, \%$ predicted $(\mathrm{n}=199)$ & -0.090 & 0.204 \\
\hline DLCO, \% predicted $(n=197)$ & 0.159 & 0.026 \\
\hline $\mathrm{PaCO}_{2}, \mathrm{kPa}$ & 0.110 & 0.122 \\
\hline $\mathrm{PaO}_{2}, \mathrm{kPa}$ & -0.026 & 0.717 \\
\hline $\mathrm{O}_{2}$ saturation, $\%$ & -0.052 & 0.461 \\
\hline 6MWD, meter & -0.205 & 0.004 \\
\hline mMRC, grade $(n=199)$ & 0.164 & 0.020 \\
\hline SGRQ, points $(n=187)$ & 0.088 & 0.229 \\
\hline
\end{tabular}

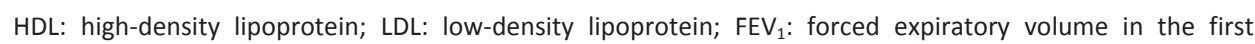
second; FVC: forced vital capacity; RV: residual volume; DLCO: diffusing capacity for carbon monoxide; GMWD: six minute walking distance; mMRC: modified medical research council; SGRQ: St. George's Respiratory Questionnaire. 
$\mathrm{BMI}$, age and mean systemic blood pressure were still significant predictors in the multivariate backward linear regression model that included all cardiovascular risk related variables. (Supplemental Table S7.1, Model 1, Figure 7.2). This model explained $28 \%$ of the variance in C-IMT.

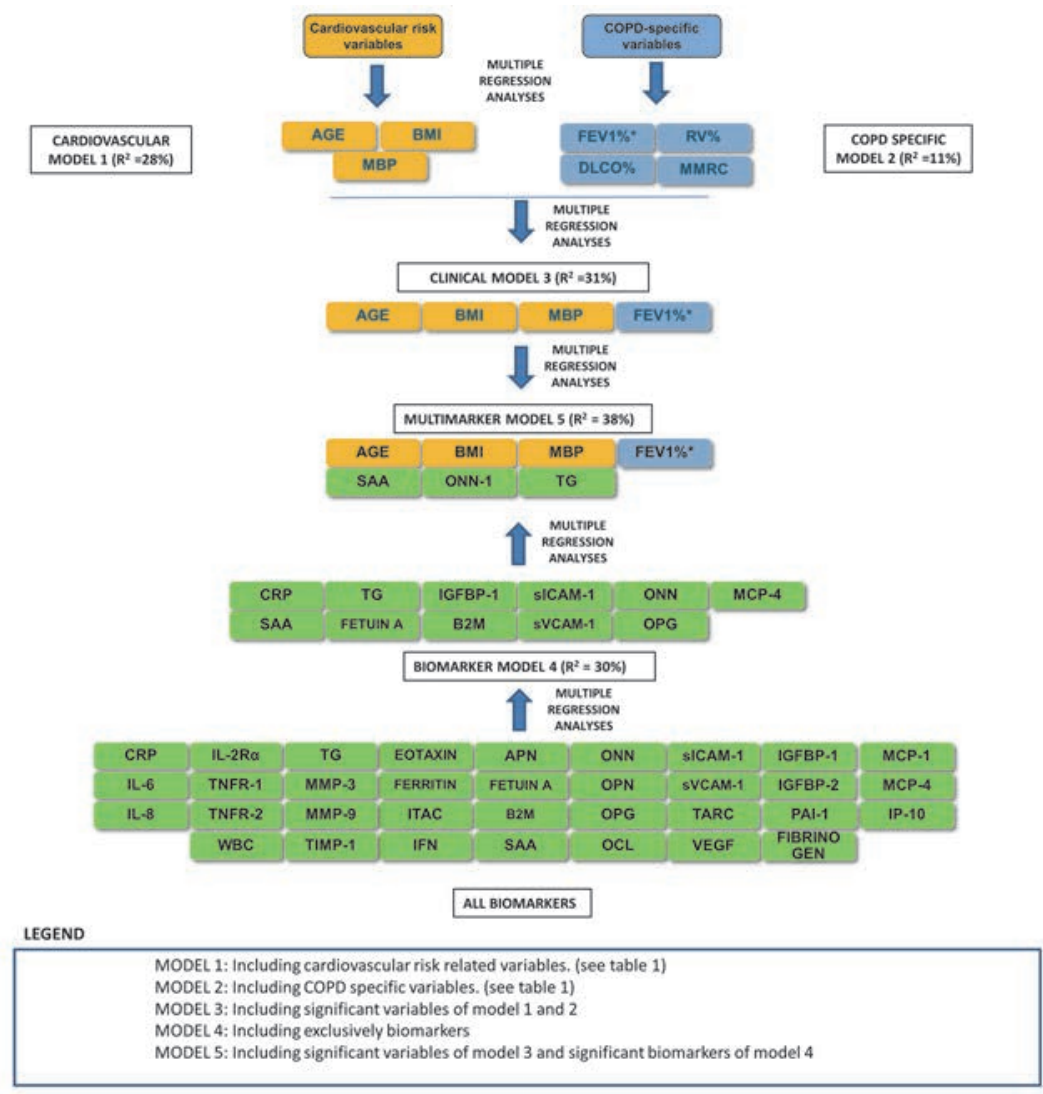

Figure 7.2 Clinical, biomarker and mixed models to predict c-IMT in COPD.

BMI: body mass index; MBP: mean blood pressure; $\mathrm{FEV}_{1} \%$ : forced expiratory volume in the first second as percentage of predicted; RV\%: Residual volume as percentage of predicted; DLCO\%: Diffusion capacity for carbon monoxide as percentage of predicted; mMRC: modified medical research council dyspnea grade; TG: triglycerides; CRP: C-reactive protein; IL-6: interleukin 6; IL8: Interleukin 8; TNFR-1: tumor necrosis factor receptor 1; TNFR-2: tumor necrosis factor receptor 2; IFNY: interferon $\gamma$; IGFBP-1: insulin-like growth factor-binding protein 1; IGFBP-2: insulin-like growth factor-binding protein 2; IP-10: interferon $\gamma$-inducible protein-10; MCP-1: monocyte chemotactic protein-1; MCP- 4: monocyte chemotactic protein-4; ITAC: interferon $\gamma$ Inducible T cell $\alpha$ chemoattractant; OCL: osteocalcin; ONN: osteonectin; OPN: osteopontin; OPG: osteoprotogerin; SAA: serum amyloid A; sICAM-1: soluble intercellular adhesion molecule 1; sVCAM-1: soluble vascular cell adhesion protein 1; TARC: thymus and activation-regulated chemokine; VEGF: vascular endothelial growth factor; APN: adiponectin; B2M: beta-2 microglobulin; IL2R $\alpha$ : interleukin-2 receptor alpha; MMP-3: matrix metalloproteinase 3; matrix metalloproteinase 9; MMP-9; PAI-1: plasminogen activator Inhibitor 1; TIMP-1: tissue inhibitor of metalloproteinases 1. 
In the model based on solely COPD specific variables, the degree of airflow obstruction ( $\mathrm{FEV}_{1} \%$ predicted), the degree of static hyperinflation (residual volume (RV) \% predicted), diffusion capacity (DLCO \% predicted) and dyspnea grade (mMRC dyspnea score) were significantly contributing to an $11 \%$ explained variance of c-IMT (Supplemental Table S7.2, Model 2, Figure 7.2).

In a combined model, age, $\mathrm{BMI}$, mean blood pressure and $\mathrm{FEV}_{1} \%$ predicted explained $31 \%$ of the variance in C-IMT. (Supplemental Table S7.3, Model 3, Figure 7.2). Of notice, $\mathrm{FEV}_{1} \%$ predicted is a predictor in the multivariate, but not in the univariate model. The inverse association between $\mathrm{BMI}$ and $\mathrm{FEV}_{1} \%\left(\mathrm{r}^{2}=0.021 ; \mathrm{p}=0.02\right)$ might partly explain this.

\section{A MULTI-BIOMARKER MODEL TO PREDICT C-IMT IN COPD PATIENTS}

A biomarker-only backward linear regression model including all biomarkers was done. (Supplemental Table S7.4, model 4, Figure 7.2) The combination of C-reactive protein, serum amyloid $A$, triglycerides, fetuin $A$, insulin growth factor binding protein 1 , soluble intercellular adhesion molecule 1 (sICAM-1), Soluble vascular cell adhesion protein 1 (sVCAM-1), osteoprotogerin, osteonectin, beta-2 microglobulin and monocyte chemoattractant protein 4 together explained $30 \%$ of the variance in c-IMT.

\section{THE COMBINATION OF BLOOD BIOMARKERS AND CLINICAL VARIABLES TO PREDICT C-IMT IN COPD PATIENTS}

A multivariate backward linear regression model (Supplemental Table S7.5, model 5, Figure 7.2) with the significant clinical variables of model 3 and the significant biomarkers of model 4 was done. Age, BMI, mean blood pressure and $\mathrm{FEV}_{1} \%$ remained in the model, together with the following biomarkers: serum amyloid $A$, osteonectin and triglycerides. The combination of biomarkers and clinical variables explained $38 \%$ of the variance in $\mathrm{c}-\mathrm{IMT}$, which is $7 \%$ more compared to the clinical variable model 2 and $8 \%$ more than the multiple biomarker model 3.

Only the log tumor necrosis factor receptor 1 and 2 were highly correlated and had a VIF between 5 and 10 in the analyses. Analyses with only log tumor necrosis factor receptor 1 or log tumor necrosis factor receptor 2 did not change the final model. There were a few outliers in the model based on Mahalanobis distance and covariance ratio. These outliers were assumed to have a low influence because none of the cases had a Cook's distance higher than 1. Further were all DFbeta's lower than 1 . There were no major violations of the normality of the residuals based on the visual examination of the P-P plots or heteroscedasticity based on the visual examination of the standardized residuals plotted against the standardized predicted value. 


\section{DISCUSSION}

This study showed that c-IMT, a robust estimate of atherosclerotic disease, is partially determined by age, BMI, mean blood pressure and the degree of airflow limitation in patients with COPD. Moreover, a combination of atherosclerosis-related blood biomarkers could equally explain the c-IMT variance. Finally, combining clinical determinants and biomarkers in a multimarker approach had incremental value in predicting c-IMT.

The present study confirms that cardiovascular risk attributes are mainly similar to what is known from the general population. ${ }^{32}$ Indeed higher age, higher BMI and higher mean blood pressure are also in the present study determinants of c-IMT. Low-density lipoprotein (LDL) cholesterol was not associated with c-IMT in the present study. The accumulation of LDL cholesterol in the subendothelial matrix of the artery wall is however a key pathological process in atherosclerosis. A possible explanation for the absent correlation is the large proportion of subjects that used anti-lipemics, specifically aimed at reducing LDL cholesterol. ${ }^{33}$

Reduced pulmonary function has been previously identified as a predictor of worse cardiovascular outcome. ${ }^{34,35}$ Similar to Iwamoto et al., ${ }^{5}$ the degree of airflow limitation $\left(\mathrm{FEV}_{1} \%\right)$, was identified as an independent predictor of c-IMT in the present study. However, Iwamoto et al. analyzed subjects with and without airflow limitation together, which limits the interpretation of the results.

We evaluated 34 blood biomarkers that have been previously associated with different disease expressions of atherosclerosis in different patient populations. When evaluating the predictive value of the combination of these biomarkers, 11 biomarkers independently contributed to the model. With $30 \%$ of the variance in c-IMT explained, these biomarkers equaled the $31 \%$ that could be explained by analyzing the clinical variables only. Since, these 11 markers are independently from each other contributing to the model, it is interesting to discuss them separately.

The presence in the model of some of the more robust inflammatory markers in atherosclerosis, like C-reactive protein and serum amyloid A might not surprise as these have been consistently related to atherosclerotic disease expressions or cardiovascular events. ${ }^{9,27,36,37}$ It is also well known that leucocyte chemotaxis plays an important role in the progression of atherosclerosis. ${ }^{38}$ Here, the CC chemokine monocyte chemoattractant protein 4, independently contributed to the model. The recruitment of inflammatory cells from the circulation and their transendothelial migration and this process is predominantly mediated by cellular adhesion molecules like sICAM-1 and sVCAM-1. Expression of SVCAM-1 has been consistently observed in atherosclerotic 
plaques and is dedicated a predictive role in patients at high risk or with overt coronary artery disease. ${ }^{14}$ Next, the growth hormone - insulin growth factor axis has been generally accepted to have its role in the development of atherosclerosis and insulin growth factor binding protein has previously been associated with c-IMT in Japanese men. ${ }^{16}$ Triglycerides are not directly atherogenic but represent an important biomarker of cardiovascular risk. ${ }^{39}$ Although the adipokines leptin and adiponectin did not contribute to the biomarker model, the hepatokine fetuin A did. In analogy with dysregulated adipose tissue, steatotic and inflamed liver produces a variety of proteins, referred to as hepatokines. ${ }^{40}$ fetuin $\mathrm{A}$ has been proven to have a major pathogenetic role in metabolic diseases. It has been associated with type 2 diabetes ${ }^{41,42}$ and cardiovascular disease risk $^{13}$ and its important role in the pathogenesis of insulin resistance, endothelial dysfunction and inflammation. ${ }^{43,44}$ Fetuin $A$ has been positively associated with c-IMT in hypertensive patients, independently of oxidative stress and renal function. ${ }^{45}$ Many of the bone regulatory proteins, such as osteoprotogerin and osteonectin have been shown to be present in atherosclerotic plaques in vitro and seem to be expressed by vascular cells in vivo as well. ${ }^{18}$ Osteoprotogerin levels have been consistently associated with the incidence and prevalence of coronary artery disease. ${ }^{19}$ Also osteonectin has been associated with coronary artery disease. ${ }^{26}$ The role of markers involved in bone metabolism in atherosclerosis in COPD patients is intriguing, since osteoporosis is a highly prevalent comorbidity. ${ }^{46}$ Free beta-2 microglobulin circulates in the blood as a result of shedding from cell surfaces, or intracellular release. Serum beta-2 microglobulin levels are increased in patients with peripheral arterial disease and independently correlated with disease severity. ${ }^{28}$ In addition, beta- 2 microglobulin levels have been associated with c-IMT. ${ }^{47}$

While ten different biomarkers had individual additional value to the biomarker-only model, only a minority of the studied biomarkers had added value over age, BMI, mean blood pressure and the degree of airflow obstruction. Namely the inflammatory marker serum amyloid $A$, the bone marker osteonectin, and triglycerides.

This study showed that clinical variables - most importantly age and BMI - are more robust predictors of c-IMT than most of the biomarkers in the biomarker model. Hence, these variables might partly explain why these biomarkers were associated with atherosclerosis. Indeed, ageing has an important impact on humans cellular and organ systems and the inflammatory response to various triggers may contribute to ageassociated morbidity later in life. Adipose tissue on the other hand, indirectly measured with $\mathrm{BMI}$, is now considered an active metabolic organ that releases a large number of cytokines and bioactive mediators, including adipokines (such as leptin and adiponectin), proinflammatory cytokines (such as C-reactive protein) that together might lead to increased oxidative stress and endothelial dysfunction, finally promoting atherosclerosis. $^{48}$ 
Clinical variables and blood biomarkers had a similar potential to explain the c-IMT variance. The combination of blood biomarkers and clinical variables considerably increased the explained variance. A panel of multiple biomarkers in combination with clinical markers might be the way to move forward in cardiovascular risk classification.

In this study, the multimarker approach could explain $38 \%$ of the variance in c-IMT. Besides the biological variability in c-IMT, other factors (e.g. physical inactivity, environmental exposures other than smoking history, or nutritional history) may also have contributed to the variance in c-IMT. Moreover, although multiple biomarkers have been studied here, we recognize that this might still not provide a comprehensive reflection of the atherosclerotic process.

This study has limitations. The present study included GOLD grade 2-4 patients with multiple comorbidities and on multiple drug treatments. ${ }^{21}$ Pharmacological treatment may interfere with the serum levels of biomarkers. Secondly, we evaluated biomarkers of atherosclerotic disease against another surrogate of the same disease, c-IMT. However, c-IMT provides important advantages as the presence and the degree of subclinical atherosclerosis can be objectively measured. Third, the data of the present study may have limited external validity towards the general COPD population, since all participants were recruited at the start of a comprehensive pulmonary rehabilitation program.

In conclusion, this study showed that c-IMT is determined by age, BMI, mean blood pressure and the degree of airflow limitation. A combination of multiple biomarkers could partly explain the c-IMT variance but only a minority of the individual biomarkers had additional value to the predictive value of clinical determinants. A panel of multiple biomarkers in combination with clinical markers might be the way to move forward in cardiovascular risk classification in patients with COPD. On the one hand these findings illustrate the complexity of cardiovascular comorbidity in patients with COPD. On the other hand this study might have identified biomarkers of interest for further prospective exploration of the cardiovascular risk assessment in patients with COPD. 


\section{REFERENCES}

1. Divo M, Cote C, de Torres JP, Casanova C, Marin JM, Pinto-Plata V, Zulueta J, Cabrera C, Zagaceta J, Hunninghake G, Celli B; BODE Collaborative Group. Comorbidities and risk of mortality in patients with chronic obstructive pulmonary disease. Am J Respir Crit Care Med 2012;186:155-61.

2. Mannino DM, Thorn D, Swensen A, Holguin F. Prevalence and outcomes of diabetes, hypertension and cardiovascular disease in COPD. Eur Respir J 2008;32:962-9.

3. Bots ML, Grobbee DE. Intima media thickness as a surrogate marker for generalised atherosclerosis. Cardiovasc Drugs Ther 2002;16:341-51.

4. Lorenz MW, Markus HS, Bots ML, Rosvall M, Sitzer M. Prediction of clinical cardiovascular events with carotid intima-media thickness: a systematic review and meta-analysis. Circulation 2007;115:459-67.

5. Iwamoto H, Yokoyama A, Kitahara Y, Ishikawa N, Haruta Y, Yamane K, Hattori N, Hara H, Kohno N. Airflow limitation in smokers is associated with subclinical atherosclerosis. Am J Respir Crit Care Med 2009;179:35-40.

6. van Gestel YR, Flu WJ, van Kuijk JP, Hoeks SE, Bax JJ, Sin DD, Poldermans D. Association of COPD with carotid wall intima-media thickness in vascular surgery patients. Respir Med 2010;104:712-6.

7. Pearson TA, Mensah GA, Alexander RW, Anderson JL, Cannon RO 3rd, Criqui M, Fadl YY, Fortmann SP, Hong Y, Myers GL, Rifai N, Smith SC Jr, Taubert K, Tracy RP, Vinicor F; Centers for Disease Control and Prevention; American Heart Association. Markers of inflammation and cardiovascular disease: application to clinical and public health practice: A statement for healthcare professionals from the Centers for Disease Control and Prevention and the American Heart Association. Circulation 2003; 107:499-511.

8. Sarwar N, Butterworth AS, Freitag DF, Gregson J, Willeit P, Gorman DN, Gao P, Saleheen D, Rendon A, Nelson CP, Braund PS, Hall AS, Chasman DI, Tybjærg-Hansen A, Chambers JC, Benjamin EJ, Franks PW, Clarke R, Wilde AA, Trip MD, Steri M, Witteman JC, Qi L, van der Schoot CE, de Faire U, Erdmann J, Stringham HM, Koenig W, Rader DJ, Melzer D, Reich D, Psaty BM, Kleber ME, Panagiotakos DB, Willeit J, Wennberg P, Woodward M, Adamovic S, Rimm EB, Meade TW, Gillum RF, Shaffer JA, Hofman A, Onat A, Sundström J, Wassertheil-Smoller S, Mellström D, Gallacher J, Cushman M, Tracy RP, Kauhanen J, Karlsson M, Salonen JT, Wilhelmsen L, Amouyel P, Cantin B, Best LG, Ben-Shlomo Y, Manson JE, DaveySmith G, de Bakker PI, O'Donnell CJ, Wilson JF, Wilson AG, Assimes TL, Jansson JO, Ohlsson C, Tivesten Å, Ljunggren Ö, Reilly MP, Hamsten A, Ingelsson E, Cambien F, Hung J, Thomas GN, Boehnke M, Schunkert H, Asselbergs FW, Kastelein JJ, Gudnason V, Salomaa V, Harris TB, Kooner JS, Allin KH, Nordestgaard BG, Hopewell JC, Goodall AH, Ridker PM, Hólm H, Watkins H, Ouwehand WH, Samani NJ, Kaptoge S, Di Angelantonio E, Harari O, Danesh J. Interleukin-6 receptor pathways in coronary heart disease: a collaborative meta-analysis of 82 studies. Lancet 2012;379:1205-13.

9. Sin DD, Man SF. Why are patients with chronic obstructive pulmonary disease at increased risk of cardiovascular diseases? The potential role of systemic inflammation in chronic obstructive pulmonary disease. Circulation 2003;107:1514-9.

10. Zhang L, Peppel K, Sivashanmugam P, Orman ES, Brian L, Exum ST, Freedman NJ. Expression of tumor necrosis factor receptor-1 in arterial wall cells promotes atherosclerosis. Arterioscler Thromb Vasc Biol 2007;27:1087-94.

11. Beaudeux JL, Giral P, Bruckert E, Bernard M, Foglietti MJ, Chapman MJ. Serum matrix metalloproteinase-3 and tissue inhibitor of metalloproteinases-1 as potential markers of carotid atherosclerosis in infraclinical hyperlipidemia. Atherosclerosis 2003;169:139-46.

12. Pischon T, Girman CJ, Hotamisligil GS, Rifai N, Hu FB, Rimm EB. Plasma adiponectin levels and risk of myocardial infarction in men. JAMA 2004;291:1730-7.

13. Weikert C, Stefan N, Schulze MB, Pischon T, Berger K, Joost HG, Häring HU, Boeing H, Fritsche A. Plasma fetuin-a levels and the risk of myocardial infarction and ischemic stroke. Circulation 2008;118:2555-62.

14. Blankenberg S, Barbaux S, Tiret L. Adhesion molecules and atherosclerosis. Atherosclerosis 2003;170:191-203.

15. Peng Y, Liu H, Liu F, Ouyang L, Cheng M, Gao L, Pan F, Liu Y, Chen X, Li J. Atherosclerosis is associated with plasminogen activator inhibitor type- 1 in chronic haemodialysis patients. Nephrology (Carlton) 2008;13:579-86. 
16. Kawachi S, Takeda N, Sasaki A, Kokubo Y, Takami K, Sarui H, Hayashi M, Yamakita N, Yasuda K. Circulating insulin-like growth factor-1 and insulin-like growth factor binding protein-3 are associated with early carotid atherosclerosis. Arterioscler Thromb Vasc Biol 2005;25:617-21.

17. Wolff B, Völzke H, Lüdemann J, Robinson D, Vogelgesang D, Staudt A, Kessler C, Dahm JB, John U, Felix SB. Association between high serum ferritin levels and carotid atherosclerosis in the study of health in Pomerania (SHIP). Stroke 2004;35:453-7.

18. Trion A, van der Laarse A. Vascular smooth muscle cells and calcification in atherosclerosis. Am Heart $J$ 2004;147:808-14.

19. Venuraju SM, Yerramasu A, Corder R, Lahiri A. Osteoprotegerin as a predictor of coronary artery disease and cardiovascular mortality and morbidity. J Am Coll Cardiol 2010;55:2049-61.

20. Spruit MA, Vanderhoven-Augustin I, Janssen PP, et al. Integration of pulmonary rehabilitation in COPD. Lancet 2008;371:12-3.

21. Vanfleteren LE, Spruit MA, Groenen M, Gaffron S, van Empel VP, Bruijnzeel PL, Rutten EP, Op 't Roodt J, Wouters EF, Franssen FM. Clusters of comorbidities based on validated objective measurements and systemic inflammation in patients with chronic obstructive pulmonary disease. Am J Respir Crit Care Med 2013;187:728-35

22. Rossi AC, Brands PJ, Hoeks AP. Automatic recognition of the common carotid artery in longitudinal ultrasound B-mode scans. Med Image Anal 2008;12:653-65.

23. Stein JH, Korcarz CE, Hurst RT, Lonn E, Kendall CB, Mohler ER, Najjar SS, Rembold CM, Post WS; American Society of Echocardiography Carotid Intima-Media Thickness Task Force. Use of carotid ultrasound to identify subclinical vascular disease and evaluate cardiovascular disease risk: a consensus statement from the American Society of Echocardiography Carotid Intima-Media Thickness Task Force. Endorsed by the Society for Vascular Medicine. J Am Soc Echocardiogr 2008;21:93-111; quiz 89-90.

24. Kasai T, Miyauchi K, Yanagisawa N, Kajimoto K, Kubota N, Ogita M, Tsuboi S, Amano A, Daida H. Mortality risk of triglyceride levels in patients with coronary artery disease. Heart 2013;99:22-9.

25. Pilz S, Horejsi R, Möller R, Almer G, Scharnagl H, Stojakovic T, Dimitrova R, Weihrauch G, Borkenstein M, Maerz W, Schauenstein K, Mangge H. Early atherosclerosis in obese juveniles is associated with low serum levels of adiponectin. J Clin Endocrinol Metab 2005;90:4792-6.

26. Ragino YI, Kashtanova EV, Chernjavski AM, Volkov AM, Polonskaya YV, Tsimbal SY, Eremenko NV, Ivanova MV. Blood level of osteonectin in stenosing atherosclerosis and calcinosis of coronary arteries. Bull Exp Biol Med 2011;151:370-3.

27. Johnson BD, Kip KE, Marroquin OC, Ridker PM, Kelsey SF, Shaw LJ, Pepine CJ, Sharaf B, Bairey Merz CN, Sopko G, Olson MB, Reis SE; National Heart, Lung, and Blood Institute. Serum amyloid A as a predictor of coronary artery disease and cardiovascular outcome in women: the National Heart, Lung, and Blood Institute-Sponsored Women's Ischemia Syndrome Evaluation (WISE). Circulation 2004;109:726-32.

28. Wilson AM, Kimura E, Harada RK, Nair N, Narasimhan B, Meng XY, Zhang F, Beck KR, Olin JW, Fung ET, Cooke JP. Beta2-microglobulin as a biomarker in peripheral arterial disease: proteomic profiling and clinical studies. Circulation 2007;116:1396-403.

29. Ardigo D, Assimes TL, Fortmann SP, Go AS, Hlatky M, Hytopoulos E, Iribarren C, Tsao PS, Tabibiazar R, Quertermous T; ADVANCE Investigators. Circulating chemokines accurately identify individuals with clinically significant atherosclerotic heart disease. Physiol Genomics 2007;31:402-9.

30. Mach F, Sauty A, larossi AS, Sukhova GK, Neote K, Libby P, Luster AD. Differential expression of three T lymphocyte-activating CXC chemokines by human atheroma-associated cells. J Clin Invest 1999;104: 1041-50.

31. Mansia G, De Backer G, Dominiczak A, Cifkova R, Fagard R, Germano G, Grassi G, Heagerty AM, Kjeldsen SE, Laurent S, Narkiewicz K, Ruilope L, Rynkiewicz A, Schmieder RE, Struijker Boudier HA, Zanchetti A; European Society of Hypertension; European Society of Cardiology. 2007 ESH-ESC Guidelines for the management of arterial hypertension: the task force for the management of arterial hypertension of the European Society of Hypertension (ESH) and of the European Society of Cardiology (ESC). Blood Press 2007; 16:135-232.

32. Lakka TA, Lakka HM, Salonen R, Kaplan GA, Salonen JT. Abdominal obesity is associated with accelerated progression of carotid atherosclerosis in men. Atherosclerosis 2001;154:497-504. 
33. Mihaylova B, Emberson J, Blackwell L, Keech A, Simes J, Barnes EH, Voysey M, Gray A, Collins R, Baigent C. The effects of lowering LDL cholesterol with statin therapy in people at low risk of vascular disease: meta-analysis of individual data from 27 randomised trials. Lancet 2012;380:581-90.

34. Enright PL, Kronmal RA, Smith VE, Gardin JM, Schenker MB, Manolio TA. Reduced vital capacity in elderly persons with hypertension, coronary heart disease, or left ventricular hypertrophy. The Cardiovascular Health Study. Chest 1995;107:28-35.

35. Johnston AK, Mannino DM, Hagan GW, Davis KJ, Kiri VA. Relationship between lung function impairment and incidence or recurrence of cardiovascular events in a middle-aged cohort. Thorax 2008;63:599-605.

36. Ridker PM, Rifai N, Rose L, Buring JE, Cook NR. Comparison of C-reactive protein and low-density lipoprotein cholesterol levels in the prediction of first cardiovascular events. N Engl J Med 2002;347: 1557-65.

37. Fyfe Al, Rothenberg LS, DeBeer FC, Cantor RM, Rotter JI, Lusis AJ. Association between serum amyloid A proteins and coronary artery disease: evidence from two distinct arteriosclerotic processes. Circulation 1997;96:2914-9.

38. Charo IF, Ransohoff RM. The many roles of chemokines and chemokine receptors in inflammation. $N$ Engl J Med 2006;354:610-21.

39. Miller M, Stone NJ, Ballantyne C, Bittner V, Criqui MH, Ginsberg HN, Goldberg AC, Howard WJ, Jacobson MS, Kris-Etherton PM, Lennie TA, Levi M, Mazzone T, Pennathur S. Triglycerides and cardiovascular disease: a scientific statement from the American Heart Association. Circulation 2011;123:2292-333.

40. Stefan N, Haring HU. The role of hepatokines in metabolism. Nat Rev Endocrinol 2013;9:144-52.

41. Ix JH, Wassel CL, Kanaya AM, Vittinghoff E, Johnson KC, Koster A, Cauley JA, Harris TB, Cummings SR, Shlipak MG; Health $A B C$ Study. Fetuin-A and incident diabetes mellitus in older persons. JAMA 2008;300:182-8.

42. Ix JH, Biggs ML, Mukamal KJ, Kizer JR, Zieman SJ, Siscovick DS, Mozzaffarian D, Jensen MK, Nelson L, Ruderman N, Djousse L. Association of fetuin-a with incident diabetes mellitus in community-living older adults: the cardiovascular health study. Circulation 2012;125:2316-22.

43. Pal D, Dasgupta S, Kundu R, Maitra S, Das G, Mukhopadhyay S, Ray S, Majumdar SS, Bhattacharya S. Fetuin-A acts as an endogenous ligand of TLR4 to promote lipid-induced insulin resistance. Nat Med 2012;18:1279-85.

44. Heinrichsdorff J, Olefsky JM. Fetuin-A: the missing link in lipid-induced inflammation. Nat Med 2012; 18:1182-3.

45. Guarneri M, Geraci C, Incalcaterra F, Arsena R, Mulè G, Vaccaro F, Luna C, Cerasola G, Cottone S. Subclinical atherosclerosis and fetuin-A plasma levels in essential hypertensive patients. Hypertens Res 2013;36:129-33.

46. Romme EA, Smeenk FW, Rutten EP, Wouters EF. Osteoporosis in chronic obstructive pulmonary disease. Expert Rev Respir Med 2013;7:397-410.

47. Zumrutdal A, Sezer S, Demircan S, Seydaoglu G, Ozdemir FN, Haberal M. Cardiac troponin I and beta 2 microglobulin as risk factors for early-onset atherosclerosis in patients on haemodialysis. Nephrology (Carlton) 2005;10:453-8.

48. Van Gaal LF, Mertens IL, De Block CE. Mechanisms linking obesity with cardiovascular disease. Nature 2006;444:875-80. 


\section{SUPPLEMENTAL MATERIAL}

Table S7.1 Model 1: Multivariate backward linear regression with c-IMT as the dependent variable including cardiovascular risk variables from Table 7.3.

\begin{tabular}{lccr}
\hline \multicolumn{4}{c}{ Multivariate backward linear regression with c-IMT as the dependent variable: } \\
Model $\mathrm{R}^{2} 28 \%$ \\
$\mathrm{n}=200$
\end{tabular}

Table S7.2 Model 2: Multivariate backward linear regression with c-IMT as the dependent variable including COPD specific variables from Table 7.3.

\begin{tabular}{|c|c|c|c|}
\hline \multicolumn{4}{|c|}{$\begin{array}{l}\text { Multivariate backward linear regression with c-IMT as the dependent variable: } \\
\qquad \begin{array}{l}\text { Model } R^{2}: 11 \% \\
n=200\end{array}\end{array}$} \\
\hline & Beta & $\mathrm{t}$ & $p$-value \\
\hline $\mathrm{FEV}_{1} \%$ predicted & -0.231 & -2.536 & 0.012 \\
\hline RV \% predicted & -0.237 & -2.810 & 0.005 \\
\hline DLCO \% predicted & 0.213 & 3.013 & 0.003 \\
\hline mMRC dyspnea score & 0.164 & 2.213 & 0.028 \\
\hline
\end{tabular}

$\mathrm{FEV}_{1}$ : forced expiratory volume in the first second; RV: residual volume, DLCO: diffusion capacity for carbon monoxide; mMRC: modified medical research council.

Table S7.3 Model 3: Multivariate backward linear regression with c-IMT as the dependent variable including the significant variables from model 1 and 2.

\begin{tabular}{|c|c|c|c|}
\hline \multicolumn{4}{|c|}{$\begin{array}{l}\text { Multivariate backward linear regression with c-IMT as the dependent variable: } \\
\qquad \begin{array}{l}\text { Model } R^{2} 31 \% \\
n=200\end{array}\end{array}$} \\
\hline & Beta & t-test & p-value \\
\hline Age, years & 0.232 & 3.8 & $<0.001$ \\
\hline Peripheral mean blood pressure, $\mathrm{mm} \mathrm{Hg}$ & 0.142 & 2.3 & 0.020 \\
\hline Body mass index, $\mathrm{kg} / \mathrm{m}^{2}$ & 0.452 & 7.4 & $<0.001$ \\
\hline $\mathrm{FEV}_{1}, \%$ predicted & -0.176 & -2.9 & 0.004 \\
\hline
\end{tabular}


Table S7.4 Model 4: Multivariate backward linear regression with c-IMT as the dependent variable including all biomarkers.

\begin{tabular}{|c|c|c|c|}
\hline \multicolumn{4}{|c|}{$\begin{array}{l}\text { Multivariate backward linear regression with c-IMT as the dependent variable: } \\
\qquad \begin{array}{l}\text { Model } \mathrm{R}^{2} 30 \% \\
\mathrm{n}=171\end{array}\end{array}$} \\
\hline Dependent variable $=\mathrm{c}$-IMT & Beta & t-test & $\mathrm{p}$-value \\
\hline Log C-reactive protein & 0.244 & 2.511 & 0.013 \\
\hline Log serum amyloid $A$ & -0.218 & -2.783 & 0.006 \\
\hline Log triglycerides & 0.181 & 2.623 & 0.010 \\
\hline Log fetuin A & -0.143 & -2.015 & 0.046 \\
\hline Log insulin growth factor binding protein 1 & -0.268 & -3.711 & $<0.001$ \\
\hline Log beta-2 microglobulin & 0.173 & 2.157 & 0.033 \\
\hline Log soluble intercellular adhesion molecule 1 & -0.275 & -2.689 & 0.008 \\
\hline Log soluble vascular cell adhesion protein 1 & 0.325 & 3.124 & 0.002 \\
\hline Log osteonectin & 0.129 & 1.784 & 0.076 \\
\hline Log osteoprotogerin & 0.142 & 1.873 & 0.063 \\
\hline Log monocyte chemo-attractant protein 4 & 0.148 & 2.108 & 0.037 \\
\hline
\end{tabular}

Table S7.5 Model 5: Multivariate backward linear regression with c-IMT as the dependent variable including the independent clinical predictors from model 3 and the independent biomarker predictors from model 4.

\begin{tabular}{|c|c|c|c|}
\hline \multicolumn{4}{|c|}{$\begin{array}{l}\text { Multivariate backward linear regression with c-IMT as the dependent variable: } \\
\qquad \begin{array}{l}\text { Model } \mathrm{R}^{2} 38 \% \\
\mathrm{n}=171\end{array}\end{array}$} \\
\hline & Beta & t-test & p-value \\
\hline Age, years & 0.283 & 4.388 & $<0.001$ \\
\hline Body mass index, $\mathrm{kg} / \mathrm{m}^{2}$ & 0.451 & 6.804 & $<0.001$ \\
\hline Peripheral mean blood pressure, $\mathrm{mm} \mathrm{Hg}$ & 0.163 & 2.530 & 0.012 \\
\hline $\mathrm{FEV}_{1}, \%$ predicted & -0.201 & -3.091 & 0.002 \\
\hline Log serum amyloid $\mathrm{A}$ & -0.143 & -2.145 & 0.033 \\
\hline Log osteonectin & 0.171 & 2.734 & 0.007 \\
\hline Log triglycerides & 0.111 & 1.698 & 0.091 \\
\hline
\end{tabular}





\section{CHAPTER 8

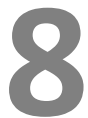

\section{Arterial stiffness in patients with COPD: the role of systemic inflammation and the effects of pulmonary rehabilitation}

Lowie E.G.W. Vanfleteren, Martijn A. Spruit, Miriam T.J. Groenen, Piet L.B. Bruijnzeel, Ziad Taib, Erica P.A, Rutten, Jos Op 't Roodt, Marco A. Akkermans, Emiel F.M. Wouters, Frits M.E. Franssen 


\section{ABSTRACT}

\section{Background}

Clear evidence for an association between systemic inflammation and increased arterial stiffness in patients with chronic obstructive pulmonary disease (COPD) is lacking. Moreover, the effects of pulmonary rehabilitation on arterial stiffness are not well studied.

\section{Aims}

We aimed to 1) confirm increased arterial stiffness in COPD; 2) evaluate its correlates including systemic inflammation; and 3) study whether or not it is influenced by pulmonary rehabilitation.

\section{Methods}

Aortic pulse-wave velocity (APWV) was determined in 168 healthy volunteers, and APWV and inflammatory markers were determined in 162 COPD patients during baseline evaluation of a pulmonary rehabilitation program. A complete post-pulmonary rehabilitation dataset was collected in 129 patients.

\section{Results}

It was found that APWV was increased in COPD patients when compared with controls, blood pressure and age predicted baseline APWV, and systemic inflammatory markers were not independently related to APWV. Although baseline APWV was predictive for the change in APWV after pulmonary rehabilitation $(r=-0.77)$, on average APWV did not change $(10.7 \pm 2.7$ versus $10.9 \pm 2.5 \mathrm{~m} / \mathrm{s} ; \mathrm{p}=0.339$ ).

\section{Conclusions}

Arterial stiffness in COPD is not related to systemic inflammation and does not respond to stateof-the art pulmonary rehabilitation. These results emphasize the complexity of cardiovascular risk and its management in COPD. 


\section{INTRODUCTION}

Chronic obstructive pulmonary disease (COPD) is considered a complex and heterogeneous condition affecting multiple organ systems. ${ }^{1}$ Indeed, cardiovascular disease is a major cause of death in COPD.,3 Persistent low-grade systemic inflammation has been suggested as the pathophysiological link between both diseases, ${ }^{4}$ but evidence is lacking.

Aortic pulse wave velocity (APWV), considered to be the gold standard for measuring central arterial stiffness, ${ }^{5}$ is an independent predictor of cardiovascular events and mortality $^{6}$ and is increased in patients with COPD. ${ }^{7,8}$ Arterial stiffness has been positively associated with levels of different systemic inflammatory markers in healthy individuals $^{9}$ and different patient populations. ${ }^{10,11}$ One COPD study showed weak correlations with interleukin (IL)-6 and soluble tumor necrosis factor receptor 1 (sTNFR1), but not with STNFR2. ${ }^{7}$

Exercise-based pulmonary rehabilitation (PR) seems to have a beneficial effect on arterial stiffness in patients with COPD. ${ }^{12,13}$ However, these results need to be confirmed in larger samples.

We sought to confirm increased arterial stiffness in patients with COPD referred for PR and to evaluate its determinants, including systemic inflammation. Moreover, we aimed to prospectively study the impact of a state-of-the-art PR program on APWV and other functional vascular outcomes.

\section{METHODS}

\section{STUDY DESIGN AND PATIENTS}

The CIRO comorbidity (CIROCO) study (approved by the local ethics and review boards (MEC 10-3-067)) was a 2-year prospective single-center study. Patients with COPD were recruited at the start of PR at $\mathrm{CIRO}+$ (Center of Expertise for Chronic Organ Failure, Horn, the Netherlands). Study design, inclusion and exclusion criteria and details of the assessments have been published. ${ }^{14}$ Briefly, in addition to comprehensive pre- and post-PR clinical assessment, patient's hemodynamic status was assessed: blood pressure, pulse pressure, pulse wave analysis and APWV (SphygmoCor; AtCor Medical, Sydney, Australia). APWV was measured by recording ECG-gated carotid and femoral artery waveforms. The Sphygmocor system software assured the quality of the pulse wave measurement. A detailed screen showed 10 seconds of recorded and analyzed waveforms, which can be examined to assess overall consistency of the waveforms. In 
addition, a detailed report helped to interpret the consistency of the waveforms during the 10 seconds measurement. A measurement was only retained when it met the predefined quality thresholds. After marking the exact location, measurements were repeated three times to secure reproducibility. A measurement was accepted when it was reproducible three times with minimal variation, as judged by the biomedical technologist. The retained APWV measurement was the mean of the three measurements.

Shortest distances from manubrium to the marked location on the femoral artery (via the navel) were measured. Wave transit time was calculated by the system software, using the R-wave of the simultaneously recording ECG as a reference frame. APWV was determined by dividing the distance between the two recording sites by the wave transit time. For baseline comparison, healthy never, former and current-healthy elderly smokers without airflow limitation underwent lung function tests and hemodynamic assessments as part of the ICE-AGEING (Individualized COPD Evaluation in relation to AGEing) study (MEC 10-3-033).

\section{PR PROGRAM}

CIRO+ provides a state-of-the-art interdisciplinary PR program for patients with COPD consisting of 40 sessions, in line with the latest official American Thoracic Society and European Respiratory Society statement on PR. ${ }^{15}$ During the baseline assessment a careful characterization of the extrapulmonary features and comorbidities of patients with COPD were performed, which determined the application of various treatments: physical exercise training, occupational therapy, dietary counseling, psychosocial counseling, education and exacerbation management. Physical exercise training was the cornerstone of the program, consisting of exercises to strengthen groups of muscle in the upper and lower extremities, treadmill walking and stationary cycling. All exercises were performed at moderate to high intensity to obtain an overload stimulus. Moreover, the training intensity increased during the rehabilitation period, based on dyspnea and fatigue symptom scores. All patients underwent flexibility exercises, general physical exercise for lower and upper extremities, and daily supervised 30-min outdoor walks.

\section{STATISTICAL ANALYSIS}

Statistics were performed using SPSS version 19.0 (SPSS Inc., Chicago, IL, USA). Results are expressed as mean \pm standard deviation or count (\%). For comparison, Chi-squared tests, independent samples t-test, paired t-test or ANOVA were used where applicable. Relationships between continuous variables were analysed using simple and/or multivariate linear regression. Figure 8.1 was obtained using SAS version 9.1 (SAS Institute Inc., Cary, NC, USA). More precisely, a model was constructed for change in 
APWV including the covariates: sex, age, body mass index (BMI), mean blood pressure, and APWV at baseline. Only fixed effects were used, as baseline APWV was included as a covariate and only two time-points were observed. Males aged 60 years with a BMI of $25 \mathrm{~kg} / \mathrm{m}^{2}$, mean blood pressure of $100 \mathrm{mmHg}$, and a baseline APWV level of $10 \mathrm{~m} / \mathrm{s}$ were the reference group. All $p$-values $<0.05$ were considered statistically significant.
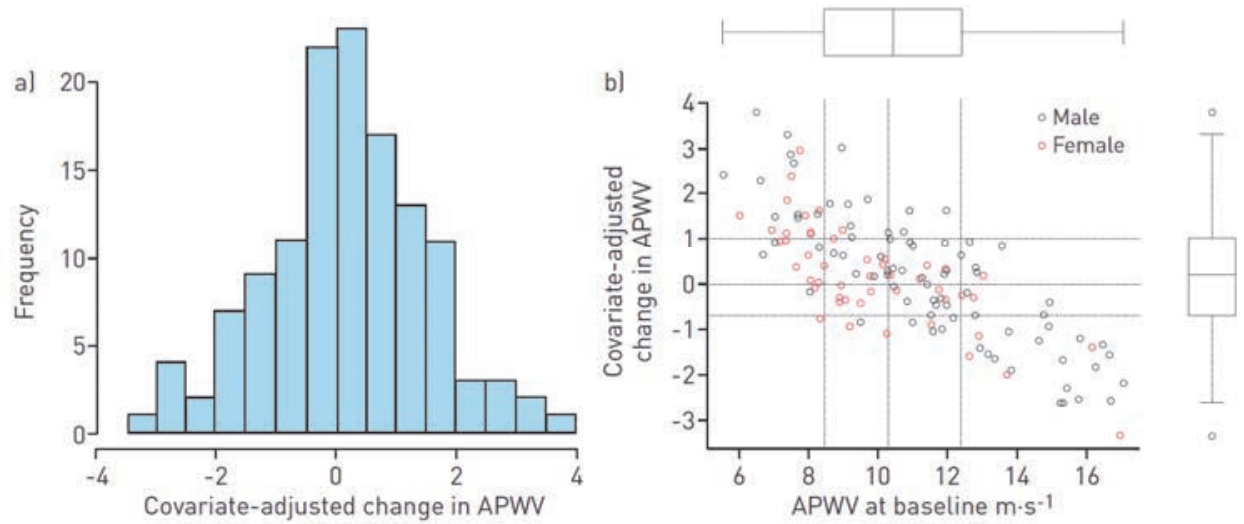

Figure 8.1 Covariate adjusted change in APWV after PR in function of baseline APWV level.

Change in APWV is adjusted for age, mean blood pressure, gender and BMI. a) shows the distribution of the change in APWV after PR. b) shows the change in APWV after PR in function of the baseline APWV level for men (black circles) and women (red circles). (Correlation: $r=-0.773, p<0.001)$.

\section{RESULTS}

\section{SUBJECTS}

Of 255 prospectively recruited patients, 42 (16.5\%) were ineligible (Supplemental Figure S8.1). 51 (23.9\%) of the 213 eligible COPD patients were excluded because of unsuccessful APWV measurements at baseline. Patients with unsuccessful APWV measurements had a significantly higher BMI, fat-free mass index (FFMI), triglycerides, glucose, diffusing capacity of the lung for carbon monoxide (DLCO), and estimated glomerular filtration rate compared with those with successful measurements (Supplemental Table S8.1). A total of 162 subjects with successful baseline assessment started PR. Of these, nine (5.6\%) subjects dropped out from the study before the end of the PR program (Supplemental Figure S8.1). In 24 (15.7\%) subjects, APWV measurements failed following PR. These subjects did not significantly differ from subjects with two successful APWV measurements in terms of baseline characteristics and PR outcome. Therefore, 129 patients with COPD had full data before and after PR. 


\section{BASELINE CHARACTERISTICS}

On average, the study sample consisted of older patients with a substantial smoking history, moderate to severe COPD, and impaired diffusion capacity, but normal arterial blood gases (Table 8.1). Almost one-third of the patients were active smokers, while $14 \%$ of the patients were on long-term oxygen therapy. Patients generally had normal $\mathrm{BMI}$ and FFMI. Most patients reported a necessity to stop while walking at their own pace.

About one-third of the patients had self-reported cardiovascular comorbidity. Subjects generally had a high normal blood pressure and resting heart rate. Other baseline measurements and inflammatory biomarkers are shown in Table 8.1.

The majority of the patients used long-acting anticholinergics and/or combined inhaled corticosteroids and long-acting beta-agonists (Supplemental Tables S8.2 and S8.3). Moreover, $40 \%$ of the patients used one or more blood pressure lowering drugs and almost 35\% used lipid lowering drugs.

Characteristics of the healthy controls, stratified for smoking history are also shown in Table 8.1. These healthy-control subjects are slightly younger and had slightly higher $\mathrm{BMI}$ and FFMI when compared with the patients with COPD. As, by definition, pulmonary function is normal in these subjects, these subjects used less antihypertensive medication and fewer anxiolytics, antidepressives, calcium supplementation, bisphosphonates or antacids when compared with the COPD patients (Supplemental Table S8.3).

\section{HEMODYNAMIC MEASUREMENT IN COPD PATIENTS AND HEALTHY CONTROLS}

Patients with COPD had a significantly higher APWV compared with never smoking and ex-smoking controls (Table 8.2). Consistently, central augmentation index (normalized for a heart rate of 75 beats per min) was higher in subjects with COPD compared with both control groups. Ex-smoking controls had a higher peripheral and central blood pressure compared with COPD patients. Although peripheral pulse pressure is higher in ex-smoking controls, central pulse pressure is higher in COPD patients. COPD patients have a significantly higher heart rate compared with both control groups (Table 8.2). 
Table 8.1 Baseline characteristics of subjects with COPD and controls.

\begin{tabular}{|c|c|c|c|}
\hline & $\begin{array}{l}\text { COPD } \\
\mathrm{n}=162\end{array}$ & $\begin{array}{l}\begin{array}{c}\text { Never smoking controls } \\
\mathrm{n}=65\end{array} \\
\end{array}$ & $\begin{array}{l}\text { Ex-smoking controls } \\
n=102\end{array}$ \\
\hline \multicolumn{4}{|l|}{ Demographics } \\
\hline Age, years & $63.8 \pm 6.9$ & $57.9 \pm 8.1^{*}$ & $61.4 \pm 6.7^{*} \#$ \\
\hline Male, n (\%) & $97(59.9 \%)$ & $31(47.0 \%)^{*}$ & $47(45.6 \%)^{*}$ \\
\hline Active smoker, n (\%) & $47(29.0)$ & 0 & 0 \\
\hline Long-term oxygen therapy, n (\%) & $22(13.6)$ & 0 & 0 \\
\hline Pack years & $45.9 \pm 27.3$ & $0 \pm 0$ & $15.4 \pm 14.4^{*}$ \\
\hline \multicolumn{4}{|l|}{ Body composition } \\
\hline Body mass index, $\mathrm{kg} / \mathrm{m}^{2}$ & $25.0 \pm 4.1$ & $26.7 \pm 3.9^{*}$ & $27.6 \pm 3.8^{*}$ \\
\hline Fat Free Mass Index, $\mathrm{kg} / \mathrm{m}^{2}$ & $16.6 \pm 2.1$ & $17.6 \pm 2.4^{*}$ & $17.9 \pm 2.4^{*}$ \\
\hline Bone mineral density, T-score & $-1.1 \pm 1.3$ & - & - \\
\hline \multicolumn{4}{|l|}{ Pulmonary function } \\
\hline $\mathrm{FEV}_{1}$, liter & $1.40 \pm 0.55$ & $3.4 \pm 0.9 *$ & $3.3 \pm 0.9^{*}$ \\
\hline $\mathrm{FEV}_{1}, \%$ predicted & $51.4 \pm 17.4$ & $119.6 \pm 14.8^{*}$ & $119.2 \pm 17.7^{*}$ \\
\hline $\mathrm{FEV}_{1} / \mathrm{FVC}, \%$ & $39,5 \pm 11,1$ & $78.0 \pm 5.0 *$ & $78.0 \pm 8.4^{*}$ \\
\hline DLCO, \% predicted & $53.8 \pm 16.7$ & $95.8 \pm 12.3^{*}$ & $91.7 \pm 17.7^{*}$ \\
\hline \multicolumn{4}{|l|}{ Blood gases } \\
\hline $\mathrm{PaCO}_{2}, \mathrm{kPa}$ & $5.3 \pm 0.6$ & & \\
\hline $\mathrm{PaO}_{2}, \mathrm{kPa}$ & $9.5 \pm 1.1$ & & \\
\hline $\mathrm{O}_{2}$ saturation, $\%$ & $94.4 \pm 7.6$ & & \\
\hline \multicolumn{4}{|l|}{ Functional outcome } \\
\hline 6-MWD, meter & $475 \pm 108$ & & \\
\hline CWRT time, seconds & $359 \pm 284$ & & \\
\hline Leg press, kg & $101 \pm 47$ & & \\
\hline mMRC, grade & $2.1 \pm 1.1$ & & \\
\hline SGRQ, points & $51.6 \pm 18.4$ & & \\
\hline Charlson comorbidy index & $1.57 \pm 0.89$ & & \\
\hline Myocardial infarction, n (\%) & $16(9.9)$ & & \\
\hline Heart failure, n (\%) & $5(3.1)$ & & \\
\hline Peripheral arterial disease, $\mathrm{n}(\%)$ & $30(18.5)$ & & \\
\hline Cerebrovascular disease, $\mathrm{n}(\%)$ & $14(8.6)$ & & \\
\hline Any cardiovascular disease, $\mathrm{n}(\%)$ & $50(30.9)$ & & \\
\hline Diabetes, $\mathrm{n}(\%)$ & $7(4.3)$ & & \\
\hline \multicolumn{4}{|l|}{ Clinical chemistry } \\
\hline Triglycerides, $\mathrm{mmol} / \mathrm{l}$ & $1.5 \pm 0.7$ & & \\
\hline $\mathrm{LDL}, \mathrm{mmol} / \mathrm{l}$ & $2.9 \pm 1.0$ & & \\
\hline $\mathrm{HDL}, \mathrm{mmol} / \mathrm{l}$ & $1.7 \pm 0.5$ & & \\
\hline Glucose (mmol/l) & $5.7 \pm 0.7$ & & \\
\hline Creatinin & $87.5 \pm 22.6$ & & \\
\hline eGFR, $\mathrm{ml} / \mathrm{min}$ & $75.9 \pm 21.5$ & & \\
\hline \multicolumn{4}{|l|}{ Systemic inflammatory markers } \\
\hline $\mathrm{CRP}, \mathrm{mg} / \mathrm{l}$ & $4,6 \pm 6,1$ & & \\
\hline IL-6, pgs/ml & $3.3 \pm 4.5$ & & \\
\hline IL-8, pgs/ml & $13.0 \pm 5.3$ & & \\
\hline sTNFR1, pgs/ml & $2186 \pm 771$ & & \\
\hline sTNFR2, pgs/ml & $3714 \pm 1435$ & & \\
\hline Leucocytes $* 10^{9} / /$ & $7.5 \pm 2.0$ & & \\
\hline
\end{tabular}

Summary variables are presented as mean \pm standard deviation for quantitative variables, and count (percentage) for discrete variables. $\mathrm{FEV}_{1}=$ forced expiratory volume in the first second; $\mathrm{DLCO}=$ diffusion factor for carbon monoxide; $m M R C=$ modified medical research council; $6 \mathrm{MWD}=$ six minute walking distance; $C W R T=$ continuous work rate test; $S G R Q=S t$-George's respiratory questionnaire, BODE index: Based on BMI, obstruction $\left(\mathrm{FEV}_{1}\right)$, dyspnea, exercise $(6 \mathrm{MWD})$; $\mathrm{LDL}=$ low density lipoprotein; $\mathrm{HDL}=$ high density lipoprotein; eGFR=estimated glomerular filtration rate; $C R P=C$-reactive protein; IL-6=interleukin 6; IL-8=interleukin 8; sTNFR1=soluble tumor necrosis factor- $\alpha$ receptor 1 ; sTNFR2=soluble tumor necrosis factor- $\alpha$ receptor 2 . * significantly $(p<0.05)$ different in comparison with subjects with COPD. \# significantly $(p<0.05)$ different in comparison with never-smoking controls. 
Table 8.2 Hemodynamic measurements at baseline of subjects with COPD and controls.

\begin{tabular}{lccc}
\hline Hemodynamic measurements & COPD & $\begin{array}{c}\text { Never smoking } \\
\text { controls } \\
(\mathrm{n}=65)\end{array}$ & $\begin{array}{c}\text { Ex-smoking } \\
\text { controls } \\
(\mathrm{n}=102)\end{array}$ \\
\hline Aortic pulse wave velocity, $\mathrm{m} / \mathrm{s}$ & $1 \mathrm{n}=162)$ & $8.7 \pm 2.2^{*}$ & $9.0 \pm 2.9^{*}$ \\
Central augmentation index, \% & $31.2 \pm 8.6$ & $24.6 \pm 8.1^{*}$ & $26.7 \pm 9.4^{*}$ \\
Peripheral systolic pressure, $\mathrm{mm} \mathrm{Hg}$ & $137 \pm 21$ & $141 \pm 17$ & $146 \pm 21^{*}$ \\
Peripheral diastolic pressure, mm Hg & $82 \pm 10$ & $84 \pm 8$ & $85 \pm 9^{*}$ \\
Peripheral mean pressure, mm Hg & $102 \pm 13$ & $105 \pm 11$ & $108 \pm 13^{*}$ \\
Peripheral pulse pressure, mm Hg & $55 \pm 16$ & $57 \pm 13$ & $61 \pm 16^{*}$ \\
Heart Rate, beats per minute & $68 \pm 11$ & $58 \pm 8^{*}$ & $59 \pm 8^{*}$ \\
Central systolic pressure, mm Hg & $129 \pm 20$ & $133 \pm 16$ & $138 \pm 21^{*}$ \\
Central diastolic pressure, mm Hg & $83 \pm 10$ & $85 \pm 9$ & $86 \pm 9^{*}$ \\
Central mean pressure, mm Hg & $102 \pm 13$ & $105 \pm 11$ & $108 \pm 13^{*}$ \\
Central pulse pressure, $\mathrm{mm} \mathrm{Hg}$ & $45.9 \pm 15.0$ & $45.5 \pm 13$ & $44.5 \pm 11^{*}$ \\
\hline
\end{tabular}

* significantly $(p<0.05)$ different in comparison with subjects with COPD; \# significantly $(p<0.05)$ different in comparison with never-smoking controls.

\section{DETERMINANTS OF APWV IN COPD}

APWV did not correlate with systemic levels of leukocytes, C-reactive protein (CRP), IL-6, IL-8 or STNFR2. A weak but statistically significant correlation was found between APWV and sTNFR1. After adjusting for age, mean blood pressure, sex and BMI none of the systemic inflammatory markers were associated with APWV (Table 8.3). Moreover, in a multivariate, backward linear-regression model, including all assessed demographics and clinical variables, only blood pressure $(b=0.380, t$-test $=4.515$; $p<0.001)$ and age $(b=0.376$, t-test $=3.283 ; p=0.001)$ were independently associated with APWV. The systemic inflammatory markers, as well as DLCO, forced expiratory volume in 1 second as percentage of predicted, bone mineral density T-score, BMI, lipids, blood glucose, renal function and smoking status did not explain the variance in baseline APWV in patients with COPD (Supplemental Table S8.4).

Table 8.3 Simple and multivariate linear regression with APWV as the dependent variable.

\begin{tabular}{|c|c|c|c|c|c|c|c|}
\hline & \multicolumn{3}{|c|}{ Simple linear regression } & \multicolumn{4}{|c|}{ Multivariate linear regression* } \\
\hline & Beta & t-test & $\mathrm{p}$-value & Beta & t-test & p-value & $\begin{array}{l}\mathrm{F} \text { change of } \\
\text { the model \# }\end{array}$ \\
\hline CRP, ngs/ml & 0.134 & 1.584 & 0.116 & 0.098 & 1.325 & 0.187 & -6.044 \\
\hline IL-6, pgs/ml & 0.065 & 0.761 & 0.448 & 0.017 & 0.231 & 0.818 & -6.477 \\
\hline IL-8, pgs/ml & 0.101 & 1.192 & 0.235 & 0.101 & 1.357 & 0.177 & -6.165 \\
\hline sTNFR1, pgs/ml & 0.171 & 2.034 & 0.044 & 0.064 & 0.791 & 0.430 & -6.373 \\
\hline sTNFR2, pgs/ml & 0.126 & 1.488 & 0.139 & -0.013 & -0.165 & 0.869 & -6.472 \\
\hline Leucocytes $* 10^{9} / \mathrm{I}$ & 0.043 & 0.547 & 0.585 & 0.022 & 0.327 & 0.744 & -3.185 \\
\hline
\end{tabular}

* adjusting for age, mean blood pressure, gender and BMI. CRP=C-reactive protein, sTNFR1=soluble tumor necrosis factor- $\alpha$ receptor 1 , sTNFR2=soluble tumor necrosis factor- $\alpha$ receptor 2, IL-6=interleukin 6; IL-8= interleukin 8. \# F of the model with age, mean blood pressure, gender and $\mathrm{BMI}=15.66$. 


\section{EFFECTS OF PULMONARY REHABILITATION}

The following parameters all improved significantly when compared with baseline: 6-min walking distance (from $478 \pm 108$ to $509 \pm 102 \mathrm{~m}$ ), cycle endurance (from $371 \pm 275$ to $569 \pm 396 \mathrm{~s}$ ), muscle strength (leg press, from $103 \pm 48$ to $128 \pm 50 \mathrm{~kg}$ ), health status (St George's Respiratory Questionnaire, from 52.0 \pm 19.9 to $48.2 \pm 18.7$ points) and dyspnea grade (modified Medical Research Council grade $2.1 \pm 1.2$ to $1.54 \pm 1.0$ points) (Supplemental Table S8.5). BMI did not change after PR in overweight and obese patients ( $n=65,28.5 \pm 2.6$ versus $\left.28.5 \pm 2.7 \mathrm{~kg} / \mathrm{m}^{2} ; p=0.744\right)$. In underweight patients $(n=23), B M I$ increased significantly $\left(18.7 \pm 1.5\right.$ versus $\left.19.4 \pm 1.3 \mathrm{~kg} / \mathrm{m}^{2} ; \mathrm{p}<0.001\right)$. The systemic inflammatory markers, lipids, fasting glucose and leukocytes did not change following PR (Supplemental Table S8.6).

APWV, central or peripheral blood pressure, or augmentation index did not change following PR, while peripheral- and central-pulse pressure increased (Figure 8.2). A statistically significant, but most probably clinically irrelevant, reduction in cardiac frequency was seen (Table 8.4). Also, after stratification of the study sample in different relevant subgroups, no changes in APWV were noticed after PR (Table 8.5).

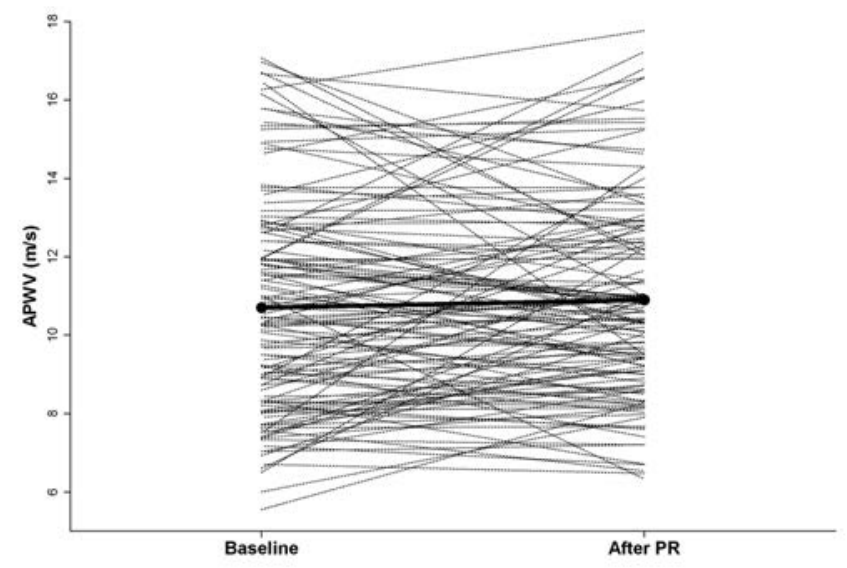

Figure 8.2 Data plot for aortic pulse wave velocity (APWV) in each patient before and after pulmonary rehabilitation. Circles and solid line represent the mean.

The change in APWV following PR was negatively correlated $(r=-0.77, p<0.001)$ with the level of APWV at baseline, after adjustment for baseline age, average blood pressure, sex and BMI in a linear fixed effects model (Figure 8.1). Interestingly, subjects with a low baseline APWV ( $<8 \mathrm{~m} / \mathrm{s}$ (25th percentile of the study sample)) whose APWV values increased by at least $0.5 \mathrm{~m} / \mathrm{s}$ after PR $(n=19)$ and patients with a high baseline APWV (12.5 $\mathrm{m} / \mathrm{s}$ (75th percentile of the study sample)) whose APWV values decreased at least 
$0.5 \mathrm{~m} / \mathrm{s}(\mathrm{n}=15)$ were not different with respect to baseline clinical characteristics, systemic inflammation or PR outcome.

Table 8.4 Differences in APWV and other hemodynamics in subjects who completed PR.

\begin{tabular}{lccc}
\hline $\mathrm{N}=129$ & Baseline & After PR & $\mathrm{p}$ \\
\hline Aortic pulse wave velocity, $\mathrm{m} / \mathrm{s}$ & $10.7 \pm 2.7$ & $10.9 \pm 2.5$ & 0.339 \\
Central augmentation index, \% & $30.8 \pm 8.1$ & $30.2 \pm 8.1$ & 0.129 \\
Peripheral systolic pressure, $\mathrm{mm} \mathrm{Hg}$ & $135 \pm 19$ & $137 \pm 19$ & 0.064 \\
Peripheral diastolic pressure, $\mathrm{mm} \mathrm{Hg}$ & $81 \pm 9$ & $81 \pm 9$ & 0.377 \\
Peripheral mean pressure, mm Hg & $101 \pm 12$ & $101 \pm 12$ & 0.427 \\
Peripheral pulse pressure, mm Hg & $54 \pm 15$ & $57 \pm 15$ & 0.004 \\
Heart Rate, beats per minute & $68 \pm 11$ & $67 \pm 11$ & 0.032 \\
Central sytolic pressure, mm Hg & $127 \pm 18$ & $129 \pm 19$ & 0.061 \\
Central diastolic pressure, mm Hg & $82 \pm 9$ & $82 \pm 9$ & 0.386 \\
Central mean pressure, mm Hg & $101 \pm 12$ & $101 \pm 12$ & 0.428 \\
Central pulse pressure, mm Hg & $44 \pm 14$ & $47 \pm 14$ & 0.003 \\
\hline
\end{tabular}

Variables are presented as mean \pm standard deviation.

Table 8.5 Difference in APWV after PR in different subgroups.

\begin{tabular}{|c|c|c|c|c|}
\hline & $\mathrm{n}$ & $\begin{array}{c}\text { APWV } \\
\text { baseline }\end{array}$ & $\begin{array}{c}\text { APWV } \\
\text { after PR }\end{array}$ & $\mathrm{p}$ \\
\hline Overweight and obese & $\mathrm{n}=65$ & $10.9 \pm 2.7$ & $11.2 \pm 2.3$ & 0.315 \\
\hline Underweight & $n=23$ & $10.3 \pm 2.8$ & $10.4 \pm 3.2$ & 0.830 \\
\hline No blood pressure lowering medication & $\mathrm{n}=79$ & $10.5 \pm 2.6$ & $10.7 \pm 2.4$ & 0.383 \\
\hline No lipid lowering drugs & $n=92$ & $10.5 \pm 2.7$ & $10.7 \pm 2.4$ & 0.209 \\
\hline No cardiovascular medical history according to the $\mathrm{CCl}$ & $n=60$ & $10.3 \pm 2.6$ & $10.6 \pm 2.5$ & 0.232 \\
\hline No blood pressure lowering or lipid lowering drugs & $n=69$ & $10.4 \pm 2.7$ & $10.7 \pm 2.5$ & 0.340 \\
\hline No cardiovascular medical history according to the $\mathrm{CCl}$ & $n=60$ & $10.3 \pm 2.6$ & $10.6 \pm 2.5$ & 0.232 \\
\hline \multicolumn{5}{|l|}{ No blood pressure lowering medication and no lipid lowering } \\
\hline drugs and no cardiovascular medical history according to $\mathrm{CCl}$ & $n=60$ & $10.3 \pm 2.6$ & $10.6 \pm 2.5$ & 0.244 \\
\hline Active smokers & $n=35$ & $10.5 \pm 2.9$ & $10.3 \pm 2.5$ & 0.593 \\
\hline Ex-smokers & $n=94$ & $10.8 \pm 2.7$ & $11.1 \pm 2.5$ & 0.151 \\
\hline Men & $\mathrm{n}=80$ & $11.2 \pm 2.8$ & $11.5 \pm 2.7$ & 0.520 \\
\hline Women & $n=49$ & $9.8 \pm 2.4$ & $10.0 \pm 1.8$ & 0.417 \\
\hline Improvement of $>50 \mathrm{~m}$ in $6 \mathrm{MWD}$ and $>4$ points on SGRQ & $n=25$ & $10.4 \pm 2.7$ & $10.4 \pm 1.9$ & 0.954 \\
\hline Normal blood pressure (<140/90 mm Hg) & $n=79$ & $10.0 \pm 2.5$ & $10.2 \pm 2.4$ & 0.395 \\
\hline Hypertensives (>140/90 mm Hg) & $n=49$ & $11.8 \pm 2.7$ & $12.0 \pm 2.3$ & 0.585 \\
\hline
\end{tabular}

Variables are presented as mean \pm standard deviation. CCI: Charlson comorbidity index; SGRQ: St. George Respiratory Questionnaire.

\section{DISCUSSION}

The main findings of this study are as follows. First, central arterial stiffness is increased in a large sample of subjects with COPD compared with healthy controls, and variance in arterial stiffness is partially determined by age and resting blood pressure. Secondly, markers of systemic inflammation do not explain the variance in arterial stiffness in 
COPD. Thirdly, although patients with COPD improved on conventional rehabilitation outcomes, arterial stiffness generally does not change following PR.

\section{ARTERIAL STIFFNESS IN COPD}

Cardiovascular disease is common in patients with COPD and affects prognosis. ${ }^{16}$ Moreover, patients with COPD have stiffer arteries compared with healthy control subjects. ${ }^{7,17}$ The current study corroborates these findings. Surprisingly, blood pressure and pulse pressure were higher in ex-smoking controls. This is probably due to less use of antihypertensive therapy in healthy subjects.

Arterial stiffness has been proposed as a mechanistic link between COPD and cardiovascular disease. ${ }^{18}$ Increasing arterial stiffness alters arterial pressure and flow dynamics and impacts cardiac performance and coronary perfusion with consequent cardiovascular disease. ${ }^{19}$ Arterial stiffness is thought to be the result of a remodeling process with elastin fragmentation and collagen replacement in the extracellular matrix. ${ }^{19}$ A systemic susceptibility to lung, skin and arterial degradation of elastin and extracellular matrix remodeling has been suggested in patients with an emphysematous phenotype of COPD. ${ }^{20}$ Indeed, McAllister et al. ${ }^{21}$ showed a positive correlation between arterial stiffness and high-resolution computed tomography (HRCT)-quantified emphysema in 77 COPD patients. HRCT was not available in our study, but DLCO (as another surrogate for pulmonary emphysema) was not associated with APWV. Although DLCO and computed tomography-quantified emphysema have shown to be only moderately correlated, ${ }^{22}$ the discrepancy in these surrogates for pulmonary emphysema is intriguing as the populations in both studies are quite similar regarding demographics and clinical characteristics.

Also, vascular calcification may have a role in arterial stiffness in COPD, as it is inversely associated with bone mineral density in the general population, ${ }^{23}$ and osteoporosis is highly prevalent in COPD. Indeed, Sabit et al. ${ }^{7}$ showed the highest arterial stiffness in nine emphysematous patients with osteoporosis at the hip, compared with 62 emphysematous subjects without osteoporosis. However, these differences were not found for the 13 subjects with osteoporosis of the spine and total T-score was not reported in that study.

In contrast, in the present study, total body bone mineral density T-score did not independently predict APWV, suggesting that this association might be more complex than assumed at present. Moreover, multivariate analysis indicated only increasing age and higher blood pressure to be independent predictors of increased arterial stiffness. This is comparable to the general population and multiple other patients groups, as was recently systematically reviewed. ${ }^{24}$ 


\section{ARTERIAL STIFFNESS AND SYSTEMIC INFLAMMATION}

Increased levels of systemic inflammatory markers (leukocytes, CRP, tumor necrosis factor-alpha, IL-6 and IL-8) have been reported in COPD, ${ }^{25}$ and several of these have been associated with subclinical atherosclerosis ${ }^{26}$ and ischemic heart disease. ${ }^{27}$ Similar to Sabit et al. ${ }^{7}$, we found a univariate association between APWV and sTNFR1, but we could not confirm the association with IL-6. However, IL-6 was reported to be significantly associated with APWV in a multivariate regression; although this needs to be interpreted with caution, as the control subjects were also included in the regression analysis. In our study, the multivariate model only included patients with COPD.

Systemic inflammation is thought to accelerate and stimulate the vascular extracellular matrix remodeling process of elastin fragmentation and collagen deposition, resulting in arterial stiffness. ${ }^{19}$ However, evidence for a causal relationship between low-grade systemic inflammation and a high incidence of cardiovascular disease in COPD is lacking. In addition, studies showed comparable circulating levels of inflammatory biomarkers in COPD patients with and without cardiovascular disease. ${ }^{28}$ Furthermore, it was recently shown that systemic inflammation does not affect all patients with COPD. Only $16 \%$ of patients in the Evaluation of COPD Longitudinally to Identify Predictive Surrogate Endpoints (ECLIPSE) cohort had long-term systemic inflammation, while onethird of the patients in this cohort did not have systemic inflammation at all during a 1 year follow-up. ${ }^{29}$ Interestingly, increasing age and having an overweight to obese BMI were independent risk factors for systemic inflammation in the ECLIPSE study, whereas self-reported cardiovascular disease was not. Also, in the present study, systemic inflammatory markers were not independent from traditional cardiovascular risk factors associated with arterial stiffness.

\section{ARTERIAL STIFFNESS AND PULMONARY REHABILITATION}

Endurance-trained athletes have higher large-artery compliance than do their sedentary counterparts, ${ }^{30}$ and training improves arterial stiffness in healthy young ${ }^{31}$ and elderly subjects. ${ }^{32,33}$ However, the effects of exercise training on arterial stiffness in elderly patient populations are contradictory. ${ }^{34-38}$ This issue is further complicated by the heterogeneity among studies in modality, frequency and duration of exercise training, and in the assessment method for arterial stiffness.

Vivodtzev et al. ${ }^{12}$ were the first to show significant improvements in brachial pulse wave velocity in 10 patients with COPD who underwent a 4-week aerobic endurance training program. Peripheral (brachial) muscular arteries are more susceptible to modification by exercise training than central (aortic) elastic arteries. ${ }^{39}$ Indeed aortic stiffening is more attributable to elastin degradation and is largely irreversible. ${ }^{40}$ Moreover, APWV is the gold standard for measurement of arterial stiffness as it predicts cardiovascular events and mortality in different populations. Gale et al. ${ }^{13}$ showed a small, but 
significant, reduction in APWV in an observational study of 32 patients with COPD following an outpatient-based thrice-weekly PR program including endurance training and resistance training. However, the change in APWV following PR was highly variable. We confirmed the variability of the change in APWV after PR but we were not able to confirm a significant reduction in APWV; even though the number of subjects, the number of PR sessions and baseline APWV were higher in the present study and subjects generally improved on classical rehabilitation outcomes.

There are several possible explanations for this lack of response. Mechanisms underlying arterial stiffness with age, such as elastin degradation, are likely to be enhanced and accelerated in patients with COPD and are unlikely to be influenced by a PR program of limited duration.

Furthermore, the possible effects of exercise training on arterial stiffness might be influenced by a patient's concurrent pharmacological treatment. Cardiovascular medication ${ }^{41}$ and combination therapy of inhaled corticosteroids and long-acting betaagonists (inhaled corticosteroids or long-acting beta-agonists) ${ }^{42}$ may decrease arterial stiffness and the majority of subjects use these medications chronically. However, nonsignificant changes in APWV were observed in patients who were not known to have cardiovascular disease or were untreated with cardiovascular medication. Earlier studies suggested that sex $^{43}$ smoking status, body composition and systemic hypertension could play a role in the effect of exercise on arterial stiffness, but none were found to significantly influence changes in arterial stiffness following PR.

The exercise modalities may explain the lack of decrease in arterial stiffness. In marked contrast to the beneficial effect of aerobic training in healthy younger individuals, it was shown that resistance training increases arterial stiffness in young healthy males. ${ }^{44,45}$ Similar opposite effects of endurance and resistance training on arterial stiffness were seen in a study in hypertensive patients. ${ }^{46}$ In patients with type 2 diabetes, an increased APWV was seen after 2 years of endurance and resistance training. ${ }^{39}$

Thus, resistance training may have outweighed the effects of endurance training on arterial stiffness. The increase in pulse pressure, which has been considered to be a key feature of arterial stiffening, may be an outcome related to resistance training. Importantly, short-term progressive resistance exercise can lead to appreciable increases in muscle strength for people with COPD, which may carry over to the performance of some daily activities. ${ }^{47}$ Indeed, the combination of constantload/interval and strength training is recommended in state-of-the-art PR to treat peripheral muscle dysfunction in chronic respiratory disease, because it results in combined improvements in exercise capacity and muscle strength. Nevertheless, it would be interesting to compare the effect of endurance versus resistance training on APWV in patients with COPD. 
Baseline arterial stiffness correlated very well with the change in arterial stiffness after $P R$, even after adjustment for possible confounders, such as age, blood pressure, sex and BMI. It is unclear whether and to what extent this correlation could be explained by statistical bias (regression to the mean). Still, the finding is interesting and worth discussing, as the correlation was highly significant. Moreover, in a study evaluating the effect of fluticasone propionate/salmeterol on arterial stiffness in patients with COPD, a decrease in APWV was only seen in patients with a baseline APWV belonging to the highest baseline tertile of the study sample. ${ }^{42}$ However, it is noticeable that patients at both extremes (decreasers with high baseline stiffness versus increasers with low baseline stiffness) did not differ in terms of disease severity, health status, age, BMI or systemic inflammation. This confirms that arterial stiffness and its change cannot be predicted by these clinical outcomes. It is of note that we did not identify other studies that evaluated differences in characteristics of responders and nonresponders in terms of arterial stiffness and exercise programs.

A limitation of this study is the lack of a nonexercising COPD control group. Although, it seems reasonable to speculate that APWV does not change during 8 weeks of usual care, a nonexercising COPD control group would have been desirable. A second limitation is the absence of a direct reproducibility analysis at the baseline of the study. Nevertheless, we are confident in the quality and reproducibility of the data in our study, given the strict quality control criteria (see Methods section). Moreover, two recent studies specifically addressed reproducibility of APWV measurements in COPD and found that this was highly reproducible and not affected by lung hyperinflation. ${ }^{48,49}$

A third limitation is that HRCT would have been preferable to evaluate emphysema against arterial stiffness. Finally, heterogeneity among the included COPD patients may have blunted any effects of PR on arterial stiffness. However, phenotyping of patients was extensive and the large number of patients in this study allowed for poststratification.

In conclusion, central arterial stiffness is increased in subjects with COPD and determined by blood pressure and age. Systemic inflammation does not explain the variance in APWV. Furthermore, although subjects improved on classic rehabilitation outcomes, arterial stiffness is resistant to modification through a state-of-the-art PR program in patients with COPD in general and in different subgroups. Nevertheless, baseline arterial stiffness did strongly predict the change in stiffness after PR in individual patients. Ultimately, this is a negative study that conflicts with the conventional knowledge that arterial stiffness may be attributed to systemic inflammation and may be a modifiable disease-specific cardiovascular risk factor in COPD. At the same time, this is the largest study performed in COPD in this field. 


\section{REFERENCES}

1. Spruit MA, Pennings HJ, Janssen PP, Does JD, Scroyen S, Akkermans MA, Mostert R, Wouters EF. Extrapulmonary features in COPD patients entering rehabilitation after stratification for MRC dyspnea grade. Respir Med 2007;101:2454-63.

2. Huiart L, Ernst P, Suissa S. Cardiovascular morbidity and mortality in COPD. Chest 2005;128:2640-6.

3. Curkendall SM, DeLuise C, Jones JK, Lanes S, Stang MR, Goehring E Jr, She D. Cardiovascular disease in patients with chronic obstructive pulmonary disease, Saskatchewan Canada cardiovascular disease in COPD patients. Ann Epidemiol 2006;16:63-70.

4. Barnes PJ, Celli BR. Systemic manifestations and comorbidities of COPD. Eur Respir J 2009;33:1165-85.

5. Mansia G, De Backer G, Dominiczak A, Cifkova R, Fagard R, Germano G, Grassi G, Heagerty AM, Kjeldsen SE, Laurent S, Narkiewicz K, Ruilope L, Rynkiewicz A, Schmieder RE, Struijker Boudier HA, Zanchetti A; European Society of Hypertension; European Society of Cardiology. 2007 ESH-ESC Guidelines for the management of arterial hypertension: the task force for the management of arterial hypertension of the European Society of Hypertension (ESH) and of the European Society of Cardiology (ESC). Blood Press 2007;16:135-232.

6. Cavalcante JL, Lima JA, Redheuil A, Al-Mallah MH. Aortic stiffness: current understanding and future directions. J Am Coll Cardiol 2011;57:1511-22.

7. Sabit R, Bolton CE, Edwards PH, Pettit RJ, Evans WD, McEniery CM, Wilkinson IB, Cockcroft JR, Shale DJ. Arterial stiffness and osteoporosis in chronic obstructive pulmonary disease. Am J Respir Crit Care Med 2007;175:1259-65.

8. Maclay JD, McAllister DA, Mills NL, Paterson FP, Ludlam CA, Drost EM, Newby DE, Macnee W. Vascular dysfunction in chronic obstructive pulmonary disease. Am J Respir Crit Care Med 2009;180:513-20.

9. Yasmin, McEniery CM, Wallace S, Mackenzie IS, Cockcroft JR, Wilkinson IB. C-reactive protein is associated with arterial stiffness in apparently healthy individuals. Arterioscler Thromb Vasc Biol 2004; 24:969-74.

10. Kocyigit I, Kaya MG, Orscelik O, Kaya C, Akpek M, Zengin H, Sipahioglu MH, Unal A, Yilmaz MI, Tokgoz B, Oymak $\mathrm{O}$, Axelsson J. Early arterial stiffness and inflammatory bio-markers in normotensive polycystic kidney disease patients. Am J Nephrol 2012;36:11-8.

11. Yiu KH, Yeung CK, Chan HT, Wong RM, Tam S, Lam KF, Yan GH, Yue WS, Chan HH, Tse HF. Increased arterial stiffness in patients with psoriasis is associated with active systemic inflammation. $\mathrm{Br} J$ Dermatol 2011;164:514-20.

12. Vivodtzev I, Minet C, Wuyam B, Borel JC, Vottero G, Monneret D, Baguet JP, Lévy P, Pépin JL. Significant improvement in arterial stiffness after endurance training in patients with COPD. Chest 2010;137: 585-92.

13. Gale NS, Duckers JM, Enright S, Cockcroft JR, Shale DJ, Bolton CE. Does pulmonary rehabilitation address cardiovascular risk factors in patients with COPD? BMC Pulm Med 2011; 11: 20.

14. Vanfleteren LE, Spruit MA, Groenen M, Gaffron S, van Empel VP, Bruijnzeel PL, Rutten EP, Op 't Roodt J, Wouters EF, Franssen FM. Clusters of comorbidities based on validated objective measurements and systemic inflammation in patients with chronic obstructive pulmonary disease. Am J Respir Crit Care Med 2013;187:728-35.

15. Spruit MA, Singh SJ, Garvey C, ZuWallack R, Nici L, Rochester C, Hill K, Holland AE, Lareau SC, Man WD, Pitta F, Sewell L, Raskin J, Bourbeau J, Crouch R, Franssen FM, Casaburi R, Vercoulen JH, Vogiatzis I, Gosselink R, Clini EM, Effing TW, Maltais F, van der Palen J, Troosters T, Janssen DJ, Collins E, GarciaAymerich J, Brooks D, Fahy BF, Puhan MA, Hoogendoorn M, Garrod R, Schols AM, Carlin B, Benzo R, Meek P, Morgan M, Rutten-van Mölken MP, Ries AL, Make B, Goldstein RS, Dowson CA, Brozek JL, Donner CF, Wouters EF; ATS/ERS Task Force on Pulmonary Rehabilitation. An official American Thoracic Society/European Respiratory Society statement: key concepts and advances in pulmonary rehabilitation. Am J Respir Crit Care Med 2013;188:e13-64.

16. Divo M, Cote C, de Torres JP, Casanova C, Marin JM, Pinto-Plata V, Zulueta J, Cabrera C, Zagaceta J, Hunninghake G, Celli B; BODE Collaborative Group. Comorbidities and risk of mortality in patients with chronic obstructive pulmonary disease. Am J Respir Crit Care Med 2012;186:155-61. 
17. Maclay JD, McAllister DA, Macnee W. Cardiovascular risk in chronic obstructive pulmonary disease. Respirology 2007;12:634-41.

18. Macnee W, Maclay J, McAllister D. Cardiovascular injury and repair in chronic obstructive pulmonary disease. Proc Am Thorac Soc 2008;5:824-33.

19. Zieman SJ, Melenovsky V, Kass DA. Mechanisms, pathophysiology, and therapy of arterial stiffness. Arterioscler Thromb Vasc Biol 2005;25:932-43.

20. Maclay JD, McAllister DA, Rabinovich R, Haq I, Maxwell S, Hartland S, Connell M, Murchison JT, van Beek EJ, Gray RD, Mills NL, Macnee W. Systemic elastin degradation in chronic obstructive pulmonary disease. Thorax 2012; 67: 606-12.

21. McAllister DA, Maclay JD, Mills NL, Mair G, Miller J, Anderson D, Newby DE, Murchison JT, Macnee W. Arterial stiffness is independently associated with emphysema severity in patients with chronic obstructive pulmonary disease. Am J Respir Crit Care Med 2007; 176: 1208-14.

22. Lamers RJ, Thelissen GR, Kessels AG, Wouters EF, van Engelshoven JM. Chronic obstructive pulmonary disease: evaluation with spirometrically controlled CT lung densitometry. Radiology 1994; 193: 109-13.

23 Schulz E, Arfai K, Liu X, Sayre J, Gilsanz V. Aortic calcification and the risk of osteoporosis and fractures. $J$ Clin Endocrinol Metab 2004; 89: 4246-53.

24 Cecelja M, Chowienczyk P. Dissociation of aortic pulse wave velocity with risk factors for cardiovascular disease other than hypertension: a systematic review. Hypertension 2009; 54: 1328-36.

25 Gan WQ, Man SF, Senthilselvan A, Sin DD. Association between chronic obstructive pulmonary disease and systemic inflammation: a systematic review and a meta-analysis. Thorax 2004; 59: 574-80.

26 Iwamoto H, Yokoyama A, Kitahara Y, Ishikawa N, Haruta Y, Yamane K, Hattori N, Hara H, Kohno N. Airflow limitation in smokers is associated with subclinical atherosclerosis. Am J Respir Crit Care Med 2009;179:35-40.

27 Sin DD, Man SF. Why are patients with chronic obstructive pulmonary disease at increased risk of cardiovascular diseases? The potential role of systemic inflammation in chronic obstructive pulmonary disease. Circulation 2003;107:1514-9.

28 Mills NL, Miller JJ, Anand A, et al. Increased arterial stiffness in patients with chronic obstructive pulmonary disease: a mechanism for increased cardiovascular risk. Thorax 2008;63:306-11.

29 Agustí A, Edwards LD, Rennard SI, MacNee W, Tal-Singer R, Miller BE, Vestbo J, Lomas DA, Calverley PM, Wouters E, Crim C, Yates JC, Silverman EK, Coxson HO, Bakke P, Mayer RJ, Celli B; Evaluation of COPD Longitudinally to Identify Predictive Surrogate Endpoints (ECLIPSE) Investigators. Persistent systemic inflammation is associated with poor clinical outcomes in COPD: a novel phenotype. PloS One 2012;7:e37483.

30 Vaitkevicius PV, Fleg JL, Engel JH, O'Connor FC, Wright JG, Lakatta LE, Yin FC, Lakatta EG. Effects of age and aerobic capacity on arterial stiffness in healthy adults. Circulation 1993;88:1456-62.

31 Currie KD, Thomas SG, Goodman JM. Effects of short-term endurance exercise training on vascular function in young males. Eur J Appl Physiol 2009;107:211-8.

32 Fujimoto N, Prasad A, Hastings JL, Arbab-Zadeh A, Bhella PS, Shibata S, Palmer D, Levine BD. Cardiovascular effects of 1 year of progressive and vigorous exercise training in previously sedentary individuals older than 65 years of age. Circulation 2010;122: 1797-805.

33 Vogel T, Leprêtre PM, Brechat PH, Lonsdorfer-Wolf E, Kaltenbach G, Lonsdorfer J, Benetos A. Effect of a short-term intermittent exercise-training program on the pulse wave velocity and arterial pressure: a prospective study among 71 healthy older subjects. Int J Clin Pract 2013;67:420-6.

34 Oliveira NL, Ribeiro F, Alves AJ, Campos L, Oliveira J. The effects of exercise training on arterial stiffness in coronary artery disease patients: a state-of-the-art review. Clin Physiol Funct Imaging 2014;34: 254-62.

35 Kitzman DW, Brubaker PH, Herrington DM, Morgan TM, Stewart KP, Hundley WG, Abdelhamed A, Haykowsky MJ. Effect of endurance exercise training on endothelial function and arterial stiffness in older patients with heart failure and preserved ejection fraction: a randomized, controlled, single-blind trial. J Am Coll Cardiol 2013;62:584-92.

36 Dobrosielski DA, Gibbs BB, Ouyang P, Bonekamp S, Clark JM, Wang NY, Silber HA, Shapiro EP, Stewart KJ. Effect of exercise on blood pressure in type 2 diabetes: a randomized controlled trial. J Gen Intern Med 2012;27:1453-9. 
37 Croymans DM, Krell SL, Oh CS, Katiraie M, Lam CY, Harris RA, Roberts CK. Effects of resistance training on central blood pressure in obese young men. J Hum Hypertens 2014; 28: 157-64.

38 Mihaescu A, Avram C, Bob F, Gaita D, Schiller O, Schiller A. Benefits of exercise training during hemodialysis sessions: a prospective cohort study. Nephron Clin Pract 2013;124:72-8.

39 Loimaala A, Groundstroem K, Rinne M, Nenonen A, Huhtala H, Parkkari J, Vuori I. Effect of long-term endurance and strength training on metabolic control and arterial elasticity in patients with type 2 diabetes mellitus. Am J Cardiol 2009; 103:972-7.

40 O'Rourke MF, Hashimoto J. Arterial stiffness: a modifiable cardiovascular risk factor? J Cardiopulm Rehabil Prev 2008;28:225-37.

41 Duprez DA. Is vascular stiffness a target for therapy? Cardiovasc Drugs Ther 2010;24:305-10.

42 Dransfield MT, Cockcroft JR, Townsend RR, Coxson HO, Sharma SS, Rubin DB, Emmett AH, Cicale MJ, Crater GD, Martinez FJ. Effect of fluticasone propionate/salmeterol on arterial stiffness in patients with COPD. Respir Med 2011;105:1322-30.

43 Collier SR. Sex differences in the effects of aerobic and anaerobic exercise on blood pressure and arterial stiffness. Gend Med 2008;5:115-23.

44 Miyachi M, Kawano H, Sugawara J, Takahashi K, Hayashi K, Yamazaki K, Tabata I, Tanaka H. Unfavorable effects of resistance training on central arterial compliance: a randomized intervention study. Circulation 2004;110:2858-63.

45 Bertovic DA, Waddell TK, Gatzka CD, Cameron JD, Dart AM, Kingwell BA. Muscular strength training is associated with low arterial compliance and high pulse pressure. Hypertension 1999;33:1385-91.

46 Collier SR, Kanaley JA, Carhart R Jr, Frechette V, Tobin MM, Hall AK, Luckenbaugh AN, Fernhall B. Effect of 4 weeks of aerobic or resistance exercise training on arterial stiffness, blood flow and blood pressure in pre- and stage-1 hypertensives. J Hum Hypertens 2008;22:678-86.

47 O'Shea SD, Taylor NF, Paratz JD. Progressive resistance exercise improves muscle strength and may improve elements of performance of daily activities for people with COPD: a systematic review. Chest 2009;136:1269-83.

48 Stone IS, John L, Petersen SE, Barnes NC. Reproducibility of arterial stiffness and wave reflections in chronic obstructive pulmonary disease: the contribution of lung hyperinflation and a comparison of techniques. Respir Med 2013;107:1700-8.

49 Vivodtzev I, Minet C, Tamisier R, Arbib F, Borel JC, Baguet JP, Lévy P, Pépin JL. Arterial stiffness by pulse wave velocity in COPD: reliability and reproducibility. Eur Respir J 2013;42:1140-2. 


\section{SUPPLEMENTAL MATERIAL}

\section{METHODS}

\section{STUDY DESIGN AND PATIENTS}

The current analysis was based on data collected as part of the CIRO CO-morbidity (CIROCO) study, a longitudinal observational single-center study. ${ }^{1}$ All subjects provided written informed consent and the study was approved by the local ethics and review board of Maastricht University Medical Center (MEC 10-3-067). Patients with moderate to very severe COPD (Global Initiative for Obstructive Lung Disease [GOLD] grades II to $\mathrm{IV}^{2}$ ), aged 40 to 80 years and in a clinically stable state were prospectively recruited between November 2007 and November 2010 during the initial evaluation of a comprehensive pulmonary rehabilitation program at CIRO+. ${ }^{3}$ Patients with a history of asthma, alpha-1 antitrypsin deficiency, any previous lung surgery, active inflammatory disease, acute myocardial infarction within the last 6 months, any known bone disease other than osteoporosis, current or recently (i.e. $<5$ years prior to the study) treated malignant disease or a high daily dose of systemic glucocorticosteroids (i.e. $>10 \mathrm{mg}$ prednisolone) were excluded from the study.

Participants demographics, smoking history and use of long-term oxygen therapy were recorded. Furthermore, patients' medical history and current pharmacological treatment was documented based on medical and pharmaceutical charts and selfreport.

\section{ASSESSMENT}

\section{Pulmonary function and arterial blood gases}

Lung function parameters: post-bronchodilator forced expiratory volume in the first second, $\left(F V_{1}\right)$ and forced vital capacity (FVC), using standardized spirometry (MasterScreen ${ }^{\circledR}$ Body, Carefusion, Germany) and diffusicon capacity for carbon monoxide (DLCO) using the single breath hold method (MasterScreen ${ }^{\circledR}$ Body, Carefusion, Germany) were determined in all patients.

The degree of severity of airflow limitation was classified according to the GOLD guidelines. ${ }^{4}$ Resting arterial $\mathrm{pH}$, arterial oxygen tension ( $\left.\mathrm{PaO} 2\right)$, arterial carbon dioxide tension ( $\mathrm{PaCO} 2)$, and oxygen saturation ( $\mathrm{SaO} 2)$ were analyzed with a blood gas analyzer (Radiometer ABL 330, Copenhagen, Denmark).

\section{Body composition analyses}

Body height was measured to the nearest $0.5 \mathrm{~cm}$. Body weight was assessed by using an electronic beam scale with digital readout to the nearest $0.1 \mathrm{~kg}$ after emptying the 
bladder and with the subjects standing barefoot and wearing light indoor clothing. BMI was calculated as body weight/height ${ }^{2}$. Fat free mass (FFM) has been assessed using an overnight-fasting bioelectrical impedance assessment (Bodystat ${ }^{\circledR}$, United Kingdom). FFM index (FFMI) was calculated as FFM in kilogram divided by squared height in meters. ${ }^{5}$ Whole-body bone mineral density (BMD) was determined using a Dual-energy $X$-ray Absorptiometry (DEXA) scan (Lunar Prodigy ${ }^{\circledR}$, Ge-Lunar).

\section{Exercise capacity}

Exercise capacity has been assessed with six minute walking distance (6MWD), cycling endurance time measured during a continuous submaximal constant work rate test (CWRT). 6-MWD was performed according to published guidelines including a practice walk. Best 6MWD was used for further analyses. ${ }^{6}$ Cycling endurance to a symptomlimited maximum was determined with a constant-load exercise test on a cycle ergometer at a work rate equal to $75 \%$ of the previously determined maximal power $\left(\mathrm{CWRT}^{7}\right)$. Patients were instructed to exercise for as long as possible. They were told to stop exercise only when dyspnea became intolerable or the required pedaling rate $(60 / \mathrm{min}$.) could not be kept up due to leg fatigue. If exercise endurance exceeded 20 minutes, the observer terminated the test.

\section{Lower-limb muscle strength}

Peripheral muscle strength was measured with 1-repetition maximum using bilateral leg press exercises (Technogym SpA, Gambettola, Italy). ${ }^{8}$

\section{Dyspnea}

Self-perceived dyspnea in relation to physical disability has been assessed by using the MRC dypnea scale. ${ }^{9}$

\section{Health status: Saint George Respiratory Questionnaire}

To assess disease-specific health status, the St. George Respiratory Questionnaire (SGRQ) has been used. ${ }^{10}$ The SGRQ is a self-administered questionnaire, designed for measurement of health impairment in patients with COPD. The SGRQ consists of 50 items, divided in three domains (symptoms, activities and impact), providing three domain scores. A total score is also provided. Scores can range from 0 (optimal) to 100 points (worst).

\section{Laboratory analysis}

A venous blood sample was collected from all patients in the fasted state. Serum samples were stored at $-80^{\circ} \mathrm{C}$ prior to their analysis. Leucocytes, high density lipoprotein (HDL), low density lipoprotein ( $L D L)$, triglycerides, glucose and creatinin were determined in all subjects. Glomerular filtration rate was estimated using the Cockroft and Gault formula. Measurement of the inflammatory serum markers was carried out on the MSD multiplex platform (Meso Scale Discovery, Gaithersburg, 
Maryland) using a preformatted panel to measure C-reactive protein (CRP) and validated, custom made arrays to determine the levels of interleukins 6 (IL-6) and 8 (IL-8) and tumor necrosis factor- $\alpha$ receptors 1 and 2 (sTNFR1, sTNFR2).

\section{HEMODYNAMICS}

Subjects were studied sober in early morning time by a trained medical technologist, blinded for clinical outcomes. All tests were performed after 15 minutes in a resting supine position. A small head pillow was accepted. Peripheral blood pressure was measured three times with interval of 5 minutes. Mean values and pulse pressure were calculated. Radial artery waveforms were recorded with a high-fidelity micromanometer (Millar Instruments, Houston, TX.). Pulse wave analysis (SphygmoCor; AtCor Medical, Sydney, Australia) was then used to generate a corresponding central waveform, using a validated transfer function. ${ }^{11}$ With the integrated software of the pulse wave analysis, augmentation index was calculated as the difference between the second and first systolic peaks and expressed in percentage of the pulse pressure. In order to control for the influence of heart rates on Aix, the integrated software normalized Aix to a heart rate of 75 beats per minute. APWV was measured by recording ECG-gated carotid and femoral artery waveforms. The Sphygmocor systems software helped to assure the quality of the pulse wave measurement. A detailed screen showed 10 seconds of recorded and analyzed waveforms which can be examined to assess overall consistency of the waveforms. In addition a detailed report helped to interpret the consistency of the waveforms during the 10 seconds measurement. Only when the pulse height and diastolic variation is less than $5 \%$, the average pulse height is more than 100 units, the augmentation index is less than $50 \%$, $\mathrm{T} 1$ is between 80 and $150 \mathrm{~ms}$ and the overall "quality index" is above 80 points data were retained.

After marking the exact location measurement were repeated three times for securing reproducibility. A measurement was accepted when it was three times reproducible with minimal variation as judged by the biomedical technologist. The retained APWV was the mean of the three measurements.

Shortest distances from manubrium to the marked location on the femoral artery (via the navel) were measured. Wave transit time was calculated by the system software, using the R-wave of the simultaneously recording electrocardiography as reference frame. APWV was determined by dividing the distance between the two recording sites by the wave transit time.

\section{PULMONARY REHABILITATION PROGRAM}

$\mathrm{CIRO}+$ provides a state-of-the-art interdisciplinary pulmonary rehabilitation program for patients with COPD, consisting of 40 sessions. The CIRO+ program is in line with the latest ATS/ERS Statement on Pulmonary Rehabilitation. ${ }^{12}$ 
The rehabilitation scheme was based on a comprehensive pre-rehabilitation assessment. $^{3}$ During the baseline assessment a careful characterization of the extrapulmonary features and co-morbidities of patients with COPD was performed (as described above), which determined the application of various treatments: physical exercise training, occupational therapy, dietary counseling, psychosocial counseling, education and exacerbation management.

Physical exercise training was the cornerstone of the program, consisting of strengthening exercises of muscle groups of the upper and lower extremities, treadmill walking and stationary cycling. All exercises were performed at moderate to high intensity to obtain an overload stimulus. Moreover, the training intensity increased during the rehabilitation period, based on dyspnea and fatigue symptom scores. For those patients unable to undergo high-intensity exercise training due to severe exercise-induced dyspnea, neuromuscular electrical stimulation of the lower-limb muscles was used. All patients underwent flexibility exercises, general physical exercise for lower and upper extremities, and daily supervised 30-min outdoor walks.

\section{STATISTICS}

Statistics were performed using SPSS version 19.0. Results are expressed as mean \pm standard deviation for quantitative variables, and count (percentage) for discrete variables. Discrete variables were compared using Chi square tests. Quantitative variables were compared using independent samples Student's $t$-test. A paired Student's $t$-test was used to investigate differences in results before and after PR. In order to examine the association of inflammatory markers with APWV, simple linear regression was used with APWV as the dependent variable and all inflammatory markers separately. To adjust the associations for a priori identified cardiovascular risk factors, multivariate linear regression was performed, adjusting each inflammatory marker for age, mean blood pressure, gender and BMI using forced entry method. In order to evaluate the determinants of APWV multivariate backward linear regression was performed, with APWV as the dependent variable and including all assessed characteristics (see legend Table S8.4) in the model. All p values $<0.05$ were considered statistically significant. Figure 8.2 and 8.3, showing the change of APWV and other clinical outcomes after PR as a function of baseline APWV and the correlation between these two, was obtained using SAS 9.1. More precisely the PROC MIXED procedures in SAS was used to model the change in APWV adjusting for age, mean blood pressure, gender and BMI. 


\section{REFERENCES}

1. Vanfleteren LE, Spruit MA, Groenen M, Gaffron S, van Empel VP, Bruijnzeel PL, Rutten EP, Op 't Roodt J, Wouters EF, Franssen FM. Clusters of comorbidities based on validated objective measurements and systemic inflammation in patients with chronic obstructive pulmonary disease. Am J Respir Crit Care Med 2013;187:728-35.

2. Vestbo J, Hurd SS, Agustí AG, Jones PW, Vogelmeier C, Anzueto A, Barnes PJ, Fabbri LM, Martinez FJ, Nishimura M, Stockley RA, Sin DD, Rodriguez-Roisin R. Global Strategy for the Diagnosis, Management, and Prevention of Chronic Obstructive Pulmonary Disease: GOLD Executive Summary. Am J Respir Crit Care Med 2013;187:347-65.

3. Spruit MA, Vanderhoven-Augustin I, Janssen PP, Wouters EF. Integration of pulmonary rehabilitation in COPD. Lancet 2008;371:12-3.

4. Vestbo J, Hurd SS, Agustí AG, Jones PW, Vogelmeier C, Anzueto A, Barnes PJ, Fabbri LM, Martinez FJ, Nishimura M, Stockley RA, Sin DD, Rodriguez-Roisin R Global Strategy for the Diagnosis, Management and Prevention of Chronic Obstructive Pulmonary Disease, GOLD Executive Summary. Am J Respir Crit Care Med 2013;187:347-65.

5. Schols AM, Wouters EF, Soeters PB, Westerterp KR. Body composition by bioelectrical-impedance analysis compared with deuterium dilution and skinfold anthropometry in patients with chronic obstructive pulmonary disease. Am J Clin Nutr 1991;53:421-4.

6. ATS statement: guidelines for the six-minute walk test. Am J Respir Crit Care Med 2002;166:111-7.

7. van 't Hul A, Gosselink R, Kwakkel G. Constant-load cycle endurance performance: test-retest reliability and validity in patients with COPD. J Cardiopulm Rehabil 2003;23:143-50.

8. Spruit MA, Gosselink R, Troosters T, De Paepe K, Decramer M. Resistance versus endurance training in patients with COPD and peripheral muscle weakness. Eur Respir J 2002;19:1072-8.

9. Spruit MA, Pennings HJ, Janssen PP, Does JD, Scroyen S, Akkermans MA, Mostert R, Wouters EF. Extrapulmonary features in COPD patients entering rehabilitation after stratification for MRC dyspnea grade. Respir Med 2007;101:2454-63.

10. Jones PW, Quirk FH, Baveystock CM, Littlejohns P. A self-complete measure of health status for chronic airflow limitation. The St. George's Respiratory Questionnaire. Am Rev Respir Dis 1992;145:1321-7.

11. Pauca AL, O'Rourke MF, Kon ND. Prospective evaluation of a method for estimating ascending aortic pressure from the radial artery pressure waveform. Hypertension 2001;38:932-7.

12. Spruit MA, Singh SJ, Garvey C, ZuWallack R, Nici L, Rochester C, Hill K, Holland AE, Lareau SC, Man WD, Pitta F, Sewell L, Raskin J, Bourbeau J, Crouch R, Franssen FM, Casaburi R, Vercoulen JH, Vogiatzis I, Gosselink R, Clini EM, Effing TW, Maltais F, van der Palen J, Troosters T, Janssen DJ, Collins E, GarciaAymerich J, Brooks D, Fahy BF, Puhan MA, Hoogendoorn M, Garrod R, Schols AM, Carlin B, Benzo R, Meek P, Morgan M, Rutten-van Mölken MP, Ries AL, Make B, Goldstein RS, Dowson CA, Brozek JL, Donner CF, Wouters EF; ATS/ERS Task Force on Pulmonary Rehabilitation. An official american thoracic society/european respiratory society statement: key concepts and advances in pulmonary rehabilitation. Am J Respir Crit Care Med 2013;188:e13-64. 


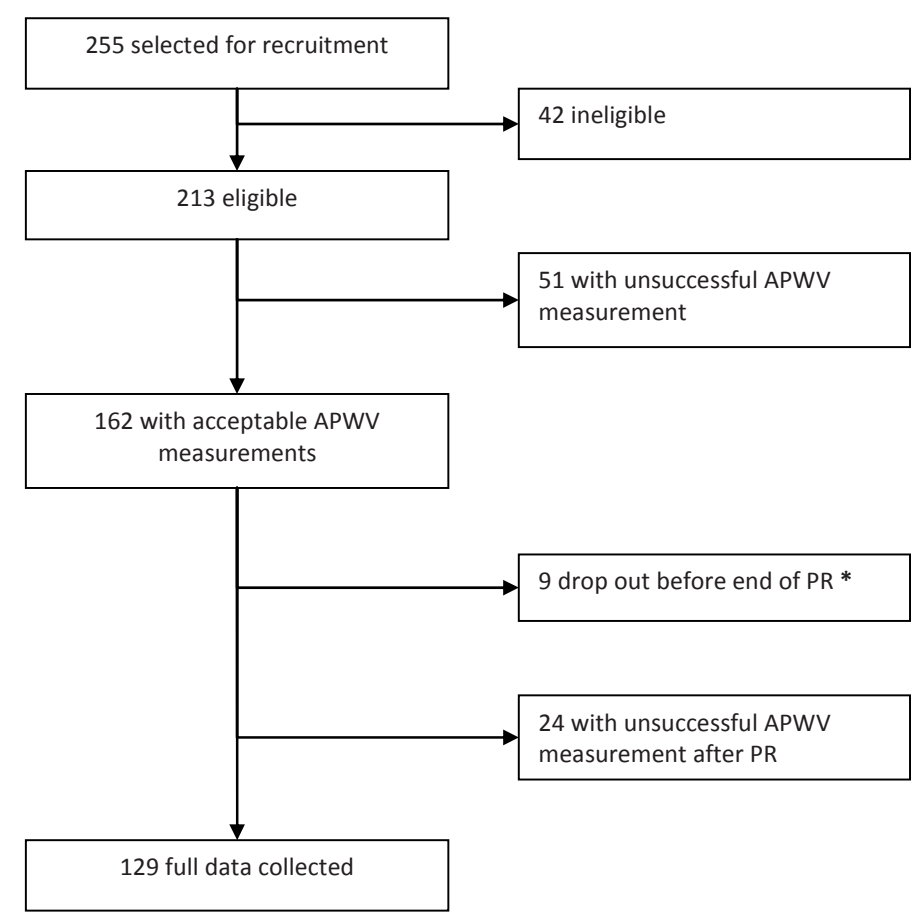

Figure S8.1 Flow chart of study participants.

* 4 patients did not want to participate in the study anymore, 1 patient died, 1 patient was diagnosed with a tongue carcinoma, one patient stopped because of personal circumstances and 3 patients dropped out because the rehabilitation program was too heavy. 
Table S8.1 Characteristics of subjects with and without successful APWV measurement at baseline.

\begin{tabular}{|c|c|c|c|}
\hline & $\begin{array}{l}\text { APWV not present } \\
n=51\end{array}$ & $\begin{array}{c}\text { APWV present } \\
n=162\end{array}$ & $\mathrm{p}$ \\
\hline \multicolumn{4}{|l|}{ Demographics } \\
\hline Age, years & $63.1 \pm 7.3$ & $63.8 \pm 6.9$ & 0.540 \\
\hline Male, n (\%) & $29(56.9 \%)$ & 97 (59.9\%) & 0.70 \\
\hline Active smoker, n (\%) & $13(25.5)$ & $47(29.0)$ & 0.383 \\
\hline Long-term oxygen therapy, n (\%) & $14(27.5)$ & $22(13.6)$ & 0.021 \\
\hline Pack years & $47.2 \pm 19.9$ & $45.9 \pm 27.3$ & 0.750 \\
\hline \multicolumn{4}{|l|}{ Body composition } \\
\hline Body mass index, $\mathrm{kg} / \mathrm{m}^{2}$ & $30.0 \pm 6.0$ & $25.0 \pm 4.1$ & $<0.001$ \\
\hline Fat Free Mass Index, $\mathrm{kg} / \mathrm{m}^{2}$ & $18.3 \pm 2.8$ & $16.6 \pm 2.1$ & $<0.001$ \\
\hline T-score & $-0.8 \pm 1.3$ & $-1.1 \pm 1.3$ & 0.220 \\
\hline \multicolumn{4}{|l|}{ Pulmonary function and blood gases } \\
\hline $\mathrm{FEV}_{1}$, liter & $1.37 \pm 0.50$ & $1.40 \pm 0.55$ & 0.762 \\
\hline $\mathrm{FEV}_{1}, \%$ predicted & $50.5 \pm 15.1$ & $51.4 \pm 17.4$ & 0.730 \\
\hline $\mathrm{FEV}_{1} / \mathrm{FVC}, \%$ & $40,9 \pm 11,0$ & $39,5 \pm 11,1$ & 0.427 \\
\hline DLCO, \% predicted & $61.3 \pm 15.1$ & $53.8 \pm 16.7$ & 0.005 \\
\hline $\mathrm{pCO}_{2}, \mathrm{kPa}$ & $5.5 \pm 0.7$ & $5.3 \pm 0.6$ & 0.067 \\
\hline $\mathrm{pO}_{2}, \mathrm{kPa}$ & $9.4 \pm 1.1$ & $9.5 \pm 1.1$ & 0.770 \\
\hline $\mathrm{O}_{2}$ saturation, $\%$ & $94.7 \pm 2.0$ & $94.4 \pm 7.6$ & 0.770 \\
\hline \multicolumn{4}{|l|}{ Functional outcome } \\
\hline 6-MWD, meter & $457 \pm 102$ & $475 \pm 108$ & 0.310 \\
\hline CWRT time, seconds & $334 \pm 220$ & $359 \pm 284$ & 0.560 \\
\hline Leg press, kg & $116 \pm 47$ & $101 \pm 47$ & 0.058 \\
\hline mMRC, grade & $2.1 \pm 1.1$ & $2.1 \pm 1.1$ & 0.880 \\
\hline SGRQ, points & $50.4 \pm 14.6$ & $51.6 \pm 18.4$ & 0.680 \\
\hline \multicolumn{4}{|l|}{ Prognostic indices } \\
\hline Updated BODE index, points & $2.9 \pm 2.6$ & $2.9 \pm 2.5$ & 0.920 \\
\hline Framingham CHD 10 year risk, \% & $9.6 \pm 7.2$ & $9.4 \pm 6.4$ & 0.243 \\
\hline Charlson comorbidy index & $1.61 \pm 0.80$ & $1.57 \pm 0.89$ & 0.809 \\
\hline Myocardial infarction, n (\%) & $6(11.8)$ & $16(9.9)$ & 0.437 \\
\hline Heart failure, n (\%) & $1(2.0)$ & $5(3.1)$ & 0.558 \\
\hline Peripheral arterial disease, $\mathrm{n}(\%)$ & $6(11.8)$ & $30(18.5)$ & 0.183 \\
\hline Cerebrovascular disease, n (\%) & $6(11.8)$ & $14(8.6)$ & 0.336 \\
\hline Any cardiovascular disease, n (\%) & $16(31.4)$ & $50(30.9)$ & 0.537 \\
\hline Diabetes, n (\%) & $5(9.8)$ & $7(4.3)$ & 0.130 \\
\hline \multicolumn{4}{|l|}{ Clinical chemistry } \\
\hline Triglycerides, mmol/l & $1.8 \pm 1.2$ & $1.5 \pm 0.7$ & 0.007 \\
\hline $\mathrm{LDL}, \mathrm{mmol} / \mathrm{l}$ & $3.1 \pm 0.9$ & $2.9 \pm 1.0$ & 0.325 \\
\hline $\mathrm{HDL}, \mathrm{mmol} / \mathrm{l}$ & $1.7 \pm 0.5$ & $1.7 \pm 0.5$ & 0.831 \\
\hline Glucose (mmol/l) & $5.9 \pm 1.1$ & $5.7 \pm 0.7$ & 0.045 \\
\hline Creatinin & $87.8 \pm 20.5$ & $87.5 \pm 22.6$ & 0.947 \\
\hline eGFR, $\mathrm{ml} / \mathrm{min}$ & $89.5 \pm 24.9$ & $75.9 \pm 21.5$ & $<0.001$ \\
\hline \multicolumn{4}{|l|}{ Systemic inflammatory markers } \\
\hline $\mathrm{CRP}, \mathrm{mg} / \mathrm{l}$ & $6.1 \pm 7.0$ & $4.6 \pm 6.1$ & 0.170 \\
\hline IL-6, pgs/ml & $3.25 \pm 2.06$ & $3.3 \pm 4.5$ & 0.931 \\
\hline IL-8, pgs/ml & $13.0 \pm 4.8$ & $13.0 \pm 5.3$ & 0.983 \\
\hline TNFRI, pgs/ml & $2256 \pm 593$ & $2186 \pm 771$ & 0.582 \\
\hline TNFRII, pgs/ml & $3908 \pm 1154$ & $3714 \pm 1435$ & 0.414 \\
\hline Leucocytes $* 10^{9} / /$ & $7.0 \pm 1.6$ & $7.5 \pm 2.0$ & 0.111 \\
\hline
\end{tabular}


Summary variables are presented as mean \pm standard deviation for quantitative variables, and count (percentage) for discrete variables. $\mathrm{FEV}_{1}$ : Forced expiratory volume in the first second; DLCO: diffusion capacity for carbon monoxide; mMRC: Modified Medical Research Council; 6MWD: Six minute walking distance; CWRT: continuous work rate test; SGRQ: St.-George's Respiratory Questionnaire, BODE index: Based on BMI, Obstruction $\left(\mathrm{FEV}_{1}\right.$ ), Dyspnea, Exercise (6-MWD); LDL: low density lipoprotein; HDL: high density lipoprotein; eGFR: estimated glomerular filtration rate; CRP: C-reactive protein; IL-6: interleukin 6; IL-8: interleukin 8; sTNFR1: soluble TNF- $\alpha$ receptor 1; sTNFR2: soluble TNF- $\alpha$ receptor 2.

Table S8.2 Use of pulmonary medication.

\begin{tabular}{lr}
\hline Patients with COPD & $\mathrm{N}=162$ \\
\hline Short-acting $\beta 2$-agonists, $\mathrm{n}(\%)$ & $50(30.9)$ \\
Short-acting anticholinergics, $\mathrm{n}(\%)$ & $20(12.3)$ \\
Combined short-acting $\beta 2$-agonists and anticholinergics, $\mathrm{n}(\%)$ & $29(17.9)$ \\
Long-acting $\beta 2$-agonists, $\mathrm{n}(\%)$ & $29(17.9)$ \\
Long-acting anticholinergics, $\mathrm{n}(\%)$ & $131(80.9)$ \\
Inhaled corticosteroids, $\mathrm{n}(\%)$ & $18(11.1)$ \\
Combined inhaled corticosteroids and long-acting $\beta 2$-agonists, $\mathrm{n}(\%)$ & $126(77.8)$ \\
Theophylline, $\mathrm{n}(\%)$ & $21(13.0)$ \\
Oral prednison, $\mathrm{n}(\%)$ & $15(9.3)$ \\
Antileukotrienes, $\mathrm{n}(\%)$ & $6(3.7)$ \\
\hline
\end{tabular}

Variables are presented as count and percentage.

Table S8.3 Use of cardiovascular and other medication.

\begin{tabular}{lccc}
\hline & COPD & $\begin{array}{c}\text { Never smoking } \\
\text { controls } \\
\mathrm{n}=65\end{array}$ & $\begin{array}{c}\text { Ex-smoking } \\
\text { controls } \\
\mathrm{n}=102\end{array}$ \\
\hline Blood pressure lowering medication, $\mathrm{n}(\%)$ & $\mathrm{n}=162$ & $15(23.1)$ & $31(30.4)$ \\
-ACE or ARB, $\mathrm{n}(\%)$ & $66(40.7)$ & $9(13.8)$ & $18(17.6)$ \\
- $\beta$-blocker, $\mathrm{n}(\%)$ & $40(24.7)$ & $4(6.2)^{*}$ & $11(10.8)^{*}$ \\
-Calciumantagonist, $\mathrm{n}(\%)$ & $32(19.8)$ & $6(9.2)$ & $7(6.9)$ \\
-Diuretics, $\mathrm{n}(\%)$ & $19(11.7)$ & $3(4.6)$ & $10(9.8)$ \\
Anti-arrythmica, $\mathrm{n}(\%)$ & $20(12.3)$ & 0 & $1(1.0)$ \\
Nitrates, $\mathrm{n}(\%)$ & $6(3.7)$ & $1(1.5)^{*}$ & $2(2.0)^{*}$ \\
Statins and other lipid lowering drugs, $\mathrm{n}(\%)$ & $15(9.3)$ & $3(4.6)^{*}$ & $22(21.6) \#$ \\
Antiaggregates, $\mathrm{n}(\%)$ & $48(29.6)$ & $3(4.6)^{*}$ & $8(7.8)^{*}$ \\
Coumarines, $\mathrm{n}(\%)$ & $51(31.5)$ & 0 & $3(2.9)$ \\
Oral antidiabetica or insulin, $\mathrm{n}(\%)$ & $10(6.2)$ & 0 & $2(2.0)$ \\
Calcium suppletion, $\mathrm{n}(\%)$ & $6(3.7)$ & $1(1.5)^{*}$ & $3(2.9)^{*}$ \\
Bisfosfonates, $\mathrm{n}(\%)$ & $17(10.5)$ & $0 *$ & $1(1.0)^{*}$ \\
Antidepressives, $\mathrm{n}$ (\%) & $17(10.5)$ & $1(1.5)^{*}$ & $3(2.9)^{*}$ \\
Anxiolytics and sleep medication, $\mathrm{n}(\%)$ & $21(13.0)$ & $0 *$ & $2(2.0)^{*}$ \\
Nsaids, morphine, other pain killers, $\mathrm{n}(\%)$ & $27(16.1)$ & $8(12,3)$ & $19(18.6)$ \\
Proton pomp inhibitors and other antacida, $\mathrm{n}(\%)$ & $24(14.8)$ & $7(10,8)^{*}$ & $7(6.9)^{*}$ \\
Antibiotics, $\mathrm{n}$ (\%) & $44(27.2)$ & $2(3.1)$ & $1(1.0)$ \\
Acetylcystein, $\mathrm{n}(\%)$ & $9(5.6)$ & $0 *$ & $0 *$ \\
\hline
\end{tabular}

Variables are presented as count and percentage. ${ }^{*}$ significantly $(p<0.05)$ different in comparison with subjects with COPD. \# significantly $(\mathrm{p}<0.05)$ different in comparison with never-smoking controls. 
Table S8.4 Multivariate backward linear regression with APWV as the dependent variable.

\begin{tabular}{lccc}
\hline & Beta & t-test & p-value \\
\hline Mean blood pressure, $\mathrm{mm} \mathrm{Hg}$ & 0.380 & 4.515 & $<0.001$ \\
Age, years & 0.276 & 3.283 & 0.001 \\
\hline
\end{tabular}

Other variables in the model: Age, gender, current smoking, $\mathrm{BMI}, \mathrm{FFMI}, 6-\mathrm{MWD}, \mathrm{CWRT}$, leg press, $\mathrm{pCO}_{2}, \mathrm{pO}_{2}$, $\mathrm{FEV}_{1} \%$ predicted, DLCO \% predicted, presence of any cardiovascular comorbidity according to the Charlson comorbidity index, mMRC grade, Bone mineral density T-score, LDL, HDL, Triglycerides, Glucose, eGFR, Leucocytes, CRP, IL-6, IL-8, sTNFR1, sTNFR2 and leucocytes.

Table S8.5 Differences in body composition, pulmonary function and functional outcome in patients who completed PR.

\begin{tabular}{lllr}
\hline $\mathrm{n}=129$ & Baseline & After PR & $\mathrm{p}$ \\
\hline Body Mass Index, $\mathrm{kg} / \mathrm{m}^{2}$ & $25.1 \pm 4.3$ & $25.3 \pm 4.1$ & 0.015 \\
Fat Free Mass Index, $\mathrm{kg} / \mathrm{m}^{2}$ & $16.6 \pm 2.2$ & $17.1 \pm 4.2$ & 0.105 \\
FEV $_{1}, \%$ predicted & $51.4 \pm 17.6$ & $50.8 \pm 18.5$ & 0.500 \\
6-MWD, meter & $478 \pm 108$ & $509 \pm 102$ & $<0.001$ \\
CWRT time, seconds & $371 \pm 275$ & $569 \pm 396$ & $<0.001$ \\
Leg press, kg & $103 \pm 48$ & $128 \pm 50$ & $<0.001$ \\
mMRC, grade & $2.14 \pm 1.2$ & $1.54 \pm 1.0$ & $<0.001$ \\
SGRQ, points & $52.0 \pm 19.9$ & $48.2 \pm 18.7$ & 0.004 \\
\hline
\end{tabular}

Variables are presented as mean \pm standard deviation. $\mathrm{FEV}_{1}$ : Forced expiratory volume in the first second; CWRT: continuous work rate test; mMRC: Modified Medical Research Council; 6-MWD: Six minute walking distance; SGRQ: St.-George's Respiratory Questionnaire.

Table S8.6 Differences in lipidemia, glycemia, renal function and systemic inflammatory markers in patients who completed PR.

\begin{tabular}{lccc}
\hline $\mathrm{n}=129$ & APWV baseline & APWV after PR & $\mathrm{p}$ \\
\hline Clinical chemistry & & & \\
Triglycerides, mmol/I & $1.4 \pm 0.7$ & $1.4 \pm 0.7$ & 0.295 \\
LDL, mmol/I & $1.7 \pm 0.5$ & $1.7 \pm 0.5$ & 0.148 \\
HDL, mmol/l & $2.9 \pm 1.0$ & $2.8 \pm 1.0$ & 0.512 \\
Glucose (mmol/I) & $5.6 \pm 0.7$ & $5.6 \pm 0.7$ & 0.537 \\
Creatinin & $87.9 \pm 23.1$ & $87.6 \pm 25.6$ & 0.782 \\
Systemic inflammatory markers & & & \\
CRP, mg/l & $4.4 \pm 6.2$ & $4.8 \pm 7.4$ & 0.552 \\
IL-6, pgs/ml & $3.1 \pm 3.0$ & $2.8 \pm 1.9$ & 0.282 \\
IL-8, pgs/ml & $13.0 \pm 5.4$ & $13.6 \pm 6.1$ & 0.265 \\
sTNFR1, pgs/ml & $2176 \pm 776$ & $2186 \pm 715$ & 0.823 \\
sTNFR2, pgs/ml & $3679 \pm 1430$ & $3644 \pm 1194$ & 0.699 \\
Leucocytes *10 $/$ I & $7.4 \pm 1.8$ & $7.5 \pm 2.2$ & 0.464 \\
\hline
\end{tabular}

Variables are presented as mean \pm standard deviation. LDL: low density lipoprotein; HDL: high density lipoprotein; eGFR: estimated glomerular filtration rate; CRP: C-reactive protein; IL-6: interleukin 6; IL-8: interleukin 8; sTNFR1: soluble TNF- $\alpha$ receptor 1; sTNFR2: soluble TNF- $\alpha$ receptor 2. 


\section{CHAPTER 9

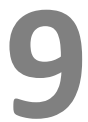

\section{Objectively identified comorbidities and changes}

in exercise capacity and health status following pulmonary rehabilitation in patients with COPD

Rafael Mesquita*, Lowie E.G.W. Vanfleteren*, Frits M.E. Franssen, Janeli Sarv, Ziad Taib, Miriam T.J. Groenen, Swetlana Gaffron, Piet L.B. Bruijnzeel, Fabio Pitta, Emiel F.M. Wouters, Martijn A. Spruit

* contributed equally to this manuscript and are joint first authors 


\section{ABSTRACT}

\section{Background}

It remains unclear whether and to what extent changes in pulmonary rehabilitation (PR) outcomes are influenced by comorbidities in chronic obstructive pulmonary disease (COPD). We aimed to investigate the impact of both individual as well as clusters of objectively identified comorbidities on changes in exercise capacity and health status after PR in COPD patients.

\section{Methods}

In a prospective study, 213 subjects ( $59 \%$ men, age $64 \pm 7$ years, FEV $_{1} 51 \pm 17 \%$ predicted) had assessed their exercise capacity (6-min walk test (6MWT) and constant work rate test (CWRT)) and health status (St. George Respiratory Questionnaire [SGRQ]) before and after a PR program. Thirteen comorbidities and five comorbidity clusters (based on the 13 comorbidities) were studied at baseline.

\section{Results}

194 subjects completed the PR program. Overall, exercise capacity and health status improved significantly and meaningfully after PR, but these improvements were not influenced by individual comorbidities. Generally, mean changes in exercise capacity and health status did not differ between comorbidity clusters.

\section{Conclusions}

Comorbidities do not prevent COPD patients from improving exercise capacity and health status after PR. COPD patients should not be withheld from rehabilitation programs based on stable comorbidities. 


\section{INTRODUCTION}

Patients with chronic obstructive pulmonary disease (COPD) often present with other chronic conditions, ${ }^{1-4}$ which are associated with increased morbidity and mortality. ${ }^{5-7}$ Indeed, as also acknowledged by the 2013 version of the Global Initiative for Chronic Obstructive Lung Disease strategy document, comorbidities importantly contribute to the overall disease severity in individual patients. ${ }^{8}$

Pulmonary rehabilitation (PR) is a comprehensive intervention recognized as a core component in the treatment of patients with COPD. ${ }^{9}$ Comorbidities have been suggested to affect outcomes of PR in this population, but conflicting results have been found. ${ }^{10}$ In a large retrospective study, Crisafulli and colleagues ${ }^{11}$ found that the presence of metabolic and heart diseases was respectively negatively and positively associated with meaningful improvements in exercise capacity following PR, respectively. In a subsequent prospective study, the same group observed that only the presence of osteoporosis was associated with poorer rehabilitation outcomes. ${ }^{12}$ Two other studies support the association between the change in exercise capacity after PR and metabolic disease, but the direction of this association was divergent between the studies. ${ }^{13,14}$ Contradictory results were also observed regarding improvements in health status and the presence of comorbidities. ${ }^{11-15}$ Most previous studies, however, have used charts reviewing to identify comorbid conditions. Furthermore, only the impact of individual comorbidities or arbitrarily grouped comorbidities was studied. ${ }^{11-15}$

Recently, Vanfleteren et al. ${ }^{16}$ identified five distinct comorbidity clusters in patients with COPD, based on 13 objectively diagnosed comorbidities. The impact of these individual comorbidities or of the comorbidity clusters on changes in widely used outcomes after PR, however, remains unknown. Therefore, the aim of the present study was to investigate the impact of both individual as well as clusters of objectively identified comorbidities on changes in functional exercise capacity (i.e., walking and cycling) and health status after PR in patients with COPD. The baseline data of this study have been published previously. ${ }^{16}$

\section{MATERIALS AND METHODS}

\section{STUDY DESIGN AND PARTICIPANTS}

This study is part of the CIRO CO-morbidity (CIROCO) study, an observational prospective single-center study performed at $\mathrm{CIRO}+$, Center of Expertise for Chronic Organ Failure, in Horn, the Netherlands. Patients were recruited between November 2007 and November 2010 and submitted to an inpatient or outpatient PR program. The following inclusion criteria were used: Global Initiative for Chronic Obstructive Lung 
Disease grades $2-4,80$ to 80 years of age, clinically stable state, and a smoking history of $\geq 10$ pack years or relevant occupational exposure. Patients were considered ineligible if they had any disease and/or condition that could compromise the proposed assessments; detailed exclusion criteria can be found in the supplemental material. All subjects gave written informed consent and the study was approved by the local ethics and review boards (MEC 10-3-067).

\section{MEASUREMENTS AND INTERVENTION}

Patients' demographic, smoking status and long-term oxygen use were documented at study entry. Moreover, the following assessments were performed: lung function, body composition, subclinical atherosclerosis, cardiac ischemia, blood pressure, functional exercise capacity, dyspnea, and psychological and health status. A sample of venous blood was obtained in fasting state for the assessment of hematology and chemistry. Details and references of these assessments can be found in the supplemental material. Functional exercise capacity (6-min walk test [6MWT] and constant work rate cycling test [CWRT]) and health status (St. George's Respiratory Questionnaire [SGRQ]) were selected as the primary outcomes of this study, and then the results on these outcomes were investigated before and after PR. These outcomes were chosen as they have shown to be the most widely used outcomes in PR. ${ }^{17}$ An improvement above the minimum important difference (MID) was considered meaningful according to the following thresholds: an increase in 6-min walk distance (6MWD) of $30 \mathrm{~m}$ or more; ${ }^{18}$ an increase in CWRT time of $100 \mathrm{~s}$ or more; ${ }^{19}$ a decrease in SGRQ total score of 4 points or more. $^{20}$

According to diagnostic criteria established by relevant international societies (see Vanfleteren et al. ${ }^{16}$ ), thirteen comorbidities were objectively investigated during initial evaluation for PR: chronic kidney disease, anemia, hypertension, obesity, underweight, muscle wasting, hyperglycemia, dyslipidemia, osteoporosis, symptoms of anxiety and depression, atherosclerosis and myocardial infarction. Based on these conditions, five comorbidity clusters were previously identified: cluster 1 (less comorbidity), cluster 2 (cardiovascular), cluster 3 (cachectic), cluster 4 (metabolic), and cluster 5 (psychologic). ${ }^{16}$ In addition, self-reported comorbidities were assessed by the Charlson comorbidity index; ${ }^{21}$ details can be found in the supplemental material. After the abovementioned assessments patients were enrolled in an 8-week inpatient $\left(5\right.$ days week $^{-1}$ ) or 14 -week outpatient ( $3{\text { days } \cdot \text { week }^{-1} \text { ) comprehensive PR program. }}^{22}$ Details of this intervention are provided in the supplemental material.

\section{STATISTICS}

Data for quantitative variables were presented as mean \pm standard deviation or mean (95\% confidence intervals), whilst data for discrete variables were presented as 
absolute and/or relative frequency. Chi-square or Fisher's exact test was used for categorical variables. Student's $t$ test was used for comparisons between patients who did or did not complete the PR program (i.e., those with or without final assessment, respectively). Within- and between-group comparisons were performed based on 95\% confident intervals. Logistic regression models adjusted for age, gender, forced expiratory volume in the first second and the baseline value in each outcome measure were built to identify the predictive role of comorbidities on meaningful improvements in exercise capacity and health status after PR. Statistical significance was considered as $\mathrm{p}<0.05$ and data analysis was carried out using SPSS 17.0 (SPSS, Chicago, Illinois) or SAS version 8.2 (SAS Institute, Cary, NC).

\section{RESULTS}

\section{GENERAL CHARACTERISTICS}

255 patients with COPD were recruited, but 213 were eligible. ${ }^{16}$ Of the 213 patients, 13 patients lacked acceptable quality carotid intima media thickness measurement, 6 did not fill out the questionnaire for symptoms of anxiety and depression, and 11 patients lacked an acceptable ECG. Table 9.1 summarizes the baseline characteristics, the distribution of individual comorbidities and the clusters identified. Details on the frequency of comorbidities in each cluster were provided by Vanfleteren et al. $^{16}$

\section{CHANGES AFTER PULMONARY REHABILITATION}

19 patients (9\%) dropped out the PR program. This group of patients had more current smokers (26\% versus $47 \% ; p=0.05$ ) and lower baseline scores in the SGRQ activity domain $(69 \pm 22$ versus $58 \pm 18$ points; $p=0.03$ ) compared with those who completed to program (Supplemental Table S9.1). Amongst completers, 57 subjects (29\%) were submitted to inpatient rehabilitation and 137 (71\%) to outpatient rehabilitation. The proportion of subjects submitted to inpatient or outpatient rehabilitation was similar amongst clusters $(p=0.37)$.

On average, the 6MWD (mean $(95 \& \mathrm{Cl}: 30(23,38) \mathrm{m})$, cycle endurance time (202 (155, 248) $m)$, and health status $(-4(-6,-2)$ points) improved significantly in the whole sample.Changes in exercise capacity and health status after PR are shown in Tables 9.2 (individual comorbidities) and 9.3 (comorbidity clusters). Results according to the SGRQ symptoms, activity and impact sub-scores can be found in Supplemental Table S9.2. Results of logistic regression models are summarized in Figures 9.1 (individual comorbidities) and Figure 9.2 (comorbidity clusters). 
Table 9.1 Baseline characteristics of the subjects.

\begin{tabular}{|c|c|}
\hline Characteristic & Value \\
\hline $\mathrm{N}$ & 213 \\
\hline \multicolumn{2}{|c|}{ Demographics, anthropometrics and clinical data } \\
\hline Age, years & $64 \pm 7$ \\
\hline Male, n (\%) & $126(59)$ \\
\hline $\mathrm{BMI}, \mathrm{kg} / \mathrm{m}^{2}$ & $26.2 \pm 5.1$ \\
\hline mMRC dyspnea grade & $2.1 \pm 1.1$ \\
\hline Current smoker, n (\%) & $60(28)$ \\
\hline Pack-years & $46 \pm 26$ \\
\hline Long-term oxygen therapy, n (\%) & $36(17)$ \\
\hline Charlson comorbidity index ${ }^{\dagger}$ & $0.6 \pm 0.9$ \\
\hline \multicolumn{2}{|l|}{ Pulmonary function } \\
\hline $\mathrm{FEV}_{1}, \mathrm{~L}$ & $1.40 \pm 0.54$ \\
\hline $\mathrm{FEV}_{1}, \%$ predicted & $51 \pm 17$ \\
\hline $\mathrm{FEV}_{1} / \mathrm{FVC}, \%$ & $40 \pm 11$ \\
\hline ITGV, \% predicted & $148 \pm 33$ \\
\hline DLCO, \% predicted & $56 \pm 17$ \\
\hline \multicolumn{2}{|l|}{ Functional outcomes } \\
\hline 6MWD, m & $470 \pm 106$ \\
\hline CWRT, s* & $353 \pm 269$ \\
\hline SGRQ total score & $51 \pm 18$ \\
\hline SGRQ symptoms score & $55 \pm 21$ \\
\hline SGRQ activity score & $68 \pm 22$ \\
\hline SGRQ impact score & $40 \pm 20$ \\
\hline \multicolumn{2}{|l|}{ Objectively identified comorbidities } \\
\hline Number of comorbidities per patient & $4 \pm 2$ \\
\hline Chronic kidney disease, n (\%) & $47(22)$ \\
\hline Anemia, n (\%) & $11(5)$ \\
\hline Hypertension, n (\%) & $103(48)$ \\
\hline Obesity, n (\%) & $50(23)$ \\
\hline Underweight, n (\%) & $30(14)$ \\
\hline Muscle wasting, n (\%) & $60(28)$ \\
\hline Hyperglycemia, n (\%) & $116(54)$ \\
\hline Dyslipidemia, n (\%) & $77(36)$ \\
\hline Osteoporosis, n (\%) & $66(31)$ \\
\hline Symptoms of anxiety, $\mathrm{n}(\%)$ & $43(21)$ \\
\hline Symptoms of depression, $\mathrm{n}(\%)$ & $33(16)$ \\
\hline Atherosclerosis, $\mathrm{n}(\%)$ & $106(53)$ \\
\hline Myocardial infarction, n (\%) & $19(9)$ \\
\hline \multicolumn{2}{|c|}{ Clusters of objectively identified comorbidities } \\
\hline Cluster 1: less comorbidity, n (\%) & $67(31)$ \\
\hline Cluster 2: cardiovascular, n (\%) & $49(23)$ \\
\hline Cluster 3: cachectic, n (\%) & $44(21)$ \\
\hline Cluster 4: metabolic, n (\%) & $33(16)$ \\
\hline Cluster 5: psychologic, n (\%) & $20(9)$ \\
\hline
\end{tabular}

Data expressed as mean \pm standard deviation for quantitative variables, and absolute and relative frequency for discrete variables. BMI: body mass index; $\mathrm{mMRC}$ : modified medical research council; $\mathrm{FEV}_{1}$ : forced expiratory volume in the first second; FVC: forced vital capacity; ITGV: intrathoracic gas volume; DLCO: diffusing capacity for carbon monoxide; 6MWD: 6-minute walk distance; CWRT: constant work rate test; SGRQ: St. George's respiratory questionnaire. ${ }^{*} \mathrm{n}=202 ;{ }^{\dagger}$ COPD is not included in the score. 


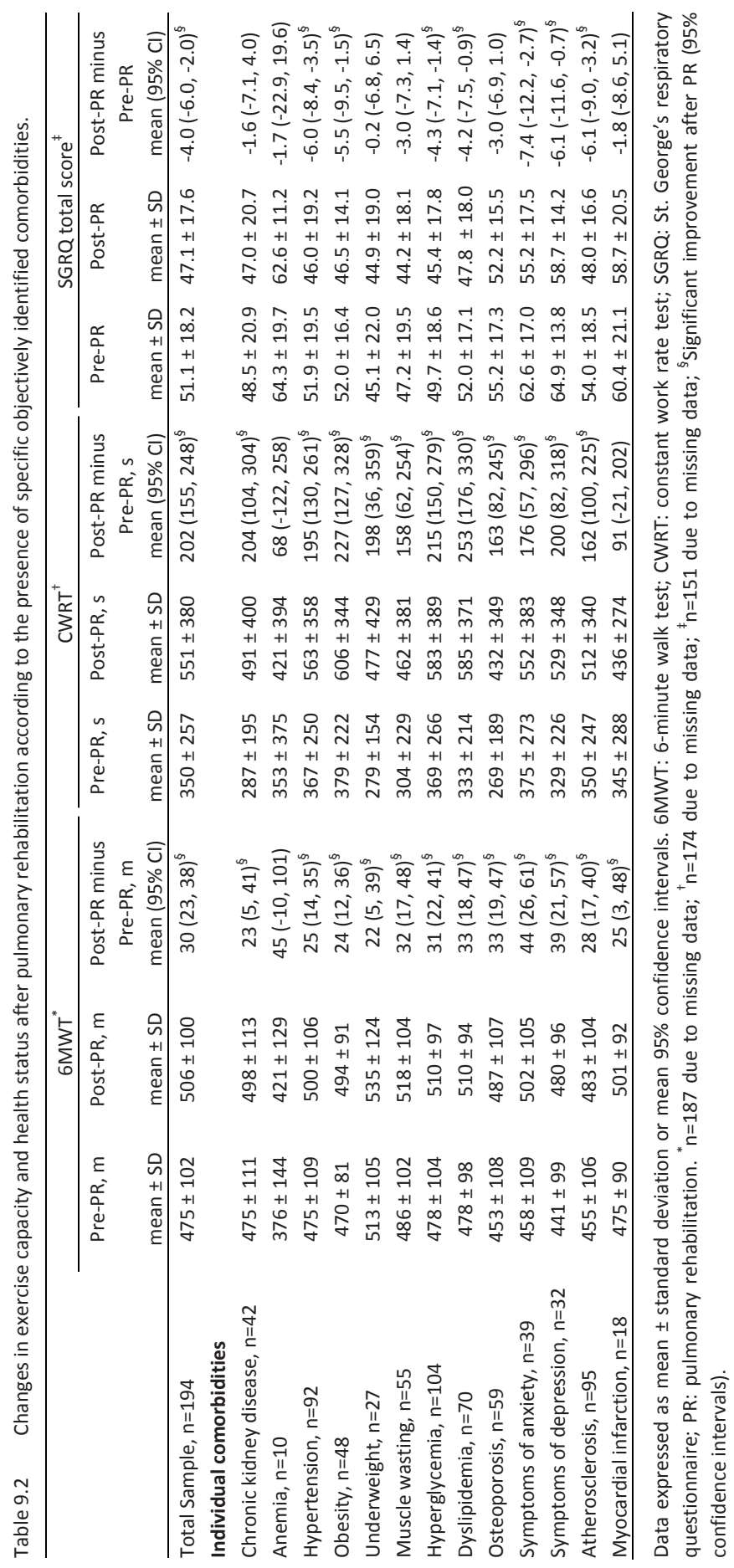


A) 6MWT

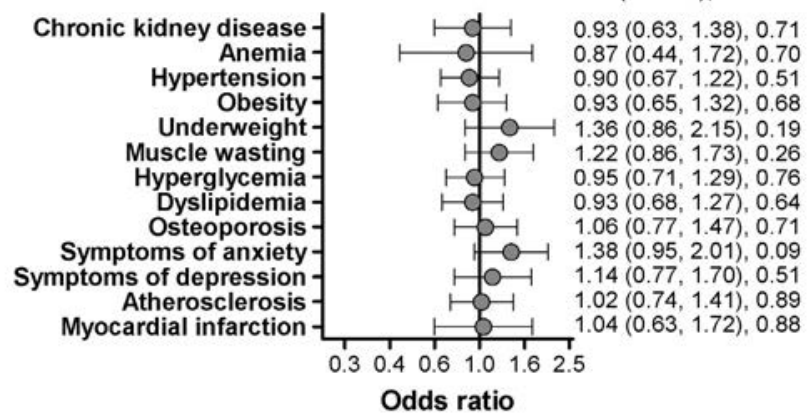

\section{B) CWRT}

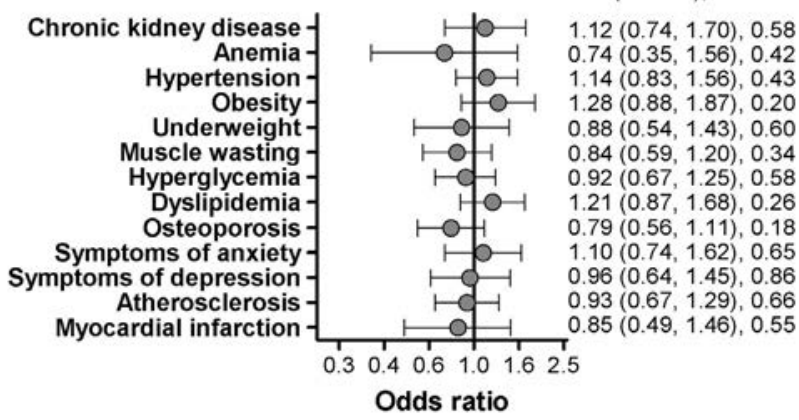

\section{C) SGRQ}

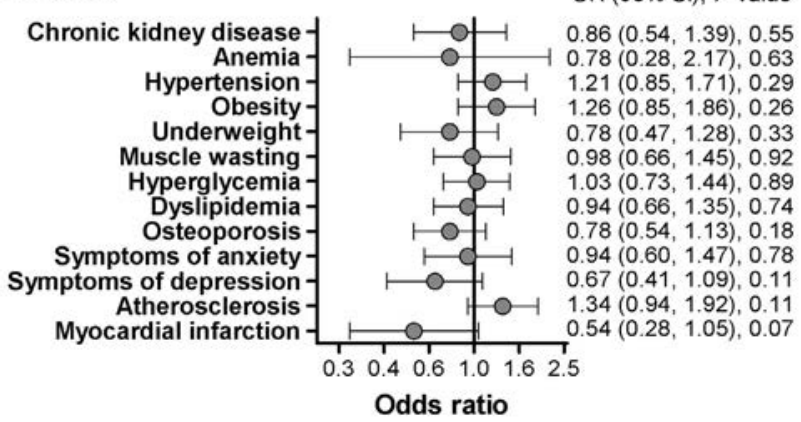

Figure 9.1 Predictive role of individual objectively identified comorbidities on meaningful improvements in (A) 6-min walk test (6MWT, $\mathrm{n}=187$ due to missing data), (B) constant work rate test (CWRT, $\mathrm{n}=174$ due to missing data), and (C) St. George Respiratory Questionnaire (SGRQ, $\mathrm{n}=151$ due to missing data) after pulmonary rehabilitation. Models adjusted for age, gender, $\mathrm{FEV}_{1} \%$ predicted and the baseline value in each outcome measure. 
A) $6 M W T$

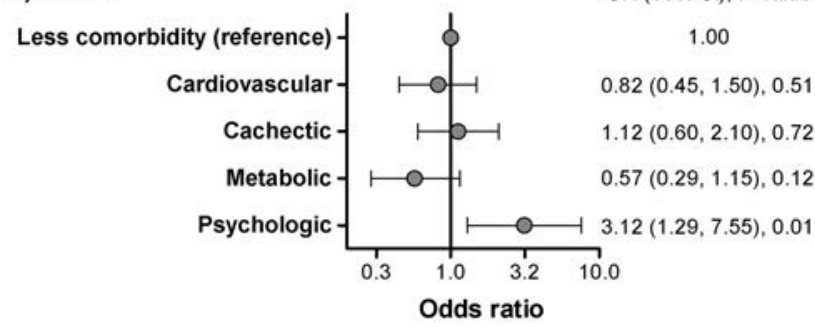

B) CWRT

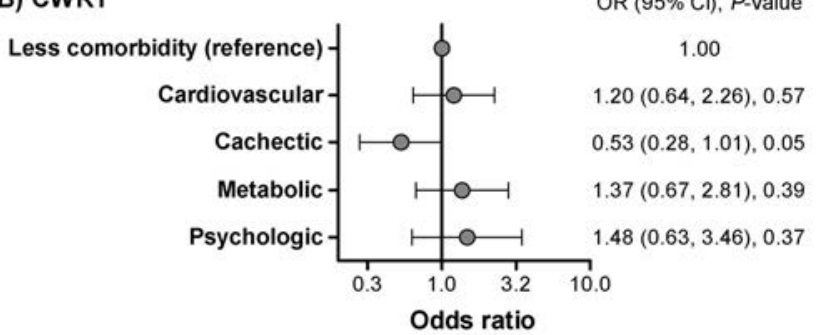

C) SGRQ

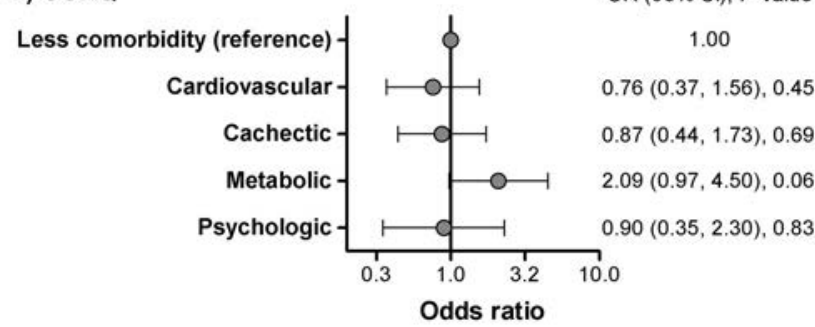

Figure 9.2 Predictive role of clusters of objectively identified comorbidities on meaningful improvements in (A) 6-min walk test (6MWT, $\mathrm{n}=187$ due to missing data), (B) constant work rate test (CWRT, $\mathrm{n}=174$ due to missing data), and (C) St. George Respiratory Questionnaire (SGRQ, $\mathrm{n}=151$ due to missing data) after pulmonary rehabilitation. Models adjusted for age, gender, FEV1\% predicted and the baseline value in each outcome measure.

\section{PR outcomes and self-reported comorbidities}

Irrespective of the final score in the Charlson index, on average, significant and meaningful improvements were found after PR in both the 6MWT and the CWRT (Supplemental Table S9.3). However, only patients with no comorbidity improved statistically and meaningfully in the SGRQ (Supplemental Table S9.3). No statistical significance was found in any of the measures when the Charlson score was taken into account in logistic regression models (Supplemental Figure S9.1). 


\section{PR outcomes and individual comorbidities}

Significant improvements in both the 6MWT and the CWRT were found in each individual comorbidity, with the exception of anemia and myocardial infarction (Table 9.2). Subjects with chronic kidney disease, underweight, muscle wasting, osteoporosis, anemia or myocardial infarction, on average did not improve in the SGRQ (Table 9.2). A logistic regression analysis revealed that none of the comorbidities was able to predict clinically meaningful changes in any of the outcome measures (Figure 9.1). The proportion of subjects with an improvement $\geq$ MID for the 6MWT, CWRT and SGRQ ranged from $40 \%$ to $59 \%, 38 \%$ to $65 \%$, and $31 \%$ to $56 \%$, respectively.

No statistical significance was found in any of the measures when the number of comorbidities (none, one, or more than one comorbidity) was taken into account in logistic regression models ( $p>0.05$ for all; Supplemental Figure S9.2).

\section{PR outcomes and comorbidity clusters}

Significant improvements in the 6MWT and CWRT were found in all comorbidity clusters (Table 9.3). The proportion of subjects with an improvement $\geq$ MID for the $6 \mathrm{MWT}$ and CWRT ranged from $38 \%$ to $74 \%$, and $40 \%$ to $66 \%$, respectively. Compared to the "less comorbidity" cluster, subjects from the "psychologic" cluster had a higher likelihood of achieving the MID for the 6MWT, whilst subjects from the "cachectic" cluster had a tendency towards a lower likelihood of achieving the MID for the CWRT (Figure 9.2).

SGRQ improved only in the "cardiovascular", "metabolic" and "psychologic" clusters (Table 9.3). The proportion of subjects with an improvement $\geq$ MID for the SGRQ ranged from $40 \%$ to $63 \%$. In a logistic regression model considering the "less comorbidity" cluster as reference, the analyses for the SGRQ did not reach statistical significance (Figure 9.2). 


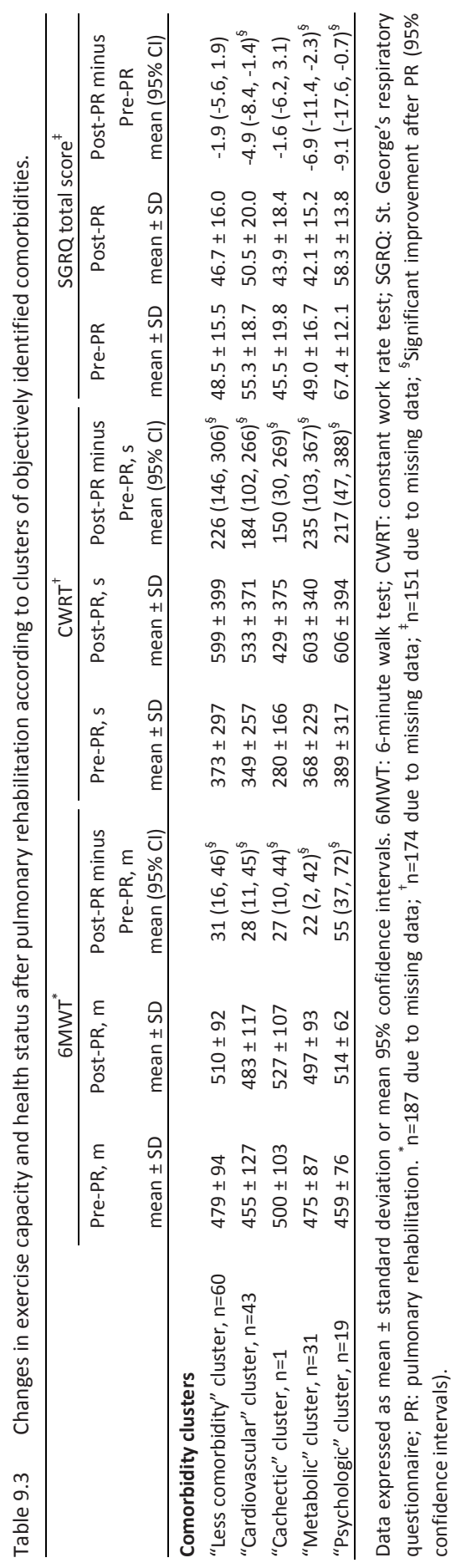




\section{DISCUSSION}

The present study showed that COPD patients with one or more objectively identified comorbidities following PR are able to obtain significant improvements in exercise capacity and health status. Moreover, the likelihood of achieving meaningful improvements in 6MWT, CWRT time or SGRQ scores was generally not influenced by the presence of individual or combinations of comorbidities.

Most of the studies published so far investigating the impact of comorbidities on PR outcomes have focused on either self-reported comorbidities or comorbidities retrieved from medical records. ${ }^{23}$ In our study, self-reported comorbidities were not able to predict meaningful improvements in terms of exercise capacity or health status. Self-reported comorbidities might provide reasonably accurate estimates, but objective measures should be preferred for a conclusive diagnosis.

Crisafulli et al. ${ }^{11}$ were one of the first groups to investigate the possible influence of comorbidities on PR outcomes in COPD patients. These authors observed that subjects with heart disease and those with metabolic disease had a higher and lower likelihood of achieving the MID for the 6MWT, respectively. ${ }^{11}$ However, in a prospective study using similar methodology the same group was not able to confirm these findings. ${ }^{12}$ More recently, two other studies from another group also found a significant association between meaningful changes in 6MWT and metabolic disease, but the direction of this association was divergent between the studies. ${ }^{13,14}$ When assessing comorbidities in an objective manner, we were not able to corroborate any of these findings. Different factors can help to explain the differences between the studies, but probably the main one is the fact that in our study we used objective measures for the assessment of comorbidities, whilst previous studies have mostly used self-reported measures or data from medical records. Nonetheless, considering the pathophysiology involved in heart and metabolic diseases, ${ }^{24}$ we believe these conditions do have the potential to influence improvements in 6MWD after PR.

Whilst subjects in the "metabolic" cluster, on average, did not reach the MID for the $6 \mathrm{MWT}$, that same cluster had the highest mean improvement in CWRT. This contrasting response suggests that excessive body weight may play an important role, as cycling can be considered a non-weight bearing exercise and walking a weight bearing exercise.

Still regarding changes in the 6MWD, the "psychologic" cluster had the highest proportion of subjects reaching the MID for this test and was the only one associated with a higher likelihood of achieving meaningful improvements compared to the "less comorbidity" cluster. The "psychologic" cluster is characterized by a higher proportion of subjects with baseline symptoms of anxiety and depression. ${ }^{16}$ Previously, 
Trappenburg et al. ${ }^{25}$ showed that the effects of PR are not affected by baseline symptoms of anxiety and depression, most probably due to the multidisciplinary approach adopted in their PR. We reason that the same is true for the current study. ${ }^{22}$ The beneficial psychological effects of PR might directly impact on improvement of exercise capacity.

Patients in the "cachectic" cluster had a tendency towards a lower likelihood of achieving the MID for the CWRT. The "cachectic" cluster was characterized by more patients with underweight, muscle wasting, osteoporosis and more static hyperinflation. ${ }^{16}$ We believe the increased static hyperinflation, which relates importantly to dynamic hyperinflation, might help to explain these results. A ventilator mask was used during the CWRT, which increases by a small amount the "dead space" of the airways and consequently might result in increased dyspnea sensation, ${ }^{26}$ primarily in patients suffering from static and/or dynamic hyperinflation. Since the $6 \mathrm{MWT}$ is performed without a mask, this might explain the differences found between CWRT and 6MWT. Important to mention that cachexia itself was not investigated in this study. Cachexia has been defined as an ongoing process of active weight loss and accelerated muscle protein degradation or muscle wasting. ${ }^{27}$ The "cachectic" cluster was given this name for reasons of clinical recognition of the cachectic phenotype in its patients, as these patients simultaneously showed low muscle mass, low bone mass and destruction of lung parenchyma. ${ }^{16}$

Individual comorbidities generally did not affect improvements in health status, although subjects with underweight, muscle wasting, osteoporosis, or chronic kidney disease were not improving significantly or in a clinically relevant magnitude. Consistently, patients in the "cachectic" cluster, on average, did not improve their health status after PR. The reasons are not completely clear. Although the "cachectic" cluster had less impaired health status at baseline when compared to the whole group, ${ }^{16}$ after running a logistic regression analysis corrected for SGRQ baseline results, this cluster was not associated with the likelihood of achieving meaningful improvements (Figure 9.2). Interestingly, we also found that the "less comorbidity" cluster did not show significant and clinically meaningful improvements in SGRQ scores, illustrating again the limited impact of comorbidities on widely used PR outcomes.

This is the first study to investigate the impact of objectively assessed comorbidities and the combinations of comorbidities (i.e., clusters) on PR outcomes. Objective assessments provide more accurate results, and the organization in clusters is probably more realistic as multimorbidity is frequently found in patients with COPD. ${ }^{2}$ Moreover, a prospective design was used in our study, supporting more accurate assessments, whilst most previous studies have used retrospective designs. ${ }^{23}$ 
Despite the strengths of our study, some limitations are acknowledged. Patients were recruited from a single center and no Global Initiative for Chronic Obstructive Lung Disease grade 1 patient was included, possibly compromising the generalizability of our results. Nevertheless, Vanfleteren et al. ${ }^{16}$ have already shown that the patients from our cohort have similar characteristics compared to patients from other cohorts. Some analyses might have been underpowered, and this may constitute another limitation. Future studies should take care to ensure sufficiently powered analyses. Due to the limited sample size, we believe that the current findings are more hypothesisgenerating than definitive.

In summary, comorbidities do not seem to preclude patients with COPD from showing significant and clinically meaningful improvements in exercise capacity and health status after pulmonary rehabilitation. COPD patients should not be withheld from rehabilitation programs based on stable comorbidities. 


\section{REFERENCES}

1. Vanfleteren LE, Franssen FM, Uszko-Lencer NH, Spruit MA, Celis M, Gorgels AP, Wouters EF. Frequency and relevance of ischemic electrocardiographic findings in patients with chronic obstructive pulmonary disease. Am J Cardiol. 2011;108:1669-74.

2. Divo M, Cote C, de Torres JP, Casanova C, Marin JM, Pinto-Plata V, Zulueta J, Cabrera C, Zagaceta J, Hunninghake G, Celli B; BODE Collaborative Group. Comorbidities and risk of mortality in patients with chronic obstructive pulmonary disease. Am J Respir Crit Care Med. 2012;186:155-61.

3. Janssen DJ, Spruit MA, Leue C, Gijsen C, Hameleers H, Schols JM, Wouters EF; Ciro network. Symptoms of anxiety and depression in COPD patients entering pulmonary rehabilitation. Chron Respir Dis. 2010;7: 147-57.

4. Graat-Verboom L, Wouters EF, Smeenk FW, van den Borne BE, Lunde R, Spruit MA. Current status of research on osteoporosis in COPD: a systematic review. Eur Respir J. 2009;34:209-18.

5. Barnes PJ, Celli BR. Systemic manifestations and comorbidities of COPD. Eur Respir J. 2009;33:1165-85.

6. Patel AR, Donaldson GC, Mackay AJ, Wedzicha JA, Hurst JR. The impact of ischemic heart disease on symptoms, health status, and exacerbations in patients with COPD. Chest. 2012;141:851-7.

7. Aryal S, Diaz-Guzman E, Mannino DM. Prevalence of COPD and comorbidity. Eur Respir Monogr. 2013;59:1-12.

8. Vestbo J, Hurd SS, Agustí AG, Jones PW, Vogelmeier C, Anzueto A, Barnes PJ, Fabbri LM, Martinez FJ, Nishimura M, Stockley RA, Sin DD, Rodriguez-Roisin R. Global strategy for the diagnosis, management, and prevention of chronic obstructive pulmonary disease: GOLD executive summary. Am J Respir Crit Care Med. 2013;187:347-65.

9. Spruit MA, Singh SJ, Garvey C, ZuWallack R, Nici L, Rochester C, Hill K, Holland AE, Lareau SC, Man WD, Pitta F, Sewell L, Raskin J, Bourbeau J, Crouch R, Franssen FM, Casaburi R, Vercoulen JH, Vogiatzis I, Gosselink R, Clini EM, Effing TW, Maltais F, van der Palen J, Troosters T, Janssen DJ, Collins E, GarciaAymerich J, Brooks D, Fahy BF, Puhan MA, Hoogendoorn M, Garrod R, Schols AM, Carlin B, Benzo R, Meek P, Morgan M, Rutten-van Mölken MP, Ries AL, Make B, Goldstein RS, Dowson CA, Brozek JL, Donner CF, Wouters EF; ATS/ERS Task Force on Pulmonary Rehabilitation. An official american thoracic society/european respiratory society statement: key concepts and advances in pulmonary rehabilitation. Am J Respir Crit Care Med. 2013;188:e13-64.

10. Cockayne DA, Cheng DT, Waschki B, Sridhar S, Ravindran P, Hilton H, Kourteva G, Bitter H, Pillai SG, Visvanathan S, Müller KC, Holz O, Magnussen H, Watz H, Fine JS. Systemic biomarkers of neutrophilic inflammation, tissue injury and repair in COPD patients with differing levels of disease severity. PLOS One. 2012;7:e38629.

11. Crisafulli E, Costi S, Luppi F, Cirelli G, Cilione C, Coletti O, Fabbri LM, Clini EM. Role of comorbidities in a cohort of patients with COPD undergoing pulmonary rehabilitation. Thorax. 2008;63:487-92.

12. Crisafulli E, Gorgone P, Vagaggini B, Pagani M, Rossi G, Costa F, Guarriello V, Paggiaro P, Chetta A, de Blasio F, Olivieri D, Fabbri LM, Clini EM. Efficacy of standard rehabilitation in COPD outpatients with comorbidities. Eur Respir J. 2010;36:1042-8.

13. Walsh JR, McKeough ZJ, Morris NR, Chang AT, Yerkovich ST, Seale HE, Paratz JD. Metabolic disease and participant age are independent predictors of response to pulmonary rehabilitation. J Cardiopulm Rehabil Prev 2013;33:249-56.

14. Walsh JR, Morris NR, McKeough ZJ, Yerkovich ST, Paratz JD. A simple clinical measure of quadriceps muscle strength identifies responders to pulmonary rehabilitation. Pulm Med. 2014;2014:782702.

15. Carreiro A, Santos J, Rodrigues F. Impact of comorbidities in pulmonary rehabilitation outcomes in patients with chronic obstructive pulmonary disease. Rev Port Pneumol. 2013;19:106-13.

16. Vanfleteren LE, Spruit MA, Groenen M, Gaffron S, van Empel VP, Bruijnzeel PL, Rutten EP, Op 't Roodt J, Wouters EF, Franssen FM. Clusters of comorbidities based on validated objective measurements and systemic inflammation in patients with chronic obstructive pulmonary disease. Am J Respir Crit Care Med. 2013;187:728-35. 
17. Spruit MA, Pitta F, Garvey C, ZuWallack RL, Roberts CM, Collins EG, Goldstein R, McNamara R, Surpas P, Atsuyoshi K, López-Campos JL, Vogiatzis I, Williams JE, Lareau S, Brooks D, Troosters T, Singh SJ, Hartl S, Clini EM, Wouters EF; ERS Rehabilitation and Chronic Care, and Physiotherapists Scientific Groups; American Association of Cardiovascular and Pulmonary Rehabilitation; ATS Pulmonary Rehabilitation Assembly and the ERS COPD Audit team. Differences in content and organisational aspects of pulmonary rehabilitation programmes. Eur Respir J. 2014;43:1326-1337.

18. Holland AE, Spruit MA, Troosters T, Puhan MA, Pepin V, Saey D, McCormack MC, Carlin BW, Sciurba FC, Pitta F, Wanger J, Maclntyre N, Kaminsky DA, Culver BH, Revill SM, Hernandes NA, Andrianopoulos V, Camillo CA, Mitchell KE, Lee AL, Hill CJ, Singh SJ. An official European Respiratory Society/American Thoracic Society Technical Standard: field walking tests in chronic respiratory disease. Eur Respir J. 2014;44:1428-46.

19. Laviolette L, Bourbeau J, Bernard S, Lacasse Y, Pepin V, Breton MJ, Baltzan M, Rouleau M, Maltais F. Assessing the impact of pulmonary rehabilitation on functional status in COPD. Thorax. 2008;63:115-21.

20. Jones PW. St. George's Respiratory Questionnaire: MCID. COPD. 2005;2:75-9.

21. Charlson ME, Pompei P, Ales KL, MacKenzie CR. A new method of classifying prognostic comorbidity in longitudinal studies: development and validation. J Chronic Dis. 1987;40:373-83.

22. Spruit MA, Vanderhoven-Augustin I, Janssen PP, Wouters EF. Integration of pulmonary rehabilitation in COPD. Lancet. 2008;371:12-3.

23. Hornikx M, Van Remoortel H, Demeyer H, Marcal Camillo CA, Decramer M, Janssens W, Troosters T. The influence of comorbidities on outcomes of pulmonary rehabilitation programs in patients with COPD: a systematic review. Biomed Res Int. 2013;2013:146148.

24. Cavaillès A, Brinchault-Rabin G, Dixmier A, Goupil F, Gut-Gobert C, Marchand-Adam S, Meurice JC, Morel H, Person-Tacnet C, Leroyer C, Diot P. Comorbidities of COPD. Eur Respir Rev. 2013;22:454-75.

25. Trappenburg JC, Troosters T, Spruit MA, Vandebrouck N, Decramer M, Gosselink R. Psychosocial conditions do not affect short-term outcome of multidisciplinary rehabilitation in chronic obstructive pulmonary disease. Arch Phys Med Rehabil. 2005;86:1788-92.

26. Chin RC, Guenette JA, Cheng S, Raghavan N, Amornputtisathaporn N, Cortés-Télles A, Webb KA, O'Donnell DE. Does the respiratory system limit exercise in mild chronic obstructive pulmonary disease? Am J Respir Crit Care Med. 2013;187:1315-1323.

27. Evans WJ, Morley JE, Argilés J, Bales C, Baracos V, Guttridge D, Jatoi A, Kalantar-Zadeh K, Lochs $H$, Mantovani G, Marks D, Mitch WE, Muscaritoli M, Najand A, Ponikowski P, Rossi Fanelli F, Schambelan M, Schols A, Schuster M, Thomas D, Wolfe R, Anker SD. Cachexia: a new definition. Clin Nutr. 2008;27:793-9. 


\section{SUPPLEMENTAL MATERIAL}

\section{METHODS}

\section{DETAILED EXCLUSION CRITERIA}

Patients were excluded if they met the following exclusion criteria: history of asthma or any other significant respiratory disease, diagnosis of alpha-1 antitrypsin deficiency, any previous lung surgery, any active inflammatory disease, acute myocardial infarction within the last 6 months, any known bone disease other than osteoporosis, current or recently (i.e., $<5$ years before the study) treated malignant disease, exacerbation requiring oral corticosteroid or hospitalization in the previous 4 weeks; high-dose (i.e., $>10 \mathrm{mg}$ daily), long term systemic corticosteroid therapy; inability to walk; any blood transfusion 4 weeks prior to the first visit; blood donor in the last 3 months prior to the first visit; suspicion of alcohol or drug abuse or any other condition associated with poor compliance in the investigator's opinion; and known infectious transmissible disease: Human Immune-deficiency virus (HIV), hepatitis B or C.

\section{DETAILS OF THE ASSESSMENT OF OUTCOME MEASURES}

\section{Lung function}

Post-bronchodilator forced expiratory volume in the first second $\left(F E V_{1}\right)$ and forced vital capacity (FVC) were collected using standardized spirometry (MasterScreen ${ }^{\circledR}$ Body, Carefusion, Germany). Static lung volumes (intrathoracic gas volume [ITGV]) and carbon monoxide transfer factor (DLCO, single breath hold method) were determined in all patients (MasterScreen ${ }^{\circledR}$ Body, Carefusion, Germany).

\section{Body composition}

Height was measured to the nearest $0.1 \mathrm{~cm}$, whilst body weight was assessed with an electronic beam scale with digital readout to the nearest $0.1 \mathrm{~kg}$ after emptying the bladder and with the subjects standing barefoot and wearing light indoor clothing. Body mass index (BMI) was calculated as body weight in kilograms per squared height in meters $\left(\mathrm{kg} / \mathrm{m}^{2}\right){ }^{1}$ Fat free mass (FFM) was assessed using an overnight-fasting bioelectrical impedance assessment (Bodystat ${ }^{\circledR}$, United Kingdom). Dual-energy X-ray Absorptiometry (DEXA) had to be used with two patients instead due to total hip replacement $(n=1)$ or presence of iron after sternal surgery $(n=1)$. FFM index (FFMI) was calculated as FFM in kilograms per squared height in meters. ${ }^{2}$ DEXA scan (Lunar Prodigy $^{\circledR}$, Ge-Lunar) was used to determine hip, lumbar spine and whole-body bone mineral density (BMD). 


\section{Sub-clinical atherosclerosis}

A high-resolution B-mode ultrasound with a $10-\mathrm{MHz}$ linear transducer (Art.LabEsaotePicus, Pie-medical Netherlands/Italy) was used for the assessment of carotid intima media thickness (c-IMT), which was thus quantified semi-automatically, reducing the interobserver variability. ${ }^{3} \mathrm{c}-\mathrm{IMT}$ measurements were performed with the patients in a supine position and throughout 10- $\mathrm{mm}$ segments across the far wall of the left and right common carotid arteries, at a point most proximal to the carotid bifurcation free of visual plaques. The probe was moved to obtain measurements of the common carotid artery at 4 angles on both sides $\left(180^{\circ}, 150^{\circ}, 120^{\circ}\right.$, and $\left.90^{\circ}\right)$. For each measured segment mean and maximum IMT values were acquired automatically throughout the $10-\mathrm{mm}$ vessel length. The average of segmental maximum carotid IMT values was determined as carotid IMT per patient.

\section{Cardiac ischemia}

The cardiac infarction injury score (CIIS) was scored by a cardiologist based on a resting electrocardiogram (ECG). This cardiologist was blinded for patient's medical history and outcome measures. CIIS is an electrocardiographic classification system developed as a diagnostic tool to determine the presence of myocardial infarctions. It is based on the power of certain electrocardiographic characteristics to discriminate between myocardial infarction patients and healthy individuals. These characteristics are weighted and combined into a single score. ${ }^{4}$

\section{Blood pressure}

Peripheral blood pressure was measured early in the morning by a trained medical technologist, blinded for clinical outcomes. Patients were instructed to rest for 15 minutes in supine position and after that three measurements were performed, with 5-minute intervals between each pair of measurements. Mean values were calculated.

\section{Functional exercise capacity}

The 6-min walk test (6MWT) and the constant work rate test (CWRT) were assessed as measures of functional exercise capacity. The 6MWT was performed according to the guidelines of the European Respiratory Society (ERS) and American Thoracic Society (ATS). ${ }^{5}$ Two tests were performed at the initial assessment to account for a possible learning effect, ${ }^{6}$ and the best test was used for analysis. The CWRT was performed at $75 \%$ of the pre-determined peak cycling load, ${ }^{7}$ based on a symptom-limited cardiopulmonary incremental cycle test ${ }^{8}$ and following the guidelines of the ATS and the American College of Chest Physicians. ${ }^{9}$

\section{Dyspnea}

The modified Medical Research Council (mMRC) dyspnea scale was used for the assessment of self-perceived dyspnea in relation to physical disability. ${ }^{10}$ 


\section{Psychological status}

Symptoms of anxiety and depression were assessed by using the Hospital Anxiety and Depression Scale (HADS), a validated and reliable self-administered instrument widely used in medically ill patients for screening clinically relevant symptoms of anxiety and/or depression. ${ }^{11}$ HADS consists of 14 questions distributed in two subscales, an anxiety subscale (HADS-A, 7 questions) and a depression subscale (HADS-D, 7 questions). Total scores for each subscale can range from 0 (optimal) to 21 (worst) points.

\section{Health status}

Health status was assessed by using the St. George's Respiratory Questionnaire (SGRQ), which consists of a 50-item questionnaire divided in three domains (symptoms, activities and impact). ${ }^{12}$ Scores per domain and a total score are provided and they can range from 0 (optimal) to 100 points (worst). ${ }^{12}$

\section{Laboratory analysis}

A venous blood sample was collected from all patients in the fasted state. Serum samples were stored at $-80^{\circ} \mathrm{C}$ prior to their analysis. Hemoglobin, leukocytes, glucose, creatinine, high density lipoprotein (HDL), and triglycerides were determined in all subjects.

\section{Self-reported comorbidities}

Self-reported comorbidities were assessed by the Charlson comorbidity index, ${ }^{13}$ which is composed of 19 categories of comorbidities. The total score reflects the cumulative increased likelihood of 1-year mortality, ${ }^{14}$ and higher scores can be translated as a higher burden of comorbidities. The total score was not adjusted for age and did not include COPD as a comorbidity, as done in previous studies. ${ }^{15-17}$

\section{DETAILS OF THE PULMONARY REHABILITATION PROGRAM}

Patients were enrolled in an 8-week inpatient (5 days-week-1) or 14-week outpatient (3 days.week-1) comprehensive pulmonary rehabilitation program. ${ }^{18}$ Briefly, both types of program were implemented by an interdisciplinary team and consisted of highintensity progressive exercise training (i.e., endurance treadmill walking and cycling and strength training of lower and upper extremities), nutritional support, occupational therapy and psychological counselling, if indicated, besides educational sessions in groups. An improvement above the minimum important difference (MID) was considered meaningful, according to the following thresholds: an increase in 6-min walk distance (6MWD) of $30 \mathrm{~m}$ or more; ${ }^{5}$ an increase in CWRT time of $100 \mathrm{~s}$ or more; ${ }^{19}$ a decrease in SGRQ total score of 4 points or more. ${ }^{20}$ 


\section{RESULTS}

Table S9.1 Baseline characteristics of completers and non-completers after pulmonary rehabilitation.

\begin{tabular}{|c|c|c|c|}
\hline Variable & Completers & Non-completers & $p$ value \\
\hline $\mathrm{N}$ & 194 & 19 & - \\
\hline Age, years & $63 \pm 7$ & $66 \pm 8$ & 0.10 \\
\hline Male, (\%) & 59 & 58 & 0.91 \\
\hline $\mathrm{BMI}, \mathrm{kg} / \mathrm{m}^{2}$ & $26.3 \pm 5.2$ & $25.5 \pm 4.0$ & 0.50 \\
\hline mMRC dyspnea grade & $2.1 \pm 1.1$ & $1.7 \pm 0.9$ & 0.13 \\
\hline Current smoker, (\%) & 26 & 47 & 0.05 \\
\hline Pack-years & $47 \pm 26$ & $40 \pm 16$ & 0.27 \\
\hline Long-term oxygen therapy, (\%) & 17 & 21 & 0.54 \\
\hline $\mathrm{FEV}_{1}, \mathrm{~L}$ & $1.40 \pm 0.54$ & $1.41 \pm 0.58$ & 0.91 \\
\hline $\mathrm{FEV}_{1}, \%$ predicted & $51 \pm 17$ & $53 \pm 17$ & 0.72 \\
\hline $\mathrm{FEV}_{1} / \mathrm{FVC}, \%$ & $40 \pm 11$ & $42 \pm 12$ & 0.31 \\
\hline ITGV, \% predicted & $148 \pm 34$ & $143 \pm 30$ & 0.52 \\
\hline DLCO, \% predicted & $56 \pm 17$ & $53 \pm 15$ & 0.44 \\
\hline Charlson comorbidity index ${ }^{+}$ & $0.6 \pm 0.9$ & $0.6 \pm 0.6$ & 0.80 \\
\hline Number of comorbidities & $4 \pm 2$ & $4 \pm 2$ & 0.75 \\
\hline 6MWD, m & $473 \pm 105$ & $449 \pm 125$ & 0.35 \\
\hline CWRT, s & $356 \pm 270$ & $321 \pm 264$ & 0.59 \\
\hline SGRQ total score & $51.9 \pm 17.7$ & $45.7 \pm 14.5$ & 0.15 \\
\hline SGRQ symptoms score & $55.1 \pm 20.9$ & $55.5 \pm 18.0$ & 0.95 \\
\hline SGRQ activity score & $69.3 \pm 22.0$ & $58.1 \pm 18.3$ & 0.03 \\
\hline SGRQ impact score & $40.2 \pm 20.0$ & $35.8 \pm 19.4$ & 0.36 \\
\hline
\end{tabular}

Data expressed as mean \pm standard deviation for quantitative variables, and relative frequency for discrete variables. See Table 9.1 for definition of abbreviations. ${ }^{*} n=202 ;{ }^{+}$This index score does not include COPD as a comorbidity. 


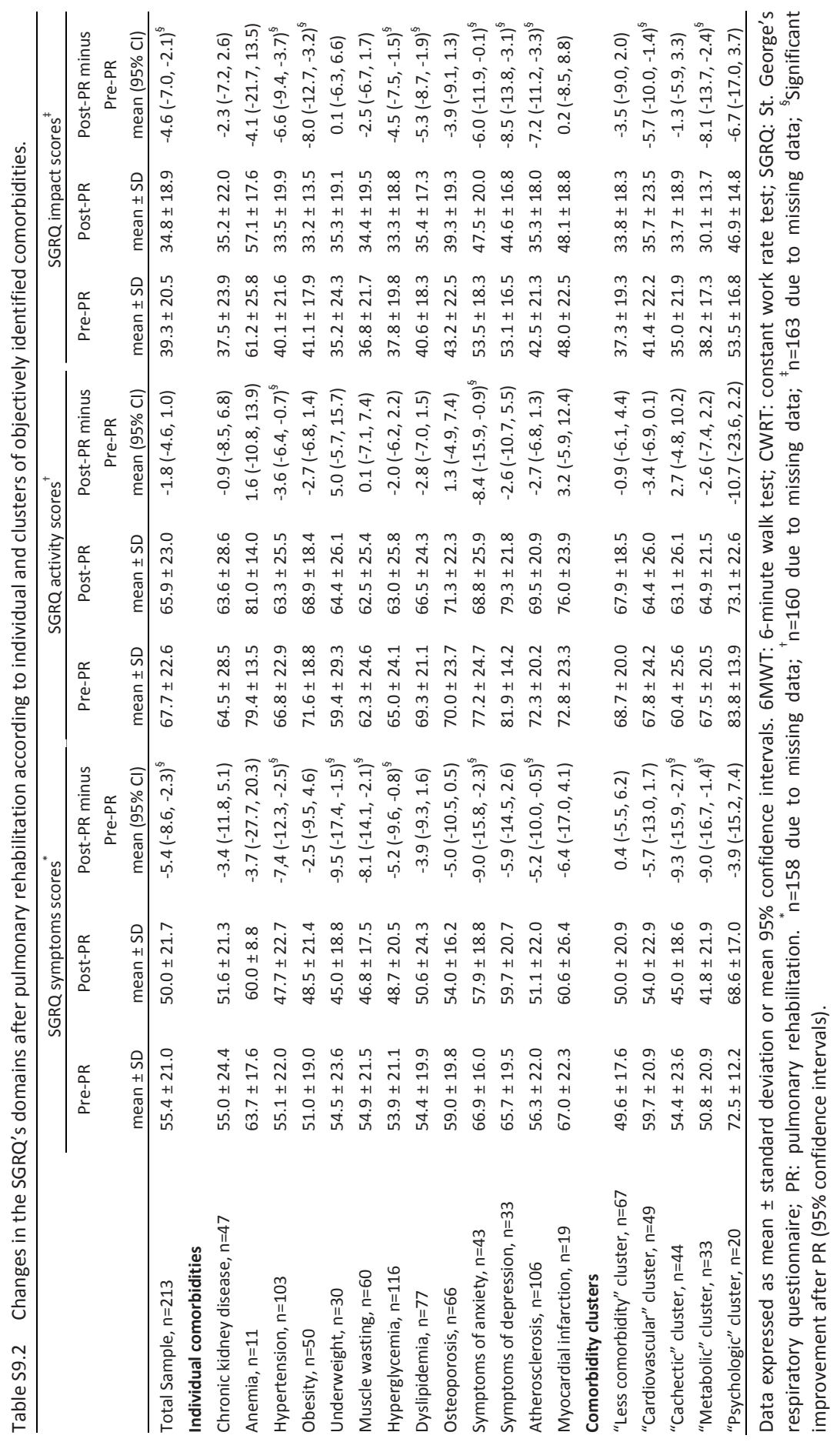




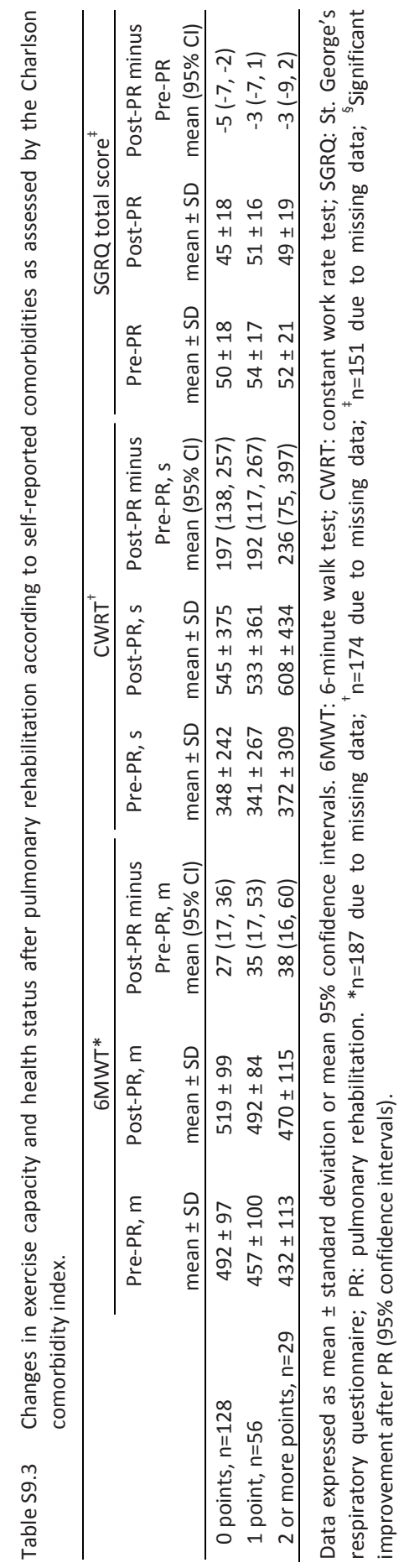




\section{A) $6 M W T$}

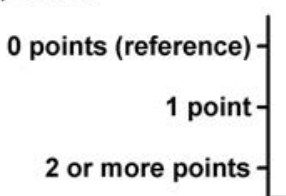

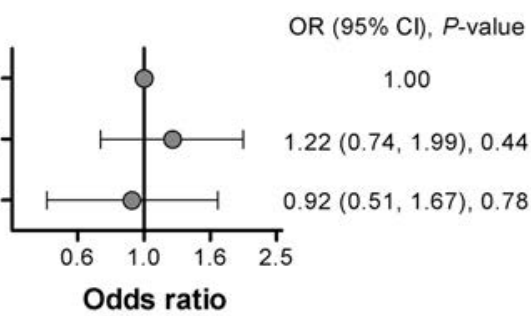

\section{B) CWRT}

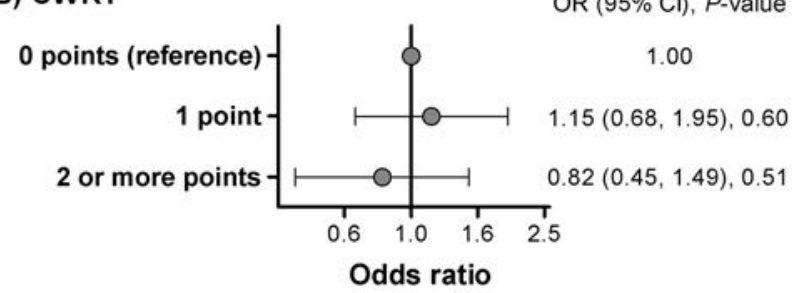

C) SGRQ

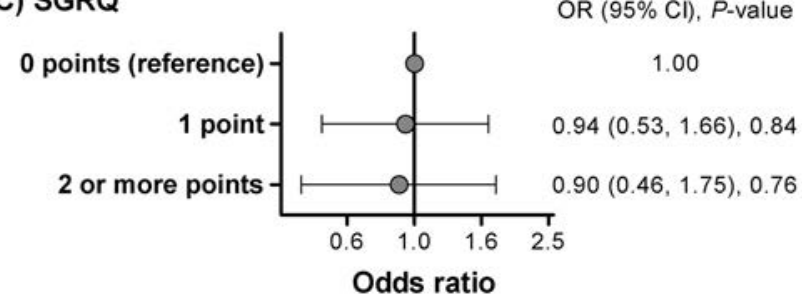

Figure S9.1 Predictive role of self-reported comorbidities as assessed by the Charlson comorbidity index on meaningful improvements in (A) 6 -min walk test (6MWT, $n=187$ due to missing data), (B) constant work rate test (CWRT, $\mathrm{n}=174$ due to missing data), and (C) St. George Respiratory Questionnaire (SGRQ, $\mathrm{n}=151$ due to missing data) after pulmonary rehabilitation. Models adjusted for age, gender, $\mathrm{FEV}_{1} \%$ predicted and the baseline value in each outcome measure. 
A) 6MWT

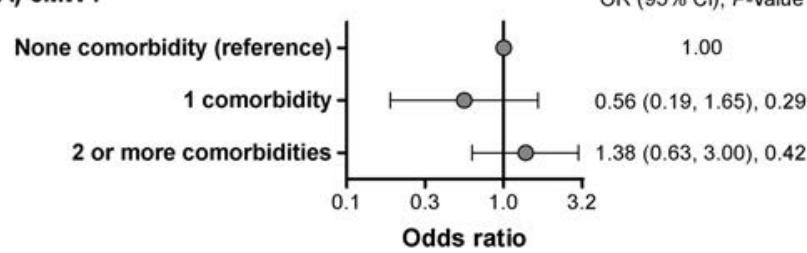

B) CWRT

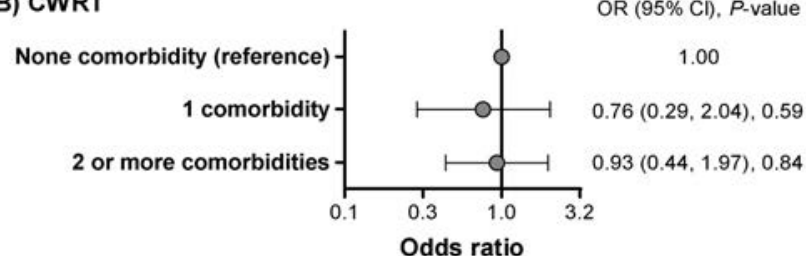

C) SGRQ

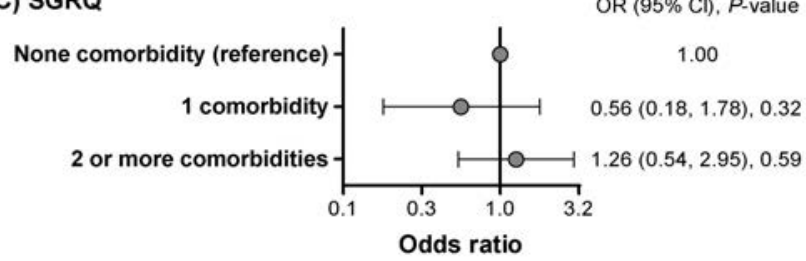

Figure S9.2 Predictive role of the number of objectively identified comorbidities on meaningful improvements in (A) 6-min walk test (6MWT, $n=187$ due to missing data), (B) constant work rate test (CWRT, $n=174$ due to missing data), and (C) St. George Respiratory Questionnaire (SGRQ, n=151 due to missing data) after pulmonary rehabilitation. Models adjusted for age, gender, $\mathrm{FEV}_{1} \%$ predicted and the baseline value in each outcome measure. 


\section{REFERENCES}

1. Keys A, Fidanza F, Karvonen MJ, Kimura N, Taylor HL. Indices of relative weight and obesity. J Chronic Dis. 1972;25:329-43.

2. Schols AM, Wouters EF, Soeters PB, Westerterp KR. Body composition by bioelectrical-impedance analysis compared with deuterium dilution and skinfold anthropometry in patients with chronic obstructive pulmonary disease. Am J Clin Nutr. 1991;53:421-4.

3. Rossi AC, Brands PJ, Hoeks AP. Automatic recognition of the common carotid artery in longitudinal ultrasound B-mode scans. Med Image Anal. 2008;12:653-65.

4. Rautaharju PM, Warren JW, Jain U, Wolf HK, Nielsen CL. Cardiac infarction injury score: an electrocardiographic coding scheme for ischemic heart disease. Circulation. 1981;64:249-56.

5. Holland AE, Spruit MA, Troosters T, Puhan MA, Pepin V, Saey D, McCormack MC, Carlin BW, Sciurba FC, Pitta F, Wanger J, Maclntyre N, Kaminsky DA, Culver BH, Revill SM, Hernandes NA, Andrianopoulos V, Camillo CA, Mitchell KE, Lee AL, Hill CJ, Singh SJ. An official European Respiratory Society/American Thoracic Society Technical Standard: field walking tests in chronic respiratory disease. Eur Respir J. 2014;44:1428-46.

6. Hernandes NA, Wouters EF, Meijer K, Annegarn J, Pitta F, Spruit MA. Reproducibility of 6-minute walking test in patients with COPD. Eur Respir J. 2011;38:261-7.

7. van 't Hul A, Gosselink R, Kwakkel G. Constant-load cycle endurance performance: test-retest reliability and validity in patients with COPD. J Cardiopulm Rehabil. 2003;23:143-50.

8. Sillen MJ, Franssen FM, Delbressine JM, Uszko-Lencer NH, Vanfleteren LE, Rutten EP, Wouters EF, Spruit MA. Heterogeneity in clinical characteristics and co-morbidities in dyspneic individuals with COPD GOLD D: findings of the DICES trial. Respir Med. 2013;107:1186-94.

9. American Thoracic Society (ATS)/American College of Chest Physicians (ACCP). ATS/ACCP Statement on cardiopulmonary exercise testing. Am J Respir Crit Care Med. 2003;167:211-77.

10. Bestall JC, Paul EA, Garrod R, Garnham R, Jones PW, Wedzicha JA. Usefulness of the Medical Research Council (MRC) dyspnoea scale as a measure of disability in patients with chronic obstructive pulmonary disease. Thorax. 1999;54:581-6.

11. Zigmond AS, Snaith RP. The hospital anxiety and depression scale. Acta Psychiatr Scand. 1983;67: 361-70.

12. Jones PW, Quirk FH, Baveystock CM, Littlejohns P. A self-complete measure of health status for chronic airflow limitation. The St. George's Respiratory Questionnaire. Am Rev Respir Dis. 1992;145:1321-7.

13. Charlson ME, Pompei P, Ales KL, MacKenzie CR. A new method of classifying prognostic comorbidity in longitudinal studies: development and validation. J Chronic Dis. 1987;40:373-83.

14. Charlson M, Szatrowski TP, Peterson J, Gold J. Validation of a combined comorbidity index. J Clin Epidemiol. 1994;47:1245-51.

15. Marti S, Muñoz X, Rios J, Morell F, Ferrer J. Body weight and comorbidity predict mortality in COPD patients treated with oxygen therapy. Eur Respir J. 2006;27:689-96.

16. Crisafulli E, Costi S, Luppi F, Cirelli G, Cilione C, Coletti O, Fabbri LM, Clini EM. Role of comorbidities in a cohort of patients with COPD undergoing pulmonary rehabilitation. Thorax. 2008;63:487-92.

17. Crisafulli E, Gorgone P, Vagaggini B, Pagani M, Rossi G, Costa F, Guarriello V, Paggiaro P, Chetta A, de Blasio F, Olivieri D, Fabbri LM, Clini EM. Efficacy of standard rehabilitation in COPD outpatients with comorbidities. Eur Respir J. 2010;36:1042-8.

18. Spruit MA, Vanderhoven-Augustin I, Janssen PP, Wouters EF. Integration of pulmonary rehabilitation in COPD. Lancet. 2008;371:12-3.

19. Laviolette L, Bourbeau J, Bernard S, Lacasse Y, Pepin V, Breton MJ, Baltzan M, Rouleau M, Maltais F. Assessing the impact of pulmonary rehabilitation on functional status in COPD. Thorax. 2008;63:115-21.

20. Jones PW. St. George's Respiratory Questionnaire: MCID. COPD. 2005;2:75-79. 



\title{
CHAPTER 10
}

\section{General discussion}

\begin{abstract}
Published in parts in:
Moving from the Oslerian paradigm to the post-genomic era: are asthma and COPD outdated terms?
\end{abstract}

Lowie E.G.W. Vanfleteren, Janwillem W.H. Kocks, Ian S. Stone, Robab BreyerKohansal, Timm Greulich, Donato Lacedonia, Roland Buhl, Leonardo M. Fabbri, Ian D. Pavord, Neil Barnes, Emiel F.M. Wouters, Alvar Agusti.

Thorax. 2014;69:72-9

\&

A possible link between increased metabolic activity of fat tissue and aortic wall inflammation in subjects with COPD. A retrospective 18F-FDG-PET/CT pilot study.

Lowie E.G.W. Vanfleteren, Aniek M.G. van Meerendonk, Frits M. Franssen, Emiel F.M. Wouters, Felix M. Mottaghy, Marinus J. van Kroonenburgh, Jan Bucerius. 



\section{COPD, AN UNDERESTIMATED AND INCREASING HEALTH PROBLEM, SCREAMING FOR ATTENTION}

The state institute for public health and environment in the Netherlands (RIVM) estimated the prevalence of chronic obstructive pulmonary disease (COPD) in 2007 as $1.8 \%$ for men and $1.6 \%$ for women, based on five databases containing registrations of physician's diagnosis of COPD, chronic bronchitis or lung emphysema in primary care. ${ }^{1}$ This reported prevalence does not approach the magnitude reported in chapter $\mathbf{2}$ of this thesis and probably underestimated the true prevalence of COPD in the Netherlands. Indeed, using rigorous methodology, in this thesis, it was shown that the prevalence of GOLD-defined COPD in the general population aged 40 years and older in Maastricht, the Netherlands is $24 \%$. Around $10 \%$ of the studied population had a forced expiratory volume in the first second $\left(\mathrm{FEV}_{1}\right)$ below $80 \%$ of predicted, corresponding with COPD GOLD stage 2 or higher.

In subjects who smoked more than 20 pack years (22\%), the prevalence of at least GOLD stage 2 was twice as high as the physician's diagnosis of COPD in the same group (11\%). This problem of underdiagnosis of COPD has been reported earlier. ${ }^{2,3}$ In the "Confronting COPD survey" the disease was underdiagnosed and undertreated, in the Netherlands as well as in the six other participating countries. ${ }^{4}$

The prevalence of COPD increases with age and the amount of smoked pack-years.

A fixed ratio for $F V_{1} / F V C$ of $<0.7$ to classify COPD as proposed in the Global initiative for Obstructive Lung Disease (GOLD) document ${ }^{5}$ may lead to increasing false positive diagnosis of COPD with age, since $\mathrm{FEV}_{1} / \mathrm{FVC}$ physiologically declines with age. ${ }^{6}$ This misclassification could be reduced by using the "lower limit of normal" (LLN), commonly defined as that value which identifies the lower 5th centile of a healthy population of non-smokers. Using the LLN for the $\mathrm{FEV}_{1} / \mathrm{FVC}$ ratio probably enables better distinction between healthy aging and obstructive lung disease. In chapter $\mathbf{2}$, using the LLN instead of the GOLD criterion to define COPD, still resulted in an overall COPD prevalence of $19 \%$, while $10 \%$ of the Maastricht population had at least GOLD stage 2 disease.

GOLD-defined COPD was found in $14 \%$ of persons who had never smoked. According to the LLN this was still 6\%. Although never smokers were less likely to have COPD than ever smokers, never smokers nonetheless comprised one fifth of all subjects with COPD. In Western countries, outdoor air pollution, occupational exposure, childhood respiratory infections and chronic asthma have been associated with COPD in never smokers. $^{7}$ 
Although the Netherlands is a developed country and COPD is a preventable disease, a surprisingly high prevalence of COPD was found. With the aging population and continuing high rates of cigarette consumption, this burden is bound to increase and imposes great demands to public health care and society. The government faces the important task to continue the efforts to prevent the population from exposure to noxious substances: tobacco smoke but also other air pollutants, from for example traffic or industry. Health care professionals should give priority to a better evaluation and diagnosis of patients with COPD, as well as improved management of COPD and take an aggressive attitude on the reduction of tobacco smoking.

As generally seen among the Burden of Obstructive Lung Disease (BOLD) sites throughout the world, ${ }^{8}$ also at the Maastricht site, the overall prevalence of COPD was higher in men than in women. It has been predicted that the expected changes in smoking behavior will result in a smaller increase of the projected prevalence in men and greater increase in women. ${ }^{9}$ Since tobacco consumption was comparable in men and women in the present study, the gender difference in the prevalence of COPD in Maastricht is expected to equalize. In fact, since women seem to be more vulnerable to develop COPD than men, ${ }^{10}$ it can be hypothesized that this gender difference will reverse. Indeed, in the youngest age group (40-49 years) in chapter $\mathbf{2}$ of this thesis, the prevalence of COPD according to the LLN tended to be higher in women than in men. This is consistent with the remarkably higher incidence of COPD in the youngest female age category of 55-59 years compared to male peers in the population-based Rotterdam study with a median follow up of eleven years. ${ }^{11}$

Also regarding experience of respiratory symptoms, gender differences are important to consider. The pathway to diagnosis and treatment of lung disease often begins with the reporting of respiratory symptoms to the physician. Chapter $\mathbf{3}$ of this thesis indicated that for the same degree of lung function impairment females tend to report more dyspnea and cough, but less phlegm/sputum production than males. Others made the same observation. ${ }^{12}$ This is also in accordance with results from the Confronting COPD International Survey, which showed that despite lower pack-years of smoking females were more likely to report severe dyspnea than males, with similar cough and less sputum. ${ }^{13}$ Anatomical differences and differences in respiratory muscle strength may partly explain this gender differences. ${ }^{14,15}$ Also neurobiological differences may contribute: Females have a higher intrinsic sensitivity to noxious somatic sensations, including dyspnea. ${ }^{16}$ Finally, females are held to an expectation of beauty and youthfulness, whereas males are expected to be physically strong and robust. These expectations may be disrupted by COPD; ${ }^{17}$ however, these expectations may influence the perception and expression of respiratory symptoms in males and females. Thus, males might be less likely to describe themselves as breathless than females, and females might be less likely to report sputum or phlegm production. Physicians should 
be aware of the gender differences in respiratory symptoms when considering a clinical diagnosis of COPD.

\section{$\mathrm{CO}^{\mathrm{p} 0 \mathrm{~S}}$ MORBIDITY}

Although defined by the presence of chronic airflow limitation, COPD is nowadays considered a complex, heterogeneous and multi-component condition. ${ }^{18}$ Comorbidities, defined as the presence of other chronic conditions in a patient with COPD, contribute to the severity of the disease. ${ }^{5}$ Commonly recognized comorbidities in COPD include cardiovascular disease, depression, osteoporosis, anemia and diabetes. They not only affect symptom burden, functional performance and health status in these patients, ${ }^{19}$ but also the risk of hospitalization ${ }^{20}$ and mortality. ${ }^{20,21}$ Therefore, the most recent GOLD definition of COPD incorporated comorbidities in the definition of the disease. $^{22}$

Most studies on the prevalence and impact of comorbidities in COPD used self-reported disease $^{18,20,21,23-30}$ or health-care databases, not specifically designed to evaluate comorbidities. ${ }^{20,26,27,30}$ Therefore, these methods probably underestimate the true prevalence of comorbidities in COPD.

In chapter 5 of this thesis, electrocardiography (ECG) was used to objectively evaluate the presence of ischemic heart disease in COPD. In patients referred for pulmonary rehabilitation, ischemic ECG changes were present in $21 \%$ of the studied population. Importantly, $14 \%$ of the patients without self-reported cardiovascular co-morbidities had an ischemic ECG. Since no additional investigation was performed, it is not possible to conclusively confirm cardiovascular disease in these patients. However, the results of this study suggest that cardiovascular disease is underdiagnosed in patients with COPD.

In addition, ischemic ECG findings in patients with COPD were associated with worse clinical outcomes, irrespective of the degree of lung function impairment, age or body composition. Based on the results of chapter 5, a diagnostic ECG could be recommended in every patient with COPD. In the presence of abnormalities on ECG, further cardiovascular work-up is warranted and primary or secondary prevention measures in lifestyle of pharmacotherapy should be considered.

The ECG only shows abnormalities when damage is done. Therefore, early identification of COPD patients at increased risk for comorbid cardiovascular disease seems even more important for prevention. In chapter 7 of this thesis, the degree of (subclinical) atherosclerosis was objectively measured with the use of ultrasound measurement of 
carotid wall intima-media thickness (c-IMT). Clinical determinants of atherosclerosis were studied and the potential value of a combination of multiple atherosclerosisrelated biomarkers in the identification of atherosclerosis in COPD was analysed. The study showed that C-IMT is partly determined by age, BMI, mean blood pressure and the degree of airflow limitation. A combination of blood biomarkers could equally explain the c-IMT variance but only a minority of the individual biomarkers had additional value to the predictive value of the identified clinical determinants. A panel of multiple biomarkers in combination with clinical markers might be the way to move forward in cardiovascular risk classification in patients with COPD. The results of this study illustrated the complexity of cardiovascular comorbidity in patients with COPD.

\section{FROM COPD AND COMORBIDITY TO THE CONCEPT OF MULTIMORBIDITY}

Multimorbidity, defined as the presence of two or more chronic diseases in the same individual, is one of the major challenges facing health care systems in the next decades. It is associated with poor outcome and increased health care utilization. ${ }^{31}$ In COPD, the concept of multimorbidity was scarcely studied. One study reported significant overlap in (self-reported) diabetes, musculoskeletal conditions and cardiovascular disease in primary care COPD patients. ${ }^{28}$

Chapter 6 of this thesis advanced the current knowledge of comorbidities and multimorbidity in COPD for several reasons. First, in contrast to studies using selfreported disease, thirteen clinically relevant comorbidities were objectively diagnosed using pre-defined internationally accepted cut-offs. Also, rather than studying correlations between individual comorbidities, hypothesis-free clustering of the comorbidities was performed. In addition to confirming the high frequency of individual comorbidities reported previously, five comorbidity clusters were found in patients with COPD: First, a large group of subjects were clustered characterized by a "lower amount of comorbidities". Second and third a "cachectic" and "metabolic" cluster were found. These 2 clusters are reminiscent of the historical description of the pink puffer (emphysematous type with a "cachectic" impression) and the blue bloater (chronic bronchitis type with a "metabolic" impression). ${ }^{32}$ The finding of the independent "cachectic cluster" characterized by underweight, muscle wasting, osteoporosis, renal impairment and pulmonary function characteristics fitting with emphysema are in support of the clinical classification of the "pink puffer" phenotype, but extends it by providing the evidence with the synchronous associations with loss of muscle mass, loss of bone mass and loss of lung tissue. In this thesis no progressive loss of organ tissue was investigated, but earlier reports suggest that subjects with an emphysematic phenotype are at risk for ongoing loss of lung tissue. ${ }^{33}$ 
Given this loss of tissue in multiple organs, rather than the respiratory orientated "pink puffer", we decided to name the cluster "cachectic", for reasons of clinical recognition of the phenotype. However, here, we did not intend to refer to the equally named syndrome. By consensus, cachexia has been defined as on ongoing process of active weight loss and accelerated muscle protein degradation or muscle wasting. ${ }^{34}$ Although we identified low fat free mass with muscle wasting in chapter 6, and loss of muscle bulk is a common complication in COPD, it is not clear whether COPD, in its stable state, is related to active muscle breakdown or proteolysis. In chronic wasting in humans, impaired protein synthesis may be the driver of reduction in muscle mass with muscle protein breakdown rates actually becoming suppressed as an adaptation to limit muscle loss. ${ }^{35}$ This was recently corroborated by the absence of increased MuRF-1 and atrogin-1, enzymes in the ubiquitin-proteasome pathway, the latter being a key final pathway of muscle protein breakdown, in patients with COPD and low fat free mass compared to COPD subjects with normal fat free mass or control subjects. ${ }^{36}$

The results of chapter 6 show that in the "cachectic" cluster, none of the investigated inflammatory markers was increased. In the Evaluation of COPD Longitudinally to Identify Predictive Surrogate Endpoints (ECLIPSE) study, CT density decreasing over the 3 years duration of the study was associated with lower levels of SRAGE and not with inflammatory cytokine levels. ${ }^{37}$ The sRAGE is thought to act as a protective decoy by buffering inflammatory ligands and thus decreasing inflammatory injury. ${ }^{37}$ The cooccurence of these conditions suggest a common pathophysiological pathway. Although many is unknown, possibly in this phenotype abnormal protection mechanisms and abnormal tissue repair capacity might be key issues.

Rather than pink puffer, in which pink refers to the absence of cyanosis, while the extent of emphysema has been related to hypoxia, ${ }^{38}$ and rather than "emphysematic phenotype" that refers only to the pulmonary component, and rather than "cachectic" which refers mainly to disease-associated continued loss of muscle mass, it might be better to describe the involvement of multiple components of the organism as an "implosive phenotype".

Similarly, different pathways may be involved in the development of cardiovascular comorbidity in COPD. Despite comparable increased cardiovascular risk according to the Framingham risk score, the "metabolic cluster" and the "cardiovascular cluster" differed concerning the presence of metabolic diseases like obesity, dyslipidemia or hyperglycemia. The recognition of a fifth "psychopathological cluster", is an important finding and consistent with growing literature as mental conditions are common in $\mathrm{COPD}^{39}$ and relevant in the setting of multimorbidity. ${ }^{40}$ 
Importantly, exercise capacity and degree of airflow obstruction were comparable between clusters, while for example health status was markedly different. Hence, traditional measures of disease severity in COPD are not helpful to predict the presence and kind of comorbidity. This is in line with chapter 5, where the presence of an ischemic ECG was independent of the degree of airflow limitation.

\section{PATHOPHYSIOLOGY OF COMORBIDITY IN COPD}

With better socioeconomic standards and the development of effective therapy for acute disease like pneumonia and acute myocardial infarction, the population is ageing. As ageing is the most important determinant in the development of chronic disorders, health care and social systems are increasingly confronted with coincidental chronic diseases. As a result, available literature concerning the topic of comorbidity in case of an index disease or multimorbidity in general has increased exponentially.

The most cited pathophysiological theory that explains the excess comorbidity in subjects with COPD has been that of an over-expression of an inflammatory process in the lungs, that spills over to the systemic circulation resulting in the involvement of different organ systems. ${ }^{41}$ However, examination of lung biological samples (sputum, bronchoalveolar lavage fluid, and lung tissue) has shown that not all patients have abnormal markers of inflammation. ${ }^{42-45}$ Furthermore, using a panel of 6 inflammatory biomarkers, the ECLIPSE study showed that only $16 \%$ of patients had persistent biomarker expression of systemic inflammation, whereas close to $30 \%$ of patients had no evidence of systemic inflammation in at least two measurements separated by one year. $^{46}$

In addition, a direct link between (chronic low-grade) systemic inflammation and comorbidities in patients with COPD remains equivocal. For example, bivariate associations between various systemic inflammatory biomarkers and pulmonary cachexia, $^{47}$ subclinical atherosclerosis, ${ }^{48}$ metabolic syndrome ${ }^{49}$ and ischemic heart disease have been reported in patients with COPD. ${ }^{50}$ Moreover, CRP, fibrinogen and leucocyte count were associated with increased risk of comorbidities in patients with COPD. ${ }^{51}$ Then again, many studies showed comparable circulating levels of inflammatory biomarkers in COPD patients with and without comorbidities, such as cachexia, ${ }^{52}$ osteoporosis, ${ }^{53}$ cardiovascular disease ${ }^{54}$ and depression. ${ }^{55}$ Hence, a causal relationship between low-grade systemic inflammation and comorbidities in COPD has not been proven yet. The current findings in chapter 6: systemic inflammatory markers within each comorbidity cluster are highly heterogeneous and mainly similar among the different clusters, show that the possible interactions between biomarkers of systemic inflammation and comorbidities in patients with COPD are very complex, if present at 
all. This is further corroborated in this thesis by the absence of an independent relationship between several inflammatory markers and arterial stiffness (measured as aortic pulse wave velocity) in patients with COPD in chapter 8.

Consequently, today, there is very little evidence that one chronic disease dominates and is the cause of the other concomitant chronic disorders; rather, it is more likely that various chronic diseases develop simultaneously in response to common risk factors (e.g., smoking, alcohol, aging, pollution, inactivity, and diet). ${ }^{56}$

Chronic low-grade systemic inflammation is a hallmark of obesity in the general population, ${ }^{57}$ suggesting a systemic origin of inflammation. Increased levels of systemic inflammation in patients with COPD have also been particularly reported in obese patients with COPD. ${ }^{46,58-60}$ In the ECLIPSE study, patients with, compared to those without systemic inflammation, had a higher BMI, lower CT emphysema score and worse outcomes, suggesting a role for fat tissue in the presence of systemic inflammation in patients with COPD. ${ }^{46}$

This may partially explain the increased levels of TNF-receptors in the "metabolic" cluster, and its lesser presence in the "cachectic" cluster in chapter 6. Fat tissue, and more particular visceral fat might be the link between systemic inflammation and atherosclerosis. ${ }^{61}$ Similarly, the increased IL-6 in the "cardiovascular" cluster might be due to the significant older age in that cluster. Indeed, a wealth of data indicates that normal aging is associated with low-grade systemic inflammation, including IL-6. ${ }^{62}$

\section{THE ENTANGLEMENT OF CHRONIC AIRFLOW OBSTRUCTION AND NUTRITIONAL STATUS}

In chapter 6 of this thesis it was clear that body composition is an important discriminating factor between different COPD phenotypes. One cluster was characterized with a high proportion of underweight. In contrast, but similar to the PAC-COPD study, ${ }^{63}$ an independent subtype of COPD was identified by a milder respiratory status but a higher prevalence of obesity, cardiovascular disease and hyperglycemia, and higher levels of systemic inflammatory markers. ${ }^{64}$

A low body mass index (BMI) is a common clinical observation in patients with advanced airflow obstruction. ${ }^{65}$ At the same time obesity is increasingly reported as an important comorbidity in COPD. Nutritional status has been associated with clinical outcome and prognosis in patients with chronic airflow limitation. ${ }^{66}$ Nevertheless, there is a scarcity of epidemiological studies on the association between BMI and chronic airflow limitation, that control for other factors that influence BMI, like age, gender, 
smoking history and geography. Therefore in chapter 4 of this thesis, the association between BMI and chronic airflow limitation was studied in detail. It was found that in a worldwide general population, the presence of objectively assessed chronic airflow limitation was associated with increased risk of low BMI and a reduced risk of obese $\mathrm{BMI}$, independent of age, gender, smoking history and geography. These findings suggest a direct association between chronic airflow limitation and low BMI, although the direction of this association cannot be established from these cross-sectional data.

Smoking is not only an important risk factor in the development of COPD, it may also adversely affect body composition. ${ }^{67}$ Nicotine has appetite suppressant effects in the brain resulting in lower nutrient intake in smokers. ${ }^{68}$ Also, one of the acute systemic effects of smoking is an increase in resting energy metabolism. ${ }^{69}$ It is well known that quitting is frequently followed by a rapid weight gain. ${ }^{70,71}$ On the other hand, chronic airflow limitation is importantly associated with older age as years of exposure to tobacco smoke precede its development. ${ }^{72}$ Older people tend to weigh less than younger adults, and old age is also associated with a tendency to lose weight. ${ }^{73,74}$ However, in this thesis it is clearly demonstrated that neither smoking, age, gender, nor regional $\mathrm{BMI}$ differences affect the relationship between the presence of chronic airflow limitation and the presence of low BMI.

The study in chapter 4 of this thesis also provides new insight in the prevalence of obesity in COPD, which had been scarcely studied until now. The study showed that the prevalence of obesity is lower in subjects with chronic airflow limitation compared to their peers, also when adjusted for gender, smoking status and age. Additionally, the influence of smoking history seemed greater than the influence of the presence of chronic airflow limitation on the presence of obesity.

Both low BMI as a risk factor for development and progression of chronic airflow limitation as well as (mechanisms of) weight loss in subjects with chronic airflow limitation need exploration in future studies. Regarding future studies, these results should be integrated with the results of chapter 6 as body composition is an important discriminator between clinical phenotypes and accelerated loss of body weight can be a key characteristics of certain COPD subgroups, i.e. the "implosive" phenotype. In the meantime, clinicians and dieticians should stay aware of what is already known, in fact that low BMI is related to poor outcome in subjects with COPD and should be appropriately managed. 


\section{WHAT ABOUT THE ROLE OF (VISCERAL) FAT TISSUE IN CARDIOVASCULAR DISEASE IN COPD?}

The results of chapter 6 suggested that increased fat mass contributes to low grade systemic inflammation in COPD and may be linked to the excess cardiovascular comorbidity in COPD. Earlier research particularly stressed the importance of the visceral fat as a metabolic active organ. Therefore, as a side-project from this thesis, we aimed to retrospectively study 42 patients ( $71 \%$ male, $48 \%$ current smokers, mean age $66.6 \pm 8.3$ years, mean BMI $25.1 \pm 4.3 \mathrm{~kg} / \mathrm{m}^{2}$ ), who underwent positron emission tomography with 18F-fluorodeoxyglucose combined with computer tomography (FDG-PET/CT) for suspected early stage bronchus carcinoma. In these subjects ${ }^{18}$ FDG-PET-assessed inflammation of the aorta and the visceral and subcutaneous fat was collected and interrelations and differences in subjects with and without COPD were evaluated.(Figure 10.1)

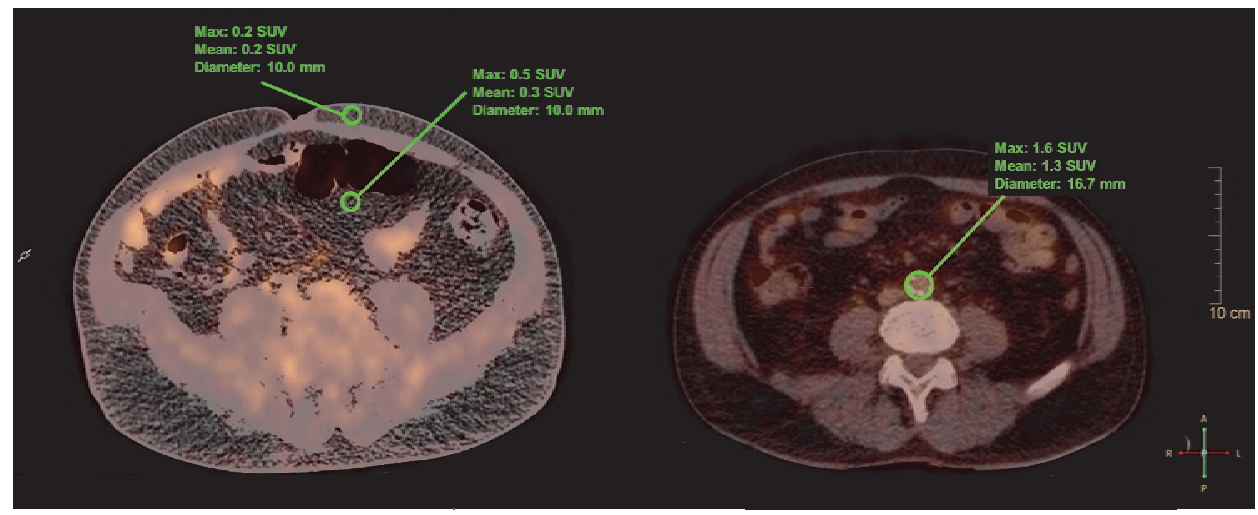

Figure 10.1 Examples of SUV measurements in regions of interest of the abdominal subcutaneous and visceral fat (left image) and the aortic wall (right image).

COPD patients had increased inflammatory activity of the aortic wall and increased metabolic activity of the abdominal visceral fat compared to non-COPD subjects. In addition, the degree of FDG uptake in the visceral and subcutaneous fat independently predicted the inflammation of the aortic wall. Finally, visceral fat was metabolically more active than subcutaneous fat as revealed by FDG-PET. These findings shed new light on the origin of increased vascular risk in subjects with COPD. Also, they emphasize the possible role of visceral fat in the atherosclerotic process in COPD. Further prospective and well-powered trials are warranted. The findings of the study however are further corroborated by recent reports on increased visceral fat (independent of total fat mass) in subjects with COPD compared to matched 
cohorts. ${ }^{75,76}$ Furthermore, a contribution of visceral fat to inflammatory pathways was demonstrated in older persons with obstructive lung disease and was associated with increased mortality. ${ }^{75}$ Interestingly, visceral fat accumulation has also been reported in other chronic diseases associated with low-grade systemic inflammation, including rheumatoid arthritis, ${ }^{77}$ Crohn's disease, ${ }^{78}$ and psoriasis. ${ }^{79}$ Future studies need to reveal whether visceral fat in these conditions is not only excessive, but also more metabolically active and related to atherosclerotic activity. The possible role of fat tissue in linking different disease manifestations is intriguing. Recently, a novel association was reported between increased BMI and the DNA methylation at the HIF3A locus in blood cells and in adipose tissue. An epigenetic change at the hypoxia induced transcription factor pathways could have an important role in mediation of some of the downstream adverse responses to increased BMI. ${ }^{80}$

The complex relationship between clinical disease manifestations, the underlying genetic and molecular pathology and the environmental interactions is part of the field of network medicine, and most probably the way to move forward to increase our understanding of a complex disease like COPD.

\section{MOVING TOWARDS PERSONALIZED MEDICINE}

Over the past decade, extensive research into COPD has led to significant improvements in our understanding and management of this disease, for example the definition of different clinical phenotypes. For many patients "COPD" is an outdated term that do not fully recognize its molecular and clinical heterogeneity. This limits the development of new and more efficient therapeutic alternatives and prevents patients from getting the best personalized medicine possible. We need a better understanding of the endotypes that underlie COPD and other chronic diseases that develop simultaneously. This will most likely result in a new classification (taxonomy) of airway diseases. This new taxonomy should use nominalist definitions based on objectively identified single defining characteristics, more specifically based upon the characterization of the endotypes and pattern of clinical expression (clinical phenotypes) of different airways diseases. In each of them, one or more biomarkers to be used in the clinic need to be identified and validated. Given the important influence of multiple environmental factors on the underlying endotypes, this new classification should consider carefully these environmental factors. After all, COPD is a paradigmatic example of gene-environment human diseases. To do this, a network approach that relates genes, environment, endotypes and clinical phenotypes, in an unbiased way (discovery-driven, rather than hypothesis-driven) will be needed. Figure 10.2 gives an overview of the interaction between the different network levels and the process by which the necessary data should be integrated. This will result in an increased understanding of COPD and related diseases and ultimately lead, to personalized 
medicine where the focus of current healthcare will shift from treating diseases (reactive medicine) to the so-called P4 medicine, a new type of medicine that is predictive, preventive, personalized and participatory. ${ }^{81}$

\section{A PERSPECTIVE ON THE PHARMACOLOGICAL TREATMENT OF MULTIMORBIDITY}

The results of chapter 6 emphasize the need to increase awareness regarding multimorbidity in COPD amongst health care professionals. This will also enhance treatment strategies and facilitate the combination of future treatment guidelines for different comorbidities.

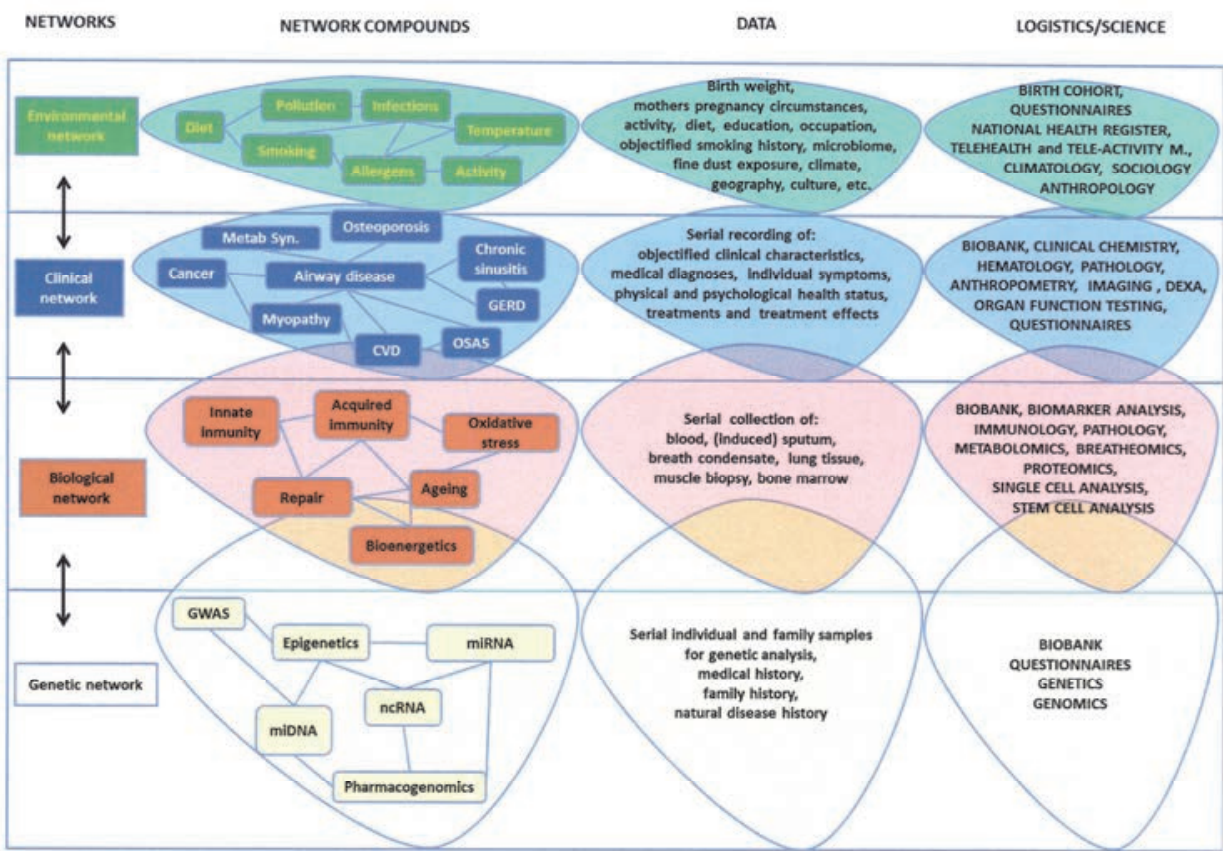

Figure 10.2 Network medicine in airway disease: Diagram illustrating the different levels of complexity of airway disease. At each level, only some of the potential components are shown to illustrate the concept (the diagram is not intended to be comprehensive). Likewise, links between the different elements of the network are drawn for illustrative purposes only and do not necessarily reflect evidence-based relationships. The middle and right-hand column show respectively the data required and the logistics and scientific knowledge needed to perform a study on a new taxonomy of airway disease. For further explanations, see text.

GERD: gastroesophageal reflux disease; OSAS: obstructive sleep apnea syndrome; CVD: cardiovascular disease; GWAS: genome-wide association studies; miDNA: mitochondrial DNA; miRNA: microRNA; ncRNA: noncoding RNA; M: monitoring. Modified with permission from ${ }^{82}$. 
It is important to actively search for comorbidities in patients with COPD. This approach enables to diagnose concomitant disorders that were not known to the patients and thus undiagnosed. Each patient presenting with COPD should be carefully and actively investigated for concomitant chronic disorders, particularly the most frequent and undiagnosed disorders, that is, hyperglycemia, atherosclerosis, hypertension, dyslipidemia, osteoporosis, anxiety and depression.(Chapter 6) In fact, although the symptoms and exacerbations of COPD can be treated pharmacologically, these treatments do not change the natural course of the disease. ${ }^{22}$ In contrast, the consequences of most of the concomitant metabolic and cardiovascular chronic diseases may be prevented and reversed by pharmacologic treatments. ${ }^{83,84}$ Interestingly, some of the treatments for comorbidities in COPD, like angiotensin converting enzyme inhibitors, angiotensin receptor blockers, beta-blockers, antiplatelet drugs, might modify the natural course of COPD in patients who are treated with them because of concomitant cardiovascular or metabolic disorders. ${ }^{85,86}$

In the daily routine consultation practice of respiratory physicians, we need to consider the assessment and integrated pharmacological management of patients with COPD and their comorbidities. Knowledge will be required of the most prevalent and most important comorbidities in COPD and their treatments, integrating the current knowledge on the effects of non-COPD pharmacotherapy on the clinical course of COPD. The rigorous treatment of comorbidity and multimorbidity also brings the challenge of dealing with pharmacological interactions and polypharmacy.

\section{PULMONARY REHABILITATION, A POTENTIAL NON- PHARMACOLOGICAL INTERVENTION FOR CARDIOVASCULAR RISK MANAGEMENT IN COPD?}

Pulmonary rehabilitation is recognized as a core component of the management of individuals with COPD as it has been clearly demonstrated to reduce dyspnea, increase exercise capacity, and improve quality of life in these patients. ${ }^{87}$

Pulmonary rehabilitation has also the potential to affect comorbidities. Rehabilitation results for example in increasing or reducing body weight in respectively underweight or obese patients, in increasing muscle mass in subjects with low muscle mass, and reducing symptoms of anxiety and depression in symptomatic subjects at baseline. ${ }^{88,89}$

To evaluate whether or not pulmonary rehabilitation potentially influences cardiovascular risk, in chapter $\mathbf{8}$, aortic pulse wave velocity (APWV), considered the gold standard to measure central arterial stiffness ${ }^{90}$ and an independent predictor of cardiovascular events and mortality, was measured before and after a rehabilitation 
program. ${ }^{91}$ Consistent with previous studies, ${ }^{92,93}$ it was shown that APWV is increased in subjects with COPD, compared to controls. A high variability of the change in APWV after pulmonary rehabilitation was found but we were not able to confirm a significant reduction in APWV, which was found in previous smaller studies. ${ }^{94,95}$

As discussed in chapter 8, there are several possible explanations for this lack of response. Probably a short-term pulmonary rehabilitation program is unable to affect the pathophysiology of arterial stiffness including the rate of elastin degradation. Also, it is known that endurance and resistance training have opposite effects on arterial stiffness. $^{96}$ Thus, by combining these training modalities, resistance training may have outweighed the effects of endurance training on arterial stiffness. The updated ATS/ERS Statement on Pulmonary Rehabilitation recommends the combination of constantload/interval and strength training in patients with COPD because it results in combined improvements in exercise capacity and muscle strength. Nevertheless, it would be interesting to compare the effects of endurance versus resistance training on APWV in patients with COPD in a future study.

\section{DO COMORBIDITIES AT ENTRANCE OF A PULMONARY REHABILITATION PROGRAM INFLUENCE REHABILITATION OUTCOMES?}

Previous studies have already investigated the influence of self-reported comorbidities on changes in relevant outcomes after pulmonary rehabilitation. ${ }^{97}$ However, the study in chapter $\mathbf{9}$ of this thesis was the first to investigate the impact of objectively assessed comorbidities and the impact of a combination of comorbidities that cluster together (as identified in chapter 6 ) on pulmonary rehabilitation outcomes.

Previous pulmonary rehabilitation trials in patients with COPD have used the presence of comorbidities as a criterion for excluding subjects. Nevertheless, this thesis has shown that patients with COPD and comorbidities can show significant improvements after pulmonary rehabilitation. Even subjects with more physically debilitating comorbidities can benefit from rehabilitation. ${ }^{98}$

A comprehensive pulmonary rehabilitation program implements a rigorous assessment of the patient's comorbidities and a multidisciplinary approach. The structure of pulmonary rehabilitation and its holistic approach ${ }^{99}$ is an optimal setting and a convenient platform to assess and treat all the relevant morbidities of the patient with COPD and to coordinate care. As such, the interdisciplinary, comprehensive, and patient centred approach of pulmonary rehabilitation mirrors the integrated care model as already proposed 40 years ago in the 1974 American College of Chest Physicians/American Thoracic Society definition of pulmonary rehabilitation: 
"Pulmonary rehabilitation may be defined as an art of medical practice wherein an individually tailored, multidisciplinary program is formulated which, through accurate diagnosis, therapy, emotional support, and education, stabilizes or reverses both the physio- and psychopathology of pulmonary diseases and attempts to return the patient to the highest possible functional capacity allowed by his handicap and overall life situation."100

\section{CONCLUSION}

In conclusion, this thesis has shown that COPD is a highly prevalent and underestimated clinical problem. The disease label COPD comprises a complex and heterogeneous group of patients who merely have persistent airflow limitation in common. It is primarily defined as a pulmonary disease, but many other aspects of the patient with COPD need to be considered. A patient with COPD commonly suffers from other chronic disease manifestations, which importantly impact on the patient with COPD and his sense of wellbeing. This directly implements that COPD-care is not limited to the prescription of bronchodilators and the treatment and prevention of COPD exacerbations, but is a comprehensive and holistic approach considering the rigorous diagnosis and the treatment of COPD-related systemic manifestations and comorbidity. We do not always need to disentangle the knots of the different morbidities to single diseases and treatments, but we rather need to increase our understanding of the coexistence of these morbidities and their concomitant impact on our patients. Steps forward have been made. The pulmonary rehabilitation setting provides a feasible platform to approach the patient with COPD in its complexity, in a coordinated comprehensive, interdisciplinary way. 


\section{REFERENCES}

1. Hoeymans N, Melse JM, Schoemaker CG. Gezondheid en determinanten. Deelrapport van de Van gezond naar beter. RIVM report. RIVM 2010.

2. Schirnhofer L, Lamprecht B, Vollmer WM, Allison MJ, Studnicka M, Jensen RL, Buist AS. COPD prevalence in Salzburg, Austria: results from the Burden of Obstructive Lung Disease (BOLD) Study. Chest 2007;131:29-36.

3. Dirven JA, Muris JW, van Schayck CP. COPD screening in general practice using a telephone questionnaire. COPD 2010;7:352-9.

4. Wouters E. The societal impact of COPD in North America and Europe: an economic analysis of the Confronting COPD survey. Respir Med 2003;97:S3-14.

5. Vestbo J, Hurd SS, Agustí AG, Jones PW, Vogelmeier C, Anzueto A, Barnes PJ, Fabbri LM, Martinez FJ, Nishimura M, Stockley RA, Sin DD, Rodriguez-Roisin R. Global strategy for the diagnosis, management and prevention of chronic obstructive pulmonary disease, GOLD executive summary. Am J Respir Crit Care Med 2013;187:347-65.

6. Hardie JA, Buist AS, Vollmer WM, Ellingsen I, Bakke PS, Mørkve O. Risk of over-diagnosis of COPD in asymptomatic elderly never-smokers. Eur Respir J 2002;20:1117-22.

7. Salvi SS, Barnes PJ. Chronic obstructive pulmonary disease in non-smokers. Lancet 2009;374:733-43.

8. Buist AS, McBurnie MA, Vollmer WM, Gillespie S, Burney P, Mannino DM, Menezes AM, Sullivan SD, Lee TA, Weiss KB, Jensen RL, Marks GB, Gulsvik A, Nizankowska-Mogilnicka E; BOLD Collaborative Research Group. International variation in the prevalence of COPD (the BOLD Study): a populationbased prevalence study. Lancet 2007;370:741-50.

9. Feenstra TL, van Genugten ML, Hoogenveen RT, Wouters EF, Rutten-van Mölken MP. The impact of aging and smoking on the future burden of chronic obstructive pulmonary disease: a model analysis in the Netherlands. Am J Respir Crit Care Med 2001;164:590-6.

10. Foreman MG, Zhang L, Murphy J, et al. Early-onset chronic obstructive pulmonary disease is associated with female sex, maternal factors, and African American race in the COPDGene Study. Am J Respir Crit Care Med 2011;184:414-20.

11. van Durme YM, Verhamme KM, Stijnen T, van Rooij FJ, Van Pottelberge GR, Hofman A, Joos GF, Stricker $\mathrm{BH}$, Brusselle GG. Prevalence, incidence, and lifetime risk for the development of COPD in the elderly: the Rotterdam study. Chest 2009;135:368-77.

12. de Torres JP, Casanova C, Hernández C, Abreu J, Aguirre-Jaime A, Celli BR. Gender and COPD in patients attending a pulmonary clinic. Chest 2005;128:2012-6.

13. Watson L, Vestbo J, Postma DS, Decramer M, Rennard S, Kiri VA, Vermeire PA, Soriano JB. Gender differences in the management and experience of Chronic Obstructive Pulmonary Disease. Respir Med 2004;98:1207-13.

14. Black LF, Hyatt RE. Maximal respiratory pressures: normal values and relationship to age and sex. Am Rev Respir Dis 1969;99:696-702.

15. Camp PG, O'Donnell DE, Postma DS. Chronic obstructive pulmonary disease in men and women: myths and reality. Proc Am Thoracic Soc 2009;6:535-8.

16. Becklake MR, Kauffmann F. Gender differences in airway behaviour over the human life span. Thorax 1999;54:1119-38.

17. Johnson JL, Campbell AC, Bowers M, Nichol AM. Understanding the social consequences of chronic obstructive pulmonary disease: the effects of stigma and gender. Proc Am Thoracic Soc 2007;4:680-2.

18. Agusti A, Calverley PM, Celli B, Coxson HO, Edwards LD, Lomas DA, MacNee W, Miller BE, Rennard S, Silverman EK, Tal-Singer R, Wouters E, Yates JC, Vestbo J; Evaluation of COPD Longitudinally to Identify Predictive Surrogate Endpoints (ECLIPSE) investigators. Characterisation of COPD heterogeneity in the ECLIPSE cohort. Respir Res 2010;11:122.

19. von Leupoldt A, Taube K, Lehmann K, Fritzsche A, Magnussen H. The impact of anxiety and depression on outcomes of pulmonary rehabilitation in patients with COPD. Chest 2011;140:730-6.

20. Mannino DM, Thorn D, Swensen A, Holguin F. Prevalence and outcomes of diabetes, hypertension and cardiovascular disease in COPD. Eur Respir J 2008;32:962-9. 
21. Divo M, Cote C, de Torres JP, Casanova C, Marin JM, Pinto-Plata V, Zulueta J, Cabrera C, Zagaceta J, Hunninghake G, Celli B; BODE Collaborative Group. Comorbidities and risk of mortality in patients with COPD. Am J Respir Crit Care Med 2012;186:155-61.

22. Vestbo J, Hurd SS, Agustí AG, Jones PW, Vogelmeier C, Anzueto A, Barnes PJ, Fabbri LM, Martinez FJ, Nishimura M, Stockley RA, Sin DD, Rodriguez-Roisin R. Global strategy for the diagnosis, management, and prevention of chronic obstructive pulmonary disease: GOLD executive summary. Am J Respir Crit Care Med 2013;187:347-65.

23. McGarvey LP, John M, Anderson JA, Zvarich M, Wise RA; TORCH Clinical Endpoint Committee. Ascertainment of cause-specific mortality in COPD: operations of the TORCH Clinical Endpoint Committee. Thorax 2007;62:411-5.

24. Antonelli Incalzi R, Fuso L, De Rosa M, Forastiere F, Rapiti E, Nardecchia B, Pistelli R. Co-morbidity contributes to predict mortality of patients with chronic obstructive pulmonary disease. Eur Respir $J$ 1997; 10:2794-800.

25. Crisafulli E, Costi S, Luppi F, Cirelli G, Cilione C, Coletti O, Fabbri LM, Clini EM. Role of comorbidities in a cohort of patients with COPD undergoing pulmonary rehabilitation. Thorax 2008;63:487-92.

26. Feary JR, Rodrigues LC, Smith CJ, Hubbard RB, Gibson JE. Prevalence of major comorbidities in subjects with COPD and incidence of myocardial infarction and stroke: a comprehensive analysis using data from primary care. Thorax 2010;65:956-62.

27. Schnell K, Weiss CO, Lee T, Krishnan JA, Leff B, Wolff JL, Boyd C. The prevalence of clinically-relevant comorbid conditions in patients with COPD: a cross-sectional study using data from NHANES 19992008. BMC Pulm Med 2012;12:26.

28. Siebeling L, Puhan MA, Muggensturm P, Zoller M, Ter Riet G. Characteristics of Dutch and Swiss primary care COPD patients - baseline data of the ICE COLD ERIC study. Clin Epidemiol 2011;3:273-83.

29. van Manen JG, Bindels PJ, IJzermans CJ, van der Zee JS, Bottema BJ, Schadé E. Prevalence of comorbidity in patients with a chronic airway obstruction and controls over the age of 40 . J Clin Epidemiol 2001;54:287-93.

30. Soriano JB, Visick GT, Muellerova H, Payvandi N, Hansell AL. Patterns of comorbidities in newly diagnosed COPD and asthma in primary care. Chest 2005;128:2099-107.

31. Tooth L, Hockey R, Byles J, Dobson A. Weighted multimorbidity indexes predicted mortality, health service use, and health-related quality of life in older women. J Clin Epidemiol 2008;61:151-9.

32. Filley GF, Beckwitt HJ, Reeves JT, Mitchell RS. Chronic obstructive bronchopulmonary disease. II. Oxygen transport in two clinical types. Am J Med 1968;44:26-38.

33. Vestbo J, Edwards LD, Scanlon PD, Yates JC, Agusti A, Bakke P, Calverley PM, Celli B, Coxson HO, Crim C, Lomas DA, MacNee W, Miller BE, Silverman EK, Tal-Singer R, Wouters E, Rennard SI; ECLIPSE Investigators. Changes in forced expiratory volume in 1 second over time in COPD. $N$ Engl J Med 2011;365:1184-92.

34. Evans WJ, Morley JE, Argilés J, Bales C, Baracos V, Guttridge D, Jatoi A, Kalantar-Zadeh K, Lochs $H$, Mantovani G, Marks D, Mitch WE, Muscaritoli M, Najand A, Ponikowski P, Rossi Fanelli F, Schambelan M, Schols A, Schuster M, Thomas D, Wolfe R, Anker SD. Cachexia: a new definition. Clin Nutr 2008;27:793-9.

35. Rennie MJ. Muscle protein turnover and the wasting due to injury and disease. $\mathrm{Br}$ Med Bull 1985;41:257-64.

36. Natanek SA, Riddoch-Contreras J, Marsh GS, Hopkinson NS, Moxham J, Man WD, Kemp PR, Polkey MI. MuRF-1 and atrogin-1 protein expression and quadriceps fiber size and muscle mass in stable patients with COPD. COPD 2013;10:618-24.

37. Coxson HO, Dirksen A, Edwards LD, Yates JC, Agusti A, Bakke P, Calverley PM, Celli B, Crim C, Duvoix A, Fauerbach PN, Lomas DA, Macnee W, Mayer RJ, Miller BE, Müller NL, Rennard SI, Silverman EK, TalSinger R, Wouters EF, Vestbo J; Evaluation of COPD Longitudinally to Identify Predictive Surrogate Endpoints (ECLIPSE) Investigators. The presence and progression of emphysema in COPD as determined by CT scanning and biomarker expression: a prospective analysis from the ECLIPSE study. Lancet Respir Med 2013;1:129-36.

38. Rodríguez-Roisin R, Drakulovic M, Rodríguez DA, Roca J, Barberà JA, Wagner PD. Ventilation-perfusion imbalance and chronic obstructive pulmonary disease staging severity. J Appl Physiol (1985) 2009;106:1902-8. 
39. Janssen DJ, Spruit MA, Leue C, Gijsen C, Hameleers H, Schols JM, Wouters EF; Ciro network. Symptoms of anxiety and depression in COPD patients entering pulmonary rehabilitation. Chronic respiratory disease 2010;7:147-57.

40. Kirchberger I, Meisinger C, Heier M, Zimmermann AK, Thorand B, Autenrieth CS, Peters A, Ladwig KH, Döring A. Patterns of multimorbidity in the aged population. Results from the KORA-Age study. PloS One 2012;7:e30556.

41. Fabbri LM, Rabe KF. From COPD to chronic systemic inflammatory syndrome? Lancet 2007;370:797-9.

42. Barnes PJ, Chowdhury B, Kharitonov SA, Magnussen H, Page CP, Postma D, Saetta M. Pulmonary biomarkers in chronic obstructive pulmonary disease. Am J Respir Crit Care Med 2006;174:6-14.

43. Franciosi LG, Page CP, Celli BR, Cazzola M, Walker MJ, Danhof M, Rabe KF, Della Pasqua OE. Markers of disease severity in chronic obstructive pulmonary disease. Pulm Pharmacol Ther 2006;19:189-99.

44. Lofdahl JM, Wahlstrom J, Skold CM. Different inflammatory cell pattern and macrophage phenotype in chronic obstructive pulmonary disease patients, smokers and non-smokers. Clin Exp Immunol 2006;145:428-37.

45. Casado B, ladarola P, Luisetti M, Kussmann M. Proteomics-based diagnosis of chronic obstructive pulmonary disease: the hunt for new markers. Expert Rev Proteomics 2008;5:693-704.

46. Agustí A, Edwards LD, Rennard SI, MacNee W, Tal-Singer R, Miller BE, Vestbo J, Lomas DA, Calverley PM, Wouters E, Crim C, Yates JC, Silverman EK, Coxson HO, Bakke P, Mayer RJ, Celli B; Evaluation of COPD Longitudinally to Identify Predictive Surrogate Endpoints (ECLIPSE) Investigators. Persistent systemic inflammation is associated with poor clinical outcomes in COPD: a novel phenotype. PloS One 2012;7:e37483.

47. Di Francia M, Barbier D, Mege JL, Orehek J. Tumor necrosis factor-alpha levels and weight loss in chronic obstructive pulmonary disease. Am J Respir Crit Care Med 1994;150:1453-5.

48. Iwamoto H, Yokoyama A, Kitahara Y, Ishikawa N, Haruta Y, Yamane K, Hattori N, Hara H, Kohno N. Airflow limitation in smokers is associated with subclinical atherosclerosis. Am J Respir Crit Care Med 2009;179:35-40.

49. Watz H, Waschki B, Kirsten A, Müller KC, Kretschmar G, Meyer T, Holz O, Magnussen H. The metabolic syndrome in patients with chronic bronchitis and COPD: frequency and associated consequences for systemic inflammation and physical inactivity. Chest 2009;136:1039-46.

50. Sin DD, Man SF. Why are patients with chronic obstructive pulmonary disease at increased risk of cardiovascular diseases? The potential role of systemic inflammation in chronic obstructive pulmonary disease. Circulation 2003;107:1514-9.

51. Thomsen M, Dahl M, Lange P, Vestbo J, Nordestgaard BG. Inflammatory biomarkers and comorbidities in chronic obstructive pulmonary disease. Am J Respir Crit Care Med 2012;186:982-8.

52. Broekhuizen R, Grimble RF, Howell WM, Shale DJ, Creutzberg EC, Wouters EF, Schols AM. Pulmonary cachexia, systemic inflammatory profile, and the interleukin 1 beta -511 single nucleotide polymorphism. Am J Clin Nutr 2005;82:1059-64.

53. Graat-Verboom L, Spruit MA, van den Borne BE, Smeenk FW, Martens EJ, Lunde R, Wouters EF; CIRO Network. Correlates of osteoporosis in chronic obstructive pulmonary disease: An underestimated systemic component. Respir Med 2009;103:1143-51.

54. Mills NL, Miller JJ, Anand A, Robinson SD, Frazer GA, Anderson D, Breen L, Wilkinson IB, McEniery CM, Donaldson K, Newby DE, Macnee W. Increased arterial stiffness in patients with chronic obstructive pulmonary disease: a mechanism for increased cardiovascular risk. Thorax 2008;63:306-11.

55. Quint JK, Baghai-Ravary R, Donaldson GC, Wedzicha JA. Relationship between depression and exacerbations in COPD. Eur Respir J 2008;32:53-60.

56. Clini EM, Beghe B, Fabbri LM. Chronic obstructive pulmonary disease is just one component of the complex multimorbidities in patients with COPD. Am J Respir Crit Care Med 2013;187:668-71.

57. Goossens $\mathrm{GH}$. The role of adipose tissue dysfunction in the pathogenesis of obesity-related insulin resistance. Physiol Behav 2008;94:206-18.

58. Poulain M, Doucet M, Drapeau V, Fournier G, Tremblay A, Poirier P, Maltais F. Metabolic and inflammatory profile in obese patients with chronic obstructive pulmonary disease. Chron Respir Dis 2008;5:35-41.

59. Breyer MK, Spruit MA, Celis AP, Rutten EP, Janssen PP, Wouters EF; CIRO Network. Highly elevated Creactive protein levels in obese patients with COPD: a fat chance? Clin Nutr 2009;28:642-7. 
60. Rutten EP, Breyer MK, Spruit MA, Hofstra T, van Melick PP, Schols AM, Wouters EF. Abdominal fat mass contributes to the systemic inflammation in chronic obstructive pulmonary disease. Clin Nutr 2010;29:756-60.

61. Vanfleteren LE, van Meerendonk AM, Franssen FM, Wouters EF, Mottaghy FM, van Kroonenburgh MJ, Bucerius J. A possible link between increased metabolic activity of fat tissue and aortic wall inflammation in subjects with COPD. A retrospective F-FDG-PET/CT pilot study. Respir Med 2014;108:883-90.

62. Ershler WB, Keller ET. Age-associated increased interleukin-6 gene expression, late-life diseases, and frailty. Ann Rev Med 2000;51:245-70.

63. Garcia-Aymerich J, Gómez FP, Benet M, Farrero E, Basagaña X, Gayete À, Paré C, Freixa X, Ferrer J, Ferrer A, Roca J, Gáldiz JB, Sauleda J, Monsó E, Gea J, Barberà JA, Agustí À, Antó JM; PAC-COPD Study Group. Identification and prospective validation of clinically relevant chronic obstructive pulmonary disease (COPD) subtypes. Thorax 2011;66:430-7.

64. Vanfleteren LE, Spruit MA, Groenen M, Gaffron S, van Empel VP, Bruijnzeel PL, Rutten EP, Op 't Roodt J, Wouters EF, Franssen FM. Clusters of comorbidities based on validated objective measurements and systemic inflammation in patients with chronic obstructive pulmonary disease. Am J Respir Crit Care Med 2013;187:728-35.

65. Schols AM, Soeters PB, Dingemans AM, Mostert R, Frantzen PJ, Wouters EF. Prevalence and characteristics of nutritional depletion in patients with stable COPD eligible for pulmonary rehabilitation. Am Rev Respir Dis 1993;147:1151-6.

66. Landbo C, Prescott E, Lange P, Vestbo J, Almdal TP. Prognostic value of nutritional status in chronic obstructive pulmonary disease. Am J Respir Crit Care Med 1999;160:1856-61.

67. Wack JT, Rodin J. Smoking and its effects on body weight and the systems of caloric regulation. Am J Clin Nutr 1982;35:366-80.

68. Mineur YS, Abizaid A, Rao Y, Salas R, DiLeone RJ, Gündisch D, Diano S, De Biasi M, Horvath TL, Gao XB, Picciotto MR. Nicotine decreases food intake through activation of POMC neurons. Science 2011;332:1330-2.

69. Perkins KA, Epstein LH, Stiller RL, Marks BL, Jacob RG. Acute effects of nicotine on resting metabolic rate in cigarette smokers. Am J Clin Nutr 1989;50:545-50.

70. Aubin HJ, Farley A, Lycett D, Lahmek P, Aveyard P. Weight gain in smokers after quitting cigarettes: meta-analysis. BMJ 2012;345:e4439.

71. Chinn S, Jarvis D, Melotti R, Luczynska C, Ackermann-Liebrich U, Antó JM, Cerveri I, de Marco R, Gislason T, Heinrich J, Janson C, Künzli N, Leynaert B, Neukirch F, Schouten J, Sunyer J, Svanes C, Vermeire $\mathrm{P}$, Wjst $\mathrm{M}$, Burney P. Smoking cessation, lung function, and weight gain: a follow-up study. Lancet 2005;365:1629-35; discussion 00-1.

72. Vanfleteren LE, Franssen FM, Wesseling G, Wouters EF. The prevalence of chronic obstructive pulmonary disease in Maastricht, the Netherlands. Respir Med 2012;106:871-4.

73. Soenen S, Chapman IM. Body weight, anorexia, and undernutrition in older people. J Am Med Dir Assoc 2013;14:642-8.

74. van den Borst B, Koster A, Yu B, Gosker HR, Meibohm B, Bauer DC, Kritchevsky SB, Liu Y, Newman AB, Harris TB, Schols AM. Is age-related decline in lean mass and physical function accelerated by obstructive lung disease or smoking? Thorax 2011;66:961-9.

75. van den Borst B, Gosker HR, Koster A, Yu B, Kritchevsky SB, Liu Y, Meibohm B, Rice TB, Shlipak M, Yende $S$, Harris TB, Schols AM; Health, Aging, and Body Composition (Health ABC) Study. The influence of abdominal visceral fat on inflammatory pathways and mortality risk in obstructive lung disease. Am J Clin Nutr 2012;96:516-26.

76. Furutate R, Ishii T, Wakabayashi R, Motegi T, Yamada K, Gemma A, Kida K. Excessive visceral fat accumulation in advanced chronic obstructive pulmonary disease. Int J Chron Obstruct Pulmon Dis 2011;6:423-30.

77. Giles JT, Allison M, Blumenthal RS, Post W, Gelber AC, Petri M, Tracy R, Szklo M, Bathon JM. Abdominal adiposity in rheumatoid arthritis: association with cardiometabolic risk factors and disease characteristics. Arthritis Rheum 2010;62:3173-82. 
78. Katznelson L, Fairfield WP, Zeizafoun N, Sands BE, Peppercorn MA, Rosenthal DI, Klibanski A. Effects of growth hormone secretion on body composition in patients with Crohn's disease. J Clin Endocrinol Metab 2003;88:5468-72.

79. Balci A, Balci DD, Yonden Z, Korkmaz I, Yenin JZ, Celik E, Okumus N, Egilmez E. Increased amount of visceral fat in patients with psoriasis contributes to metabolic syndrome. Dermatology 2010;220:32-7.

80. Dick KJ, Nelson CP, Tsaprouni L, Sandling JK, Aïssi D, Wahl S, Meduri E, Morange PE, Gagnon F, Grallert H, Waldenberger M, Peters A, Erdmann J, Hengstenberg C, Cambien F, Goodall AH, Ouwehand WH, Schunkert H, Thompson JR, Spector TD, Gieger C, Trégouët DA, Deloukas P, Samani NJ. DNA methylation and body-mass index: a genome-wide analysis. Lancet 2014;383:1990-8.

81. Agusti A, Sobradillo P, Celli B. Addressing the complexity of chronic obstructive pulmonary disease: from phenotypes and biomarkers to scale-free networks, systems biology, and P4 medicine. Am J Respir Crit Care Med 2011;183:1129-37.

82. Agusti A, Vestbo J. Current controversies and future perspectives in chronic obstructive pulmonary disease. Am J Respir Crit Care Med 2011;184:507-13.

83. McMurray JJ, Adamopoulos S, Anker SD, Auricchio A, Böhm M, Dickstein K, Falk V, Filippatos G, Fonseca C, Gomez-Sanchez MA, Jaarsma T, Køber L, Lip GY, Maggioni AP, Parkhomenko A, Pieske BM, Popescu BA, Rønnevik PK, Rutten FH, Schwitter J, Seferovic P, Stepinska J, Trindade PT, Voors AA, Zannad F, Zeiher A; Task Force for the Diagnosis and Treatment of Acute and Chronic Heart Failure 2012 of the European Society of Cardiology, Bax JJ, Baumgartner H, Ceconi C, Dean V, Deaton C, Fagard R, FunckBrentano C, Hasdai D, Hoes A, Kirchhof P, Knuuti J, Kolh P, McDonagh T, Moulin C, Popescu BA, Reiner Z, Sechtem U, Sirnes PA, Tendera M, Torbicki A, Vahanian A, Windecker S, McDonagh T, Sechtem U, Bonet LA, Avraamides P, Ben Lamin HA, Brignole M, Coca A, Cowburn P, Dargie H, Elliott P, Flachskampf FA, Guida GF, Hardman S, lung B, Merkely B, Mueller C, Nanas JN, Nielsen OW, Orn S, Parissis JT, Ponikowski P; ESC Committee for Practice Guidelines. ESC guidelines for the diagnosis and treatment of acute and chronic heart failure 2012: The Task Force for the Diagnosis and Treatment of Acute and Chronic Heart Failure 2012 of the European Society of Cardiology. Developed in collaboration with the Heart Failure Association (HFA) of the ESC. Eur J Heart Fail 2012;14:803-69.

84. Vandvik PO, Lincoff AM, Gore JM, Gutterman DD, Sonnenberg FA, Alonso-Coello P, AkI EA, Lansberg MG, Guyatt GH, Spencer FA; American College of Chest Physicians. Primary and secondary prevention of cardiovascular disease: Antithrombotic Therapy and Prevention of Thrombosis, 9th ed: American College of Chest Physicians Evidence-Based Clinical Practice Guidelines. Chest 2012;141:e637S-68S.

85. Luppi F, Franco F, Beghé B, Fabbri LM. Treatment of chronic obstructive pulmonary disease and its comorbidities. Proc Am Thorac Soc 2008;5:848-56.

86. Harrison MT, Short P, Williamson PA, Singanayagam A, Chalmers JD, Schembri S. Thrombocytosis is associated with increased short and long term mortality after exacerbation of chronic obstructive pulmonary disease: a role for antiplatelet therapy? Thorax 2014;69:609-15.

87. Spruit MA, Singh SJ, Garvey C, ZuWallack R, Nici L, Rochester C, Hill K, Holland AE, Lareau SC, Man WD, Pitta F, Sewell L, Raskin J, Bourbeau J, Crouch R, Franssen FM, Casaburi R, Vercoulen JH, Vogiatzis I, Gosselink R, Clini EM, Effing TW, Maltais F, van der Palen J, Troosters T, Janssen DJ, Collins E, GarciaAymerich J, Brooks D, Fahy BF, Puhan MA, Hoogendoorn M, Garrod R, Schols AM, Carlin B, Benzo R, Meek P, Morgan M, Rutten-van Mölken MP, Ries AL, Make B, Goldstein RS, Dowson CA, Brozek JL, Donner CF, Wouters EF; ATS/ERS Task Force on Pulmonary Rehabilitation. An official American Thoracic Society/European Respiratory Society statement: key concepts and advances in pulmonary rehabilitation. Am J Respir Crit Care Med. 2013;188:e13-64.

88. Harrison SL, Greening NJ, Williams JE, Morgan MD, Steiner MC, Singh SJ. Have we underestimated the efficacy of pulmonary rehabilitation in improving mood? Respir Med 2012;106:838-44.

89. Franssen FM, Broekhuizen R, Janssen PP, Wouters EF, Schols AM. Effects of whole-body exercise training on body composition and functional capacity in normal-weight patients with COPD. Chest 2004;125:2021-8.

90. Mansia G, De Backer G, Dominiczak A, Cifkova R, Fagard R, Germano G, Grassi G, Heagerty AM, Kjeldsen SE, Laurent S, Narkiewicz K, Ruilope L, Rynkiewicz A, Schmieder RE, Struijker Boudier HA, Zanchetti A; European Society of Hypertension; European Society of Cardiology. 2007 ESH-ESC Guidelines for the management of arterial hypertension: the task force for the management of arterial hypertension of 
the European Society of Hypertension (ESH) and of the European Society of Cardiology (ESC). Blood Press 2007; 16:135-232.

91. Cavalcante JL, Lima JA, Redheuil A, Al-Mallah MH. Aortic stiffness: current understanding and future directions. J Am Coll Cardiol 2011;57:1511-22.

92. Sabit R, Bolton CE, Edwards PH, Pettit RJ, Evans WD, McEniery CM, Wilkinson IB, Cockcroft JR, Shale DJ. Arterial stiffness and osteoporosis in chronic obstructive pulmonary disease. Am J Respir Crit Care Med 2007;175:1259-65.

93. Maclay JD, McAllister DA, Mills NL, Paterson FP, Ludlam CA, Drost EM, Newby DE, Macnee W. Vascular dysfunction in chronic obstructive pulmonary disease. Am J Respir Crit Care Med 2009;180:513-20.

94. Vivodtzev I, Minet C, Wuyam B, Borel JC, Vottero G, Monneret D, Baguet JP, Lévy P, Pépin JL. Significant improvement in arterial stiffness after endurance training in patients with COPD. Chest 2010;137: 585-92.

95. Gale NS, Duckers JM, Enright S, Cockcroft JR, Shale DJ, Bolton CE. Does pulmonary rehabilitation address cardiovascular risk factors in patients with COPD? BMC Pulm Med 2011;11:20.

96. Collier SR, Kanaley JA, Carhart R Jr, Frechette V, Tobin MM, Hall AK, Luckenbaugh AN, Fernhall B. Effect of 4 weeks of aerobic or resistance exercise training on arterial stiffness, blood flow and blood pressure in pre- and stage-1 hypertensives. J Hum Hypertens 2008;22:678-86.

97. Hornikx M, Van Remoortel H, Demeyer H, Marcal Camillo CA, Decramer M, Janssens W, Troosters T. The influence of comorbidities on outcomes of pulmonary rehabilitation programs in patients with COPD: a systematic review. Biomed Res Int 2013;2013:146148.

98. McNamara RJ, McKeough ZJ, McKenzie DK, Alison JA. Water-based exercise in COPD with physical comorbidities: a randomised controlled trial. Eur Respir J 2013;41:1284-91.

99. Spruit MA, Vanderhoven-Augustin I, Janssen PP, Wouters EF. Integration of pulmonary rehabilitation in COPD. Lancet 2008;371:12-3.

100. Hodgkin JE, Farrell MJ, Gibson SR, Kanner RE, Kass I, Lampton LM, Nield M, Petty TL. American Thoracic Society. Medical Section of the American Lung Association. Pulmonary rehabilitation. Am Rev Respir Dis 1981;124:663-6. 


\section{Summary}



Chronic obstructive pulmonary disease (COPD) is a common airway and lung disease characterized by persistent airflow limitation. COPD is a serious public health problem throughout the world, with an increasing morbidity and mortality especially in countries with an ageing population. Although COPD is defined by the presence of chronic airflow limitation, it is increasingly recognized that the presence of other chronic conditions (comorbidities) such as cardiovascular disease, depression, osteoporosis, anemia and diabetes substantially contributes to disease severity. Comorbidities not only affect symptom burden, functional performance and health status in patients with COPD, but also the risk of hospitalization and mortality. As a consequence, COPD is nowadays considered a complex, heterogeneous and multicomponent condition.

Controversy exists about the etiology of comorbidities in patients with COPD. Persistent low-grade systemic inflammation has been suggested as a link between COPD and comorbidities. Indeed, markers of inflammation in the systemic circulation have shown to be increased in subjects with COPD as well as in subjects with cardiovascular disease. Systemic inflammation have been associated with an increased risk of comorbidities in COPD, in particular cardiovascular disease. Also other factors like physical inactivity, nutrition and ageing have been suggested to play a role.

Pulmonary rehabilitation is a comprehensive intervention recognized as a core component in the treatment of patients with COPD. It results in a reduction of symptoms and an optimization of the functional status. In addition, research has illustrated that pulmonary rehabilitation results in an increased societal participation and reduction in healthcare costs. Comorbidities have been suggested to affect outcomes of pulmonary rehabilitation in this population, but conflicting results have been published. In addition, the effects of pulmonary rehabilitation on cardiovascular risk have not been extensively studied.

The first aim of this thesis was to estimate the prevalence of COPD and to study gender differences in a general elderly population. Chapter $\mathbf{2}$ describes the results of a study that evaluated a random gender-stratified sample of the general elderly ( $>40$ years) population in the area of Maastricht for the presence of COPD using high quality postbronchodilator spirometry. It was shown that $24 \%$ of subjects had at least mild (stage 1 or higher) COPD, and $10 \%$ had at least moderate (stage 2 or higher) COPD. The frequency increased importantly with age and the amount of smoked pack years and COPD was more frequent in men than in women. A substantial proportion of subjects that never smoked had COPD. An important proportion of subjects were previously undiagnosed. 
Chapter 3 evaluated the differences in respiratory symptoms between men and women, with and without COPD in an international elderly general population. The study showed that women report more dyspnea compared to men, and that men report more phlegm compared to women. Possible explanations for these findings are differences in muscle strength, lung volumes, but also differences in perception and reporting of the perceived symptoms.

A next aim of this thesis was to study the complex relationship between the presence of chronic airflow limitation and body weight. In an international large sample of the general population, described in chapter 4 of this thesis, the presence of chronic airflow limitation was associated with lower body weight (using the body mass index) independent from factors that potentially could influence this association, including smoking, age, gender or geography. Due to the cross-sectional nature of the study, the direction of this association was not clear. Subjects with airflow limitation may lose weight. On the other hand, naturally thin subjects may be at higher risk to develop COPD.

A detailed study of the prevalence, impact and co-occurrence of different comorbidities and extrapulmonary manifestations, the relation of these comorbidities with systemic inflammation, and the study of the interplay between comorbidities and pulmonary rehabilitation in patients with COPD were other aims of this thesis. In Chapter 5, COPD patients referred for pulmonary rehabilitation were evaluated for cardiac ischemia using a structural coding system for abnormalities on electrocardiography. In total, $21 \%$ of patients had evidence for cardiac ischemia which was related to worse outcome measures including predictors of survival. Moreover, ischemia was seen in $13 \%$ of subjects who were not previously known with cardiovascular disease.

Chapter 6 objectively evaluated the presence of 13 of the most prevalent and most impactful comorbidities in COPD in patients at the initial evaluation of a pulmonary rehabilitation program. All evaluated comorbidities were present but their presence varied importantly. The most prevalent comorbidities were hyperglycemia, hypertension and atherosclerosis. Almost all patients had comorbidity, and more than $50 \%$ of patients had at least four comorbidities. The co-occurrence of some specific comorbidities was more present than others. Using a statistical program that creates a model (using self-organizing maps) that ordered the patients based on their profile of comorbidities, five different clusters of patients could be identified: A cluster of patient with less comorbidity, a cardiovascular cluster, a cachectic cluster, a metabolic cluster and a psychological cluster. The clusters had a comparable degree of airflow limitation and exercise limitation but differed in health status, cardiovascular risk and other pulmonary function measures. In addition, systemic inflammatory markers within each comorbidity cluster were highly heterogeneous and mainly similar among the different 
clusters, illustrating that the possible interactions between biomarkers of systemic inflammation and comorbidities in patients with COPD are very complex, if present at all.

Chapter 7 described a detailed study of the intima-media thickness of the carotid wall (also referred to as subclinical atherosclerosis) in patients with COPD. It is a robust predictor of future cardiovascular events. It was found that traditional cardiovascular risk factors, like older age, higher blood pressure and higher body weight, but also the severity of airflow limitation were predicting factors for subclinical atherosclerosis. It was further evaluated whether a panel of blood markers which have been previously related to atherosclerosis could identify subjects with COPD with subclinical atherosclerosis. Only a minority of markers contributed to increase the predictive power of the clinical measurements. Nevertheless, serum amyloid A, triglycerides and osteonectin are interesting markers for further exploration.

Chapter 8 showed that arterial stiffness, another independent and robust marker of cardiovascular risk, is increased in patients with COPD and determined by older age and higher blood pressure. This study clearly showed the absence of an independent correlation of several markers of systemic inflammation with arterial stiffness in patients with COPD. Also it was shown that, in contrast to earlier smaller studies, arterial stiffness in patients with COPD was not responsive to a state-of-the-art pulmonary rehabilitation program.

Chapter 9 studied the influence of the presence of specific comorbidities at the initial evaluation of a pulmonary rehabilitation program on rehabilitation outcomes like exercise capacity and health status. The presence of a specific comorbidity did not prevent patients to improve after a rehabilitation program compared to subjects without the specific comorbidity. However, in chapter 6 it was made clear that the majority of this study population suffered from multimorbidity. Comparing the rehabilitation response of the different clusters identified in chapter 6 showed that this response was mostly comparable. Some differences were noticed between clusters. In relation to the "less comorbidity cluster", the psychological cluster had increased likelihood to improve their walking distance. The cachectic cluster had a tendency towards a decreased likelihood to improve their submaximal cycling time.

In Chapter 10, the results of this thesis were discussed in a broader context, from the epidemiology of airflow obstruction towards the complex multimorbid disease COPD. The heterogeneity of systemic inflammation in COPD was discussed, and it's role in the etiology of comorbidity was questioned. Excessive fat tissue, and mainly visceral fat might be an important origin of inflammation and related to atherosclerotic activity. Other pathophysiological important issues were discussed, mainly the interaction 
between genetic and environmental factors, like nutrition, smoking and physical inactivity. Finally, the role of pharmacological and non-pharmacological treatments of the multimorbid patient with COPD were placed in perspective. 


\section{Samenvatting}



Chronisch obstructieve longziekte (COPD) is een vaak voorkomende aandoening van de luchtwegen en de longen die gekenmerkt wordt door een blijvende beperking van de luchtstroom tijdens de ademhaling. COPD is een groot maatschappelijk probleem en zorgt voor een enorme belasting van de gezondheidszorg in landen over heel de wereld. De invaliditeit en vroegtijdige sterfte nemen jaar per jaar toe, vooral in landen met een ouder wordende bevolking.

COPD is primair een longaandoening. In recente jaren is het echter steeds duidelijker geworden dat de ernst van de ziekte ook in belangrijke mate mee bepaald wordt door het gelijktijdig voorkomen van andere chronische aandoeningen (ook wel comorbiditeiten genoemd), zoals hart- en vaatziekten, depressie, botontkalking ondergewicht, bloedarmoede en suikerziekte. Comorbiditeiten beïnvloeden niet alleen de symptoomlast, het welbevinden en het inspanningsvermogen, maar ook het risico op hospitalisatie en overlijden. Hedendaags wordt COPD dan ook gezien als een complexe, heterogene aandoening met vele componenten en verschillende facetten, zowel in de longen als daarbuiten.

Er heerst nog veel onduidelijkheid omtrent het ontstaan van comorbiditeiten bij COPD patiënten. Persisterende laaggradige ontsteking, gemeten in het bloed (systemische inflammatie) zou een link kunnen zijn. Er werden inderdaad verhoogde concentraties van ontstekingsstoffen aangetroffen in de bloedcirculatie van zowel COPD patiënten als patiënten met hart- en vaatziekten. Toch spelen ook andere factoren zoals de mate van fysieke activiteit, voeding en veroudering waarschijnlijk ook een rol.

Longrevalidatie is een allesomvattende interventie die erkend wordt als een zeer belangrijke component in de behandeling van patiënten met COPD. Het resulteert in een vermindering van symptomen, vermindering van ziektelast en een verbetering van het inspanningsvermogen. Ook heeft onderzoek aangetoond dat longrevalidatie leidt tot een verbetering van de maatschappelijke participatie en een vermindering van consumeren van gezondheidszorg. Eerder onderzoek suggereert dat comorbiditeiten de uitkomsten van longrevalidatie kunnen beïnvloeden, maar de resultaten zijn niet eenduidig. Bovendien werden de effecten van longrevalidatie op hart- en vaatrisico niet uitvoerig bestudeerd.

De eerste doelstelling van deze thesis was het inschatten van het voorkomen van COPD en het bestuderen van geslachtsverschillen in de algehele oudere bevolking. Hoofdstuk 2 beschrijft de resultaten van de aanwezigheid van COPD bij een willekeurige steekproef van evenveel mannen en vrouwen uit de algehele oudere (>40 jaar) bevolking van Maastricht. Hiervoor werd, in lijn met internationale richtlijnen voor de diagnostiek van COPD, longfunctieonderzoek uitgevoerd na de toediening van luchtwegverwijding. De studie toonde aan dat $23 \%$ van de mensen minstens mild COPD 
(stadium 1 of hoger) hadden en 10\% minstens matig COPD (stadium 2 of hoger). De frequentie steeg in belangrijke mate met toenemende leeftijd en het aantal gerookte pakjaren. Een substantiële groep van mensen die nooit gerookt hadden, voldeed aan de criteria voor COPD. Opvallend was dat een belangrijk deel van de mensen waarbij eveneens COPD vastgesteld werd daar niet mee bekend was

Hoofdstuk 3 bestudeerde de verschillen in symptomen tussen mannen en vrouwen met en zonder COPD in een internationale populatie. De studie toonde dat vrouwen meer klachten van kortademigheid rapporteerden, en mannen meer slijm. De redenen hiervoor zijn in dit onderzoek niet bestudeerd, maar verschillen in spierkracht en longvolumina zouden een rol kunnen spelen. Ook verschillen in de perceptie van symptomen en verschillen in het rapporteren van de gepercipieerde symptomen zouden een rol kunnen spelen.

Een volgende doelstelling van deze thesis was het bestuderen van de complexe relatie tussen chronische luchtstroom beperking en lichaamsgewicht. In een grote internationale steekproef van de algehele oudere bevolking, beschreven in hoofdstuk 4 van deze thesis, bleek de aanwezigheid van chronische luchtstroombeperking geassocieerd te zijn met een lager lichaamsgewicht (gebruik makend van de "body mass index"). Deze relatie was onafhankelijk van andere factoren die mogelijk van invloed kunnen zijn zoals roken, leeftijd, geslacht of geografie. Doordat de studie een doorsnede van de bevolking is en er geen opvolging in de tijd beschikbaar is, kon er geen uitspraak gedaan worden over de richting van deze relatie. Mensen met luchtstroombeperking kunnen gewicht verliezen, maar slankere mensen zouden ook een hoger risico kunnen hebben op het ontwikkelen van COPD.

Het gedetailleerd bestuderen van het voorkomen, de impact en het samen voorkomen van verschillende comorbiditeiten en extra-pulmonale ziekte-manifestaties, de relatie met systemische inflammatie en het bestuderen van de interactie tussen comorbiditeiten en longrevalidatie bij patiënten met COPD waren andere doelstellingen van deze thesis. In hoofdstuk 5 werden patiënten met COPD die verwezen werden voor een longrevalidatieprogramma systematisch geanalyseerd voor het voorkomen van hartschade door vernauwing van de kransslagaders. Hiervoor werd het elektrocardiogram van alle deelnemers structureel nagekeken, gebruikmakend van een gevalideerd coderingssysteem. In totaal werden bij $21 \%$ van de COPD patiënten aanwijzingen gevonden voor hartschade, en deze bevinding was gerelateerd aan slechtere uitkomsten, inclusief slechtere overlevingsindicatoren. Bovendien werd er hartschade gevonden bij $13 \%$ van de patiënten die voordien niet bekend waren met cardiovasculaire ziekte. 
Hoofdstuk 6 evalueerde op een objectieve manier de aanwezigheid van 13 van de vaakst voorkomende en meest impactvolle comorbiditeiten bij patiënten met COPD aan het begin van een longrevalidatieprogramma. Alle geëvalueerde comorbiditeiten waren aanwezig maar er bestond een grote variatie in de frequentie. De vaakst voorkomende comorbiditeiten waren verhoogde bloedsuiker, hoge bloeddruk en atherosclerose (vaatverkalking). Bijna alle patiënten hadden comorbiditeiten en meer dan $50 \%$ van de patiënten had minstens 4 comorbiditeiten. Sommige comorbiditeiten kwamen vaker samen voor dan andere. Een statistisch computerprogramma dat een model creëerde (gebruik makend van "zelf-organiserende kaarten", in het Engels: "selforganizing maps") waarbij de patiënten geordend werden op basis van hun profiel van comorbiditeiten bracht 5 patiëntenclusters aan het licht: Een cluster van patiënten met minder comorbiditeiten, een cardiovasculair cluster, een cachectisch cluster, een metabool cluster en een psychologisch cluster. De clusters hadden een vergelijkbare ernst van luchtstroombelemmering en inspanningsbeperking maar verschilden in welbevinden, hart- en vaatrisico en andere longfunctiemetingen, zoals de zuurstofopname capaciteit. Bovendien waren de gemeten ontstekingsstoffen in het bloed heel heterogeen binnen elke cluster en over het algemeen vergelijkbaar tussen de verschillende clusters. Dit wijst erop dat als er al interacties aanwezig zouden zijn tussen de ontstekingsstoffen in het bloed en comorbiditeiten, dat deze heel complex zijn.

Hoofdstuk $\mathbf{7}$ is een gedetailleerde studie van het voorkomen van (subklinische) atherosclerose van de halsslagader bij patiënten met COPD, een robuuste voorspeller van toekomstige hart- en vaatziekten. De studie toonde dat traditionele risicofactoren voor hart- en vaatziekten, zoals oudere leeftijd, hogere bloeddruk en hoger lichaamsgewicht voorspellende factoren waren voor atherosclerose. Bovenop deze traditionele factoren was ook de ernst van luchtstroombeperking bijdragend. In deze studie werd ook geëvalueerd of een panel van bloedmerkers, die eerder in verschillende populaties met uitingen van atherosclerose in verband gebracht werden, COPD patiënten kon identificeren met atherosclerose. Enkel een minderheid van de merkers waren bijdragend aan de voorspellende waarden van de klinische metingen. Desalniettemin zijn serum amyloid A, triglyceriden en osteonectine interessante merkers voor verder onderzoek.

Hoofdstuk 8 liet zien dat vaatstijfheid, een andere onafhankelijke en robuuste merker van cardiovasculair risico, verhoogd is bij patiënten met COPD en bepaald wordt door oudere leeftijd en hoge bloeddruk. Deze studie toonde duidelijk aan dat er geen onafhankelijk verband is tussen de aanwezigheid van verschillende ontstekingsstoffen in het bloed en een verhoogde vaatstijfheid. Ook toonde deze studie aan dat, in tegenstelling met eerdere kleinere studies, de vaatstijfheid niet beïnvloed wordt door een longrevalidatieprogramma. 
Hoofdstuk 9 bestudeerde de invloed van het hebben van specifieke comorbiditeit aan de start van een longrevalidatieprogramma op de uitkomsten van het programma. Het werd aangetoond dat comorbiditeit de patiënten niet verhindert om te verbeteren na longrevalidatie. In hoofdstuk 6 was het duidelijk dat de meerderheid van de studie populatie lijdt aan meerdere comorbiditeiten tegelijkertijd (multimorbiditeit). Bij het vergelijken van de revalidatierespons van de verschillende clusters was deze over het algemeen vergelijkbaar. Toch vielen enkele verschillen op. In vergelijking met het cluster met minder comorbiditeit, verbeterde het psychologische cluster meer op de wandelafstand. Bij het cachectische cluster was er een tendens naar een mindere verbetering op de duur van submaximaal fietsen.

Hoofdstuk 10 bespreekt de resultaten van deze thesis in een bredere context, van de epidemiologie van luchtwegobstructie tot de complexe multimorbide ziekte COPD. De heterogeniteit van systemische inflammatie bij COPD wordt bediscussieerd en de rol daarvan in de etiologie van comorbiditeit wordt in vraag gesteld. Excessief vetweefsel, en vooral het vet rond de organen, kan een belangrijke bron van inflammatie zijn en gerelateerd zijn aan atherosclerotische activiteit. Andere pathofysiologische belangrijke punten worden bediscussieerd, zoals de interactie tussen genetische factoren en omgevingsfactoren zoals voeding, roken en fysieke inactiviteit. Tenslotte wordt de farmacologische en niet-farmacologische behandeling van de multimorbide patiënt met COPD in perspectief geplaatst. 


\section{Valorization}



Knowledge valorization refers to the "process of creating value from knowledge, by making knowledge suitable and/or available for social (and/or economic) use, and by making knowledge suitable for translation into competitive products, services, processes and new commercial activities"

\section{RELEVANCE}

COPD is a highly prevalent disease, which is projected to further increase in the coming decades. The economical and societal burden is high. Although the WHO recognized its increasing incidence, robust epidemiological studies on the prevalence of COPD are lacking.

Although diagnostic criteria for COPD and criteria for disease severity have been well described, in recent years important clinical heterogeneity was seen within patients with a comparable disease severity, defined by the degree of airflow limitation. Extrapulmonary manifestations, most importantly low body weight and low muscle mass, have been associated with the severity of COPD, but also here, these features were not seen in all patients. Meanwhile, it was increasingly recognized that subjects with COPD are at high risk for other comorbid diseases, mainly cardiovascular disease, but also metabolic or psychological disease. These comorbidities contribute importantly to the symptom burden and outcome of individual patients and are an important contributing factor to the heterogeneity of COPD. Indeed, most patients with COPD die from another disease than COPD itself.

This thesis provided new evidence in this field of expertise:

First, our findings showed that the real prevalence of COPD in the general elderly population in Maastricht was much higher than the documented prevalence in primary care as seen in the data published by the national health care register in the Netherlands. Even after correction for the effects of normal ageing and considering only moderate to severe airflow limitation, the prevalence is still a multifold of what was thought. Thus, the data reported in this thesis contribute to raise awareness about this chronic disease.

Secondly, we showed clear differences in COPD related respiratory symptoms between men and women which are important to consider in the diagnostic trajectory.

Third, our findings provide important new insights in the specificity of alterations in body weight in patients with COPD. It was found that independent of factors that are known to impact on body weight, like age, gender and smoking, the presence of COPD is associated with lower body weight compared to control subjects. 
Fourth, this thesis importantly emphasizes the high prevalence of comorbidity in patients with COPD and the importance to actively and routinely screen these patients for the most impactful and most prevalent comorbidities. This study objectively documented for the first time that patients with COPD cluster together based on their different comorbidities. This means that the presence of one comorbidity is associated with the presence or absence of another, suggesting differentiated pathophysiological pathways.

Fifth, this thesis provides important insights about the presence and role of systemic inflammation in patients with COPD, related to comorbidities. We did not find a relationship between arterial stiffness in patients with COPD and different traditional markers of systemic inflammation. Furthermore, after identifying different clusters of patients based on their comorbidities, we found that within each cluster, whether it consists of patients with less comorbidities, or patients with a high number of comorbidities related to either a cachectic or metabolic profile, systemic inflammatory markers are very heterogeneous within each cluster and do generally not differ between the different clusters. These findings shine new light on the role of systemic inflammation in COPD.

Sixth, we demonstrated that the degree of atherosclerosis, measured by the thickness of the intima-media layer of the carotid arterial wall in patients with COPD was mainly determined by traditional cardiovascular risk factors like age, body mass index and mean blood pressure but also for a small amount by the degree of airflow limitation. The combination of multiple biomarkers, previously related to atherosclerosis could only moderately increase the prediction of atherosclerosis, when added to clinical variables. This study illustrated on the one hand the complexity of atherosclerosis in COPD and on the other hand the limited value of biomarkers in its identification.

Seventh, in contrast with earlier smaller studies, we could not confirm that state-ofthe-art pulmonary rehabilitation could reduce the cardiovascular risk as measured by the degree of arterial stiffness. Although we confirmed that arterial stiffness was increased in patients with COPD compared to controls and determined by age and blood pressure.

Eight, this thesis clearly demonstrated that the presence of comorbidities does not prevent patients with COPD to improve from a state of the art pulmonary rehabilitation program. Although the different identified clusters of patients with comorbidities have a differential response to some of the measured outcomes after rehabilitation. 


\section{ACTIVITIES, PRODUCTS, INNOVATION FOR DIFFERENT TARGET GROUPS}

\section{GOVERNMENT, HEALTH INSURANCE}

COPD importantly impacts on the socio-economic system, on the one hand by the loss of quality adjusted life years (QALY) including the loss of productive working years and on the other hand by a high burden of health care consumption. It is the task of policy and law makers to continue their efforts to reduce the exposure of the people to noxious substances, mainly cigarette smoke. Great strides forward have been made, still with the ageing of the population and still a considerably high smoking prevalence, the incidence and prevalence of COPD is bound to increase. Therefore, it is of upmost interest to have high quality epidemiologic data about the burden of disease.

The results of the current thesis have been discussed on regional radio and television (L1) with live interviews with the authors. Also regional (de Limburger), national (nu.nl) and international (Het belang van Limburg) newspapers reported on the topic. This resulted to discussions in the provincial parliament of Limburg concerning the improvement of outdoor air quality. Questions from a political party (PvdA) have been answered by the "Gedeputeerde Staten" after consultation of the first author of the present thesis.

With COPD as a use-case, this thesis also importantly emphasizes the challenges for future medicine. With the ageing population, and more successful cure for acute lethal disease, more people suffer from chronic non-communicable diseases. It is clear that patients suffer from multiple diseases at the same time which increases the complexity of care. A paradigm shift from the treatment of the single disease to a holistic approach which also involves the human aspect regarding psychology, behavioral change, selfmanagement is needed. These are important insights for health policy makers and insurance companies.

\section{HEALTH CARE PROVIDERS}

The present thesis gives important insights for health care providers. It was shown that COPD is highly prevalent, underestimated and underdiagnosed. An increased awareness of the presence of the disease is warranted as well as a continued and intensified attitude to stimulate healthy behavior and to quit smoking.

Secondly, this thesis gives handhold for health care providers to actively evaluate patients with COPD for the most prevalent and impactful comorbidities in these patients. Almost all patients with COPD suffer from one or more comorbidities. With a 
thorough assessment and treatment of a patients extrapulmonary manifestations and comorbidities, health status and prognosis can be altered.

\section{PULMONARY REHABILITATION PROGRAMS}

The interplay between pulmonary rehabilitation and COPD related comorbidities is clinically relevant as almost all patients in rehabilitation programs suffer from comorbidities. This thesis showed that despite comorbidity, patients are still able to benefit from rehabilitation. This thesis also creates new opportunities. The identification of different clusters of patients with differential comorbidity pattern emphasizes the heterogeneity of the disease and the need for tailored individualized diagnostics and management strategies, also within pulmonary rehabilitation programs.

\section{COPD PATIENTS}

The patient him- or herself can clearly benefit from the output of the present thesis. Not only by the increased awareness of the disease COPD and the increased awareness of the high burden of comorbidities in these patients by their health care providers, but also by increasing awareness within patient groups and the general population. Different press releases on the findings of the prevalence of COPD in Maastricht and on the concept of multimorbidity in COPD have been done. The discussions on radio and television, and the different interviews in papers or patient-oriented folders contribute to a general education of people of the existence of COPD and comorbidity and the importance of diagnosis and comprehensive management.

\section{SCIENCE: FUTURE RESEARCH QUESTIONS}

The relevance of this thesis and the contribution to the scientific field is discussed above. Meanwhile this thesis might be important for researchers in the field as every answer to previous questions reveals multiple unanswered questions. Although this thesis shines new light on the role of systemic inflammation in COPD, the origin and the role of systemic inflammation and the role of the (visceral) fat in the development of cardiovascular disease in patients with COPD remains to be elucidated.

The longitudinal evolution of body composition in different COPD phenotypes is of future interest. The optimal management of comorbidities in rehabilitation programs and the way how to adapt the program to specific clusters of comorbidities need to be explored. In addition, the differential response after rehabilitation illustrates that multiple and probably tailored outcomes need to be considered. This also is food for further research. 


\section{PERSONAL DEVELOPMENT}

The results of the studies in this thesis have resulted in multiple scientific abstracts on international respiratory conferences. Several chapters have been published in high quality peer reviewed scientific journals in the respiratory and cardiovascular field. Chapter 6 has been published in the American Journal of Respiratory and Critical Care Medicine, which is the most important journal in the field of respiratory medicine. In addition, the figures of the article reached the cover of the journal. It was the most cited original research paper of that journal in 2013.

The press release was picked up on multiple scientific internet sites. Ultimately, recently the article was discussed in "de Volkskrant", a major newspaper in the Netherlands.

As discussed above, the results of chapter 2 were discussed in regional, national and international newspapers and discussed with the author on regional radio and television.

After publication, the author was invited on national and international symposia to discuss the results of the scientific work performed. In addition, he was invited to write an editorial in the European Respiratory Journal concerning the topic of comorbidity.

\section{SCHEDULE AND IMPLEMENTATION}

The studies of this thesis are published or submitted in international scientific journals and contribute to the scientific community.

This thesis has resulted in an increasing awareness for early diagnosis of COPD which directly gave synergy for the existing plans of the NHG (Nederlands Huisartsen Genootschap) en Astmafonds to include spirometry in preventive settings.

As already acknowledged in the international Global inititative of Obstructive Lung Disease document, patients with COPD need to be considered as high risk patients for the most prevalent and impactful comorbidities. This thesis contributed to the awareness and the importance of the topic. There is a paradigm shift of a respiratory focus towards a holistic approach of the patient with multimorbidity.

In this view, this thesis can contribute to future guideline development. The realization of the existence of different groups of patients with different disease expression can be helpful in a guided evaluation of the most suspected comorbidities. For example the presence of one comorbidity can indicate the presence or absence of another. 
The results of this thesis have also immediate consequences and implementations for pulmonary rehabilitation. Comorbid conditions do not prevent patients to benefit from rehabilitation. In addition, rehabilitation programs are evolving to tailored programs shaped to the needs and comorbid conditions of the patients. 


\section{Dankwoord}



Beste Miel, mijn eerste date met Kristien was een trip naar Maastricht voor een sollicitatiegesprek naar de opleiding longziekten, intussen bijna dag op dag 10 jaar geleden. Jij gaf mij de kans om longarts te worden en in de loop van mijn opleiding zag je dingen in mij die ik zelf nooit gezien had. Ik werd onderzoeker en bleef aan de slag in CIRO en in Maastricht. We hebben elkaar altijd vrij vlot begrepen en daar waren niet altijd veel woorden voor nodig. Een deel van mijn leven heb jij mee vorm gegeven en waar ik nu sta in mijn huidige carrière heb ik voornamelijk aan jou te danken. Mijn respect voor jouw kennis en wat je opgebouwd hebt tijdens jouw carrière is zeer groot. Je bent een visionair en ik hoop een stuk van die visie meegekregen te hebben en verder te kunnen uitbouwen.

Beste Frits en Martijn. Jullie zijn mijn copromotoren, naaste collega's en goede vrienden. Ik heb ontzettend veel bewondering voor jullie en ben zeer blij deel te mogen uitmaken van ons "team". Het aanstekelijk enthousiasme waarmee jullie in het leven en in het werk staan, straalt af en maakt ons en CIRO zo succesvol. Ontelbare keren liggen we in een deuk van het lachen. Maar nog vaker wisselen we enthousiast ideeën uit. Zo is het idee voor de comorbiditeitenclusters ontstaan op een servet in het restaurant. Jullie waren gedroomde begeleiders van dit traject. Bedankt ook voor jullie geduld met de chaos die ik soms op jullie afstuurde. Ik heb de laatste jaren van dichtbij ook jullie vlucht mogen meemaken, hoe jullie internationaal steeds vooraanstaander werden binnen het vakgebied en hard aan de weg timmeren. Het is fijn vertoeven in jullie kielzog!

Miriam, Riny, Annie en Irma, ik wil jullie ontzettend bedanken voor jullie ongelooflijke werk voor het datamanagement van de CIROCO studie. Laat het duidelijk zijn, dat ik een lucky bastard was, die zijn doctoraat grotendeels heeft kunnen baseren op data die hij zelf niet heeft verzameld. Dat hebben jullie gedaan, en zonder jullie was dit proefschrift niet in deze vorm tot stand gekomen.

In het bijzonder wil ik ook de afdeling biometrie bedanken, met name Marco, Koen, Jos, Tim en Linda. De vaatmetingen werden omwille van logistieke redenen vaak onmenselijk vroeg in de ochtend gepland. De toewijding en inzet is ongezien en typeert ook de sfeer binnen CIRO.

Uiteraard geen proefschrift zonder onderzoekssubjecten. Graag wil ik alle patiënten en gezonde vrijwilligers uitdrukkelijk bedanken. Hopelijk hebben we samen een klein bouwsteentje bijgedragen aan verbetering van de zorg voor chronisch zieke mensen.

Beste Daisy, Loes, Eefje, Nicole en Manu. Het medische team dat we zijn in CIRO is heel bijzonder. We zijn zo laagdrempelig in ons overleg en onderlinge benadering. We staan altijd klaar voor elkaar, zowel in als buiten CIRO. Bedankt voor de afgelopen tijd, ook 
toen jullie een tandje bij moesten steken, zodat ik een hoofdstuk kon klaarkrijgen. Daisy, afgelopen jaren deelden we samen met Frits de kamer. Bedankt voor alle tips, de schouderklopjes, je geduld met "dr. Chaos" en het opruimen van de vuile koffiekopjes.

Ook de overige onderzoekers en doctoraatstudenten in CIRO wil ik graag bedanken. Erica, Sarah, Fiona, Dionne, Dionne, Wai-Yan, Jeannet, Nienke, Carmen, Coby, Rafael, Vasilis, Esther, we maken elkaar en CIRO beter en jullie enthousiasme is aanstekelijk. Rafael, thanks again for your hard work on the last chapter of this thesis.

Beste Ingrid, ook jou wil ik bedanken! Als bestuurder in CIRO spreek jij altijd jouw waardering uit voor de innovatie en het onderzoek binnen CIRO, terwijl je waakt over de kwaliteit van het primaire proces.

Ik zou velen in CIRO tekort doen, als ik niet een woord aan dank zou uitspreken aan iedereen binnen de organisatie. Het is ontzettend fijn om te werken binnen CIRO en ik ben heel blij er deel van uit te maken.

Ook mijn collega's in Maastricht: Geertjan, Gernot, Monique, Anne-Marie, Arne, Roy, Nicolle, Astrid en Lizza wil ik niet vergeten. Hierbij uiteraard ook de enthousiaste groep arts-assistenten! Dank voor de fijne samenwerking.

De leden van de beoordelingscommissie van het proefschrift wil ik oprecht bedanken voor het grondige nazicht en goedkeuren van het manuscript. Naast de voorzitter, prof. dr. Stehouwer, wil ik graag prof. dr. Leunissen, prof. dr. Brunner - La Rocca, prof. dr. Vogelmeier (Universiteit van Gießen en Marburg) en prof. dr. Fabbri (Universiteit van Modena) bedanken.

Professor Fabbri, Leo, I would like to thank you for the enthusiasm and appreciation for my work. You mentioned me in person in your lectures at several international meetings. Moreover, as editor of the European Respiratory Journal you recently invited me to write my first editorial. Thank you for the support!

A special word of thank I would like to address to prof. Studnicka, dr. Lamprecht and Mr. Kaiser. Michael, Bernd and Bernhard, we had a very interesting and fruitful collaboration on the BOLD dataset. I am very glad that we succeeded to finish Chapter 4 of this thesis. I won't forget our meetings in Salzburg and Horn, the never-ending discussions on reference equations, the evening we had dinner at Michaels, etc. I hope we can continue our collaboration in the future.

Een speciaal woord van dank gaat uit naar mijn paranimfen, Rémy en Andreas. Andreas, we hebben memorabele tijden beleefd tijdens onze studententijd, laagtes en 
hoogtes in het leven getrotseerd en ik ben dan ook zeer blij dat je bij dit (hopelijk) hoogtepunt aan mijn zijde kan staan. Doe wel een beetje voorzichtig tijdens mijn promotiefeestje he! Geen ambulances deze keer! Rémy, jou heb ik voor het eerst leren kennen in mijn vooropleiding in Heerlen. We konden het al snel goed met elkaar vinden en kwamen elkaar later in de opleiding nog heel vaak tegen. Onvergetelijk was die carnavalsavond in Eupen, met Kristien en Meera die toen in het ziekenhuis in Eupen werkten! Je bent meer dan een collega, en ik ben heel blij dat ook jij aan mijn zijde staat tijdens de verdediging!

Ook AstraZeneca wil ik graag bedanken, uiteraard voor de financiële ondersteuning van de CIROCO en BOLD studie, maar ook voor de ondersteuning voor het organiseren van het symposium rondom dit proefschrift deze morgen. Hierbij wil ik met name Wandena en Mylène bedanken.

Een bijzondere dank je wel ook voor mijn ouders. Mama en papa, zonder jullie stond ik hier niet, en dit niet enkel biologisch gezien. Jullie hebben mij in alle vrijheid mijn eigen keuzes laten maken in het leven en bijgestuurd waar nodig. Bedankt voor alle steun en toewijding tijdens mijn groei naar volwassenheid en in het begin van een professionele carrière. Mijn ouders brengen me ook bij mijn broers en zussen! Eline, Michiel, Maxime en Charlotte, ik ben zo blij en trots met de fantastische band die we hebben. Ondertussen telt ons gezin 18 mensen en mensjes. Onvoorstelbaar! Ook mijn schoonouders Rik en Maggy wil ik graag bedanken voor alle steun en interesse. Maggy, een keertje extra oppassen op Lux was nooit een probleem voor jou!

Tenslotte wil ik mijn lieve vrouw Kristien en ons dochtertje Lux bedanken. Kristientje, ik weet niet hoe hard ik jou kan bedanken voor alles wat wij samen zijn en bereikt hebben. We timmeren beiden hard aan de weg en allebei zaten we in een doctoraatstraject. We hebben in die periode een huis gekocht, ons Luxje gekregen, we zijn getrouwd en we hebben aan de zijde van je papa gevochten tegen zijn ziekte. (Een deel van het valorisatiehoofdstuk heb ik in de uren bij hem aan bed in het ziekenhuis geschreven.) Soms werd het heel erg veel, maar samen lukt het ons. Ik ben nu klaar, nu jij nog! Lux, jij kan dit nu nog niet lezen, maar wellicht vind je het heel erg leuk om deze zinnen later zelf te kunnen lezen. Het is onvoorstelbaar wat jij in mij kan losmaken. 's Avonds thuiskomen en jou enthousiast zien opveren en naar me toewaggelen om een knuffel te krijgen, dat vult me helemaal met vreugde en energie. Jij gaf me zonder dat je het zelf weet, vaak ook de goede moed die ik nodig had. 
Inkt op papieren servet. Originele aantekeningen van een brainstorm sessie tijdens een lunch in CIRO die de basis vormden voor een publicatie in de "blue journal".

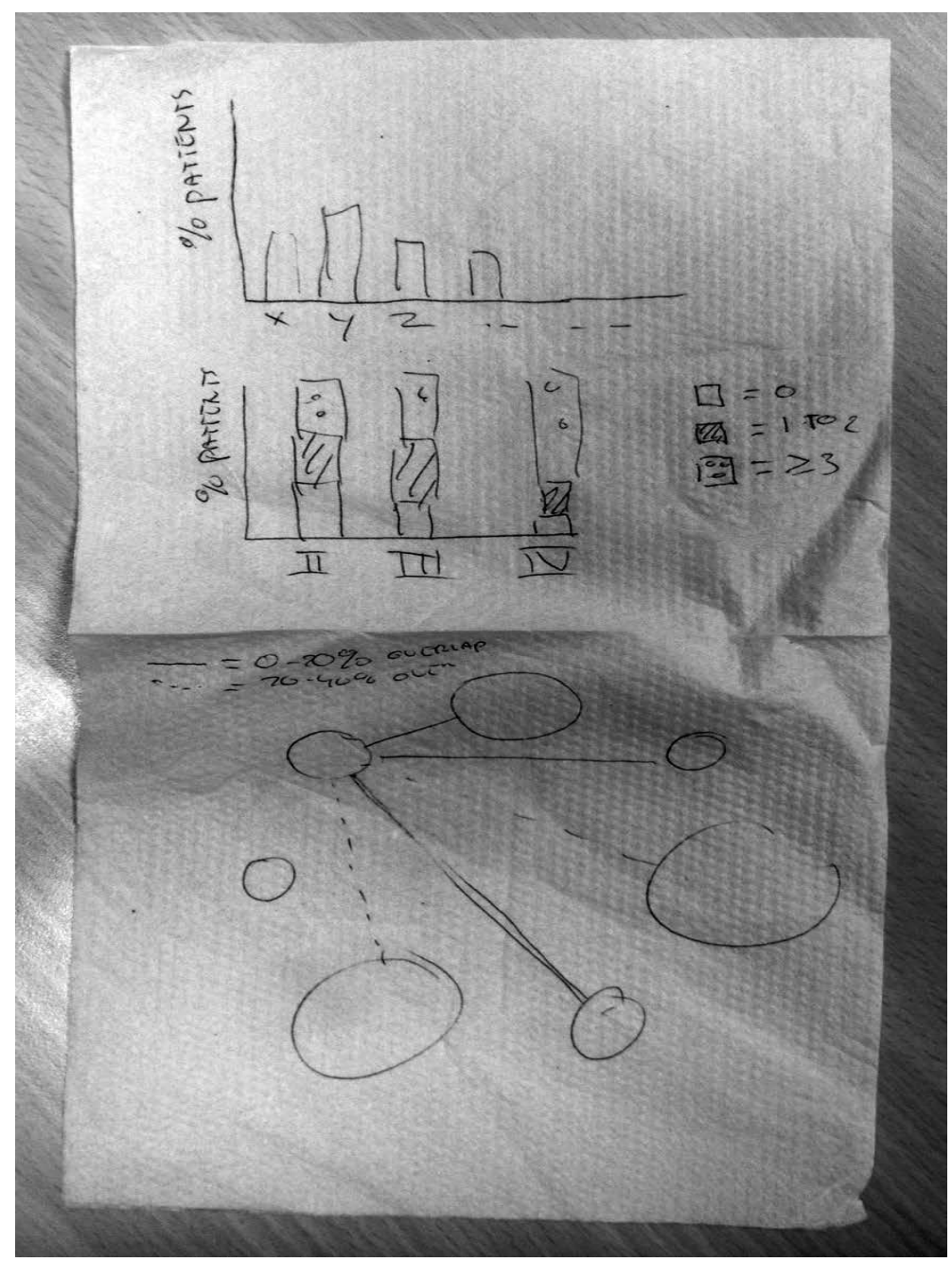




\section{Curriculum Vitae}



Lowie Vanfleteren werd geboren op 24 september 1980 in Leuven. Hij behaalde zijn diploma Latijn-Wiskunde van de middelbare school in het Spes Nostra instituut in Heule, Kortrijk. In 2005 behaalde hij zijn diploma geneeskunde cum laude aan de Katholieke Universiteit Leuven. Aansluitend begon hij de opleiding tot longarts in het Maastricht Universitair Medisch Centrum (MUMC). De twee jaar vooropleiding algemene interne geneeskunde genoot hij in het Atrium Medisch Centrum Heerlen, waarna hij tot longarts opgeleid werd in het MUMC in Maastricht. Tijdens de opleiding publiceerde hij reeds verschillende overzichtsartikelen en casuïstiek in het Tijdschrift voor Geneeskunde, alsook in internationale vakbladen. Op eigen initiatief onderzocht hij het voorkomen van longembolieën bij patiënten met verhoogde D-dimeren, aangevraagd en verwezen door de huisarts. Dit resulteerde in een abstract op het Europese longcongres en een publicatie. Daaropvolgend startte hij tijdens zijn opleiding een $\mathrm{PhD}$ project in $\mathrm{CIRO}+$ aangaande extrapulmonale manifestaties en comorbiditeit bij patiënten met COPD onder supervisie van prof. Dr. Emiel Wouters als promotor en Dr. Frits Franssen en Dr. Martijn Spruit als copromotores. In juli 2011 werd hij longarts. Sinds die tijd is hij werkzaam in $\mathrm{ClRO}+$, een expertisecentrum voor chronisch orgaanfalen in Horn met detachering naar de longafdeling van het MUMC. Hij is lid van de Europese longvereniging en actief binnen de "pulmonary rehabilitation assembly". $\mathrm{Hij}$ is reviewer voor meerdere tijdschriften. In het kader van zijn proefschrift publiceerde hij al in vooraanstaande tijdschriften en werd hij uitgenodigd op nationale en internationale congressen. Hij is in 2014 getrouwd met Kristien Daenen, samen hebben ze een dochtertje Lux. Hobby's zijn voetballen met vrienden, muziek op vinyl, goede film, reizen, en van het leven genieten. 



\section{List of publications}




\section{ARTIKELS IN TIJDSCHRIFTEN}

Fevery J, Vanfleteren LE, Dockx S, Perez-Gutierrez N, Nevens F. Hoe inactief is de leverziekte bij hepatitis B-"surface"-antigeenpositieve patiënten met normale transaminasen? Tijdschr Geneeskd 2007;63:549-55.

Vanfleteren LE, Wesseling G, Wouters EF. Allergische bronchopulmonale aspergillose bij cystische fibrose. Tijdschr Geneeskd 2009;65:68-72.

Vanfleteren LE, van der Schaar P, Goedhard J. Ileus related to wireless capsule retention in suspected Crohn's disease: emergency surgery obviated by early pharmacological treatment. Endoscopy 2009;41 Suppl 2:E134-5.

Vanfleteren LE, Peulen HM, Creytens DH, Smulders NM, Utama I, de Ruysscher DK, ten Velde GP. Complete metabolic remission of an irresectable mediastinal solitary fibrous tumour with concurrent chemoradiation. Thorax 2009;64:822-3.

Vanfleteren LE, Boomars KA, Wouters EF. Een man met maagklachten, thoracale pijn en dyspneu. Tijdschr Geneeskd 2009;65:904-5.

Vanfleteren LE, Abdul-Hamid M, Sprooten R. Groente imiteert bronchuscarcinoom. Tijdschr Geneeskd 2010;66:374-6.

Vanfleteren LE. Rol van micro-organismes bij interstitiële longaandoeningen. ild care today. 2009;3.

Vanfleteren LE, Linssen CF. Role of microorganisms in interstitial lung disease. Curr Opin Pulm Med 2010;16:489-95.

Vanfleteren LE, van Stiphout R, Riedl RG, Jansen R, De Ruysscher D, Dingemans AM. Primary Ewing's sarcoma presenting as a Pancoast tumour. Thorax 2011;66:89-90.

Vanfleteren LE, Wesseling G. Evaluation of the diagnostic yield of D-dimer testing in suspected venous thromboembolism in primary care: a 2-year retrospective analysis. Prim Care Respir J 2011;20:102-3.

Vanfleteren LE, Franssen FM, Uszko-Lencer N, Spruit MA, Celis M, Gorgels A, Wouters $E F$. Frequency and relevance of ischemic electrocardiographic findings in patients with chronic obstructive pulmonary disease. Am J Cardiol 2011;108:1669-74. 
Vanfleteren LE, Franssen FM, Wesseling G, Wouters EF. The prevalence of chronic obstructive pulmonary disease in Maastricht, the Netherlands. Respir Med 2012;106: 871-4.

Vanfleteren LE, Spruit MA, Groenen M, Gaffron S, van Empel VP, Bruijnzeel PL, Rutten EP, Op 't Roodt J, Wouters EF, Franssen FM. Clusters of comorbidities based on validated objective measurements and systemic inflammation in patients with chronic obstructive pulmonary disease. Am J Respir Crit Care Med 2013;187:728-35.

Sillen MJ, Franssen FM, Delbressine JM, Uszko-Lencer NH, Vanfleteren LE, Rutten EP, Wouters EF, Spruit MA. Heterogeneity in clinical characteristics and co-morbidities in dyspneic individuals with COPD GOLD D: findings of the DICES trial. Respir Med 2013; 107:1186-94.

Vanfleteren LE, Kocks JW, Stone IS, Breyer-Kohansal R, Greulich T, Lacedonia D, Buhl R, Fabbri LM, Pavord ID, Barnes N, Wouters EF, Agusti A. Moving from the Oslerian paradigm to the post-genomic era: are asthma and COPD outdated terms? Thorax 2014;69:72-9.

Lamprecht B, Vanfleteren LE, Studnicka M, Allison M, McBurnie MA, Vollmer WM, Tan WC, Nielsen R, Nastalek P, Gnatiuc L, Kaiser B, Janson C, Wouters EF, Burney P, Buist AS, BOLD Collaborative Research Group. Sex-related differences in respiratory symptoms: results from the BOLD Study. Eur Respir J. 2013;42:858-60.

Vanfleteren LE, Spruit MA, Groenen MT, Bruijnzeel PL, Taib Z, Rutten EP, Roodt JO, Akkermans MA, Wouters EF, Franssen FM. Arterial stiffness in patients with COPD: the role of systemic inflammation and the effects of pulmonary rehabilitation. Eur Respir J 2013;43:1306-15.

Cleutjens FA, Wouters EF, Dijkstra JB, Spruit MA, Franssen FM, Vanfleteren LE, Ponds RW, Janssen DJ. The COgnitive-Pulmonary Disease (COgnitive-PD) study: protocol of a longitudinal observational comparative study on neuropsychological functioning of patients with COPD. BMJ Open 2014;4:e004495.

Vanfleteren LE, van Meerendonk AM, Franssen FM, Wouters EF, Mottaghy FM, van Kroonenburgh MJ, Bucerius J. A possible link between increased metabolic activity of fat tissue and aortic wall inflammation in subjects with COPD. A retrospective 18F-FDGPET/CT pilot study. Respir Med 2014;108:883-90.

Andrianopoulos V, Wagers SS, Groenen MT, Vanfleteren LE, Franssen FM, Smeenk FW, Vogiatzis I, Wouters EF, Spruit MA; CIRO+ Rehabilitation Network. Characteristics and 
determinants of endurance cycle ergometry and six-minute walk distance in patients with COPD. BMC Pulm Med 2014;14:97

Breyer MK, Spruit MA, Hanson CK, Franssen FM, Vanfleteren LE, Groenen MT, Bruijnzeel PL, Wouters EF, Rutten EP. Prevalence of Metabolic Syndrome in COPD Patients and Its Consequences. PLoS One 2014;9:e98013.

Vanfleteren LE. Does COPD stand for "COmorbidity with Pulmonary Disease"? Eur Respir J 2015;45:14-7

\section{BOEKBIJDRAGE}

Vanfleteren LE, Cobben N. Chronische respiratoire insufficiëntie. in Probleemgeoriënteerd denken in de longgeneeskunde. Een praktijkboek voor de opleiding en de kliniek. S.M. de Hosson, M.J. Tip, J.W.G. van Putten, T.S. van der Werf (redactie). Uitgeverij de Tijdstroom. 2010.

Vanfleteren LE. Longaandoeningen. in Het geriatrie formularium. Een praktische leidraad. P. Jansen, J. van der Laan, J. Schols. (redactie). Uitgeverij Springer. 2013.

Vanfleteren LE. Comorbiditeit bij COPD in huidige richtlijnen. In: Wouters EF (redactie). Esculaap Media. 2014. 
